\title{
HUMAN PHYSIOLOGY
}

$$
\text { T. L. NICHOLS, M.D. }
$$




Digitized by the Internet Archive in 2007 with funding from Microsoft Corporation 


\section{HUMAN PHYSIOLOGY}

THE BASIS OF

\section{SANITARY AND SOCIÁL SCIENCE.}

$B Y$

\section{T. L. NICHOLS, M.D.}

WITH NUMEROUS ILLUSTRATIONS.

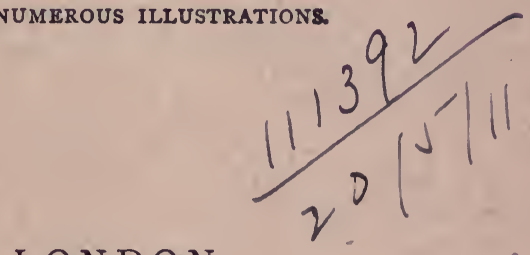

LONDON :

NICHOLS \& CO., 23 OXFord StreEt, W. 1893.

[All Rights Reserved.] 


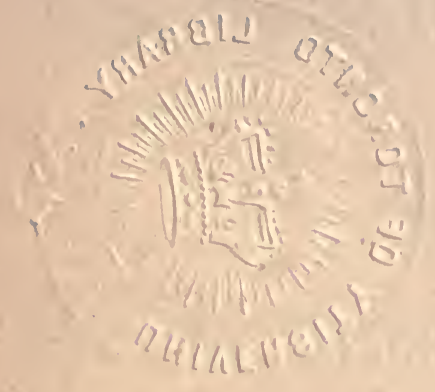

Fia) Nisbe! \& Co., Frinters, 25 Jamaica Street, Glasgow, AND i69, Fleet Streel, London. 


\section{$P R E F A C E$.}

I HAVE written this book to show that the Law of Life for man is written in his organisation; that we have but to study the physical nature of man to know the conditions of health, the causes of disease, the means of preventing diseases, and the best methods of cure; that, in the same way, we have but to understand his moral nature, his social requirements, and the constitution of his mind, in order that we may know the moral, social, and educational conditions most conducive to his welfare and happiness. That is, I have endeavoured to prove the proposition laid down in my title-that Human Physiology is the true basis of Sanitary and Social Science.

But why, it may be asked, is it necessary to write a volume of nearly five hundred pages to demonstrate and illustrate a self-evident proposition? Of course, the law of every creature's life is written in its organisation. It is true of every plant, every animal, and must therefore be true oi man. We have only to understand his whole nature to see its adaptations, and the modes of life and activity, the manners and morals, government and society, education and religion, that will best suit his requirements.

But it has seemed to me that the great difficulty is that men have little knowledge of their own natures. Men understand but little of their physical constitutions; not much more of their mental and moral characters. Physiology, the science of life, has been handed over to the medical profession, which has an unfortunate interest in the popular ignorance of sanitary laws; 
while metaphysicians, moralists; and theologians have confused rather than enlightened our ideas as to the moral nature of man, and his consequent social requirements.

I have endeavoured to write a plain, practical work, as free as possible from technicalities, which will enable every reader to understand the present condition of human society; the structure and functions of the human body; the laws of generation, or the methods by which the species is continued and character determined by hereditary influences; the laws of health ; the nature, prevention, and cure of diseases ; the moral and social nature of man, and that state of morals and constitution of society which will secure his highest earthly good, and bis greatest happiness.

With this end I have divided my work into six distinct portions, each in a certain degree independent of the others, yet all integral parts of the same general design.

PART FIRST treats of the actual condition of humanity in what are considered the most advanced human societies, giving statistics of disease, and premature or preventable mortality ; of poverty, and its evils and miseries; ignorance, drunkenness, dishonesty, crime, immorality, and prostitution and its consequences. This morbid social anatomy is a very painful, but, it seemed to me, a very necessary examination of the symptoms of a disordered and diseased society.

PART SECOND, which will be to many readers the most interesting portion of the book, and from its subject and illustrations the most delightful, treats of Matter, Force, and Life; the vegetable and animal creation; of man, and the wide differences between him and all other creatures, and of the peculiar nature and immortal destiny of humanity. This Part contains the principles of general physiology, or the science of life, which are applied and illustrated in the succeeding portions.

PART ThIRD contains a description of the human body anri its most important organs and functions - those of locomotion, 


\section{Preface.}

sensation, thought, feeling, and will; the building up, sustain. ing, and repairing of the organism; the removal of its waste matter and impurities; the peculiarities of individual organisations; and the phenomena and laws of life and death.

PART Fourth treats of the most important superadded function of generation, or reproduction, as it exists in vegetables, animals, and the human species; the unfolding of the body from its germ; the relations of the sexes in love and marriage; the laws of paternity, or the influence of parents upon the physical and moral characters of their children; the laws of sexual morality, and those problems of the sexual relation, so difficult to treat in a popular work, and yet so necessary to be known, that they cannot with any propriety be omitted. A work on Human Physiology which does not treat of the function of reproduction, is as great a monstrosity as would be a human being in whom that function did not exist. I believe that the whole subject is treated in this work in such a manner as will satisfy every reasonable requirement, and at the same time give no reasonable offence. I have earnestly endeavoured, in the letterpress and illustrations, to give all necessary and useful information upon subjects of vital importance, and, at the same time, to avoid any possible injury.

PART FIFTH treats comprehensively of Health, its laws and conditions; and of.Disease, its causes, prevention, and cure. This will probably be considered by many the most valuable, and practically useful portion of the work; and I am sure the chapters on medical systems and practice, and Hydropathy, or the water cure, will be read with interest and profit.

PART SiXTH contains the application of the leading principle or idea of the work to Education, Morals, and Society; and is an attempt to point out the kind of social organisation required by the nature of man-that which would give occupation to all his faculties, bring out his higher, and restrain or subordinate 
his lower nature, and give to every individual his greatest use, and therefore his highest good and happiness.

I wish, therefore, that this Book may be read by all Christians and Philanthropists; by all Clergymen, Lawyers, and Physicians; by all Professors and Teachers; by Editors and Authors; by Legislators and Magistrates, Lánded Proprietors and Capitalists; by Working Men and Working Women; by all Fathers and Mothers; by all Young Men and Young Women, who specially need to know. what it teaches; and I believe that it may also be safely, wisely, and with great benefit, placed in the hands of every child who is old enough to understand it: but of this every parent will form his own judgment.

- The whole book is the result of the study, observation, experience, and thought of an active and varied life, passed in two hemispheres, and now wearing to its close. Its motives will be found in every chapter, and appreciated, I trust, by every reader. I believe that it will do great good-first to individuals, by giving a knowledge of the laws of health; later, to society, by aiding in those great social reformations which are destined to change the face of the world, bring peace to . nations, plenty to populations, and a higher and purer life to all mankind. For I devoutly believe that the prophecy of the prayer-"Thy kingdom come, Thy will be done on earth as it is in heaven "-must be fulfilled; and I humbly hope, with God's help, to contribute my mite towards its fulfilment.

Asking the fraternal co-operation of all who sympathise with me in this object, I remain, ever a humble worker for humanity.

T. L. NICHOLS.

Malvern, I 872. 


\section{CONTENTS.}

PART 1.-ACTUAL CONDITION OF HUMANITY.

\section{Chapter I.-MAN and his Relations.}

Physiology defined-The Law of Life in Organisation-The Natural Basis of Morality-Human Progress-Man differs from all other AnimalsMoral Responsibility-Reason and Instinct-Man alone a Religious Being-Population of the Earth-Destiny of Savages-England a Model Nation, . . . . - . . . I-8

Chapter II.-Premature and Preventable Mortality.

Natural Death-The Age of Man-His Triple Warfare-Responsibilities of the Governing Classes-Statistics of Mortality-Death-Rate in the English Metropolis-The Battle of Life, . . . . 8-13

Chapter III.-The Mortality of Classes and Conditions.

Death-rate in Town and Country-Sanitary Influence of Altitude-Drainage - Comparative Longevity of Gentry, Tradesmen, and Working MenMoral Causes of Excessive Mortality - Whose the Fault? . 13-17

Chapter IV.-Infant Mortality and Infanticide:

Conditions of Infancy-General Statistics of Infant Mortality-Infant Mortality in Certain Places and Classes-Workhouse Murder of Infants-How far Preventable - Gentry, Tradesmen, OperativesInfanticide-Child-killing by Opium-Testimony of Rev. J. Clay, Mr. Simon, Dr. Lankester, \&c. - Murder of Illegitimata ChildrenChild Murder in France and America, . . . 17-27

Chapter V.-Poverty and its Evills.

A Network of Evils-The Root of all-The First Step in Reform-Condition of Agricultural Labourers-Former Condition of the PoorRecent Slavery of Women and Children-Horrors of the Workhouse -Dwellings of the Poor-Crowding, Filth, and Indecency-Berkshire Cottages-London Lodgings-English Yeomen-Condition of Children Physical Effects of Poverty-Social Rights and Duties, . 28-37

Chapter IV.-Ignorance.

The British Labourer-Statistics of Education-Dangers of IgnoranceIgnorance and Crime-Compulsory Education-Much more is needed --Matters of Life and Death-Responsibilities of the Educated Classes, and especially of the Clergy-Sins of Ignorance, . . 37-4I 


\section{Chapter VII.-Drunkenness.}

The Prevalence of Druikenness-Causes and Consequences-Cost of Stimulants-Numbers Supported by the Trade-The Spectacle of Drunkenness - Scenes in Liverpool and Manchester-Increase of Drunkenness - The Temperance Movement in England-Medical Testimony-Balance Sheet, . . . . . . 42-47

\section{Chapter VIII.-Dishonesty and Crime.}

Man alone Criminal-Crimes of English Life-Lying and CheatingPerjury-Pecuniary Dishonesty-The Criminal Classes-Statistics of Crime-Cost of Crime-Dishonesty of Servants-Dishonesty ripens into Crime-The Gardens of Guilt, . . . . . 48-55

\section{Chapter IX. - Vice and Immorality.}

Crime and Vice Exceptional-Statistics of Illegitimacy-Morals of England, Scotland, and Sweden-Immorality of the Lower Orders-Mortality of Illegitimate Children-The Gang System-South Wales-Rural Morals-Statute Fairs and Hirings-Middle and Upper ClassesUnequal Numbers of the Sexes-Preference for Unmarried WetNurses-Children Born to Vice-A Sensual Literature-A Lower Deep, $55-64$

\section{Chapter $\mathrm{X}$.-Prostitution and its Consequences.}

Sexual Abuses peculiar to Humanity-Women driven to ProstitutionCorruption by Fraud or Force-Seduction and Prostitution of Children - East End of London-In the Parks-Garrisons-Characters of Prostitutes-Scenes at the West End-Toleration of ProstitutionDemand and Supply - The Evil Consequences-The Plague of Syphilis -Extent of its Ravages-Frightful Disease and Mortality-Effect on the Army-Right and Despotism-Liberty and Law, . 65-80

\section{PART II.-MATTER, FORCE, AND LIFE.}

\section{Chapter I.-MATter.}

Evils and their Remedy-Matter a Mystery-Solid, Liquid, GaseousAtoms and Molecules-No Contact of Atoms-Expansion, Contraction, Elasticity, Vibration-Size of Atoms-Microscopic WondersElementary Bodies and their Combinations-The Earth-The Chief Elements of Nature-Points of Force, . . . . 8I-92

\section{Chapter II.-Force.}

What is Gravitation?-Magnetism-Atomic Attraction and Heat-Cohesion - Repulsive Forces-Attraction of Liquids and Solids for GasesSolution and Crystallisation-Capillary Attraction-Electricity-Galvanism-Is Heat a mode of Motion?-What is Heat?-Force of the Sun-Unused and Unrecognised Forces, 


\section{Chapter III. - Life.}

Organisation-What is Life ?-A Guiding Intelligence-Life precedes Organisation-Necessity of a Self-existent Cause-Genesis of Species - The Darwinian Hypothesis - Characteristics of the Vegetable Kingdom-Variety of Products from the same Elements-Vital Chemistry - Sexual Life in Plants-Vital Mechanism-Nutritive ContrivancesSeed Distribution--Plant Aromas-Functions of Leaves-Contrivances for Reproduction-Protection-Mind, . . . I05-II8

Chapter IV.-Animal Life.

Life in Anımalculæ-Mollusca-Wonders of Insect Life-Insect Transformations-Flies-Bombardier Beetle-Honey Bee-Ants-Fire F'liesSpiders-Fishes-Snails-The Rattlesnake-Birds, their Forms and Plumage-Butterflies-Beetles-Life in the Deep Sea, . 118-132

Chapter V.-Life in the Higher Orders of Animals.

Mammalia-Resemblances and Diversities-Adaptations of Domestic Animals to the wants of Man-The Horse-The Dog-The Camel-The Elephant-Ready Submission to Man-Sagacity and HumanityCharacter expressed in Organism-The Manis-The Beaver-Monkeys-The Gorilla and Orang Outang-The Life of Man-Unity of Life-Infinite Power and Wisdom, . . . 132-145

Chapter VI.-Human Life and Immortality.

The Highest Powers of Life in Humanity-Sexual Life-Social LifeHealth and Disease-Health Forces Spiritual-Radiation of LifeSpiritual Attractions and Repulsions-Spiritual Powers of Animals -Clairvoyance, Dreams, Trance-The Spirit Life-Proofs of Immortality, .

\section{PART III.-THE HUMAN BODY.}

\section{Chapter I.-Bones and Muscles.}

The Human Form our Highest Ideal-Symmetry-The Vital System-The Spine-Cranium-Thorax-Pelvis-Extremities-Mechanism of Joints -Protection of Brain and Organs of Sense-Muscles of the Neck, Face, Eye, Fore-arm-Tendons-Nervous Control of Muscular Action, Habitual Movements-Force of Muscular Contraction, . I6I-1 72

\section{Chapter II.-Brain and Nerves.}

The Brain-Form and Structure-The Ganglionic Nervous System-Mode of Nervous Action-Complexity and Mystery-Origin of NervesThe Brain the Organ of the Mind-Has each Faculty of the Mind a distinct Organ? 


\section{Chapter III.-The Five Senses.}

Sense of Touch-Skin and Nerves of Sensation-Taste-Aided by SmellPapillæ of the Tongue-Uses of Taste-Smell-Odours-Powers of Smell in Men and Animals-Hearing-Phenomena of Sound-Structure of the Ear-Uses of Hearing-Sight-Structure of the EyeWonders of Vision, . . . . . . I8r-I93

\section{Chapter IV.-The Alimentary System.}

Food Elements-Organs of the Oyster-Alimentary Canal of an InsectMucous Membrane-Teeth of Herbivorous, Carnivorous, and Frugivorous Animals-Saliva- -The Stomach-Gastric. Juice-Small Intestines-Ciliæ-Pancreas-Bile-Villi and Follicles-IymphaticsConstipation-Relations of Food to Health, . . 193-202

\section{Chapter V.-The Blood.}

Matter taking on Life-Mechanism of the Heart-Aëration of the Blood-.Course of the Circulation-Capillaries-Distribution of Arteries and Veins-Circulation in a Frog's Foot-Forces of the Circulation-Controlled by Nervous Power,

\section{Chapter VI.-Secretions and Excretions.}

Action of the Lungs-Ventilation-The Liver-The Spleen-The Kidneys -Effects of Animal Food-The Intestinal Glands-Action of Cathartics-The Skin-Pores-Sweat Glands-Chill-How to Strengthen the Skin, 2IO-2I7

\section{Chapter VII.-IDIOSYNCRasies.}

The Four Temperaments-Nature's Counterpoise to Variations-Causes of Idiosyncrasies-Singularities-Physical and Mental Diseases-Moral Responsibility - Manias - Good Souls in Diseased Bodies-SleepInstincts of Time, Locality, Number, . . . . 217-224

\section{Chapter ViII.-Laws of the Bodily Life.}

The Law of Exercise-Effects of Training-Musical and Artistic-Natural Talent-Early Training-Effects of Bodily Exercise-Laziness-Curse of Childhood-Boys and Girls-Law of Habit-Physical HabitsMoral and Religious Habits-Moral Responsibility, . 225-232

\section{Chapter IX.-Life and Death.}

Subjects postponed to Part Fourth-Vital Heat-Equality of Heat-Life in High and Low Temperatures-Origin of Animal Heat-Radiation and Evaporation-The Phenomena of Death-Possibility of the $R e$ surrection-Conscious Identity-Pleasure and Pain, $233-240$ 


\section{PART IV.-THE LAWS OF GENERATION.}

\section{Chapter I.-Vegetable Reproduction.}

Dignity and Importance of the Function of Reproduction-Various Modes of Reproduction in Vegetables-Functions of Flowers-Processes in Fertilisation-Pollen and Germ-True Generation-Formation of Bulbs-..Tubers-Slips, Buds, and Grafts-Spores-Loves of the Plants, . . . . . . . . . 24I-245

Chapter II.-Animal Reproduction.

Varieties of Modes of Reproduction in Animals-Gemmation-FissionRapid Multiplication-Artificial Reproduction-Production of EggsMasculine and Feminine Elements-The Propagation of Fishes, Insects, Birds, the Mammalia-Size of Eggs, . . . 246-250

\section{Chapter III.-Germination and Fecundation.}

Production of Germs in Vegetables, Insects, and Animals - Varying Powers of Reproduction-Office of the Ovaries-Anatomy of the TestesEvolution of Spermatozoa-Results of Impregnation-Changes at Puberty-Peculiarities and Mission of Woman, . . 250-257

\section{Chapter IV.-Embryology.}

Changes at Conception-Fotus in Utero-Size and Development of the Human Ovum-The Hen's Egg-Development of Chick in Process of Incubation-Development of Fishes-Growth of HumanFœetus-Peculiarities of Fœtal Life-Phenomena of Birth-Lactation, 257-266

\section{Chapter V.-Physical Love.}

Sexual Attractions-Blind and Regulated Instinct-Phenomena of Impregnation--Law of Sexual Union among Animals-Normal Period of Conception-Natural Laws of Human Sexual Relations-Law of Exercise-Law of Chastity-Dangers of Childhood and Youth, . 267-274

\section{Chapter VI. - Love and Marriage.}

Sexual Attraction-Various Kinds of Love--Attraction of Opposites-First Love-Spiritual Loves-Loves that should not End in MarriageVarious Forms of Marriage-Sexual Relations of Animals-Reasons for Monogamy-Celibacy-Who Have a Right to Marry-Should Marriage be for Life?-Divorce, . . . . . 275-283

\section{Chapter VII.--Hereditary Transmission.}

Laws of Breeding - Plants and Animals-Darwin on Marriage-Hereditary Transmission of Peculiarities of Race-Mixed Characters Transmitted -Law of Hereditary Vices-Qualities given by each Parent-Influences during Gestation - Blood or Race - Inherited Disease and Moral Predispositions-Fruitfulness and Longevity-Ante-Natal Im. pressions, $2 S_{4}-293$ 


\section{Chapter VIli. - The Laws of Sexual Morality.}

All Laws founded in Nature-The Law for Childhood-The Law for Youth-Equality of the Sexes-Opinion of Dr. Carpenter-Waste of Life-The Law of Chastity-The Law of Marriage - Worldly Morality - "Sexuai Religion"-An Abhorrent Doctrine-The Christian Doctrine of Marriage--The Law of Progress, . . . 293-308

Chapter IX.-Problems of the Sexual Relation.

of the True Marriage-The Relation of Marriage to Love-Limitation of the Number of Offspring-Marital Rights-Woman's Rights and Wrongs - The Religious Rule-The Population Question - Food Resources of Great Britain and Ireland-The Physiological Solution -Ought the Sexes to be Educated together-Dangers of Seduction -Jealousy, . . . . . . . . . 308-320

\section{PART V.-HEALTH, DISEASE, AND CURE.}

\section{Chapter I.-Health.}

What is Health?-Beauty-A Picture of Health-Harmony of LifeActivity - A Condition of Happiness-Exceptional Happiness in Disease-Health Natural-Health of Plants and Animals-Natural Life and Natural Death-The Attainment of Health a moral and religious Duty,

\section{Chapter II.-The Conditions of Health.}

Birth-The Care of Infancy-Diet of Infancy and Childhood-Temperature and Clothing-Influence of Light-Pure Air-Ventilation--Size of Rooms-Ventilation of Towns-Duty of Architects-Sanitary Police-The Natural Food of Man-Stimulants and IntoxicantsClothing and Shelter-Bathing-Sleeping-Work-Society-Chastity -Religion-Righteousness, . . . . . . 328-34I

\section{Chapter III.-Disease.}

What is Disease? - The Mystery of Pain-Theories of Pathology-Classification of Diseases: Zymotic, Constitutional, and Local-Most Diseases Preventable-Efforts of Nature to Expel Matter or Remedy Disordered Action-Two Elements in Zymotic Diseases-Cancer, Scrofula, Consumption-Brain, Digestive Organs, Kidneys-Phenomena and Seat of Diseased Action,

34I-349

\section{Chapter IV.-The Causes of Disease.}

Hereditary Taint and Predisposition-Darkness-Malaria - Contagion Impure Air-Food, Famine, Excess - Condiments-Impure and Hard Water-Stimulants--Clothing and Shelter-Mortality from ColdDiseasing Fashions-Excessive Labour and Unhealthy Employments 
-Amative Excess-Solitary Vice-Moral Causes of DiseaseDouble Origin of Contagious Diseases-Scrofula-Consumption Syphilis-Brain and Nervous System-Effects of Narcotics-Heart and Circulation-Dyspepsia-Constipation-Vegetable, Animal, and Mineral Poisons_Drugs as causes of Disease, . . 349-368

Chapter V.-The Prevention of Disease.

Sanitary Legislation-Testimony of Dr. Playfair-Status of the Medical Profession-Case of the Murdered Convicts-Sanitary EducationEffects of Disinfectants - Quinine-Vaccination - Sanitary Inspection, . • • • .

Chapter VI.-Medical Systems and Practice.

Priests Anciently Physicians-Hippocrates-Celsus-Galen-Paracelsus - Conflicting Theories of Disease and Medicine-Medical Delusions Herbalists-Homœopathy-Hydropathy-All Systems Successful-Nature Cures-The Gift of Healing-Women as PhysiciansEclecticism, . . . . . . 375-384

Chapter Vil.-Hydropathy; or, The Water Cure. Water Cure Natural-Its Wide Repute-Its Striking Effects-The Wet Sheet Pack - Water Cure in Miasmatic and Contagious Diseases-Diseases of Women-Childbirth-Turkish Bath and Artificial HeatDangers of Heroic Treatment-Law of Adaptation-Invigoration of Cold-Sitz Baths - Bandages-Apoplexy-Fasting-Cancer-Scrofula -Obesity-Change of Air-Consumption-Asthma - Will-LightFaith, . . . . . . . 384-400

\section{PART VI.-MORALS AND SOCIETY:}

Chapter I.-The Moral Basis of a True Society.

The Law of Life-Human Disorder-Man a Social Being-Upward Tendencies of Humanity - Natural Conscience-Perception of Justice-The Laws of Morality Simple and Self-Evident-Morality the Basis of a True Society-Morality of the Bible-War and Peace, . 401-407

Chapter II.-Human Rights and Responsibilities.

A True Society Natural-The Rights of Man-Individual Property in Light, Air, Water, Land - No Absolute Right of Property-Eminent Domain - Mines and Fisheries - Emigration - Responsibilities of Ownership or Possession-Production and Distribution, . 407-414

\section{Chapter III.-LeAdership.}

The Principles of Social Order-Every Body must have its Head-Illustrations in Music and Architecture-The Uses of an AristocracyCaptains of Industry - The Work for Noblemen, Landed Proprietors, and Capitalists,

$4^{14}-418$ 


\section{Chap'ter IV.-Economies of a True Society.}

The Waste of Life-A Nation of Shopkeepers-The Robbery of IdlenessCo-Operation and Trade Reform-The True System of Trade-False Ideas of Gentility-Examples of True Dignity and Nobility-The Frauds of Labour-General Distrust and Social War-Higher Aspirations-Economy of Honesty-Efforts at Reform-Mr. Roebuck on Working-men,

$419-426$

\section{Chapter V.-Social Theories.}

Social Systems of Moses, Plato, the Early Christians-Communism of the Religious Orders-Shakers, Rappites, Mormons-Owen, Cabet, IVarren-Fourierism-The Phalanstery-Adaptation to English Life -Rural Associations-Social Organisation in Towns-Economies and Advantages-Working Men's Clubs-Suburban Societies, 426-439

\section{Chapter VI.-Difficulties of Social Organisation.}

The Difficulty of Caste-What should determine Social Position-Moral Influences of Association-Habit and Education-Feminine Helplessness-The Difficulty of Bad Manners-Masculine Professions-The Religious Difficulty,

439-449

\section{Chapter VII.-Government and Political Economy.}

Social Tendencies-Functions of Government-Circulation of Intelligence - Transport of Goods and Passengers-Insurance-Distribution of the Necessaries of Life-Order and Regulation of Social Interests-Diabolic Elements of Political Economy-The True Principle of WagesRent, . . . . . . . . . . 449-462

\section{Chapter VIII.-Education.}

Its Power Limited by Natural Differences-Effects of Early TrainingClassical Learning, Pagan-The Motives of Education-Success in Life-Competitive Examinations-True Object of Education-Must be Physiological-Education of the Bodily Powers, Senses, and all Faculties, . . . . . . . . . 462-468

Chapter IX.-Social Principles and Preparation.

Remedies for Social Wrongs-Revolutions-Division of Property-Burthens of Labour-Abuse of Riches-True Uses of Wealth-Rapid Social Transformations-Individual Preparation-Orderly Progress-Training in Honesty-A True Society can only be founded in Equity-The Speaker, Earl Derby, Lord Napier-The Human Constitution the Model of Human Society. 
Snow Crystals,

Section of a Leaf Magnified,

Section of a Pistil Magnified,

Gnats Emerging,

Sting of the Honey Bee Magnified, .

Poison Fang and Rattles of the Rattlesnake,

The Bird of Paradise,

The Manis, .

Skull of the Beaver,

Tail and Feet of the Beaver,

Skull of the Orang-Outang, .

Foot of the Orang-Outang, .

Brain and Nerves of Man,

The Vital System,

The Brain Exposed,

Muscular Fibre,

Transverse Section of the Neck,

Muscles of the Face,

Muscles of the Eyeball,

Pronators of the Fore-Arm, .

Tendons and Arteries of the Hand, .

Termination of Muscular Nerves,

Longitudinal Section of the Brain, .

Brain and Nerve Matter Magnified, .

Minute Nervous Structure,

Nervous System of Insects,

Ganglion of a Sympathetic Nerve,

Pores, Papillæ, and Neryes of the Skin

Blood Vessels in Papillæ of the Tongue,

Labyrinth of the Ear,

Section of the Eye, .

Organs of the Oyster,

PAGE

98

I 14

I 14

123

126

129

130

137

137

I 38

140

I4 I

I 63

I 63

I 65

167

I67

I 67

168

169

170

I 7 I

173

174

I 75

176

180

182

I 84

I 88

I 90

194 
Alimentary Canal of an Insect, Skull of Carnivora,

Glands in the Coat of the Stomach, .

Ciliated Epithelium, .

Villi and Follicles of Intestines,

Lymphatics of Small Intestines,

Heart and Lungs,

Heart and Lungs, showing Blood and Air Vessels, . Arteries and Veins of Head and Neck,

Capillaries in the Skin,

Injected Veins from Coat of Intestine,

Circulation of the Hand,

Arteries and Veins of an Intestinal Villus,

Circulation in a Frog's Foot,

Section of Kidney and Portion Magnified,

Section of Skin and Sweat Gland Magnified,

Vertical Section of the Skin,

Uterus, Ovaries, Fallopian Tubes,

Anatomy of the Testes,

Evolution of Spermatozoa,

Fotus in Utero,

Human Ovum,

Ideal Section of Hen's Egg,

Hen's Egg, Third Day of Incubation,

Embryo Fowl of Eight Days,

Mammal Ovum,

Diagram of Natural Birth, .

Mammary Gland, 


\section{HUMAN PHYSIOLOGY}

THE BASIS OF SANITARY AND SOCIAL SCIENCE,

$$
\text { PART FIRST. }
$$

THE ACTUAL CONDITION OF HUMANITY.

\section{CHAPTER I.}

\section{MAN AND HIS RELATIONS.}

Physiology defined-The Law of Life in Organisation-The Natural Basis of Morality-Human Progress-Man differs from all other AnimalsMoral Responsibility-Reason and Instinct-Man alone a Religious Being-Population of the Earth-Destiny of Savages-England a Model Nation.

Physiology means, literally, the Science of Nature (physis, nature, and logos, discourse or science); but the word is used to signify Science of Life. The term Biology more accurately expresses this meaning, but it is not so generally understood, and has been perverted to other uses.

Humau Physiology is the science which treats of the organs of the human body and their functions. In treating of the brain, or the organs of sensation, perception, or thought, we enter upon the domain of Psychology (psyché, the soul, and logos, a discourse), so that Physiology includes Psychology. We have also Vegetable, Animal, and Comparative Physiology, 
the latter being a comparison of the organs and functions of various forms of life.

In this work I propose to consider, first, the actual condition of Man, and of Humanity; to say something of man's origin and place in nature; of his relations to the material world; and then to give such an account of his organs and their functions, in every part of his being, as may enable the reader to understand his nature-its capacities for use and enjoyment, and the causes of the evils of life and their remedies. The nature of man must reveal the law of his life.

As I have said in the Prospectus to this work:-

"The Law of Life for Man, as for all living things, is written in his organisation.

"'The Constitution of Man; his Physiology, including his Psychology; his relations and adaptations to nature; his instincts, passions, sentiments, and intellectual faculties show us his origin, his natural condition, and his destiny.

"In the physical and mental organisation of man we have a guide to the conditions of health, the causes of disease, and the best methods of prevention and cure. Human Physiology contains, therefore, the whole ground work of Sanitary Science.

"We must also look into the nature of man for a true system of Education, the foundation of Morality, a rational system of Politics, the principles of Political Economy, and the laws of Industry, Art, and Society.

"The Science of Physiology, profoundly and comprehensively considered, shows us man's place in nature and his relations to his fellow-men, and gives us the clearest view 'we can have of his powers, duties, and responsibilities, his capacities, attractions, and possihilities of happiness ; and also, in harmony with Divine Revelation, gives us the evidence and assurance of a continuous existence, or conscious immortality.

"Human Physiology is, therefore, for us, the science of sciences, displaying the mind of God as written in the most 
perfect of His works subject to our observation, and giving us that knowledge of ourselves which must be the basis of individual and social progress and well-being.

" To live wisely on the earth we must know our relations to matter, elements, and forces, and the vegetable and animal creation. To live usefully and happily with our fellow-men, we must know ourselves and them, and our mutual relations and duties, sympathies and antipathies. Especially must we know the mutual relations of the sexes, and of parents and children, for these are the basis of morals and society. Lacking the instincts which guide the lower animals infallibly into the conditions and modes of life to which they are adapted, we need knowledge, science, the guidance of reason, and an enlightened conscience, which cannot fail to be in harmony with the will of a beneficent Creator.

"Every portion of this Science of Man needs to be carefully and reverently studied. No part can be rightly or safely omitted. The propagation of the human race, and the hereditary transmission of physical and mental qualities, are subjects of the highest importance to every human being. Nor is it possible to treat of morals and society, and the duties of men and women in their most intimate and sacred relations, without a knowledge of the elements which form the basis of such relations; for I believe that it can be clearly shown that the laws of nature are in perfect harmony with the demands of morality, and that virtue and religion require nothing which is not the highest good of every creature."

If I am right in this belief, those who hold and teach the contrary are fearfully wrong. Professedly scientific works are very widely circulated which denounce the morality of law and religion as an injury to man and society; which counsel the young of both sexes to throw off all restraint, and abandon even the pretence of virtuous principles and conduct. It is time that such doctrines, propagated with the avowed intention 
of introducing universal licentiousness, should be inet upon purely scientific grounds. It is not enough to exhort people to temperance and chastity: we must show them that Nature herself requires them, and that they lie at the foundation of health and happiness.

Man has lived upon the earth we know not how many thousand years. His records and monuments reach back at least four thousand years. At the earliest historic period he had a considerable degree of civilisation-he worked in metals, made clothing, ornaments, arms, and musical instruments, built magnificent edifices, and spoke and wrote noble and beautiful languages. It can hardly be said that man has made much progress in language from Sanscrit or Greek; in architecture, from the temples of Egypt and Greece; or in sculpture and poetry, from Praxiteles and Homer. Assuredly, the course of humanity has not been regularly progressive; development has been arrested; the countries and races which led and governed the world three or four thousand years ago, have fallen into barbarism. There are monuments whose meanings are unknown, and whose builders are forgotten, dead languages and lost arts, architecture and sculpture we are content to imitate, but have no hope of excelling.

We need but glance at the little that is known of human history, to see how much man differs from all other animals. As far back as we can trace him, he built cities and temples; organised empires ; and led armies to conquest ; and revelled in beauty and song. Some animals prey upon others to satisfy hunger; men alone organise great armies to slay each other. The males of some species of animals combat for the possession of females; men fight for ambition, glory, and a name which shall be honoured or execrated by posterity. Animals are content to satisfy hunger and thirst with the food nature provides for their wants; men have 


\section{Human Physiology.}

invented luxuries of food for gluttony, drinks that intoxicate, narcotics that excite, deprave, stupefy, destroy health, and shorten life.

Every animal lives simply and honestly, according to the law of his life, and we call no beast immoral, or hold him to any responsibility for his conduct. Men we love and hate, praise or blame, honour or despise, as they are good or bad-as they obey or transgress what we feel to be the true law of humanity.

Man is thus a distinct being, widely and radically different from all others on our planet-a moral being, knowing right and wrong, good and evil; an intellectual being, measuring the stars, calculating the eclipses of the sun for thousands of years to the fraction of a second; writing poems and composing operas; painting pictures; modelling statues and building cathedrals - $\mathrm{a}$ religious being, believing in God and immortality.

In his knowledge and his ignorance, his virtues and his vices, his benevolence and his cruelty, his heroic deeds and his base and shameful misdeeds and crimes, man is widely separated from the whole animal creation. We cannot conceive of a dog or an elephant becoming a Homer or a Plato, a Shakespeare or a Newton; yet we see that every animal has the knowledge it requires. Every bird knows how to obtain its food, build its nest, and rear its young. It can find its way from England to the shores of the Mediterranean in the autumn, and in the spring come back to the tree on which it first broke through its shell. The salmon, without chart or compass, after its wanderings through many seas, comes back to its native river. The bee does not go to school to learn how to gather wax and honey, construct its cells, and order its government, economies, and sanitary regulations. Man must learn everything he requires to know, and often perishes for lack of knowledge. He eats food that shortens his life, 
drinks beverages that destroy his health and senses, and from sheer ignorance, lives in conditions that breed pestilence and destroy whole populations. Man is the only creature on this earth who is, in multitudes of instances, ignorant and helpless, while he is the only one capable of vast acquirements of knowledge. Every other creature is limited in its capacities for improvement, and most of them through thousands of generations show neither improvement nor deterioration. But man can rise to the sublimest heights of wisdom and virtue, or sink into the lowest depths of ignorance, vice, crime, and misery.

Man alone, of all earthly creatures, believes in God and inmmortality. Either he has had the power to conceive the ideas of a Creator of the universe, and of a life beyond the grave, or they have been revealed to him. We have no reason to believe that any of the animals to which man is by some supposed to be allied, or from which he is held to have been descended, ever conceived, or is capable of receiving the idea of a creative intelligence or a spiritual life.

Man is the only creature we know, who is capable of studying his own nature, faculties, duties, and destiny. To all others such knowledge would be useless. To man it is of the most urgent necessity. Let us, then, consider what man is, and what he should be.

The human population of this planet is estimated at about one thousand or twelve hundred millions. The population of China alone is said to be three hundred millions. As the Chinese Empire is not one tenth of the earth's surface, it is evident that the earth is but sparsely peopled. The surface of the earth has an area of one hundred and fifty millions of geographical square miles. If we deduct two-thirds of this space for water and other uninhabitable regions, we have left fifty millions of square miles. Portions of Belgium have five 


\section{Human Physiology.}

hundred people to the square mile. There are tropical countries that can sustain one thousand to the square mile. If we take the actual population of some of the Belgian provinces as a fair average of the capacity of land under high culture to support inhabitants, the earth might feed twentyfive times its present population-twenty-five billions. For ages to come, therefore, the population question which has given so much trouble to political economists, is only a question of emigration, colonisation, the distribution of surplus populations, and the subjugation and cultivation of man's heritage.

The life of each generation of men is reckoned at thirty years. In a thousand years, therefore, thirty-three generations -thirty-three thousand millions pass through this stage of being.

In considering the present and probable future condition of man on the earth, it is not necessary to take much account of the savage tribes which are disappearing from America, Australia, South Africa, and the Islands of the Pacific Ocean. In a few generations these countries will be entirely peopled by descendants of English, Scotch, Irish, and German emigrants, with lesser intermixtures of the Scandinavian and Latin races of Europe. The Chinese and Japanese may help to people the western shores of America; China and India may rise to a higher phase of civilisation, or sink before the more energetic populations of the Sclavonic or Anglo-Celtic races. The problem of the civilisation or extinction of the Negro tribes of Africa will be settled during the coming century.

I propose in this work to consider the condition of man in the highest civilisation to which he has attained, and I shall therefore take England as an example of the highest development of human industry, commerce, wealth, and moral and political power and greatness. Other nations, no doubt, are in advance of England in certain particulars. Education is more general and thorough in Germany and Switzerland, and 
there is more equality of condition and intelligence in America; the French excel in taste and art culture; the lower classes are more comfortable in Spain and Italy; still England may be taken as, on the whole, an example of what is called civilisation, progress, science, Christianity, and the highest condition of humanity. What this condition really is, I propose now to consider.

Being of English race and American birth, and writing primarily for English-speaking peoples, I can the better and more properly draw my examples from the countries in which I have mostly lived, and with which I am best acquainted.

\section{CHAPTER II}

\section{PREMATURE AND PREVENTABLE MORTALITY.}

Natural Death-The Age of Man-His Triple Warfare-Responsibilities of the Governing Classes-Statistics of Mortality-Death-Rate in the English Metropolis-The Battle of Life.

To the physiologist it is evident that the only natural death is the death of old age. We expect every living thing to come to maturity, perform its uses; decay and die. A plant springs from its germ in the spring, produces its flowers and seeds in summer and autumn, and in winter perishes. A tree may last a thousand or several thousand years, bearing as many generations of leaves, flowers, and fruitage. There are insects of a day, and animals that live for more than a century; but, accidents or violence excepted, all things live out their natural term of life.

In the order of nature men should live about one hundred years. There are numerous instances of men and women 
living more than a century, and there are several modern instances of persons living from one hundred and twenty to one hundred and forty years. The obituary column in the Times newspaper nearly every day gives numerous cases of persons living from eighty to one hundred years. Men not unfrequently marry and have families when past seventy, and men of eighty, and even of ninety, have led armies, governed kingdoms, and filled the highest offices of state. A man who is well born, and who lives well, should live long. With a healthy constitution inherited from a pure and vigorous ancestry, with proper habits and employments; breathing pure air, eating pure food, drinking pure water, avoiding all diseasing influences and conditions, what is to hinder any one from enjoying the blessing of length of days, the ripening of wisdom, the full use and benefit of this earthly life?

When we look at the human body, with its powers of nutrition and reparation, we cannot see why its life should ever come to an end. But all nature shows us that the bodily life is a limited quantity, and cannot last for ever. It is the law that all earthly forms of existence should cease; but it is no less an evident intention of nature that all should live out their proper term of existence.

It will be seen, however, that men are at war with nature, with each other, and with themselves; and in this triple warfare they are destroyed with a great slaughter. They war with nature in poisoning the air they breathe, the water they drink, and the food with which they are nourished; by living in the indulgence of exhausting passions and vices, and engaging in unhealthy and destructive occupations. They war with each other by competition, lying, cheating, corruption, seduction, robbery, oppression, slavery. Men are robbed of the soil which is their common birthright; of the stored up treasures of coal, iron, tin, copper, silver, and gold, which are the property of all; and in all our towns are robbed of needful space, fresh 
air, and enlivening sunshine-robbed of life itself, in being. robbed of its necessities and enjoyments. And man makes war upon himself by his vices. Contented with his ignorance he does not seek enlightenment; wallowing in his pestiferous filth, he will not even wash and be clean, or open his windows for pure air; and he stupefies and embrutes himself with stimulants and narcotics-beer, spirits, and tobacco-spending on them the money that would place himself and his family in comfortable and healthful conditions.

Vast numbers are born and bred in these conditions and habits of life, and are too ignorant to know what is bad or good for them. It is their misfortune rather than their fault. But it is the fault of somebody that they are born, and live, and die in such conditions. The men who govern England are responsible for England's condition, as the captain of a ship is responsible for the condition of ship, cargo, and crew. They have acknowledged their responsibility for the sustenance of every member of society by the Poor Law; and for the ignorance of vast populations by enacting a law for universal education. They are beginning to confess their responsibility for disease and premature mortality by various acts of sanitary legislation. There is much more to be done, but this is a beginning; and it is a good thing that men of intelligence, wealth, and influence, should acknowledge in these matters the brotherhood of humanity. The time is not distant when no man will feel that he has a right to send his son to Eton and Oxford while the poorest child in England is untaughtas every one must feel that he has no right to sit down to a luxurious dinner while there are people within the circle of his horizon dying of hunger.

I know of nothing which shows more terribly the inequity of human life-or call it, if you will, iniquity-than the statistics. of mortality.

In Germany, Austria, and all the central parts of Europe. 


\section{Human Physiology.}

the average death-rate is 29 to 30 per rooo per annum. This means that in none of these countries do the people live on an average thirty years. In the cool and sparsely-peopled Scandinavian countries, the average life is forty-four years. But for lust and drunkenness, it would be sixty years. In Belgium, with the densest population of Europe, the death-rate is the same as in France and England-22 in 1000; while in Ireland and Scotland, two of the healthiest countries in the world, the death-rate is $\mathbf{I 7}$ in rooo. The lowest death-rate in the healthiest rural districts of England is I I per roo०; and even here there is a considerable proportion of preventable mortality. All do not die of old age. But if we take I I per rooo as the minimum, or a fair approximation to healthful life and natural mortality, what shall we say of the national average, 22 per rooo-just double; or of the mortality of such towns as Liverpool and Manchester, where the death-rate rises at times to 45 per rooo?

In the metropolis, the general death-rate is about 24 in 1000; but it varies very widely in different districts. In the West End, and many of the suburbs of London, such as Hampstead, Highgate, Campden Hill, Kensington, Brompton, Clapham, Brixton, where there is a gravelly soil, good drainage, open spaces, and a wealthy and intelligent population, the death-rate is not above 15 in rooo; and, but for the mews and slums into which the poorer classes are crowded even in the best districts, would be still lower-as low perhaps as the minimum in the rural districts. But in the centre and East of London, in St. Giles's, Gray's Inn Road, Lambeth, Bethnal Green, and a score of similar districts, the mortality is as great as anywhere in England.

A map of the metropolis shaded according to the rate of mortality, would be very light, with dark spots here and there, over a large area; while certain portions, perhaps one-fifth of the whole, would be the blackness of darkness. And in these 
portions would be found crowding, filth, imperfect drainage, stagnant air, bad or deficient water-supply, adulteration of food, the refuse of the markets, drunkenness, vice, crime, and every form of human wretchedness.

It is only in the human race, or among animals subjected to the rule of man, that we find such differences of condition.

It is calculated that, by public sanitary measures alone, the general death-rate of the metropolis could be reduced from 24 to 18 per 1000. This would be saving the lives of more than twenty thousand persons yearly, for whose deaths the authorities are now responsible.

The amount of sickness prevented would be in proportion to the saving of life; and for this sickness also, and all its cost, and loss, and suffering, those who govern the country are strictly responsible - for the pain endured, the anxiety felt, the loss of labour and wages, cost of medical attendance, increase of rates; the thousand miseries of fever-stricken populations. If parliament or municipal bodies did their duty there would be few deaths by measles, scarletina, small-pox, typhus or syphilis.

We shudder at the slaughter of great battles, but the annual preventable mortality of our large towns is equal to that of most battle-fields. The yearly account of London is,-killed, 20,000; wounded, 200,000; while Liverpool, Manchester, Glasgow, \&c., suffer in still darger proportions.

Is it not time that the educated and influential members of society-the nobility and gentry, the clergy, the press, members of parliament and of municipal bodies-should take an account of their responsibilities, and be ready to answer the cry of God - "Where is thy brother Abel?" 
CHAPTER III.

THE MORTALITY OF CLASSES AND CONDITIONS.

Death-rate in Town and Country-Sanitary Influence of AltitudeDrainage - Comparative Longevity of Gentry, Tradesmen, and. Working Men-Moral Causes of Excessive Mortality-Whose the Fault?

IT was shown in a sanitary report made to parliament some years ago, that in the healthy and almost entirely rural county of Hereford the annual mortality was $\mathrm{I}$ in $64-15 \frac{2}{3}$ in 1000 of the population; in Oxfordshire, $I$ in 50 ; in Lancashire, I in 32.

In the town of Preston the annual deaths were $\mathbf{I}$ in 33 ; in Broughton, a rural suburb, $\mathbf{x}$ in $5^{6 .}$

In London, the mortality in some districts was $\mathbf{I}$ in 28 ; in others, $\mathbf{I}$ in $\mathbf{5 7}$.

In Manchester one twenty-eighth of the people were swept away annually, while in one of its suburbs the deaths were only one sixty-third.

In the best part of Rochdale the deaths among citizens of the same class were I in 43; in the worst, I in 22.

In Leicester, the stocking-weavers living in the best parts of the town lived on an average $25 \frac{1}{2}$ years; those in the worst, I 7 years: the difference here was chiefly in drainage, as in Rochdale.

In London the average of fever was I case to 690 people; but in certain alleys the proportion rose to $I$ in 20 ; and there were parts of Liverpool where the fever cases were I to every 7 or ro of the population.

Elevation often makes a great difference in healthfulness. It was not for nothing that castles and villages were perched upon the hills. A high position has a finer and purer air, and 
a better chance for drainage. At the fine pleasure town of Bath the deaths in a low-lying district were $I$ in 40 ; in an elevated quarter, $\mathrm{I}$ in 76 ; but it is to be observed that the high district was inhabited by the rich, the low one by the poor, and that in this country the crime of poverty is punished by death. Still, elevation, or the lay of the land, makes a great difference. Three regiments were quartered on a hill rising 872 feet above the sea. The regiment on the top lost $27 \mathrm{I}$ men; that on the side, 368 ; the one at the bottom, 486 .

In the drained streets of Nottingham artizans lived $30 \frac{1}{2}$ years; in the undrained, 17. A sensitive person can feel the difference in dryness and warmth between a London street on a clay soil and one on gravel, and a well and ill-drained district. Farmers say the drained land makes the difference of a great-coat in the temperature, and more, in freedom from rheumatism. Perched on the gravelly Malvern hills, I can see a thin veil of mist hovering over every cold, damp spot in the Severn valley, and could make a map of the healthy and unhealthy localities. Clay and gravel, damp and dry soils, are different as sickness and health-death and life.

The difference in mortality among different classes in society, living in the same distrists, but in very different conditions, is very remarkable. The rich have good houses, plenty of room, the conditions and generally habits of cleanliness, gardens and open spaces, pure air, more sunshine, more and better clothing, and better food than the classes below them. Shopkeepers live among their customers, breathe the same air, and are subject to many of the same evils. The workmen, artizans, and the poorer classes take the refuse of all; live in the worst districts, crowded together, and in the worst habits and conditions.

In Bath, a pleasure town, and of course a remarkably healthy one, the average age at which the gentry, professional classes, and their families die was, in 1845,55 years; tradesmen and 


\section{Human Physiology.}

their families, 37 years; mechanics, labourers, and their families, 25 years.

In the county of Wilts the gentry reach the average age of 50 ; farmers and their families, 48; agricultural labourers and their families, 33 .

Contrast this comparatively healthy rural district with some of the towns of England at the period mentioned.

AVERAGE AGE AT DEATH.

York, city

Preston $\ldots \quad \ldots \quad \ldots$

Sheffield ... $\quad . . \quad \ldots$

Liverpool

Swansea

Merthyr Tydvil

Manchester

Gentry. Tradesmen. Workmen.

In London, as I have already observed, there are great differences in the different districts. Thus, three unions, each comprising very poor and wretched districts, gave the following results :-

St. George's, Hanover Sq.

Strand

Bethnal Green

Gentry. Shopkeepers. Artizans.

$$
\begin{array}{lllll}
45 & \ldots & 29 & \ldots & 27 \\
43 & \ldots & 33 & \ldots & 22 \\
45 & \ldots & 26 & \ldots & 16
\end{array}
$$

The differences in Liverpool as to salubrity of districts, and the astonishing mortality of shopkeepers, as well as the working classes, were stili more remarkable:-

Gentry. Shopkeepers. Artizans.

Great Howard Street

St. Thomas

St. George

Islington ...

Mount Pleasant

Dale Street $\begin{array}{llllll}62 \frac{1}{2} & \ldots & 17 \frac{1}{4} & \ldots & 14 \frac{1}{4}\end{array}$

$\begin{array}{llllll}62 & \ldots & 20 \frac{1}{4} & \ldots & 17\end{array}$

$\begin{array}{llllll}41 \frac{1}{4} & \ldots & 18 \frac{3}{4} & \ldots & 15\end{array}$

$\begin{array}{lllll}39 \frac{1}{4} & \ldots & 18 & \ldots & 16 \frac{3}{4}\end{array}$

$\begin{array}{lllll}39 & \ldots & 20 & \ldots & 19\end{array}$

$\begin{array}{lllll}34 \frac{1}{2} & \ldots & 18 & \ldots & 17\end{array}$ 
Thus the "chances of life" of people of one class, living in one street are 15 years, and of people of another class, in another street, 60 years-four times as great. The wicked, it is said, do not live out half their days; but these figures prove that the poor and ignorant people of this Christian countrythe working people who support themselves and all above them by their labour, do not, in whole districts, live out one quarter of their days.

It must be observed, also, that there are moral differences in these classes, which are not without their sanitary influence. The rich, and especially the gentry who live on fixed incomes, have a freedom from care which tends to increase longevity. A pension or annuity prolongs life, and removes its sorest burthens. The struggling tradesman, and the artizan half his time out of work, have cares and anxieties that kill. Care eats deep lines into the faces of the poor. The rich also have variety and recreation in their lives, society and amusement. The lives of the poor are dull and monotonous, and all their conditions and surroundings are depressing. What of liveliness is there in the lives of great multitudes around us?

Clearly it is not the fault of these short-lived people that they are born in poverty, and grow up in ignorance. It is not their fault that they are nursed on gin, play in the gutter, and are, in their earliest years, saturated with all the evils around them. They have no power to help themselves. The slaves of the Carolinas were better provided for, and not more helpless. The wealth they create they do not enjoy. Those who have it, without ever doing one day's work in their lives, live in luxury for sixty years ; those who create it crowd filthy lanes and courts, garrets and cellars, and live on an average fifteen or twenty years.

This average of mortality, of course, includes a vast and terrible amount of infant mortality. One-third of all who die in England are under five years old; in many towns, of 
districts of towns, and among great masses of our population, this proportion reaches to one-half or more-so cheap is human life in the highest civilisation. But this "Massacre of the Innocents" requires a separate chapter.

\section{CHAPTER IV.}

INFANT MORTALITY AND INFANTICIDE.

Conditions of Infancy-General Statistics of Infant Mortality-Infant Mortality in Certain Places and Classes-Workhouse Murder of Infants-How far Preventable - Gentry, Tradesmen, OperativesInfanticide-Child-killing by Opium-Testimony of Rev. J. Clay, Mr. Simon, Dr. Lankester, \&c.-Murder of Illegitimate ChildrenChild Murder in France and America.

THE causes which produce the premature mortality of men and women, act with double force on children. Healthy and long-lived parents have vigorous offspring; but the children of the poor and wretched inhabitants of our large towns inherit weakly constitutions; they are poisoned before their birth; their natural food is poisoned; the air they breathe is corrupted ; they are deprived of maternal love and care ; in many cases they are drugged into insensibility by those who consider them a burthen, and they die by thousands. When it is stated in official reports that the average age of all who died during certain periods of time, in Bethnal Green, was twenty-one years; in Leeds, twenty-one; in Manchester, twenty; in Bolton, nineteen; in Liverpool, seventeen years, it is meant that more than half of all that were born, died before they were five years old.

Such mortality, let me observe in passing, can be found in no other species of animals. They may be killed, but they do 
not die. In a state of nature, ninety-nine hundredths of all animals born would live out their natural lives, if they were not shortened by violence. Among men, from one-third to one-half die in infancy, and in many places the average life is but one-fourth or one-fifth of what nature intended. If natural selection has brought the human species to this condition, a reversion to some anterior type would be progress in the right direction. Mr. Darwin cannot think that nur monkey ancestors had such bad luck with their babies.

A report of the Registrar-General tells us that- "of the deaths in England in 1859, no less than 184,264-two in every five of the deaths of the year-were of children under five years of age; and above half of these-ro5, 629 -had scarcely seen the light, and never saw one return of their birthday."

More recent reports put the infant mortality of the kingdom at 43 to 45 in roo. It is probable that the infant mortality of England exceeds that of any country in the civilised world. And the published statistics are below the facts; for, there can be no doubt that thousands of infants perish whose remains are never discovered. Multitudes of the still-born are never recorded. By acciderr or design, or, as the result of men's disordered passions, there is ever going on a vast destruction of human life, in its earliest stages, such as does not exist in any other species; for of man alone can it be said, "Sin came, and death by sin."

But the recorded mortality in infancy is sufficiently terrible. In the ten years, $185 \mathrm{I}-60$ four million deaths were recorded for England and Wales, and of these nearly two millions occurred in children under five years of age.

The destruction of infant, as of adult life, is enormously greater in some places, and in some classes, than in others; and in this view of the evil, we have a full grasp of the remedy. We have only to raise the worst places, and the lowest classes, 


\section{Human Physiology.}

to the level of the best and highest, in respect to the conditions of health, and we shall secure to all the minimum of disease, and the maximum of longevity.

According to an official report, out of roo deaths of all ages, those of children under five years of age were in

Children.

Children.

$\begin{array}{lllllll}\text { Ashton } & \ldots & 57 & \text { Manchester } & \ldots & 48 \\ \text { Preston } & \ldots & 53 & \text { Leicester } & \ldots & 43 \\ \text { Liverpool } & \ldots & 5^{2} & \text { Gloucester } & \ldots & 4 \text { I } \\ \text { Salford } & \ldots & 5^{2} & \text { York } & \ldots & \ldots & 3 \text { I } \\ \text { Bradford } & \ldots & 5^{1} & \text { Lancaster } & \ldots & 29 \\ \text { Sheffield } & \ldots & 49 & \text { Whitby } & \ldots & \ldots & 26\end{array}$

Observe that infant mortality in Liverpool was exactly double that in Whitby, and more than double in Preston and Ashton. If we could take accounts of the worst parts of some of these towns, and the poorest, and therefore worst-lodged portion of their inhabitants, the figures would be more striking. The mortality among the children of factory operatives is simply appalling, when contrasted with that among the children of the gentry.

More than half the children of the working classes die,-and in some cases the proportion reaches nearly two-thirds-and only one-fifth of the children of the upper classes die, before they are five years old. "Of one thousand children born of poor parents, in Manchester, there are five hundred and seventy who die before they have reached their fifth year. In seven years, thirteen thousand three hundred and sixty-two children have died there, above the average rate of deaths."

In Sunderland, just one half of all that are born, die in infancy. In special cases, the mortality among infants amounts to extermination. A writer in the Financial Refor mer, some years ago, endorsed as "a gentlemen of station and high character," said:- "I state as a fact, which I am 
prepared to prove by credible witnesses before a committee of the House of Commons, that in the united parishes of St. George, Bloomsbury, and St. Giles, for which I am rated, there is not one instance, in living memory, of an infant surviving the treatment in this workhouse. There are now in this workhouse between 80 and 90 infants; and, according to all experience, not one of these will be living this time next year. One wretched pauper woman has the charge of all the poor victims of this brutal system. Their food is the coarse workhouse bread, soaked in boiling water, tinged with what is. called milk. With this, as they lie in rows, they are stuffed till they die, as, of course, they very soon do; or very soon. there would be no room to lay them out in. They are coming. in every hour of the day and night, and as they come so they go. Nobody knows-nobody cares."

Mr. Chadwick, one of a deputation from the Metropolitan Association of Officers of Health to Lord Palmerston, to whom they went to tell their experiences of the state of dirt and disease in which they found children in the public schools, stated his belief that, out of about sixty thousand children who died annually in England and Wales, within the school ages, as many as fifty thousand might be saved!

Lord Palmerston told the deputation that in respect to pure air and pure water he was a converted man; but since that time, though the nation has spent many millions on army, navy, useless officers of state, and wars that might have been avoided, little has been done to save the lives of the fifty thousand school children who every year needlessly perish.

That vast numbers perish who might be saved, is proved by such a return as the following:-

In the Gray's Inn district of London of too deaths of all ages in the best houses, 29 were children under 5 years; in the worst houses, 55 under 5 years.

In Preston, of roo deaths in each of the classes of gentry. 
tradesmen, and artizans, those under five years of age weregentry, 18; tradesmen, 36 ; artizans, 55 .

Many taxes press most heavily on the poor; but the taxes of disease and death most heavily of all The infant deathrate of the tradesman is just double that of the gentleman; that of the artizan is treble!

According to the town registers, if 100 of each class were born at the same time-

\section{Gentry. Tradesmen. Operatives.}

Born . . . $100 \quad \ldots \quad 100 \quad \ldots \quad r \quad 100$

There would remain

$\begin{array}{lllllll}\text { at end of } 1 \text { st year } \ldots & 90 & \ldots & 79 & \ldots & 68 \\ \text { end of } 2 \text { nd year } & \ldots & 87 & \ldots & 73 & \ldots & 57 \\ \text { end of } 3 \text { rd year } & \ldots & 82 & \ldots & 6 r & \ldots & 44\end{array}$

So that at the end of 5 years the gentry would have lost 28 of their children, the tradesmen 49 , and the operatives 57 .

A still darker shade must be added to this dark chapter. On England, more than on any civilised nation, rests the sin and shame of infanticide. All preventable death is murder, though not all wilful murder. But great numbers of children are wilfully, as well as ignorantly or carelessly, put out of existence. Later, I shall have to recur to the destruction of foetal life, the practice of which seems to have been rapidly increasing in the two countries which consider themselves in the van of religion, morals, and civilisation; but I must now give some of the facts of infanticide.

In Lincoln, some years ago, thirty gallons of laudanum were sold every week-enough to kill 6000 men. Dr. Playfair says:- "We have three druggists in one district of Manchester, selling respectively five and a half, three and a half, and one, in all ten gallons weekly; two of them testifying that almost all the families of the poor in that district habitually drug their children with opiates." A respectable druggist in Manchester 
assured Dr. Playfair, that he sold, in retail alone, above five gallons per week of "Quietness," and half a gallon of "Godfrey;" the former preparation being so strong as to contain roo drops of laudanum in an ounce; a single teaspoonful is the prescribed dose; so that, allowing one ounce weekly to each family, that one druggist supplies 700 families every week.

Narcotics are used in all the manufacturing districts. Mothers are obliged to leave their children to go to the mills and manufactories, and they are left drugged until they return. Great numbers of such children die. Burial societies equalise funeral expenses. The children are a burthen, instead of a blessing.

In Preston, according to the report of the Rev. J. Clay, twenty-one chemists sold in a week the following quantity :-

\begin{tabular}{|c|c|c|c|c|c|c|}
\hline Godfrey's co & dial, & ... & ... & $\ldots$ & $£ 23$ & 5 \\
\hline Child's prese & ver, & $\ldots$ & $\ldots$ & $\ldots$ & 18 & 4 \\
\hline Syrup of pop & jies, & ... & ... & ... & I 6 & 9 \\
\hline Opium, & $\ldots$ & ... & ... & ... & I & I \\
\hline Laudanum, & ... & ... & ... & ... & 7 & 8 \\
\hline Paregoric, & ... & ... & $\ldots$ & $\because$. & $\circ$ & 9 \\
\hline
\end{tabular}

The reverend gentleman observes on this statistical account: - "The system of drugging children is quite common; it is one of the principal causes of the mortality to which they are subject. The consequences of this homicidal custom are lunacy, caused by an effusion of blood on the brain, and a series of mesenteric and glandular affections; the child falls into a state of stupor, his body becomes a mere skeleton, except the stomach, which swells out like a balloon. Those who survive this treatment remain weak and withered."

Have we anything worse than this in the Baby Farming, about which a short time since there was so much interest?

On this subject I can scarcely quote higher authority than 
that of Mr. Simon, medical officer of the Privy Council, who, in his evidence before the select committee on the Chemists and Druggists Bill, mentioned some startling facts as to the destruction of infant life by opium. He said:-

"There are some country districts of England, where childkilling by opium is monstrous. Every one knows that in some of the manufacturing districts where mothers are employed and children are neglected, the mortality of infants is twice or thrice what one would call the normal rate of dying, and that a considerable share of this undue mortality is caused by dosing with preparations of opium. But it is not equally well known that in certain country districts the same amount of mortality of infants is to be observed; and when the particulars of this are inquired into, it appears that the conditions are very similar to those which operate in the manufacturing districts, and that even a greater proportion of the mortality is caused by the domestic administration of opium. I should not like you to suppose that I think much of it is intentional. I do not think that, but there is a carelessness as to the result that is hideous. On this subject the committee would find the facts given in my last annual report, and especially with reference to the marsh districts of England. The women work in gangs, and travel about the country, leading often a very reckless and rollicking life, and leaving their children a great deal to chance as they travel about. The children fare very badly, as the children do in manufacturing towns. To be kept quiet they are drugged with opium. The peasantry have a tradition that opium is useful in their ague, and have got so familiar with it that many of the adults are opium-eaters. Having this local knowledge of opium, they give it to children very largely, the children dying monstrously. The mothers (namely, the agricultural gang-womer) appear often to be very reckless whether the children live or die. The children are an encumbrance to them." 
And gin and beer are poisons as well as opium. What, then, must be the condition of children begotten by drunken fathers, nourished by the alcoholic blood of drunken mothers before they are born, fed on alcoholic milk from the breasts of drunken mothers or nurses,-children drunk in the cradle, drunk at the breast, drunk in the womb?

During the year 1862, inquests were held by coroners in England and Wales on the bodies of 3239 infants under one year of age. In 124 cases verdicts of wilful murder were returned. In the same year inquests were also held on 2763 children above one year, and under seven. In 1863 there were 3664 inquests on infants under one year; the verdicts of wilful murder numbered 166 . There were also 2842 inquests in the same year on children above one and under seven.

A writer in the Pall Mall Gazette tells us that "every living man of average health possesses in himself the power for the creation of sufficient wealth to support himself and a family in comfort, provided the machinery of civilisation is in healthy working order. It is only through individual vice or crime, or from some radical defect in the social or political system, that the birth of a child is a source of poverty, and not a positive addition to the prospective wealth and well-being of the world. The hideous sanitary and moral debasement of the cholera beds of East London, and the wholesale slaughtering of men and women, and still more of children and infants, which is always going on there, is the work of man, although no hand is literally.lifted up to strike the fatal blow."

I read in the same journal that the crime of child murder prevails to such a frightful extent in Liverpool that the attention of Government has been directed to it, with the view of stringent measures being taken for its suppression, and the Home Secretary has authorised, the Borough Coroner to offer rewards for the detection of the guilty parties.

Dr. Lankester, Coroner of Middlesex, has publicly stated 
that "over 300 dead children are found in the streets of London every year, and that it is a notorious fact that in some other large towns child desertion and child murder are just as rife as in London, and that the rural districts are scarcely, if at all, in a more favourable condition." In presiding at a lecture by the Rev. W. W. Malet on child murder, he said-"Child murder had attained to such horrible proportions in London that he had no hesitation in saying that one out of every 30 women you saw in the streets was a murderess-in other words, there were 12,000 women in the metropolis to whom this crime could be attributed. The extent of the crime was positively appalling."

"Coroners have declared," says the Daily Telegraph, "that child murder is a flourishing business in England," and it goes on about "people in silks and satins-the damnable Locastas of a civilisation crueller than Rome's-who drive carriages and fare sumptuously upon the fees of infanticide."

And the Morning Star asks, "Is it not certain that all over the country, in great cities and small villages, there is going on a daily and nightly massacre of the innocents, not limited even by the Herodian condition? The horrible truth must be spoken - a truth which it would be perfectly idle to gainsaythat child murder is now an institution in certain classes of English society. Dr. Lankester has over and over again proclaimed the fact as one which cannot be denied. Nor is it the unmarried mothers alone who destroy, or allow to be destroyed, the infants that have lain in their bosoms. It is but too well known that married women are, in certain classes, growing into this appalling practice. It is but too well known that in a large number of instances the cases of what are called 'children overlain' are simply cases of children purposely smothered. Let no one affect ignorance of the growth, the wild, rank spread, of infanticide in England."

A writer in the London Revieze says:- "The crime of 
infanticide is now so common in all its cool detail of deliberate cruelty; there is, from the repetition of the same features, so. little of novelty, that the most persevering student of theproceedings of criminal courts passes over, as wholly uninteresting, the cases of wilful child murder. We can safely predicate, three times out of four, at what time the murder was done, how it was done, where the little victim was hid, and how it was discovered. The inquest is dull, the trial at the assizes more so; there will be no verdict of murder--the poor creature only concealed the birth. The Judge will, in compassionate tones, pass a sentence of some eight or ten months' imprisonment; the officers of the prison, with a certain sort of pitying. gallantry, will show the culprit the way from the dock; she will be gently dealt with in the gaol; be an object for what is called interest; she returns to her home, having been well fed and kindly treated; none will shun her-has she not suffered for her crime? Who shall call it murder, when the old gentleman. in scarlet, with the wig, told the jury. they had no law to say it was?"

A Report of the Harveian Society informs us that "sincethe great change which was effected in the law in 1834 by which the burden of sustaining illegitimate children was removed from the shoulders of the putative father to those of the mother, the population has increased less than a third, whilst the number of illegitimate births has more than doubled. The growth of infanticide has been more rapid still. We must not suppose, however, that the destruction of life among illegitimate children is to be measured by the statistics of infanticide alone. We are told that in certain districts of Marylebone from 45 to 96 per cent. die while out to dry-nurse, the mothers being required to wet-nurse the children of the upper and respectable classes. Thus, the families of one set are succoured and sustained by the sacrifice of the families of another set; and grand ladies who are too proud and delicate to be natural. 


\section{Human Physiology.}

see their little sons and daughters thrive on the food for the want of which other children perish."

Three-fourths of the illegitimate children born in the United Kingdom die during their infancy-die in workhouses, or in the hands of paid nurses-paid, in many cases, to allow the child to perish of neglect, or be drugged into unconsciousness. and death. The mere deprivation of a mother's love and carehas much to do with the feebleness and death of a child; and unmarried mothers are often tempted to become wet-nurses in: the families of ladies who do not hesitate to advertise their preference for those who have become qualified without the encumbrance of a husband.

The practice of putting children out to nurse, that theirmothers may be left free, has been shown to be itself a mode of infanticide, as practised in Paris, and investigated by a Committee of the Academy of Medicine. "I have seen," said M. Chevalier, addressing the Academy, "one woman undertake to nurse seven infants, who had neither milk herself nor. the means of procuring cow's milk." Badly fed and badly cared for, the mortality amongst the wretched children is frightful. Out of 20,000 babies who are annually sent out of Paris en nourrice not more than 5000 survive; 15,000 die of: cold, hunger, and neglect.

Even in the large American cities children perish by thousands, and multitudes are not permitted to be born alive.

When we think that vast regions of the earth are lying waste-that there is room and food for a hundred-times its present population-that every healthy, well-trained human being may be of priceless value to the rest, such waste of human life should fill us with horror. 
A Network of Evils-The Root of all-The First Step in Reform-Condition of Agricultural Labourers-Former Condition of the PoorRecent Slavery of Women and Children-Horrors of the Workhouse -Dwellings of the Poor-Crowding, Filth, and Indecency-Berkshire Cottages-London Lodgings-English . Yeomen-Condition of Children-Physical Effects of Poverty-Social Rights and Duties.

PREMATURE mortality, we have seen, exists chiefly among the poor ; but the bad air, the crowd-poison, gendered in the filthy haunts of poverty often invades the luxurious dwellings of the rich. With poverty we find ignorance, drunkenness, brutality, vice, and crime. Poverty drives men to drink; and drink increases poverty. Poverty causes ignorance; and ignorance keeps men poor Poverty and ignorance produce disease; and disease intensifies poverty and ignorance. We are bound in a network of evils, each depending upon and causing the others.

But poverty in one class, the result of the love of money in other classes, lies at the root of all. The monopoly of lan 1; the gathering of the great bulk of the wealth of the country into the hands of a few; the greed of gold, and the power which it gives to the manufacturing, trading, and professional classes, are coincident with the miserable wages of agricultural and much artizan labour, the wretched and crowded dwellings of the poor, the privation of every comfort and the conditions of decency and health, the wasting disease, the welcome death. "Care," says Coleridge, "like a foul hag, sits on us all; one class presses with iron foot upon the wounded heads beneath, and all struggle for a worthless supremacy." The first thing to be done for the poverty-stricken masses is to house and clothe them decently-to give them the first conditions of health and 
morality; the next is to educate and employ them. They cannot do these things for themselves; philanthropic individuals and societies can do but little. It is the work of the governing classes of the nation-of Parliament-of the State.

It may be said that, bad as our condition is, it has been worse; that there is progress and improvement, and promise of still greater. I heartily rejoice in that promise. Historians tell us that, in the reign of Henry VIII., mendicants wandered about in crowds, extorting alms from terrified passengers. A statute was passed to brand any beggar $\mathrm{V}$ on his breast, and he was made to serve the informer two years with an iron ring. on his neck. If he ran away he was branded $S$ on his cheek. or forehead, and became a slave for life. If he ran away again, he was hanged.

During the reign of Henry VIII., 72,000 persons werehanged, the greater part of them for petty thefts, to which they. were brought by sheer want.

In the reign of Edward VI., "poverty prevailed; inclosures. and rack-rents drove the people into the large towns; the rich were hard-hearted, frauds common; criminals escaped punishment by corruption; church livings were given to laymen, marriages were dissolved by private authority; haunts of $\sin$. multiplied beyond measure."

This state of things was owing to the changes in property. and other changes at the period of the Reformation, previous to which there was no Poor Law, and much less suffering from. poverty than at any subsequent period.

During the present century, there were thousands of women. and girls working almost naked, drawing loads like cattle, in the coal mines, and living much worse than beasts of burden; working in deep mines, as women and young children now work in brickfields and labour-gangs in the light of day. Loads. of children were sent from the workhouses to the cotton mills, and worse treated than the slaves that grew the cotton. They, 
were worked in relays, one set got into beds as another got out, until fevers broke out in their filth, and carried off great numbers. - Those apprenticed to farmers and mechanics fared little better. They were beaten and starved, hired out and sold by inhuman masters.

And at this time, in spite of much humane legislation, the condition of several millions of the people of this country is most deplorable. The condition of agricultural labourers is generally bad. Their wages average about twelve shillings a week, and they are crowded into poor, old, unventilated hovels, a whole family living in one or two rooms, and much worse lodged and fed than their employer's cattle. "I know agricultural labourers well," says Professor Fawcett. "Their wages are so small that they are insufficient to provide them with the bare necessaries of life. They live in dwellings which scarcely deserve the name of human habitations. They are so poor that parents cannot afford to keep their children at school. The result of this is, that the whole of our agricultural population is growing up in a state of absolute ignorance. The English labourer has to pass a life of toil for wages which are scarcely sufficient to provide him with the bare necessaries of life; and when his strength is exhausted and his vigour spent, all he has to come to is to be buffeted about by relieving officers, and to come as a suppliant mendicant to claim parish relief."

The workhouse is the final, one may say the only, home of great multitudes. In London, I3,000 persons die in a year in public institutions; more than 7000 of whom die in its 46 workhouses. And a workhouse, says the Pall Mall Gazette, "is a shapeless agglomeration of the following institutions : a hospital for the sick, a school for orphans and foundlings, an almshouse for the aged, a refuge for the able-bodied when out of work, and a quasi-prison for casuals. This mass of institutions is governed by a committee of jobbing shopkeepers, who dele- 


\section{Human Physiology.}

gate powers, of the true nature and right use of which they are utterly ignorant, to an ignorant clerk of less education and lower position than themselves, through whose eyes they are content to see, or rather to avoid seeing, the most loathsome abuses."

And the Times tells us that "it was long before the air of truth and publicity could penetrate into these gloomy prisons; but since they have been once thrown open, the corruption within has become more and more apparent and appalling." These institutions, the horror of the poor, and the reproach of civilisation and religion, are the sole resource of millions of Englishmen, and cost the people some six millions of pounds a year-a considerable portion of which goes as profits into the hands of interested shopkeepers.

In a postscript to one of his latest works, the late Mr. Charles Dickens wrote:- "I believe there has been in England, since the days of the Stuarts, no law so infamously administered-no law so openly violated-no law habitually so ill supervised, as the Poor Law. In the majority of the shameful cases of disease and death from destitution that shock the public and disgrace the country, the illegality is quite equal to the inhumanity, and known language could say no more of their lawlessness."

So people beg or starve rather than go to the House; some starve while receiving out-door-relief, when it ranges from an average of eightpence to one shilling a week, as it does in sixteen London Unions. Some get into the House only to die; as happened when seventy-two deaths occurred in the two Dublin Workhouses, from Saturday to Monday, among those just admitted, after extreme suffering from cold and hunger.

But bad as the workhouses may be, the dwellings of the poor are worse. In the great towns, and notably in London, they are, as the Pall Mall Gazette says, "mere filthy lairs and dens of pollution, destitute of all the conditions of health-air, 
drainage, light, water, and also of the requisite provisions for decency and modesty. Every year the plague centres become more and more crowded and loathsome. Every year the labouring classes more grievously suffer from want of house accommodation, as our public works one after another narrow the area. of their old habitations, at the same time that their numbers keep constantly on the increase; and this while the lower order of labouring men in London pay, according to Lord Derby's calculations, as much for their wretched lodgings, in proportion to the accommodation, as a Duke in Belgravia."

The filth of persons living in such conditions is simply indescribable. They sleep in their day-clothes, and have no others; they huddle together on straw, or rags, or filthy pallets, to keep. each other warm-men, women, and children-a dozen in a room, with every crevice stopped to keep out the cold. Sanitary inspectors have found in Edinburgh and Glasgow, and in great numbers of the courts of London, whole blocks of houses, in which every inhabited room, and the physical condition of their inhabitants, were more horrible than the worst of the dungeons Howard found in Europe-with more filth, more physical suffering, and more hideous moral disorder. The Times may well say- "It is a scandal that such horrible dens should exist within a civilised city."

In town and country, in what seems to the stranger the most beautiful rural villages, in the Lake Country-perhaps the most. picturesque portion of England-and in the hideous Black Country, the condition of the poorer classes is much the same. They are very ignorant, very sensual, and partly from poverty, partly from habit, live crowded together, in the worst sanitary conditions, and with little regard to the decencies of life. What can be expected where families and lodgers, men and women, and grown up sons and daughters, all sleep in the same room, and in many cases on the same bed? It can only be said that their moral character closely corresponds to their physical condition. 


\section{Human Physiology.}

The common decencies of life are unknown to them. They have no modesty, no shame; need we ask if they have any virtue?

A few years ago, Mr. Tucker, a Berkshire magistrate, employed two persons to obtain correct information respecting. the condition of the rural cottages, and he laid the result before a meeting of the Farringdon Agricultural Library. In doing this he expressed his belief that the condition of Farringdon Union is only a sample of the agricultural population of England.

Here are a few items from the report:-

"FERnhav.-Eleven persons sleeping in two bedrooms, both on the ground floor; seven persons do.; ten persons do.; son and daughter, over sixteen years of age, with two other persons, sleeping in one room; three sons and a daughter and two younger children, with father and mother, sleeping in a room eight by twelve feet; two single men lodging with a man and wife, with four children, making eight persons sleeping in one room; two brothers and two sisters, above sixteen years of age, with father, mother, and four children, making ten persons sleeping in one room.

"I.ECHLADE. - A man and wife, with a female lodger and five children, sleeping 'pell mell' together.

"BUCKLAND.-A man and wife, with two grown-up girls and two other children, all sleeping in one room; a man and wife, with four children, including a grown-up girl, all sleep in one room; a widow, with grown-up son and daughter, and a lodger, all sleep in one room; a woman slept for a long time with a son aged twenty-four.

"Kingston Lisle. - Most of the cottages have only one small bedroom, yet the families are large, and the majority take lodgers. Example - Man and wife, with five children and two men and three women lodgers, making twelve persons sleeping in one room.

"BALKING.-Man and wife, with grown-up daughter and son, and four illegitimate children of daughter, all sleep in one small room."

A writer in Macmillan's Magazine asserts that the condition of the British agricultural labourer is now far inferior to what it was in the r.4th century. The Pall Mall Gazette says,"The misery of the agricultural poor is the great blot in our whole system of government." 
In London the state of things is worse, for pure air and good water can generally be found out of doors in the country. The working classes in London are cramped for space; multitudes are in a state of semi-starvation; the water supply is intermittent and bad over a large and crowded area.

The lodging houses of the large towns a few years ago presented spectacles which should have made England blush in the presence of Dahomey. They are now better regulated, but it is not long since in forty-seven lodging houses in Birmingham men; women, and children slept indiscriminately together-since an officer of police reported 40 persons of both sexes sleeping in the same room in Manchester, and more than a hundred cases in which he found both sexes, married and unmarried, lodging crowded together. In the London lodging houses, where the charge was only a penny a night, "abandoned girls, thieves, beggars, vagabonds, all slept pell-mell, in a small room, with no convenience, and in the utmost looseness and degradation. Beds were unknown. The owners of these dens - male and female-men, women, boys and girls, all slept in a mass on the floors, comprising, on an average, about thirty beings, the most unfortunate, the most infamous, on the face of the earth - a mass of poverty, filth, vice, and crime-an assemblage of all that is physically nauseous, and morally odious-a chaos of destitution, intemperance, ignorance, libidinism, and depravity, which cannot be met with in any other part of the globe."

Such has been, and to a great extent such is the condition of some millions of the poorer classes in England; and we talk of progress! Where are the yeomanry of England?-those whom an English dramatist has described as-

\section{"These gallant yeomen,}

England's peculiar and appropriate sons,

Known in no other land. Each boasts his hearth

And field as free, as the best lord his barony,

Owing subjection to no human vassalage, 


\section{Human Physiology.}

Save to the king and law. Hence they are resolute.

Leading the van in every day of battle,

As men who know the blessings they defend.

Hence they are frank and generous in peace,

As men who have their portion in its plenty.

No other kingdom shows its worth and happiness,

Veiled in such low estate." - Hallidon Hill, Act 3, Scene 2.

There is a strong and general movement among the working classes in England to diminish the hours of labour; and something is being done to lessen its severity and improve its sanitary conditions. Slavery is a mild and inadequate term to express what it has been, for the owners of slaves, as a rule, do not destroy their health and shorten their lives. In the slavery of wages there has been little care or scruple. It was but a few months ago that Parliament was called upon to afford some protection to one million four hundred thousand children, working at various trades in England. I have seen little girls from six to twelve years old huddled upon the steps of the unopened doors of their workshops before daylight, fearful of being too late, and so losing a day's employment. In some trades men work eighteen or twenty hours at a stretch. Women and girls work at forges and in brickfields. Children, boys and girls of tender age, work day and night at nailmaking. A large part of the manufacturing labour of England is done by children who ought to be half their day-time in school and the other half in the open air, either at play or engaged in some light, varied, and healthful employment. A gentleman who has seen the brickfields says of them:- "Let the hardest heart that can be found in England visit those spots, and if he be not moved, he must at least be ashamed of his sex and of his country. There the female seems to be brought to the lowest point of servile ignorance and degradation. Hundreds of little girls, from eight to eleven years of age, half naked, and so besmeared with dirt as to be barely distinguishable from the soil they stand on, are put to work in these abodes of oppression. 
Bearing prodigious burdens of clay on their heads and in their arms, they totter to and fro during many hours of toil. When I spoke to them they either remained aghast with astonishment or ran away screaming as though some evil spirit had appeared to them. I could not restrain my indignation, nor can I now, at this wicked scorn of female rights, this wicked waste of female excellence and virtue."

For the physical effects of labour look at the once stalwart and hardy, but now stunted and miserable weavers of Spitalsfields; at the dwarfed and short-lived operatives of Lancashire; at the Sheffield grinders, who seldom live to the age of thirty; at pale tailors stitching in hot and crowded rooms in an atmosphere that meets one like the breath of pestilence; at the vast multitudes of women and children who earn the most meagre fare by sewing, making lace, artificial flowers, matches, boxes; -in the thousand trades that make up the industry of London or Birmingham.

A boy born in a workhouse, or taken to one in infancythere are thousands such-who never knows father or mother, is bound apprentice with a small premium, to a master locksmith, or maker of any kind of small iron or brass work, and learns to file-files through his apprenticeship, files all his life, his monotonous work only interrupted by drunken holidays, until he goes to the workhouse to die. His children follow the same career, or do worse. There are few who rise above this condition, but many sink below it, and become thieves and prostitutes.

If the hours of tabour could be diminished and the wages of many of the labourers increased, and the time and money gained could be spent in improving their physical, mental, and moral condition, it would be a great blessing; but, in the state of ignorance and vice to which great masses of working men are reduced more time and money will mean more drunkenness and depravity. A man of impulsive 
benevolence gave a five-pound note to a wretched family in a London "court." Returning a few hours after, he found the whole population drunk and fighting. For such people more must be done than to give them more time and more money. It is the right of society, for its own protection, to compei cleanliness, order, intelligence, honesty, sobriety, good manners, and good morals. It is the duty of society to rescue human beings from the deep pit of ignorance, vice, and misery into which they have fallen. Until we do so our boasted civilisation is a hollow sham, our benevolence a mockery, our religion the most selfish hypocrisy. It may well be said to us, "Inasmuch as ye did it not to the least of these my brethren, ye did it not to me."

\section{CHAPTER VI.}

IGNORANCE.

The British Laboures-Statistics of Education-Dangers of IgnoranceIgnorance and Crime-Compulsory Education-Much more is needed -Matters of Life and Death-Responsibilities of the Educated Classes, and especially of the Clergy-Sins of Ignorance.

Mr. Roebuck once gave an account of the British labourera man, he said, who "swears at his wife, beats his children, caresses his dog, eats, sleeps, gets drunk, and gets sober." When he told his gardener, a shrewd man of fifty, that the Duke of Wellington was dead, he replied, "I am very sorry for he-but who was he?"

In 1843,33 men and 49 women in every roo married, made their marks in the parish registers. In some counties the per centage was 50 men and 56 women. There were then eight millions who could not read and write, and four millions were 
described as being "as destitute of moral and religious training as men can be." According to Lord John Russell, one-half the working-classes could not read, and one-third were sunk in social barbarism - and this in a Christian land, with its wealthy aristocracy, its Established Church, far the richest in Europe, its great universities and schools, and all its religious and philanthropic organisations.

Recently it was estimated that 100,000 children in London were without instruction; 48,000 in Liverpool; and in other large towns in some such proportion. It was time to move for universal compulsory education.

Mr. Kay, a travelling Bachelor of Cambridge, who investigated the state of popular education in several countries of Europe, summed up the state of primary education in England and Wales, from official reports and his own investigations, as follows :-

"It has been calculated that there are, at present, in England and Wales, NEARLy EIGHT MILlions OF PERSONS who cannot read and write.

"Of all the children in England and Wales, between the ages of five and fourteen, MORE THAN THE HALF are not attend. iing any school.

"Even of the class of farmers, there are great numbers who annot read and write.

"Here, with our vast accumulated masses, with a population increasing by a thousand per diem; with an expenditure on abject pauperism, which in these days of our prosperity amounts to $£ 5,000,000$ per annum; with a terrible deficiency in the numbers of our churches and of our clergy, with the most demoralising publications spread through the cottages of our operatives; with democratic ideas of the wildest kinds, and a knowledge of the power of union daily gaining ground among them;-here, too, where the poor have no stake whatever in the country; where there are no small properties; where the 


\section{Human Physiology.}

most frightful discrepancies exist between the richer and the poorer classes; where the poor fancy they have nothing to lose and everything to gain from a revolution; here, too, where we are stimulating the rapid increase of our population by extending and steadying the base of our commercial greatness; where the majority of our operatives have no religion; where the national religion is one utterly unfitted to attract an uneducated people; where our very freedom is in danger, unless the people are taught to use and not to abuse it; and here, too, where the aristocracy is richer and more powerful than that of any other country in the world, the poor are more oppressed, more pauperised, more numerous in comparison to the other classes, more irreligious, and very much worse educated, than the poor of any other European nation."

Mr. Kay excepts a portion of Eastern and Southern Europe; but I doubt if there can be made any such exception. Assuredly, the peasantry of Spain, Portugal, and Southern Italy are less pauperised, and not worse educated than the corresponding class in this country.

Lord Howard of Glossop, in a letter on the poverty and crime of Liverpool, says that of 4227 prisoners there, only 12 could read and write well; I244 could read and write imperfectly; 864 could read only; and 2107 could neither read nor write. Every prison in England tells nearly the same story.

In 1854 , Lord John Russell stated that "thirty-five persons in every hundred could neither read nor write ; and that ignorance was incredible, and crime incalculable amongst the masses of the labouring people."

Mr. Bruce, M.P., at the Social Science Congress at Manchester, said :- " Everywhere a majority of the children between the ages of three and twelve are found to be neither at school nor at work, owing to the poverty of their parents. In the lowest districts of the manufacturing towns, only a small 
proportion of the children could be got into schools, and in Salford and Manchester 42,000 children were receiving no education." He estimated that $\mathrm{r}, 000,000$ children in England were receiving no kind of education.

All this is to be changed. The nation has resolved that, in future, every child shall be educated; but generations must pass before vast numbers can be rescued from the evil influences of past ignorance. The very brains of the people are to be expanded during a series of generations, and gradually recovered from the paralysing and embruting effects of past and present ignorance.

But there must be much more done for the people than to provide schools and compel attendance, say between the ages of five and twelve years. The boy who goes into the fields to labour when he is twelve years old has only the rudiments of education, and these are soon forgotten. Children ot poverty-stricken town populations, driven to ragged schools,and with compulsory attendance, what other than ragged and hungry schools can there be in the poorer districts of most English towns?-can get no useful education. Reading, writing, and arithmetic will not neutralise the influence of their homes; will not make them cleanly in the midst of filth, nor pure in an atmosphere of moral pollution. No, the education of home precedes that of the school, and its influence is much greater. When the people of England are housed, clothed, and fed as human beings have a right to be, there will be little need of compulsory education.

The sad truth is, that the great mass of the people need to be educated in much more than the rudiments of knowledge, for they are deplorably ignorant of the most important things -ignorant of what are matters of life and death to them. Three-fourths of the people are ignorant of the necessity of pure fresh air for the maintenance of health. A large portion have no proper idea of the importance of cleanliness in their per- 
sons, clothing, and surroundings. Very few know much about the wholesomeness of food and drinks, or what constitutes a healthy and sufficient diet. Children and youth, from pure ignorance, fall into the most destructive habits and vices. Young girls, from lack of right teaching and direction, have their characters destroyed and their lives wrecked. Young people marry and take upon them the cares of a family in utter ignorance of all the duties and responsibilities of such a position. Men enter upon the business of life with no know ledge of political economy ; they assume the duties of the suffrage in profound ignorance of politics or history. Farmers know little of agriculture; artizans are almost destitute of the technical education necessary to success in the various mechanic arts. The higher classes learn more or less of Latin and Greek, rowing and cricket, as a preparation for the responsibilities of wealth and power, the care of great estates, and the government of the nation.

Had the clergy of the Church of England, for the last three centuries, been rightly educated for their duties, the people would also have been educated during all this period. Had they only done their duty, the people placed under their charge - the flocks of which they have been the legally appointed shepherds-could never have fallen into the poverty, ignorance, vice, and crime, the physical and moral wretchedness which we see around us, and for which we see at last that there must be found some remedy, or the whole nation will be lost.

A great part of the sins of England are sins of ignorance, heavily punished now ; less heavily, we have a right to hope, hereafter; but there must be retribution for those who have selfishly and wickedly allowed a people to fall into and continue in such a state of ignorance and its accompanying degradation and misery. 


\section{CHAPTER VII.}

DRUNKENNESS.

The Prevalence of Drunkenness-Causes and Consequences-Cost of Stimulants - Numbers Supported by the Trade-The Spectacle of Drunkenness-Scenes in Liverpool and Manchester-Increase of Drunkenness - The Temperance Movement in England-Medical Testimony-Balance Sheet.

ONE of the sad effects of ignorance, poverty, and the depressing conditions of a life of monotonous and often ill-requited labour, is the prevalence of intemperance and drunkenness. Intelligent, free, and happy men, with pleasant occupations, comfortable homes, and intellectual and artistic recreations, have no need of stimulants. It is the wretched home that drives men to the pot-house, where they must drink. Men stimulate nerves jaded with long and monotonous toil-they drown dull care in drink. Thousands find their only solacetheir only relief from the tedium and misery of life, in intoxication. Agricultural labourers swill immense quantities of thin cider and beer; the poor in towns crowd the hundreds. of low tippling shops, and get intoxicated on adulterated liquors. Husbands spend in drink the earnings of their wives, and then abuse and beat them in their drunken fury. One can hardly open a daily newspaper without finding cases of horrible ill-usage, often ending in murder, of women and children, by drunken husbands and fathers. The men who leave their families to suffer by cold and hunger, while they spend all their wages in drink, may be found by thousands. No small portion of the infant mortality, and infanticide by neglect, which form so dark a stain upon the social life of England, is the direct result of drunkenness in one or both of the parents. Women spend the earnings of their husbands on 


\section{Human Physiology.}

'drink, neglect their children, and make home a hell. Children rob their parents or become vagabonds, thieves, and prostitutes, and may be seen in dozens reeling drunk along the streets. In the iron and coal districts of England, and in all its industrial centres, a large portion of the earnings of the working classes. are expended for drink, and two or three days in every week are wasted by thousands in getting drunk and recovering from intoxication.

Drunkenness is the parent of many vices. It leads to poverty, ignorance, disease, and crime. But who has told us what are the causes of drunkenness, and how they can be removed? Intoxicating liquors produce drunkenness, but the appetite for drink is not created by the presence of intoxicants. The manufacture and sale of liquors supplies a demand which, as in other cases, it also increases. It is doubtful if the supply can be stopped, while the demand continues; but it may be possible to remove the causes which create the desire for intoxication.

I shall speak later of the causes of the morbid craving for stimulation and intoxication, shown in the use of opium, hashish, caco, maté, tea, coffee, tobacco, and spirituous. liquors -in the use of which man differs from all other animals. In these habits, as in so many others, England stands in the front rank, if not absolutely in the van, of modern civilisation. In no other country are such quantities of stimulants and intoxicants consumed; and no other shows such numbers of miserable, besotted, drunken, depraved victims of these hideous and abominable vices. For drunkenness produces and intensifies the evils of ignorance and poverty. It is the proximate cause of at least three-fourths of the pauperism, vagabondism, crime, prostitution, disease, and premature mortality that afflict and oppress this ccuntry. Drink fills our ragged schools, reformatories, asylums, hospitals, workhouses. prisons, and graveyards. Drink, directly and indirectly, costs. 
the nation more than government, army, navy, church, education, and national debt.

The bare cost of the spirits, wines, beer, and cider, drunk yearly in the United Kingdom, is more than $£ \mathrm{I} \circ 0,000,000$. Add tobacco, opium, and other stimulants, narcotics, and intoxicants, and the cost for these useless and pernicious articles is much more than $£$ r50,000,000. Add land and labour wasted, time spent in getting drunk and sober, cost of sickness produced by drink, money spent on police, lawyers, magistrates, prisons, workhouses, asylums, and other charities to the destitute, made so by drunkenness, and the cost will be found to be more than $£ 200,000,000$ per annum.

The entire national expenditure of the year 1871 , was $£ 68,218,919$; less than one half of the mere money loss caused by the use of intoxicating substances. The physical and moral losses are incalculable; but some of them will be treated of in the chapter on the causes of disease and premature mortality.

In the cost of drinking must be reckoned the time of all persons engaged in importing, making, and selling intoxicants. That enters, as well as the land wasted and produce destroyed, it may be said, into the cost of the liquors, but society loses all they might produce by useful industry. There were in 1865, 109,000 publicans, retailers of spirits in the United Kingdom; retailers of beer, not publicans, 52,566. Add manufacturers and importers and their employées, and we have, say, 200,000 men engaged in the liquor businessI to $\mathrm{r} 50$ of the population. If we allow five persons to constitute the family of each person engaged in this business, there is $\mathrm{I}$ in 30 of the population; one million of persons in the United Kingdom supported by the liquor traffic, not counting those engaged in supplying the materials of manufacture, malt, hops, \&c. The grain destroyed in making intoxicants was in $1869,62,000,000$ bushels. 
Home-brewed ale and cider do not come into this account; and it is estimated that England and Wales drink 700,000,000. gallons of beer. Cider, as is well known, is drunk in several counties by the agricultural labourers in enormous quantities, and with the most deplorable consequences.

The spectacle of drunkenness in many of the large towns of England is one that can never be described or forgotten. Visit the public houses of any populous district of London at Io to II o'clock on Saturday or Sunday night, and see the crowds of men and women far advanced in intoxication. Stand in Liverpool where street crosses street, with a flaring public on each of the four corners, each full, and its doors surrounded by such men and such women as the pencil of a Hogarth or a Cruikshanks could alone depict.

In one recent year, 94,908 persons were prosecuted before Justices in England for drunkenness, of whom 22,560 were females. But it is well known that none are ever arrested for merely being drunk. They must be "drunk and incapable," or "drunk and disorderly;"-friendless as well, for the police do not trouble those who have friends to take care of them. In the single town of Liverpool there are usually from 100 toI 50 cases of drunkenness brought before the magistrates every Monday morning, and sometimes twenty of these have been boys and girls under seventeen years of age. Processions of drünken boys and girls are not unknown to the streets of Manchester. The drunken cases in Liverpool are $\mathbf{I}$ in 33 of the population; in Shields, $I$ in 45 ; in Sunderland, $I$ in 95. In such places children go drunk to school; women pawn or sell every stick of rurniture and rag of clothing, and even their hair, for drink. In one court in Liverpool all the women were found drunk one Sunday afternoon, and the children club all the pennies they can beg or steal and get drunk like their parents. Thousands of births are never registered, the chiltren being "sided"-overlaid-by their mothers, swelling the 


\section{Human Physiology.}

records of premature mortality by this horrible drunken infanticide.

The consumption of intoxicants is increasing on the Continent, as well as in England. Formerly the French drank only their light wines, and intoxication was very rare. Now they drink twenty times as much spirits as they did a century ago, and the consumption of tobacco is very large. It is no longer a rare thing to see a drunken Frenchman, and the nation has shown evident signs of demoralisation.

There is now a strong movement in England for the better regulation, or entire suppression, of the liquor traffic. I cannot hope for the latter while great brewers are members of Parliament and of the Government, nor while private houses and the clubs of the aristocracy are furnished with liquors. Law must be equal, or it cannot be enforced. The demand must be stopped before the supply will cease; and how people may be induced to discontinue the common use of intoxicants I shall discuss in a future chapter. That it may be done with safety, is the testimony of most physicians. The following statement has been signed by I600:-

"We, the undersigned, are of opinion,-

"I.-That a very large portion of human misery, including poverty, disease, and crime, is induced by the use of alcoholic or fermented liquors, as beverages.

"II. - That the most perfect health is compatible with total abstinence from all such intoxicating beverages, whether in the form of ardent spirits, or as wine, ale, porter, cider, \&c., \&c.

"III. - That persons accustomed to such drinks, may, with perfect safety, discontinue them entirely, either at once, or gradually after a short time.

"IV.-That total and universal abstinence from alcoholic liquors and intoxicating beverages of all sorts, would greatly contribute to the health, the prosperity, the morality, and the happiness of the human race." 
In 1869 , the Executive of the United Kingdom Alliance isslied "An Address to the People of Great Britain and Ireland," which contained the following balance sheet of the results of the liquor traffic:-

"What do we get in return for the waste of 150 millions of money by the liquor traffic?

"The following are some of the principal items we get in exchange:- -

"Nearly one and a half million paupers in the United Kingdom, or $\mathbf{I}$ in 20 of the entire population; nine-tenths of this pauperism being caused by drink.

" 600,000 drunkards, each one a source of sorrow and .annoyance both to his family and neighbours.

" 60,000 human beings slain, it is estimated, through drink every year.

" 43,000 lunatics in our asylums, and 25,000 inquests yearly, in both cases mainly owing to strong drink.

" 140,000 criminals, nearly all the fruit of the liquor traffic.

"Gambling, prostitution, families neglected and cruelly treated, domestic squabbles, rows and brawls in our streets, and social disorder that is appalling.

"Last in our list, but not least, the liquor traffic is the great obstructive to progress in all that is good and elevating, and the great demoraliser of the people."

Let us consider some more of the facts of this wide-spread demoralisation. 


\section{CHAPTER VIII.}

\section{DISHONESTY AND CRIME.}

Man alone Criminal-Crimes of English Life-Lying and CheatingPerjury-Pecuniary Dishonesty-The Criminal Classes-Statistics of Crime-Cost of Crime-Dishonesty of Servants-Dishonesty ripensinto Crime-The Gardens of Guilt.

MAN differs from all other creatures, in that he has fallen into. the depravity of crime. Animals obey the laws of their lives; men violate them. We drive away or destroy insects and animals when they annoy us, but we do not blame them. Men we blame and punish when they lie, slander, bear false witness, cheat, steal, assault, and murder. If man were descended, or had ascended, from the lowest forms of animal life through. anthropoid apes, and been gradually developed by natural selection to his present status of civilisation and religion, how are we to account for the evident fact that he alone of all creatures is guilty of crimes against Nature, against himself, and against his fellow-creatures? Man alone, at his best a little lower than the angels, can sink below the brutes.

The common crimes of English life are neglect, ill-treatment, and spoliation of the poor, ignorant, and helpless; enslaving them by requiring too long or too hard labour; the robbery of paying inadequate wages; cheating them by the truck system of payment; grinding and oppression of children and apprentices; the robbery of stopping wages as tines; the worse than robbery of compelling men to take their wages in drink. In trade we have the frauds and robberies of bad qualities, sham articles, adulterations, often noxious, and even murderous; the sale of diseased meat and poisoned liquors; cheating by false weights and measures; overcharges ; duplication of accounts; 


\section{Human Physiology.}

getting money and goods by false pretences; swindling; forgery; theft; burglary; robbery with violence; robbery by threats of infamous charges ; frauds of sham companies ; sham benevolent societies; begging impostures; robberies of enormous fees; robberies of pawnbrokers, leaving shops, moneylenders, and all the criminal cormorants who prey upon the weakness and misfortunes of others. More detestable than these are the crimes of lust; the corruption of children and the young by immoral and shameful publications; the seduction of innocent and helpless girls, especially of servants in families, and girls who work for a living; trade in prostitution. criminal assaults, rapes, abortions, infanticide, unnatural crimes.

Lying in trade is all but universal ; lying and deception are very common among servants and workmen. We have cheating in materials, cheating in work, cheating in charges. In plumbing and house repairs there is habitual and systematic robbery. Bakers adulteratc our bread; brewers put coculus indicus into our beer; wine-dealers sell us poisoned decoctions; grocers mix burnt sugar and roasted liver with our coffee; our milk is watered, or worse; our clothes are shoddy; our furniture falls in pieces; our houses are sham carcases, cracking and splitting in every direction; sham drains connect with no sewer, or, from their bad construction, poison us with noxious gases. Quacks are ready on every side to poison us with their nostrums; and regular physicians combine with apothecaries to drench us with medicines, and run up heavy and needless bills. Undertakers are not the least remorseless of the cormorants that devour us.

Thousands not only lie and cheat, but have no scruple at perjury. In all our law courts we have sets of trained witnesses swearing point blank against each other, and not in one case in a hundred are any temporal pains and penalties ever inflicted. The Divorce Court is a hideous public exposure of 
perjuries, as well as adulteries, and every sort of immorality and outrage.

It may be imagined that these statements are exaggerated, and these charges of too sweeping a character. Let me copy a paragraph on this subject from one of the most respectable of English periodicals, The Spectator :-

"Perhaps no race ever existed among whom pecuniary dishonesty was so general, or so deeply affected the structure of society. We consider ourselves a virtuous people, the salt of the earth, and it is not too much to say that, at this moment, the basis of half our laws - the cause of half, or more than half, our administrative weakness-the root of three-fourths of our commercial difficulties, is the well-founded belief that a middle-class Englishman, if he gets anything like a chance, will thieve, will expend his brain, his time, and his energies in able efforts to steal money which is not his. Our municipal difficulty is jobbery, that is theft-the practice every municipality is certain, unless watched, to indulge in, of robbing the citizens to enrich its own members, or other favoured individuals. Even Parliament, even the Cabinet, the flower, or supposed flower of parliamentary life, is not beyond the same suspicion. Our railway system is breaking down under habitual theft. Our commerce is shattered at this moment by every variety of elaborate and carefully devised plunder; by companies whose prospectuses are drawn up with the intention of robbing the ignorant; by banks which make over shareholders' money to directors; by manufacturers who sell shoddy for cloth; by tradesmen who cannot be trusted to avoid actual stealing of pennies from women and children, actual theft of coppers out of a blind man's tray, by false weights and measures. The worst of all is, that one sees no cure for it. Every nation suffers from periods of violence or of licentiousness, or of bigotry, or of apparent weakness, and after a time they pass away, to re-appear at more and more distant intervals; but the habit of theft is in its 
nature chronic. The desire for 'comfort' without work, which is its root, is one which every year intensifies. The single remedy, it is to be feared, is national poverty, which, by making all men watchmen, prevents the very inception of crime."

In the criminal statistics of England and Wales for I866, we find that crime gives employment to 23,728 policemen, who cost the country $\mathcal{E}^{1}, 827,105$. This sum of nearly two millions must be doubled to show the real loss to the country in this one item. We lose what we pay them, and also what they would profit us, if engaged in some productive industry. Thus we lose by army and navy more than double their cost, and the same by the useless lives of crowds of servants kept for show rather than use. To the cost of police must be added that of magistrates, judges, juries, officers of courts, criminal lawyers, prosecutors, witnesses, prisons, \&c. "One sinner destroyeth much good."

The criminal classes "at large," in I 866, in spite of the exertions of 23,728 policemen, are set down at II3,566, of whom 33,191 are classed as tramps and vagrants. Of the criminals not at large, 16,708 were in local prisons, 7,018 in convict establishments, and (most inadequate number) 3,635 in reformatories. Magistrates and police allowed the existence, in England and Wales, of 20,249 houses of bad character, such as houses of prostitution, resorts of thieves, and of the receivers of stolen goods. There were registered 50,542 indictable offences, and 27,190 persons were committed for trial, while 481,770 cases were dealt with summarily by the magistrates. There were 131 murders, 45 attempts to murder, 679 cases of shooting, stabbing, \&c., 259 cases of manslaughter, 8 of attempts to procure miscarriage, 2 II of concealment of birth, I 55 of unnatural offences, 257 of rape, 322 of assaults with intent, \&c., 272 of assaults and bodily harm, 207 of common assault. In 1865 , the criminal classes were registered I 16,626 , 
of whom 66,000 were males, and over 50,000 females, and I 5,000 were under 16 years of age.

By the returns of $186 \mathrm{r}$, it appears that nearly 500,000 . offences, great and small, came under the cognisance of the police, and that nearly 300,000 persons were punished; but 263,500 of these were for small offences, such as petty thefts, drunkenness, assaults, \&c. Of the 30,000 known thieves and depredators, the 3,800 receivers, very few were in any way dealt with. In $\mathrm{r} 86 \mathrm{r}$, the cost of police and prisons was said to be-

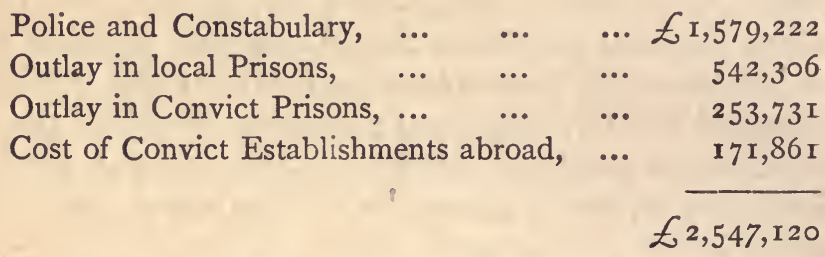

"But how," asks the writer, from whom I borrow these figures, "are we to estimate the expense of keeping the known but unconvicted criminals? It is certain that they live at the cost of the community, and that in many cases they live very well. They do not work, and they do steal. They are maintained by a local rate, just as surely as the malefactors whom we shut up in gaol, though it is a rate assessed and levied by themselves. Few who know the recklessness, and sometimes. the luxury, and always the wastefulness of the criminal class, will be disposed to think that the undetected depredators. (those out of prison) can be maintained at as small a cost. as those who are provided for during their confinement on. a systematic scale, at the public table, and in public buildings. The average cost of a prisoner in local gaols is $£ 26$. a-year, in convict prisons it is $£ 33$. We believe that very few thieves and ruffians at large spend much less than 20 s. a-week. But we will take a more moderate estimate, and calculate- 
their cost at I2S., or the same as their incarcerated fellows, say $£ 30$ a-year. At this rate the 90,800 registered pilferers and rascals at large cost us not less than $£^{2,724,000}$ per annum. If we add this to the figures previously given, we shall arrive at the startling but undeniable result that our criminal classes cost us-in guarding against them, in detecting them, in punishing them, and in supporting them in idleness in and out of prison-not less than Five Millions a-year, and this without including either Scotland or Ireland in the calculation."

Such is the army of outlaws preying upon society, eating up the products of industry, and necessitating another army of policemen, magistrates, lawyers, \&c., merely to hold them in check, and in certain cases to capture, imprison, and hang them. But what a stupid muddle it is! Of the 15,000 under I6 years of age, every one should be in a reformatory. For the rest, they should be placed under such surveillance as to make unpunished crime impossible. Every known burglar, pickpocket, thief, should be watched, and caught, and caged. Every beggar and tramp could surely be made to earn an honest living. There is no economy in having 100,000 criminals at large, living upon the public.

But the suppression of crime-the crime that employs policemen and fills prisons-is the smallest part of the work to be done. Great masses of people are to be trained into the love of truth, honesty, fair dealing-into doing as they would be done by, and loving their neighbour as themselves. Dishonesty, if I can credit the testimony of English writers, pervades society. A writer in Frazer's Magazine says :- "Our daily lives are full of falsehood, from the time when our boys get their tasks done for them at school, till they represent their country through the trickeries of a contested election." "Dishonesty is, we must all admit," says London Society, "the rule, and not the exception, among our domestic servants. Chronic 
dishonesty reigns in the kitchen, occasional dishonesty in the pantry ; cooks are detestably unfaithful; man-servants more or less dishonest, and more dangerous."

"England," another publicist informs us, "is aghast at the disclosure of her frauds in the adulteration of food, of drugs, and of almost every fabric in her mills and shops; finding that milk will not nourish, nor sugar sweeten, nor bread satisfy, nor pepper bite the tongue, nor glue stick. In true England all is false and forged."

If there be so much dishonesty in England, we cannot wonder that, when united to courage, or driven to desperation, it culminates in crime. Where there is no sense of truth, and justice, and honour, to keep people to the path of right-doing -nothing but the fear of exposure and disgrace, or the dread. of punishment-we must expect that thousands will be held in check by no such dread.

The popular instinct makes the bold highwayman, the daring burglar, and even the adroit pickpocket, a sort of hero; and he is a hero, in comparison with cheating tradesmen and pilfering domestics.

The gardens of guilt are everywhere. There are parts of London where every house is inhabited by thieves and other open plunderers of society. Children are born and educated to a life of crime, as others are bred from infancy to prostitution. The favourite reading of many thousands of the boys of London and other towns, consists of the adventures of highwaymen, pirates, burglars, and thieves, in which their exploits. are described in the most exciting and seductive fashion. The favourite dramas at some of the minor theatres are based on the exploits of noted criminals. The boys most devoted to this kind of literature, form themselves into gangs for purposes of plunder. Every returned or released convict is a teacher of crime; every prison a college. 'The thieves' public-houses, thieves' coffee-houses and kitchens are seminaries. 
By a strange folly of criminal legislation, short sentences are continually inflicted, and therefore the worst criminals are often at large; and known criminals, with no visible means of support, who must therefore be living on the community, are allowed to go on for years in their depredations. The guilt-gardens are pruned and cultivated, instead of being thoroughly uprooted and destroyed. When the people and their parliament say there shall be honesty, and there shall not be crime, some way will be found to make the popular will effectual-

\section{CHAPTER IX.}

\section{VICE AND IMMORALITY.}

Crime and Vice Exceptional-Statistics of Illegitimacy-Morals of England, Scotland, and Sweden-Immorality of the Lower Orders-Mortality of Illegitimate Children-The Gang System-South Wales-Rural Morals-Statute Fairs and Hirings-Middle and Upper ClassesUnequal Numbers of the Sexes-Preference for Unmarried WetNurses-Children Born to Vice-A Sensual Literature-A Lower Deep.

THE crime of any country, it will be said, is exceptional. We are not to judge a conmunity by its worst members, or a country by its outlaws. It will not, however, be disputed, that there is a wide-spread dishonesty in this country, ready for circumstances to ripen into crime. It may also be said that the instances and statistics of vice and immorality I propose to give in this chapter are exceptional. Let it be admitted; still the facts exist, and must be considered. We lessen no evil by shutting our eyes. A noble lady has said of English society:- "The received maxim of certain circles is 
that anything may be done, but nothing must be talked about." This was said before the discussion of the Contagious Diseases Act. But no one who reads the leading English newspapers, can be supposed to be ignorant of what is going on in the world around him. I am very desirous, in all this work, to give no offence tc the purest minded of my readers; and I shall give no fact without a much higher motive than a wish to make a sensation, or satisfy mere curiosity. What we have to do is to rescue millions from very debased and unhappy conditions; and, to do this, we must know something about them.

In 1863 more than 47,000 children were registered in Fingland as born out of wedlock. In Norfolk the proportion reached II.3 per cent-in beautiful Cumberland I 2 per cent. In Scotland the proportion is considerably greater than in England; in Ireland very much less. The Pall Mall Gazette says:- "Wherever the labouring class is ignorant, badly lodged, poorly fed, and half stupefied for lack of rational amusement, sensual indulgences of the most debasing kind will be eagerly sought. . . . There is not much in the condition of an English peasant to make him anything but immoral. . . . The English farm labourer does not, as a rule, get enough meat to eat; what schooling he has is wholly useless to him; he is worse lodged than a calf or a pig; his life is one of incessant toil, and in his old age he has nothing to look forward to except the union workhouse." It is no wonder, then, the writer thinks, that he should do very much wo' se than "make a beast of himself."

Vhatever the cause or causes may be, the fact that the lower classes of the English and Scottish people are not scrupulous in regard to sexual morality, is sufficiently notorious. In 1860 the number of illegitimate children born in the workhouses of England and Wales was 7077 ; in 1861,8020 ; in 1862,8115 . For the lowest class, every workhouse is a lying- 


\section{Human Physiology.}

in asylum and foundling hospital; yet England is too virtuous to have foundling hospitals. There are about 14,000 illegitimate children in English workhouses, a small proportion of the whole number; for where the father can be made to pay the customary $2 \mathrm{~s}$. or $2 \mathrm{~s}$. 6d. a-week for the support of his child, it does not go to the workhouse; and three or four such children in the cottage of a labourer, whose wages are but $\mathbf{1 2 S}$. a-week, is a considerable addition to the family income.

A writer in the Daily Telegraph says-"Shame there is none: it is nothing more than a 'misfortune;' and if a misfortune is profitable, can we wonder if it is welcomed? Practically, no punishment whatever falls on the mother of an illegitimate child, and no disgrace. Her parents will be much obliged to her, and the public opinion of her own class will not condemn her. Among the poor, a girl loses nothing in the good opinion of her friends by having a child, and gains an income which is probably not much less than her annual wages."

Of the legitimate children in workhouses, according to a recent return, 6344 had been deserted by their fathers, 2 102 by their mothers, and 1880 by both parents ; while the fathers of 1031 were transported or in prison for crime. In the same workhouses-those of England and Wales-there were 560 single women pregnant with their first child; 2847 single women who had had one child; single women who had had two children, I7II; who had had three, 877 ; who had had four or more, 782 .

I give these figures as indications of the state of feeling, opinion, and action, with respect to the relations of the sexes in the lower strata of English life. Excepting Scotland, I know of but one country so immoral. Sweden, I believe, is more irregular in its manners than any portion of the United Kingdom; while Ireland, and especially the west and south of 
Ireland, is one of the most moral countries in the world. Of Sweden, Mr. Lloyd, a recent tourist, says :- " It is with regret that I declare the Swedish peasant to be a great drunkard! Finkel, or potato-brandy, is the curse of thecountry; it stupefies the faculties of the people, and makes them old before their time." In the towns, the proportion of illegitimate to legitimate births is very large, and much on the increase. In Stockholm, in 1848 , the last return. noticed by Mr. Lloyd, the legitimate births numbered 1558 , the illegitimate r $30 \mathrm{r}$. In the rural districts the proportion. was $\mathbf{I}$ to $\mathbf{I} 3$.

What is the significance of these statistics? They mean that, in the lower classes in England and Scotland-say the lower third - the proportion of children born of unmarried mothers is. from 15 to 30 per cent., rising in such counties as Cumberland. to 36 per cent. They mean that, in many portions of this. country, among the poorer and more ignorant classes, no value is attached to chastity; that modesty and virtue are unknown; that there are licentiousness and promiscuity almost universal. And these figures do not reveal half of the truth. When children are registered as born in wedlock, the marriage of the parents. has been, in many cases, the forced result of previous immorality. The Pall Mall Gazette says of the frequent and seldom prosecuted, and lightly punished bigamies of the poor:- " A. labouring man must have a housekeeper and a servant, and the c ily possible form in which he can obtain one is in the shape of a wife. That the bigamies of the poor are so little madepublic in the newspapers, arises partly from the unwillingness. of the wives to expose their own unhappiness and ill-usage, and partly because the standard of right and wrong among them is, in so many ways, unlike that which prevails among therich. What is called 'a misfortune' produces none of the results to a peasant or a city working girl, which it would do. in a higher class of life. And many a woman who has been 
tricked into marriage by a married scoundrel, only regards her injury as 'a misfortune' of a peculiar kind."

One terrible consequence of immorality is shown in a fact stated in Parliament, by Professor Playfair, in the debate on Baby Farming. He said:- "The loss of infant life, even under the most favourable circumstances, was very great, being about 15 or 16 per cent. That loss was doubled, the moment infants were transferred from the hands of the mother to those of strange nurses. If those children were illegitimate, the loss of life, even in comparatively good homes, amounted to 40 or 50 per cent.; and when transferred to homes of a. worse character, the loss of life rose to about 80 or even 90 . per cent." So surely do children die, when they are not wanted to live; and this has a physiological as well as moral reason. In infancy, as in the womb, the child lives upon the loving life of its mother. With that the most puny survivewithout it the most robust perish.

In the same debate, Mr. Mundella said that "two hundred and seventy-six children had been found dead in the areas and streets of London within twelve months."

A strange revelation of immorality startled Parliament and the respectable classes, a year or two ago, in the discussions on the gang system of labour in the eastern counties of England. Women, boys, and girls, working in gangs, 6000 in public gangs; 20,000 , or, as some computed, 60,000 in private gangs, exhibited a grossness of language, and an open immorality of conduct, which could be matched probably in no Christian country. They are described as trooping along the roads for miles, talking with each other, or saluting those they meet with the vilest language, and singing abominable songs, while their conduct was utterly shameless.

The Saturday Revieze says- "It is not the solitary fact of adult female labour, or of juvenile female gangs, which causes female immorality. It is the concurrence of this with home 
training which precedes and accompanies the field-work, which, while it confirms the coarseness, saps the morality. It is the herding together of girls and boys, young men and young women, in the one room of the insufficient and crowded cottage. It is the enforced and unnatural suppression of the native instinct of modesty in the miserable hovels which the unwise and unholy parsimony of the landlord or the speculator has stinted in quantity and quality. It is the foul and incestuous life in the cottage which generates the open and flagrant immorality in the fields." No doubt there must be a previous demoralisation which makes the scandals of such labour gangs possible. Another writer on the crowded dwellings of the poor says_-"What must be the state of morals in such deplorable circumstances? Prostitution has become a rule; incest is by no means uncommon in a family, which is compelled to live in a single room-sometimes on a common litter-where father, mother, sister, and brother pig together like domestic animals."

One of the Commissioners of education gives the following account of the moral condition of one of the mining districts in South Wales:- "Evil in every shape is rampant here; demoralisation is everywhere dominant; and all good influences are comparatively powerless. The people drink to the most brutal excess; they have little regard for modesty or truth; and even the little children in the streets, who can scarcely articulate, give utterance to imprecations. The bodies and the habits of the people are almost as dirty as the towns and houses of the swarthy region in which they swarm. The whole district, with the exception of Newport, teems with crime, and all the slatternly accompaniments of animal power and moral disorder, with scarcely a ray of spiritual and mental intelligence. The people are savage in their manner, and mimic the repulsive rudeness of those in authority over them:" 
I do not wish to exaggerate the evils of our social state, but we must look them in the face. I am willing to make fair allowance for the excited feelings of clergymen and philanthropists, and would fain believe that Mr. Gee of Lincolnshire was in error when he said that, of the lower class of women in the country, forty-nine in fifty were bad; and that the Rev. Mr. Worsley exaggerated in saying that "the almost universa" absence of chastity and purity among the labouring classes in our country villages is notorious to every one at all acquainted with them."

Another clergyman, whose name I do not now recall, testified that, to the best of his belief, there was not one virtuous girl over fourteen years of age in the labouring class of his rural parish.

Among the causes, as they are called, but rather outlets or manifestations of immorality, effects and causes combined, have been the statute fairs and yearly hirings in many districts. The farm and domestic servants gather to be hired. The roughs of the neighbourhood congregate, and the whole becomes a saturnalia of drunkenness and debauchery.

Justice to the lower classes requires us to admit, however, that it is not they alone who are guilty. The middle and upper classes have their full share in this iniquity. Of the million female servants in England and Wales, a great many are led into evil by their masters or the grown-up sons of the families in which they live. One hears of so-called respectable men, fathers of families, with whom no female servant is safe. A great number of cases of infanticide come from the class of domestic servants. Then, nearly the whole class of prostitutes, of whom we have yet to speak, are supported in their wasteful and miserable lives by men of the middle and upper ranks of life; and they, too, are guilty of most of the seductions which recruit the ranks of the army of abandoned women. If the women of the lower classes are to a large extent licentious, a 
much larger proportion of the men of the middle and upper classes are worse-more selfish, more reckless and cruel, more abandoned to debauchery. Women have more excuse. They are ignorant; bad conditions and associations deprave them almost from their infancy; they are the victims of want, of loneliness, of love. Men have seldom any of these excuses. They simply seek a sensual gratification, regardless of consequences. Multiply the number of women in England who abandon themselves to promiscuous intercourse by the average number of men with whom each one associates, and you have the number of men who are in like manner abandoned.

The inequality of the sexes may have some influence on the demoralisation of women. There are in England and Wales between 300,000 and 400,000 women more than men of marriageable age. Of women between 20 and 40,58 in roo are married; 3 in roo widows; 39 in roo live in celibacy; and to a large portion of these-to 27 in 100-celibacy is a necessity, from which nothing but emigration or polygamy can save them. The young men of England go to America, Australia, the army or navy; the women are left in a condition which many consider very dangerous and deplorable. When two-fifths of the women of a country are single and must so remain, a certain number must be expected to find some substitute for a condition sought and envied, but which fate has deried them.

The selfish disregard of the moral condition of the lower classes by those in a higher position is curiously shown in the custom of ladies advertising for single women as wet nurses for their children. The Pall Mall Gazette copied some time ago, I think from the Times, two advertisements like this- "Wet Nurse, Single, aged 25. Baby a month old." The fact of being single was paraded as a special qualification. Ladies preter unencumbered nurses, but what becomes of the nurse's 
baby? The poor baby's life, in many instances, is sacrificed; and the rich baby may not be a gainer.

The sin of lust, the deep taint of impurity, is restricted to no class, no position, no age. The respectable married people of the luxurious middle and upper classes are probably the most flagrant violators of the laws of true morality. Children born of lust and the abuses of marriage inherit the taint in their constitutions, and in all the innocence of ignorance, utterly unwatched and unwarned as they generally are, fall into the physical evils and contamination of vice from their tenderest years. A vice so inherited is propagated to others, and every school may become-and most schools, it is to be feared, do become centres of sensuality and the most destructive vice. The highest public schools and the universities are not free from this pervading evil. Of this great and terrible evil which poisons the life of the best children and youth of both sexes, I shall have to write seriously, scientifically, and I trust effectually, in a later chapter. I can here say that a perverted sensuality, which has its origin before birth, spares no age or sex, and afflicts individuals and societies with some of its most dreadful evils and sufferings.

This sensuality, stimulated by unnatural modes of living, by luxury in food, in drinks, in narcotics, in dress and amusements, is the cause and also the effect of licentious literature. Poets pander to sensuality and stimulate a life of lust. Circulating libraries 'teem with what an English review coarsely called "hot novels," and these novels form a great part of the amusement-almost the whole employment of thousands of idle women. Do we not see them lolling at their windows, or sitting on the shore at the sea-side places every summer, deep in the last sensation novel from Mudie's?

Lower down-down in the depths of this depravity-we have a grosser form of impure literature, to the supply of vhich nearly every shop in two streets in the heart of London w's not 
long since devoted. Now they are more widely scattered; but everywhere to be found. And there is at least one newspaper, of very large circulation, which advertises all over the United Kingdom the most depraved and depraving of books, filled with every species of abomination.

Even this, it seems to me, is not the lowest deep. The worst-the most dangerous book to public morality I have ever seen in England, is one professing to be written by a physician, who does not give his name, who advocates universal lust and licence as a matter of science and philanthropy!

And this book, which I will not mention by name, becauseI do not wish to advertise a publication so utterly abominable, expresses boldly the carefully whispered opinions of many medical men, who, immoral themselves, advise their patients, male and even female, to practice immorality, just as doctors. who freely indulge in intoxicating drinks also freely prescribe them for their patients. All this is fearfully wrong and fearfully mischievous; mischievous, as any one can see who looks beneath the varnished surface of respectable society; wrong, as. I believe I can show from the highest authority, and as a deduction of Physiological Science, for nothing which is not contrary to nature can be opposed to a true morality. 


\section{CHAPTER X.}

\section{PROSTITUTION AND ITS CONSEQUENCES.}

Sexual Abuses peculiar to Humanity-Women driven to ProstitutionCorruption by Fraud or Force-Seduction and Prostitution of Children - East End of London-In the Parks-Garrisons-Characters of Prostitutes-Scenes at the West End-Toleration of ProstitutionDemand and Supply - The Evil Consequences-The Plague of Syphilis - Extent of its Ravages-Frightful Disease and Mortality-Effect on the Army-Right and Despotism-Liberty and Law.

MAN is the only creature on this planet who buys and sells, abuses and outrages, enslaves and degrades, the females of his own species. The female bee is the queen as well as the mother of the hive, and is served by her subjects with devoted loyalty. The male bird woos the female with plumage, song, and a thousand delicate attentions, and, when accepted, helps to build the nest, feeds his mate, or takes her place at times during the hatching process; cheers her with music, and assists in feeding the young. Among the mammalia, the male may fight for, but never with the female; he is ready to serve her, but never forces himself upon her; and never makes her the mere instrument of his sensual gratification. The intercourse of the sexes throughout the animal creation has but one purpose-the production of offspring; and the rights of the female sex, when animals are living in natural conditions, are never violated. Seduction, rape, prostitution, impure diseases, and sexual intercourse during pregnancy, are unknown to animals. It was left to man, and in respect to some of the evils, to civilised man, to fall into such depravities, mis. of tunes, crimes, and abominations.

If women were as well treated by men as female ar itutes 
are by males, the earth would be a paradise. Human depravity is shown in nothing more painfully than in the treatment of women in marriage and in prostitution-in marriage, when it is made the excuse of gross licentiousness and cruelty; in prostitution, when thousands of women, girls, and young children, are made the victims of the selfishness and lusts of men. Women in England work in brickfields, chemical works, glass houses, paper mills, shoddy mills, glue works, nail works, fields and gardens; toil at many hard and repulsive employments. Forty-three thousand work as out-door agricultural labourers; but Mr. Lecky estimates that not less than 50,000 are driven to the far more degrading slavery of prostitution. He puts the number in London at 18,000. Of 9000 in one English sea port, 1500 were under 15 years of age.

"Woman is driven into prostitution," says the Westminster Reviere, "by the weight of all society pressing upon her." She is forcibly excluded from many professions and employments; she is paid less than men in most of those which are permitted to her; advantage is taken of her ignorance, her innocence, her affections. In thousands of instances, she is the victim of fraud or violence, and becomes first the victim of one man, and then, deserted by him, of many.

It is stated that upwards of 400 persons in this country get their living by trepanning girls from eleven to fifteen years old for the purposes of prostitution. Many houses in London are kept solely for girls of tender age, and frequented chiefly by old men. Hundreds of women follow the trade of pimp, or procuress, and get young and ignorant girls from the country or from foreign countries, by agents, or advertisements offering -mployment. Men advertise for servants, apprentices, even rernesses, to get girls into their power, whom they seduce,

if necessary, or ravish with the aid sometimes of former , and then plunge them into a life of prostitution for rn gain. Sisters corrupt sisters, and mothers prostitute 
their own daughters for a living. Mr. William Tait gives the result of an investigation in Edinburgh, by which it appeared that there were in that town two mothers with four daughters: each, five mothers with three daughters each, ten mothers with two daughters each, twenty-four mothers with one daughter each -all, mothers and daughters, living by prostitution.

Official returns give the number of common prostitutes under sixteen years of age in England and Wales, at about 5000 ; but a great many are unknown to the police, and those who are so young often do not give their ages correctly. Any man of experience who watches the streets of London, Birmingham, Liverpool, or Manchester, will be surprised and shocked at the number of mere children, girls of ten to fifteen, who unmistakeably belong to the class of prostitutes. In the poorest parts of London, the girls of seven years of age are turned into the streets to sell fruits, flowers, matches, \&c.- - to beg or pilfer-for a subsistence. By the time they are fifteen or sixteen, most of them become prostitutes. A relieving officer of St. George's in the East says most of the daughters of the coalwhippers, among the most oppressed and drunken of working men, become prostitutes.

Of 472 unfortunates received at the Queen Street Refuge by the Society for the Rescue of Women and Children, 47 at the period of their ruin were 17 years old; 80 were $16 ; 52$ were I5; 55 were $14 ; 36$ were $13 ; 37$ were 12 : 10 were $11 ; 9$ were $10 ; 4$ were 9 ; and 2 were only 8 years old.

Another report of the same society states that out of 538 cases of young girls relieved by its officers, 365 had been seduced before they were 16 years of age, and 106 before they were 12 years of age. The report further states that amongst the girls admitted to the asylum last year I was seduced at 5 , I at 7,5 at 8,7 at $9, \mathbf{I} 2$ at 10,7 at $\mathrm{II}, 73$ at $\mathrm{I} 2,29$ at $\mathrm{I} 3,60$ at $\mathrm{I} 4$, and 50 at 15 years of age.

The actual number of children, girls from eight years old to 
sixteen, thrown upon the streets of London, is something so frightful to contemplate, that I cannot wonder if many people resolutely shut their eyes against such horrors. It is so dreadful, and it seems so hopeless !

The portion of London lying along the Docks, east of London Bridge, with its large floating population of native and foreign sailors, and its vast and crowded resident population of dock labourers, coalwhippers, \&c., presents a spectacle of human depravity such as can be found only in great English and American seaports. The principal streets seem to consist chiefly of public-houses; the side streets are lines of brothels. Of 230 houses in one district of the parish of St. George's in the East, I 50. are houses of ill-fame, mostly belonging to publicans, who own the women; as really as a Cuban proprietor owns his negroes. Every public-house, as a rule, has its dancing-room behind the bar-room; and every week-day night the blowsy and tipsy girls $o$ f the house, tricked out in coarse finery, and exposing their persons as freely as a West End belle, induce the sailors to dance, drink, treat, get rid of their senses and money as soon as. possible, so that after a few days and nights of drunken debauch, in which they are robbed of the earnings of months, they may be sent dead drunk upon an outward-bound ship, and tugged down the river.

This is life at the East End of London. I have alluded to the fact of som? scores of wretched girls sleeping in the summer in Hyde Park; others have been arrested for making. their home in the Great Park at Windsor, sleeping under the trees, washing their faces and clothes in the Deer Pond, and running absut half naked while they were drying on the trees. For combs they used small pieces of wood, or lucifer matches, and their rude toilettes had been performed without shame in the presence of the general public, and ladies in carriages as they passed through the park. They were principally supported by the soldiers, who brought them their rations, 


\section{Human Physiology.}

which they were enabled to take from the barracks without attracting observation, by concealing the food within the lining of their caps.

Every garrison is surrounded with its colony of prostitutes; every barrack is the nucleus of a cluster of houses of ill-fame. Every seaport swarms with the lower order of prostitutes: Every ship in her Majesty's navy, besides officers, sailors, marines, \&c., has her complement of these outcasts of society, who as really live on the taxes, and are provided for in the estimates, as if they had honourable mention by the Secretaries. An army of so many thousand gallant men means another army of so many hundred abandoned women. And the civil population of every town has its own similar provision -its multitude of victims to what many believe to be an inevitable condition of things-a necessity of civilisation.

Every class of men, single and married-for, as we shall soon see, it is not the single alone for whom the "social evil" exists-has its corresponding class of women, from those who drive in their elegant carriages in the West End Parks to those who frequent the dancing-rooms in Ratcliffe Highway-from those whose portraits adorn the shop-windows of Regent Street, to the lowest street-walkers of the lowest streets of the metropolis. And among them one sees, at times, beauty, grace, kindness, tenderness, and often a frank simplicity and honesty of character, which compel respect and pity, and one ceases to wonder that great numbers of such find men who are willing to forget what they have been, and rescue them from the evil course into which they have been pushed, or have fallen.

Miss Mulock tells us that many are lost through pure ignorance, and that the best girls are most likely to be seduced. She has found them capable of deep love-and self-sacrifice, and of becoming excellent mothers and nurses. Mr. Acton stated to a Commission of the House of Lords, that London prostitutes 
as a class are "the picked population of England;" and they are certainly superior in physical beauty, and often not inferior in mind and heart. More the shame and pity that they should. be what they are.

It is a great mistake to think that all, or even a very large number of public women became such from evil dispositions and tendencies. Any commercial distress in the manufacturing towns in Lancashire increases the number of unfortunates in Liverpool and the larger towns of the district. Want ruins more than passion; and very few women, far fewer than men, ever have the desire for promiscuous amours. Even great numbers of common prostitutes have lovers to whom they are as faithful and devoted as they can be. Nearly all the women in the hospitals of seaport and garrison towns, generally of the lowest class, are declared by the surgeons to be obedient, civil, respectful, and their conduct quite satisfactory. One of them says:- "What we find is, that they are entirely creatures of impulse. As far as my experience goes, I do not at all think that you would find any very large per centage of those women who are what $\dot{I}$ would call radically bad; they have never had any education; they do not know really good from bad; and, as I said before, they are entirely the creatures of impulse, and the first thing that comes across them they will do without thinking exactly what the consequences are. But I have seen amongst them a great disposition to help each other, and to be kind to each other, and they certainly are amenable to kindness and careful and good treatment to an extent which is very satisfactory." Their treatment of their babes, and those of their companions, is tender and beautiful. "Creatures of impulse," they become what those with whom they associate make them. And what they can be made, thosewho know London at night do not need to be told.

The Morning Post, the most fashionable journal in England, describing the scenes at the West End of London, says:- "Let 


\section{Human Physiology.}

us ask simply, is there any capital in Europe where such undisguised profligacy is permitted to force itself upon the gaze of the public? In the Haymarket and the adjoining streets, from eleven o'clock at night to three or four in the morning, the pavement presents a crowd composed of the lowest prostitutes and those who come there for the purpose of encountering them. A sprinkling of professional thieves hovers on the verge of this assemblage, as sharks prey round a shoal of herrings; and harpies of both sexes, ready to pander to any extent of depravity, make their hideous trade but too apparent. Children of tender years are hawked about for the most profligate purposes (two vile offenders in this particular were committed for trial at Bow Street lately); obscenity of language and indecency of demeanour meet the ear and the eye at every step; every respectable man avoids the street; no decent woman dare venture near it; and drunkenness and dissipation, enlivened with a little variety of robbery, reign supreme. We permit these gross orgies to take place every night of our lives, and on some of the morrows we attend meetings and subscribe for missionaries to distant climes for the civilisation of the swvages! Bushmen at the Cape, the most untutored denizens of the remotest isles in the Indian Ocean, have far less real need of such aid than the habitual frequenters of that locality, which has earned for itself the infamous sobriquet of Hell Corner.

The public tolerance for gross immorality has never been shown more strangely in England than by the exposure in thousands of shop windows in the most fashionable streets of London, and even in country towns, of photographs of notorious women of ill-fame. They were exhibited by the side of portraits of Royal and celebrated personages, because there was a large demand for them. What but interest in, and sympathy for vice, could make thousands of people pay their shillings for the portrait of a common prostitute, who has been 
frequently before the police magistrates for being "drunk and disorderly"?

Prostitution is very open and bold in England; tolerated, recognised, written about in public journals, investigated by Royal Commissioners, recorded in statistics, discussed by writers on medical and social science, morals, philanthropy, and religion. It is contrary to law; but the law does not even attempt to suppress, and only in a bungling and spasmodic way to restrict or regulate it. It is contrary to morality; yet moral, respectable, and even religious people, are not ashamed to grow rich upon the profits of such immorality. It is contrary to religion; yet how seldom is its tolerance and support denounced from the pulpit. The hundreds of houses of illfame in London are well known to the police and public authorities, but how seldom are they disturbed; and there is no thought of their being abolished. The ball-rooms, casinos, and other notorious resorts of public women, are kept open year after year, and many streets of London are thronged night after night by thousands of these women plying their vocationoffering to sell themselves to every comer at the lowest prices for which human bodies and souls were ever sold. I have seen the infamous traffic going on in a church-yard. Philanthropic societies and religiuus communities, like the Sisters of the Good Shepherd, pluck a few brands from the burning, but the numbers seen everywhere, and the prices demanded, show that the supply exceeds the demand-that there are more women anxious to sell their bodies for only bread enough to escape from starvation than there are men ready to buy them. For it is certain that women every day go into the streets to get bread for sick, perhaps drunken, husbands, and needy parents, and starving children, and hundreds seem to know no other way to live, and are driven to this dreadful trade by sheer want. And the worst of all is, that no real, generous, earnest, effectual effort is made to remedy this gigantic evil. Society 
has come to regard it as a necessary evil-a safety-valve for the lust of men-the safeguard of marriage, and the security of virtuous women; virtuous women, who seem content that so many thousands of their sisters should be sacrificed for their protection.

The evil consequences of prostitution are proverbialwritten in the Proverbs of Solomon, and those of all nations. Its depraving influence upon its victims is obvious; the modest, gentle girl becomes in a short time the brazen, shameless, abandoned, and often dishonest, profane, and drunken "creature." Drunkenness becomes the habitual condition of great numbers, for it is only by drink that they can endure the disgusting horrors of their daily life. If the harlots of loveless marriage fly for solace to drink, how much more must they who are also the constant victims of lust, without the compensating advantages of a good name and respectable position; Many prostitutes are thieves, and the greater number are, in one way or another, the robbers of their dupes. No class is so reckless, so extravagant, or costly to the public on which they live. The wasted money must be reckoned by millions; but what shall we say of wasted honour, reputation, prospects of happiness, virtue, health, and life? These losses are incalculable.

England has become familiar with the subject of the contagious diseases propagated by prostitution, the worst of which have been known to the civilised world less than four centuries. It was after the discovery of America by Columbus that the plague of syphilis fell upon Europe like one of the seven vials of the wrath of God. It was not known to ancient Rome in its most licentious epochs-it was not one of the scourges of the middle ages; but when it was introduced, whence or how is not known, it quickly spread over Europe, and ever since has filled the world with its horrors and desolations.

Mr. Berkeley Hill has stated in a letter to the Times (Feb. 22, 5869 ), that in English towns 69 per cent. of children who 
die under one year old, and 25 per cent. of those who die under five years old, are the victims of this disease ; that onehalf the out patients of St. Bartholomew's Hospital-3,000. a-year-are so affected; that in 1864 , of 68,000 patients. admitted to the hospitals of London, 20,600 were affected with diseases which had their origin in syphilis; that 56,000 of the poorer classes of London were every year the victims of "contagious diseases."

In an official Blue Book of the House of Lords (1868-9), it. is stated that a considerable portion of the soldiers in the army and sailors in the navy are constantly in the hospitals, and that the greater number become poisoned for life, so that they must communicate the taint of the disease to their posterity; that multitudes of virtuous married women are infected by their husbands, and give the disease to their children-the most of whom perish miserably, being still-born, dying in infancy, or growing up with scrofulous diseases; that it would be very difficult to overstate the amount of damage that syphilis does to the population; that it produces blindness, deafness, and a peculiar decay of the teeth; that diseased children infect their nurses ; that by causing the early death of children, it seriously diminishes population; that one surgeon, Mr. James Paget, F.R.S., had known five surgeons die, and fifty others severely suffer, poisoned by accidental scratches in operations on syphilitic patients; that surgeons are infected and sometimes. die of contagious diseases taken while attending women in childbirth; that it causes diseases of the lungs, liver, spleen, brain, and spinal marrow, producing a constantly increasing mortality; that, according to the testimony of Sir W. Jenner, a large portion of the chidren, in and out patients of the London hospitals, suffer from constitutional syphilis, though. registered as dying of bronchitis, inflammation of the bowels, cholera infantum, \&c. ; that in thirteen years one-fourth of the patients in St. George's Hospital were suffering from complaints 


\section{Human Physiology.}

of syphilitic origin ; that no disease is so terrible, or so general throughout all classes of society, but especially terrible in its results to innocent women and children.

Sir Thos. Watson, F.R.S., declares that this disease "counts its victims not only among the vicious and self-indulgent, but among virtuous women and innocent children, by hundreds of thousands."

Dr. Balfour, in his Medical, Sanitary, and Statistical Report of the Army Medical Department for I860, says :- "More than one-third of all the admissions into hospitals have been on account of venereal diseases ( 369 per 1000) and the average number constantly in hospital is equal to 23.69 per 1000 of strength. The inefficiency is constantly equal to about $2 \frac{1}{2}$ regiments. It may be doubted whether army or navy suffer worse than the same numbers in ,towns of the civil population."

I have put these statements, taken from the testimony of medical men of the highest ranks, into the most compact, and, I trust, unobjectionable form; and, were it possible, I would gladly have omitted it altogether. The origin of this fearful disease is unknown; but there is no doubt that it is kept up and spread by prostitution, and aggravated by the filth, intemperance, and general bad habits of the lower order of public women. In the rural districts there are many illegitinate children, but comparatively little of contagious disease. But all the large towns, and especially the large seaports, where prostitution abounds, are the centres of this destructive pestilence which affects successive generations. It is evident that, if by any means this disease could be effectually stamped out, there would be a diminution to the extent of one-third, perhaps one-half, of preventible diseases and premature mortality.

Marriage might be supposed to be a safeguard. To a large extent, no doubt it is; but the evidence before the Select Committee of the House of Lords shows that great numbers of married men, married women, and children are affected. All 
this has been going on for centuries, sapping the life of the nation, destroying vast populations-the innocent as well as the guilty, even more than the guilty-and nothing effectual has been done to stay the pestilence. A timid and partial effort to economise the strength and cost of army and navy has met with a violent opposition, and there is little hope of legislative remedy. Prostitution and its evils must go on until men and women are wise and good enough to lay the axe at the root of this deadly upas. "Wise and good." Education of the intellect alone, and even of the taste, is not sufficient. A very learned and, in many respects, tasteful man may be a profligate. Very accomplished women have been very immoral. There must be moral elevation which will bring men into higher and purer modes of life. There must come to men a strong and deep sense of what is best in life, and of their duty to God and their fellow-men. They must see and feel that selfish sensuality is a sin-that seduction is a crime which may' be worse than murder-a dishonesty that is more base than theft. When every man treats every woman as he would wish his mother, sister, or daughter to be treated-when every woman requires purity in man as she does in woman-when a crime against chastity is as severely reprobated and punished as a crime against property-when the sins that drive women from society shall be punished in men with the same severity - and when, more than all, both men and women understand their own natures, and know the real objects of life, and what will give them the highest and purest enjoyments in this and every stage of being, we may expect to see an end of all this guilt and crime and misery.

If prostitution and its consequences are really necessary evils; if their victims suffer for the greatest good of humanity; if a certain proportion of our women, even of the loveliest and best, must go down into this horrible gulf to secure the safety and happiness of the rest; if nothing can be done even to save us from the pestilence that walketh in darkness, then we ought 
to trankly and bravely meet the dreadful necessity. The question which every man should ask of his heart and conscience is,-Am I willing that $m y$ sister-my daughter-the woman $I$ love, should be one of these victims of social order, and bear her part of this necessary evil? Every harlot in the streets is some one's daughter, and therefore mine. I should guard every child as if she were my child-every woman as if she were my sister. In this spirit of human brotherhood the world may be redeemed.

It may be thought that in this and the preceding chapters I have drawn too dark a picture of the evils of our social statethat I have made it too gloomy and repulsive. There is a brighter, fairer side. There are thousands of honest, pure, generous, and heroic men-thousands of women as virtuous as they are lovely. I know it well. No country in the world has more of courage, honour, and benevolence. And it is for this reason that I have the courage to point out these evils, and the hope that there are men and women who will try to understand them, and seek to know, and endeavour to apply, the remedy.

Let us learn the nature of man, the evils to which he is iable, the causes of those evils, and their cure. When a plague falls upon the cattle of a country there is alarm, inquiry; it is the talk of every circle, written about in every journal; Royal Commissions are appointed, learned men are consulted, the exp erience of other countries cited; the Ministers bring forward measures in Parliament, bills are passed, supplies voted.

But when half a nation falls into the depths of poverty; when half the children die in infancy; when great numbers are wilfully destroyed; when the bone and sinews of the nation (its working men and working women) are perishing of foul air, crowd-poison, and other bad- conditions of life; when these conditions and the lack of education are driving vast numbers of them to drunkenness, and filling worknouses and 
prisons; when the most wronged, ill-treated, and enslaved women are driven into the most hideous of all evils and curses -into prostitution and its avenging plagues-how little is thought, or said, or done, to remedy these evils.

In the forty thousand churches and chapels how little is done! In a thousand journals and periodicals how little! By hundreds of religious and philanthropic societies how little! In almost omnipotent Parliament how least of all! Least there, because it is there that the will of the nation is not formed, but only finally recorded. The will must be elsewhere formed. Parliament does not originate. It is not the brain of the nation-neither Lords nor Commons can claim that. The thinkers and teachers of the nation are not, to any great extent, in either House, nor in high office anywhere. The work must be done in the minds and hearts of the people, and when it is done, Parliament will do what they require. We must go to the sources of power. They lie with the people, but not in mere numerical majorities. In a goud cause "one may chase a thousand, and two put ten thousand to fligla:." Moral power is stronger than any majority. Right will overcome wronggood will prevail over evil, whatever may be at any moment the opposing numbers.

And in respect to the functions of Government, and the right of the wise and good of any community to enforce order and equity, there is the same right that exists in the human body, where a few ounces of brains control a hundred and fifty pounds of bones, muscles, and viscera. Will must govern-the force of mind; happy if wisdom guides the will.

And all government, that of the good as well as that of the bad, is an absolute despotism. There is and can be no other. If it is merely a majority, wise or foolish, compelling the submission of a minority, it is none the less an absolute despotism. Force governs with police, military, courts of law, prisons, the 


\section{Human Physiology.}

cat, and the gallows. We need only that intelligence shall give our forces the right direction.

"The liberty of the subject," or some vague notion that Magna Charta gives every man a right to do as he likes, bars the way o: reformation. The only real liberty any man has under any charter, great or little, is THE RIGHT TO DO RIGHT. There is $n 0$ right to do zerong. No man can have any right to injure himself, for he belongs to others. No man has a right to injure another, for each belongs to all and all to each. We are all members one of another. Every man is his brother's keeper. No one has the right to taint the common life of ma:1 with fraud or sin-with any physical or moral evil. He who defiles the air that men breathe, or the thoughts they think, equally commits a nuisance. Men have the right to do right; and it is right to free themselves and society, and the world itself, from all the evils that darken and degrade humanity.

The evil of ignorance, which lies at the root of so many others, can be removed, and the work of universal education is begun. It is seen to be a matter of national safety. The evil of poverty is not a necessary evil. The yearly production of the necessaries of life in England is abundant for the needs of all her people. Her own soil, well cultivated, would feed a much larger population. Her manufactures, were their profits fairly distributed, would provide comforts and luxuries for millions. With intelligence, and moral culture corresponding to intellectual development, would come a taste for refined enjoyments, and men would no longer drink to intoxication, or stupify themselves with narcotics; and two hundred millions of money spent on intoxication would be saved for higher and nobler uses. The causes of disease and premature mortality would be removed, and nine-tenths of the miseries that afflict humanity. Abolish ignorance, poverty, and drunkenness ; raise all human life to higher levels of dignity and virtue; give tc the lower millions the comforts, respectabilities, and sanctities 
of home; teach men and women their true natures, and their relations to each other, and marriage would be sacred, and we should have done with prostitution and its consequences, or they would be reduced to the lowest minimum.

And when children inherit health from healthy parents, and purity from parents whose lives have been pure, good will begin to triumph over evil, and knowledge and virtue will fill the earth with happiness. Then will the prayer and the prophecy be fulfilled- "Thy Kingdom COME, ThY WILL TE DONE ON EARTH AS IT IS IN HEAVEN." 


\title{
PART SECOND.
}

\author{
MATTER, FORCE, AND LIFE.
}

CHAPTER I.

MATTER.

Evils and their Remedy-Matter a Mystery-Solid, Liquid, Gaseous-Atoms and Molecules-No Contact of Atoms-Expansion, Contraction, Elasticity, Vibration-Size of Atoms-Microscopic WondersElementary Bodies and their Combinations-The Earth-The Chief Elements of Nature-Points of Force.

IN Part First of this volume I have treated briefly of the actual condition of man in the highest civilisation to which he has attained, and shown that millions of the population of this country are subject to preventable diseases, and preventable mortality, beyond all other species of animals; that infant mortality and infanticide destroy nearly half the population, and more than half in certain classes and conditions; that ignorance and poverty produce vice, drunkenness, crime, and misery; and that the hardships of the poor and the slavery of women culminate in prostitution and its consequences. The way out of this strange conglomeration of moral and physical evils may, I believe, be found in a knowledge of the nature and destiny of man, with, of course, obedience to laws, and their enforcement, when needful, after they have once been ascertained. We are to govern ourselves as we would govern 
any race of creatures committed to our care, and for whose welfare and happiness we were held responsible by a higher power.

Man, in his physical body, is composed of matter, subsists on matter, is subject to material laws and conditions; therefore we must try to understand something of matter-to see, at least, how wonderful a thing it is, and to know how little is known, and probably can be known, about it.

It seems to be proved by spectrum analysis that the whole visible universe, all the stars that sprinkle the firmament, and the millions that the telescope reveals to us, with all their attendant planets, are composed of the same kind of matter that forms our own solar system. Universal analogy is the law of creation; and there can be little doubt that all the worlds of the universe are full of vegetative and animal life.

This matter of which all worlds are made seems to us a greater mystery than mind, of which we are conscious. We think and feel, and know something of our thoughts and feelings; but of matter, beyond the impression it makes upon our senses, we know so little that many have doubted the existence of any matter-of anything but ourselves and our sensations. Such philosophers must, of course, believe only in themselves. All other persons, like all other things, are sensations only; and the mother is not sure of the material reality of the babe on her bosom.

Matter exists in the visible and tangible world about us in three forms-solid, liquid, aëriform or gaseous; as rock, water, air. But the same matter may take all forms, as ice, water, steam, or the invisible vapour of water dissolved in the atmosphere, condensed at times into visible clouds, rain, snow, or hail. So mercury, a liquid metal, congeals into a lead-like solid, or turns to vapour with sufficient heat. So gases can be compressed into liquids, and then into solids. Most simple substances take on these three forms of matter. 


\section{Human Physiology.}

The atoms of gases are kept far apart by elastic repelling forces, but, under certain conditions, they come nearer, as when hydrogen unites with oxygen to form water; and water will dissolve salt, sugar, and other substances without much increase of bulk. So solid a substance as gold will drink up mercury as a sponge does water; but in this case the attraction of the atoms of gold for each other is destroyed. The gold is dissolved in mercury like salt in water. Heat the gold, so as to drive off the mercury in vapour, and it resumes its solid form.

But a solid body is not really what we commonly conceive of as solid. All matter is perhaps composed of molecules, or assemblages of atoms; and we cannot conceive of matter but as composed of atoms. A gas is matter with its atoms driven far apart by their mutual repulsion, and moving freely and almost independently of each other. Condense the gas-bring the atoms a thousand times, perhaps ten thousand times, nearer together, and we have a free flowing liquid, where the atoms do not interfere much with each other's motions, but dense, visible, and tangible, bearing us up, like water. In what we call a solid body, the atoms come still nearer to each other, and are held by their mutual attractions and repulsions in fixed positions, but still they do not touch each other. No two atoms in the universe ever touched each other. No two atoms remain for an instant at the same distance from each other. The atoms of iron, gold, glass; of the keen edge of knife or lancet, the point of a needle, the angle of a diamond which cuts glass, are all equally distinct from each other, held in their places by forces of which we shall speak hereafter.

What is the proof? It is that all bodies expand by heat-that is, their atoms go further apart in all directions. They contract with cold, or the diminution of heat; and they could not do this if the atoms already touched each other. Temperature changes every moment, and the diamond on a lady's 
finger, and a granite obelisk, alike grow larger and smaller with every change of temperature, just as the liquid mercury in the thermometer rises and falls. It is proved by experiment that a granite obelisk, exposed to the rays of the sun, morning, noon, and night, bends towards its shadow. And this absolute, necessary separation of the atoms of matter is proved no less by elasticity. When I bend my knife blade, or a piece of glass, the atoms on one side are pressed nearer together; those on the other are drawn apart; but repulsion on one side and attraction on the other restore them to their former position. If atoms touched each other, nothing could be elastic.

It is not easy to believe that when a bullet is crushed against a wall, or a chisel is driven through a bar of iron, there is no. contact of atoms-that the diamond does not touch the glass it cuts, nor the diamond dust the diamond it polishes; but the fact is undoubted. In every case there is a struggle of forces, but the atoms are never in actual contact.

It is the fact of matter existing in distinct atoms, and equally distinct molecules, each holding its position by forces of attraction, repulsion, and polarisation; each returning to its position when for an instant jostled out of it, like soldiers in a welldrilled military corps, that gives to bodies vibratory and sonorous qualities. When I strike a rod of steel, or ring a bell, I send through it a series of rapid vibrations of all its. myriads of atoms, which are communicated to the atoms of the atmosphere, and thence to my nerves of hearing. Were matter solid, there could be no sound, for all sound is first produced by vibrations of elastic bodies, and elasticity depends upon the absolute separation of the atoms of matter from each other. They are forced together and then fly apart, settling to rest after a multitude of oscillations, or they are drawn asunder, and then fly together with a similar result. Observe, in the same way, the rebounds of an india-rubber ball, or the wonderful elastic power of a cord of the same material. 
In all elastic bodies there is a partial yielding of the attractive and repelling forces. A steel spring will bend to a certain point, and then it breaks. A thread of india-rubber will stretch several times its usual length, when it becomes rigid like a cord of silk or catgut, and any further strain breaks it. So a gas can be compressed until it becomes a liquid, when it suddenly resists, and further compression requires an immense increase of force.

Atoms are inconceivably small. Gold plated upon silver wire can be drawn so thin that one foot of wire contains only $\mathrm{I}-6000$ th of a grain of gold; and this can be divided so that $1-72,000,000$ th of a grain is visible to the naked eye, and I-72,000,000,000th can be seen with the microscope; but this microscopic particle probably consists of millions of atoms. A platinum wire can be drawn to the diameter of I-3000th of an inch; gold to I-500oth. And a silver wire 13,000 feet in length, weighing one ounce, is completely gilded by eight grains of gold. One grain of certain dyes will colour vast quantities of water, through which the myriad atoms must be diffused. Nitrate of silver divided into one hundred billionths is distinctly visible. The stone called tripoli, used for polishing metals, is composed of the siliceous - sand-like-shields of fossil animalculæ which are the I-288th of a line in length, and of which there are $4 \mathrm{I}, 000,000$ to a cubic inch; yet this animal has its organs, and feeds on still smaller animals or vegetables composed of organs, and these of atoms of matter.

The rocks now filling up the seas on the coasts of the Carolinas, are composed of shells of sea animalcules, of which there are $3,840,000$ in an ounce; yet each of these is composed of an infinity of atoms. The Alps, the Appenines, the stones of the Pyramids, and those of which Paris is built, are composed to a great extent of microscopic shells, secreted by animal existences, which seem to us but a film of slime. A cubic inch of chalk contains the shells of ten millions of highly organised 
creatures; each shell composed of an immensity of molecules of carbon, oxygen, and calcium.

The microscope opens to us worlds on worlds of the infinitely little, as the telescope displays to us new universes, vast and sublime, in the filmy specks of the sky. What are we to think. of the dimensions of the atoms composing the perfect organisation of each of the 17,000 eyes of the butterfly, or the 25,000 of the mordilla, each with its lens, pupil, retina, as perfect as our own? What of those which form each of the elaborately constructed 360,000 suckers on the head of one species of Pteropoda-the whole animal an inch long?

A microscopic fungus is said to multiply into countless: millions in the body of a single fly; and a drop of water may contain 500 millions of living animalcules, each an organised being, feeding upon more minute organisations. One drop of water may contain, and have ample space for, as many living. creatures as there are human beings on the earth-an ocean in which they move with great activity, eat with voracity, and multiply at such a rate that a philosopher has calculated that they would in four days generate 170 billions. Such being the case, what is the probable size of the compound molecules of water, and what of the oxygen and hydrogen of which it is. composed? Mr. Herbert Spencer says:-

"In the minutest visible fragment of matter there are millions. of units severally oscillating with unimaginable speed; and physicists show us that the amplitudes of their oscillations vary from moment to moment, according as the temperatures of surrounding objects vary. Nay, much more than this is now inferable. Each unit is not simple, but compound-not a. single thing, but a system of things. Spectrum-analysis has. made it manifest that every molecule of this so-called elementary substance is a cluster of minor molecules differing in their weights and rhythms. Such being the complexity of matters. we lately thought simple, judge what is the complexity of 
matters we knew as compounds. In each molecule of an oxide or an acid the chemist sees one of those systems united with one, two, three, or more systems of another kind that are similarly involved. Ascending to orders of compounds successively more heterogeneous, he finds himself obliged to recognise molecular complexities unrepresentable in thought; until, in reaching organic matter, he comes to molecules each of which (taking into account the composite nature of its so-called elements) contains literally more atoms than the visible heaven contains stars-atoms combined, system within system, in such ways that each atom, each system, each compound system, each doubly-compound system, has its motion in relation to the rest, and is capable of perturbing the rest and of being perturbed by them; . . . . and molecules of each kind are specially affected by molecules of the same kind existing in the farthest regions of space. Units of sodium on which sunlight falls beat in unison with their kindred units more than 90 millions of miles off, by which the yellow rays of the sun are produced."

And Mr. Nicholas Odgers has written a work on "The Mystery of Being; or, Are Ultimate Atoms Inhabited Worlds?" -a very queer absurdity; for an inhabited world must be composed of an infinitude of ultimate atoms.

Professor Tyndal tells us that the blue colour of the atmosphere is caused by myriads of spores or germs of vegetable and animal life, filling the whole air, but quite invisible under the highest power of the microscope. Of course a spore or germ must be composed of innumerable atoms. The sense of smell makes us acquainted with atoms of matter which "no eye can see, no glass can reach." A little violet fills a room with perfume for days; and perfume is particles or atoms of matter floating in the atmosphere; not simple atoms, of course, but violet molecules, each composed of several elements, as carbon, hydrogen, oxygen, uniting in such forms or combinations 
as to produce the particular odour, or make a distinct and peculiar impression upon the nerve of smell. A grain of musk will fill a room with musky particles by myriads for years, without any perceptible loss of weight. The minute subdivision of the virus of contagious diseases, such as small-pox, must be evident. But organic nature affords, after all, the most astounding evidences of divisibility of matter. Thus 50,000 vibrios, long, slender, worm like, organised beings, are found in a single grain of wheat; each one, of course, composed of multitudes of atoms. One ounce of flesh has been found to contain 325,000 of those terrible parasites which are found in pork, the trichinæ, so that a man might contain $x, 950,000,000$.

But even this is nothing to the minuteness of organic life in infusoria, of which a cubic inch of water may contain $8,000,000$. What then must be the size of the atoms of which they are made; of the water in which they live, feed, and multiply; of the elements, oxygen and hydrogen, which compose it?

Such is the infinite or immeasurable minuteness of ali the matter that makes up the material world. No one can tell how small an atom is, but eminent physicists have calculated that an atom must be less than $\mathrm{r}-6,000,000$ th of a line in diameter, and that it must take at least $888,490,000,000,000$ atoms of lead to make a cubic inch.

Chemistry has discovered more than sixty elementary bodies. or distinct kinds of matter, which have not been resolved into more simple elements. But it is the belief of many eminent physicists that all these may be composed of only one element, or one kind of atoms, which group in different ways to form the molecules of all kinds of matter. Suppose, for example, that hydrogen, the gas that fills balloons, the lightest of known substances, is this primitive matter, then oxygen would be composed of molecules, each made of eight atoms of hydrogen, and so on.

The simple elements of matter combine together to form all 
that we see in the world around us. Oxygen and nitrogen, mingled together, make the air we breathe. Oxygen and hydrogen, chemically combined, make the water we drink, and which forms four-fifths of all vegetable and animal bodies. Oxygen and metals combine to form the earth on which we live, and from which we draw our subsistence. Carbon' unites with oxygen and hydrogen to form vegetables and then animals; it is the basis of all life on the earth, and the vast stores of fuel laid up for man in remote ages.

The same ultimate elements or atoms, combining in slightly varying proportions, or with some unknown variation of form, produce a wonderful variety of substances. The same elements found in a dunghill enter into the composition of multitudes of delicious fruits and odorous flowers. The most stinking gas and otto of roses are composed of the same elements in the same proportions. With very slight changes in proportions we have sugar, starch, celulose, alcohol, lactic acid. The foetid excretions of animals become the food of the most delicate and beautiful products of the vegetable kingdom. From the same food we have milk, wax, honey, poison; from the blood of animals come sweet milk, salt tears, bitter gall, odorous musk, and the deadly venom of the rattlesnake and cobra.

Two collections of atoms separately invisible, become visible when joined together. If I write with a clear solution of tannic acid, the letters cannot be seen. Wet them with an equally colourless solution of sulphate of iron, and they come out black. So cloths are dyed by being dipped successively into two colourless liquids.

Lime water is perfectly liquid and transparent. Take a tube and blow in it. and you have an opaque solid, which first clouds the water, and then settles to the bottom. Transparent glass, if stirred when cooling, becomes opaque. In transparent bodies the atoms seem to arrange themselves in straight lines, that the vibrations of light can pass through them in every 
direction. A different arrangement of atoms in opaque bodies absorbs, or breaks up, or reflects the vibrations.

The earth on which we live is a globe of matter, nearly eight. thousand miles in diameter, small and dense compared with the outer planets of our solar system, Jupiter, Saturn, Uranus, and Neptune. Of the great mass of the earth we have no. knowledge. It is believed to be composed of melted metals. The external crust is supposed to be some twenty-five miles in thickness-a mere film on such a globe. In most deep mines, and in artesian wells, heat increases regularly with the depth. Volcanoes, hot springs, earthquakes, and many geological phenomena, indicate the intense heat and liquid condition of the earth's interior.

The crust of the earth is composed of rocks, or gravel, sand, clay at the surface, which has been rock, mingled with vegetableand animal matter-soil, or loam. Rocks are of two kinds; igneous and sedimentary. The igneous have been thrown up. from the molten masses of the earth's interior; as volcanic, trappean, granite. The sedimentary rocks are formed of the crumbled, broken down matter of the igneous rocks, or of minerals dissolved in water, and slowly deposited at the bottom of lakes and seas. These rocks and the earths into. which they crumble, under the action of water and frost, are metallic oxides. Slate and clay are composed of aluminium. and oxygen. Rock crystal and sand, of silicium and oxygen. Marble, limestone, chalk, of calcium and oxygen. Magnesium and iron also enter largely into the composition of soils. Iron rust-ashes of iron-is, in many places, reddening earth and rock. Upon a close inspection we find that all this land has been for ages under the deep sea. The solid rock is full of shells of marine animals. The limestone strata, hundreds of feet in thickness, has been deposited atom by atom in the deep waters, and is composed of the shells of microscopic animalculæ. The flints are collections of shields found upon 
the bodies of minute creatures. The limestone that forms vast mountain ranges, or covers continents, has been separated atom by atom from the water in which it was dissolved, by the agency of animal life.

The surface of the earth is formed of metals, oxygen and carbon, the latter uniting first with oxygen and forming carbonic acid gas, which always exists in minute proportions in the atmosphere, enters into the composition of all vegetables, and is given out by all animals. Hydrogen, oxygen, nitrogen, chlorine, carbon, sulphur, phosphorus, calcium, sodium, magnesium, iron, enter into the composition of vegetables and animals.

It will be seen that the most important elements of nature exist in the lightest, or most attenuated forms. Hydrogen is the lightest of gases-eight times lighter than oxygen - yet it is the chief element of water, without which there could be no soil, no life; and it enters largely into the composition of oil, fat, woody fibre, and animal tissues. Oxygen is the vital. element of air, is eight-ninths by weight of water, in union with metallic bases it forms the whole crust of the earth, and enters into the composition of all vegetables and animals. Nitrogen forms four-fifths of the bulk of the atmosphere, and in combination with hydrogen, as ammonia, is the basis of manures, a component of vegetables and an important element of animal life. Chlorine unites with sodium to form the important substance, common salt. Carbon, forming a gas with oxygen, is the basis of regetable and animal matter, is stored in the earth in coal, and crystallised in the diamond.

There are physicists who deny the existence of matterthat is, of solid atoms and material molecules, and refer all the phenomena of matter to points of force. Hydrogen, oxygen, carbon, etc., are different kinds of force, acting from mathematical points. Every object in nature is simply a collection of such points of force acting upon our senses. A still more 
ethereal class of philosophers deny both matter and force, and admit only of sensation-and one of the most distinguished has defined a lamp-post, against which one may break his head in the street- "a permanent possibility of a sensation."

Mr. J. S. Mill says, - "We never touch matter even if it exist, and that we never see it is admitted alike by physiologist and metaphysician, for vision is merely a mental affection, called up by an impulse on the optic nerve, made by the movement of the luminous ether, which not the chair or table, but the force existing and acting external to the chair or table, or other object, radiates off." Huxley says, "Every form is force visible; a form of rest is a balance of forces; a form undergoing change is the predominance of one over others." We will, therefore, consider force and see if we know any more about it than we do of matter, of which the greatest discoveries of science only reveal more and more the unfathomable mysteries. "We push back the mystery of nature one step," says Professor Tyndall, "but it is as impenetrable as ever." Professor Huxley admits that "no ultimate fact in nature is known;" and the ultimate facts seem to belong to the infinite and incomprehensible, like infinite space and infinite duration, which no intellect can grasp-no mind conceive. 


\title{
CHAPTER II.
}

\author{
FORCE.
}

Wha: is Gravitation?-Magnetism-Atomic Attraction and Heat-Cohesion - Repulsive Forces-Attraction of Liquids and Solids for Gases Solution and Crystallisation-Capillary Attraction-Electricity-Galvanism-Is Heat a mode of Motion?-What is Heat?-Force of the Sun-Unused and Unrecognised forces.

IF we know but little of matter, we know less, if possible, of the nature of force and its mode of action. If I hold a stone in my hand I feel it pressing downward with a certain weight or force; but why downward rather than upward or sideways? If I remove my hand it goes in a straight line with increasing velocity toward the centre of the earth. My own body is drawn toward the same centre so powerfully, that I can only overcome it by the counteracting force of muscular contractions, equal to I 50 pounds. What draws the atom, my body, all bodies, even the atmosphere and the lightest gases toward the earth's centre? Newton called this force, gravity, another name for weight, and not an explanation. "Every particle of matter in the universe," he said, "attracts every other particle with a force, direct as the mass, and inversely as the square of the distance." He showed that the same force, gravitation, attraction, drawing-to, or pulling, that brings a stone to the ground, holds the moon in its orbit round the earth, the earth and all planets round the sun, and holds the sun to some unknown centre of the universe. But Newton did not even venture to guess at the nature of this force or its mode of action.

The earth has no visible hold upon the stone I throw, or the bullet I shoot into the air, but it draws them down. Two 
bodies floating on the water are drawn together by a mutual attraction. Sticks on a pond gather in a mass. A leaden weight let down by a string from the top of a precipice is drawn toward the rock. The constant pull of the earth keeps all pendulums swinging. The facts of gravitation are in every moment's experience-the cause or mode of action is utterly inscrutable.

But if I take a bit of loadstone, or magnetic iron ore, or a piece of steel which has become magnetic, I see the action of a similar force. Pieces of iron move toward it from short distances, and cling to it with great tenacity. Holding it under a sheet of paper on which I have sprinkled iron sand, or filings, I see them drawn to it, arranging themselves in regular forms, and even rising, one upon another, like crystals or vegetable growths. The action of a force is evident. I can trace the curves in which it moves; but how one mass of matter can so act upon other masses, even through intervening substances, I cannot imagine. The earth is a magnet, held with its north pole always pointing to one spot in the heavens, as it goes spinning on its axis round the sun and drawing all things to itself. The sun is a huge magnet, held in its own place by immense forces, and holding all its planets, from Vulcan $14,000,000$ miles, to Neptune $2,746,27 \mathrm{r}, 000$ miles distant. How can we conceive of bodies of matter attracting each other at such distances?

It may be that all forms of matter are modifications of one form, if indeed matter be not itself a form of force; and that all forms of force, energy, and motion, are modifications of one force, one infinite energy and power. Sunshine seems to be transformed into the vital force and stored up energy of great forests and deposits of coal. These, in turn, warm our houses, smelt our ores, feed our furnaces, drive our steam engines, propel steamers and locomotives. It is sunshine which produces cotton, and then transports it, and spins and weaves it 


\section{Human Physiology.}

to keep us warm. All life, and light, and power, are from the sun. Its force is also stored up in earth, water, and air, as electricity. When oxygen in water parts with its hydrogen to unite with zinc, a force is set free that shines as a spark, explodes, gives a sensible shock, develops magnetic attraction in a piece of iron, propagates its force along the atoms of thousands of miles of wire, spells out a message on the other side of the world.

The forces that hold the untouching atoms of matter in their places are incomprehensible as to their nature, but their action may be seen in a thousand familiar examples. A fine silken thread will sustain the weight of many pounds. Its atoms do not touch; therefore the weight is sustained by the attraction of atom for atom, and is the measure of that force. A small steel wire will hold up a thousand pounds. Warm the wire and it lengthens, and allows the weight to descend; cool it and the weight rises, by the diminished repulsion or increased attraction of the atoms for each other. The walls of buildings are drawn together by the cooling of iron rods. So of pressure. The weight of a column rests upon the repulsive force of its lowest atoms. This force, in slender iron pillars, sustains immense weights of masonry, which rise and fall hour by hour as heat increases or cold lessens this repulsive force.

The action of matter upon matter without contact is at every distance equally incomprehensible. Newton thought that atoms were as distant from each other, in proportion to their size, as the stars; and that if the atoms of our earth could be brought into actual contact, it might perhaps be compressed into the space of a cubic inch; yet we have seen that the attractions, repulsions, and polarity of these atoms give its point to the needle or the sting of a bee, and its hardness to the diamond.

The attraction of gravitation or weight acts through inconceivable distances. Another attraction, that of cohesion, acts only at distances immeasurably minute. By this, molecules 
cohere in masses; so that we have masses of matter, drops of water, lumps of clay, trees, rocks, masses of metal. Two fresh surfaces of India rubber will adhere to each other; two masses of moist clay or warm wax stick together; dry clay, chalk, etc., require to be pressed together with great force to make a solid body. Two surfaces of perfectly clean, polished plate glass will sometimes cohere. The strength of wood, iron, stone, is in proportion to its molecular cohesive force-of the nature of which we have no more idea than we have of gravitation.

The ultimate atoms of matter have forces as astounding as those of the greatest masses. Atoms of hydrogen and oxygen at a certain temperature unite with a force which produces a burst of flame and a loud noise, which is caused by the production of a sudden vacuum. But the repulsive forces are still more striking in their results.

Upon what hypothesis can we explain the force of gunpowder? What so inert as charcoal-what safer than sulphur, or saltpetre? Mix them together and touch to them a spark of fire, and we have a thunder that shakes earth and heaven - an explosive force that lays a city in ruins. What seems more simple than cotton moistened with acids? We have storehouses filled with both. But, placed in certain conditions, gun cotton has a force ten times as great as gunpowder. And what theory of physics, what calculation of the conservation and correlation of forces. gives us the faintest notion of the way in which force is stored up and then let loose in nitro-glycerine, an oily liquid or crystalline solid? Who can explain fulminating silver or mercury?

Gases, which some consider the natural condition of all matter, solids and liquids being only its transient and accidental states, and all visible and ponderable bodies being but temporary condensations of gases, have some curious properties. They are all soluble in water, seeming to be attracted by its particles, and to fill up their interstices. Water will absorb 
some gases to the extent of 400 to 600 times its own bulk. A pint of water absorbs, holds within itself, 600 pints of gas. Atmospheric air is taken up by water to a large extent, so that fishes can breathe it. They drown as quickly in water without air, as we do in water. Gases, also, adhere to solids, forming, it would seem, an atmosphere round each atom or molecule. Powdered platinum condenses 800 times its volume of oxygen. Charcoal takes up great quantities of gases, hence its use in purifying the ventilators of sewers, and to form respirators. It is by the strong adhesion of air to metals that iron filings and needles swim on the surface of water.

The phenomenon of dissolving matter is very remarkable. A crystal of common salt is very hard-that is, the forces of attraction and repulsion hold its atoms rigidly in their places, but each atom of salt has a stronger affinity for atoms of water than for its own brother atoms. The moment water atoms come near, even in a moist atmosphere, the salt atoms lose their attraction for each other. A force seems annihilated. Drive off the water by heat and the salt atoms take up their old relations. This is one of many thousands of things I am not able to account for; but chemistry is full of the play of such forces.

I put some iron filings in a bottle with water and a little sulphuric acid. Iron atoms hold to each other with immense force, but they will leave each other instantly to join atoms of oxygen. They lay hold of the oxygen atoms in the water, which also leave their atoms of hydrogen. The hydrogen rises in bubbles, and may be used to fill a balloon; or, bring a match, set it on fire-that is, make it join more oxygen and become water. The iron has become an oxyde, but only for an instant, for it is seized by the sulphuric acid, and you have but to evaporate the water to get crystais of sulphate of ironcopperas-which, uniting with tannic acid, another crysta' dissolved in water, makes the ink with which I write. 
Water has the power of separating the atoms of the hardest substances-lime, silica, salts of various kinds. Water dripping from the roofs of caverns covers them with beautiful icicle-like stalactites. But why the forces that give hardness to crystals of salts should cease to act in the presence of water; why atoms of steel should leave each other to make a miserable rust with oxygen, we know no more than we do why sulphur, saltpetre, and charcoal, which burn quietly apart, should so tremendously explode when brought together, or why a pocket handkerchief, washed in acidulated water and dried, needs but a spark of fire to blow up a house.

Atoms arrange themselves in certain positions in relation to other atoms in what is called crystallisation, forming in lines like soldiers, and with these lines making cubes of many beautiful forms. In the same matter the forms may vary but the angles are always alike, as may be seen in the snow crystals :-

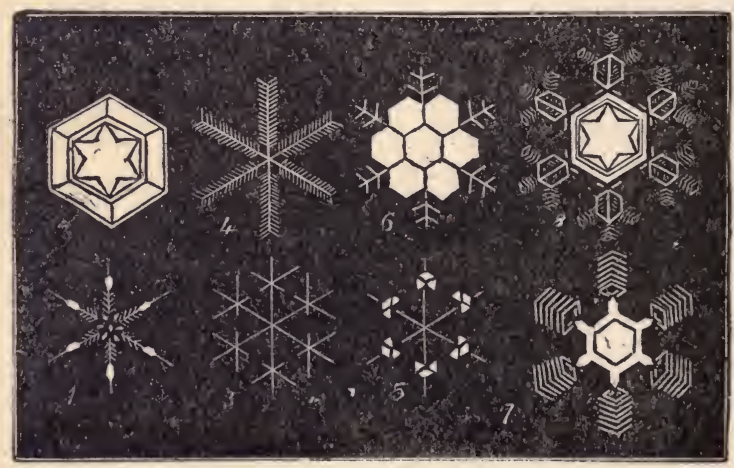

Fig. I-SNOW CRYSTALS.

The forces that hold atoms in their places in rock crystal or diamond are marvellous; but the forces exerted in the formation of crystals are perhaps still more so. The atoms of 
water drawn nearer together with the diminution of heat, at a certain coldness again fly apart, so that ice forms on the surface, and protects the water and its inhabitants below. But for this all lakes and streams in cold countries would become solid ice and so remain. Ice is water crystallised, and the expansive force of this crystallisation is so great that it will burst the heaviest cannon in which water is closely confined. May not the crystallisation of harder bodies be accompanied with force enough to upheave mountain ranges and whole continents?

A form of cohesive force or attraction is that called capillary. Oil rises in the small interstices of a cotton wick. Water rushes eagerly up the pores of a sponge or lump of sugar. It stands at a certain height above the general surface in a small tube, and the smaller the tube the higher it mounts, apparently by the cohesive attraction of the sides of the tube. Plants and trees are full of microscopic tubes in which the sap ascends from the roots to the most distant branches even if three hundred feet high. In animals, fluids circulate through an immense number of hair-like tubes; moving forward where no force can propel, and no attraction but this of the vessels themselves can draw. Liquids also pass through the pores of vegetable or animal membrane with sufficient force to sustain a column of water in a tube several feet high, or burst closed membranous sacs with considerable violence.

The force of electricity is equally wonderful and incomprehensible. I pass a vulcanite or hard india-rubber comb through my hair, and on holding my knuckle near it, draw from it a spark of fire with a corresponding explosion. I rub a stick of sealing-wax or a glass tube on my coat sleeve, and it will draw and then repel bits of paper, or give off a spark. A cloud approaches the earth-suddenly falls a bolt of fire as large as a hogshead-a blinding flash-an explosion that shakes the earth, and I find a pine tree shivered into a thousand fragments. Faraday says that the electricity set free 
by the union of one drop of water with four grains of zinc would make a strong flash of lightning.

Galvanism is a more manageable form of electricity, usually produced by the union of metals with oxygen. An atom ot oxygen seizes upon an atom of zinc, and sets free the force with which the zinc atom held to its fellows. This force, ready for action, passes along a wire from atom to atom with inconceivable rapidity, a rapidity like that of light. When the conducting wire passes with many turns round a piece of soft iron, the latter becomes a magnet, having an attractive force proportioned to the intensity of the current and the number of turns in the coil; break the circuit and you have a spark or flash; let it pass from point to point of charcoal in a vacuum and you have the electric light. You can reverse this action and by the motion of permanent magnets produce an electric current. A small stream of water, or a steam engine can be used as well as the chemical action of oxygen and metals. Wilde's MagnetoElectric Engine converts the force of a three horse-power steam engine into electricity, heat, and light. As heat, it melts iron rods 15 inches long and 1 -inch diameter. The light at two feet distance has three times the intensity of sunshine; and in it at the distance of a quarter of a mile the flames of gas street lamps cast shadows. Galvanism appears to act with the same force through all distances. The same current operates at one point or a hundred. It heats a wire of any length to the same redness; just as the same telegraph wire gives with the same force a message at one or a thousand different places; facts which seem to me quite irreconcilable with the current doctrines of the conservation of forces.

Count Rumford, about the beginning of the century, superintending the boring of cannon at Munich, observed the heat produced by the friction when the borers became dull. Boring in a vessel of water, he made it boil ; and came to the conclusion that heat was a mode of motion. A rifie ball flattened 
against a target is very hot. When motion is stopped, or even impeded, heat is produced in proportion to the destroyed momentum. A blacksmith hammers a soft nail rod red hot to light his pipe and fire. A mass of stone passing through our atmosphere is heated to whiteness by the friction of the atmosphere, and becomes a shooting-star, or meteor. I believe, however, that in the case of the hammered iron, the heat is that which, acting as a repulsive force, kept its atoms apart. Driven together, this latent heat becomes active, just as when air, suddenly compressed in a tube, gives out heat enough to light a bit of tinder. But heat is a form of force, if not always a form of motion. It may be the expansive force, or repulsive power of all bodies. It may constitute, as it undoubtedly increases, the atmosphere of repulsion which surrounds every atom of the universe, and keeps it wide asunder from every other. Heat acts with an immense force, for it expands the hardest substances in nature-mountains of granite, and masses of the most tenacious metals. It expands solids to liquids, and liquids to gases. Heat added to water gives us the tremendous powers of steam. Heat maintains the fluidity of the earth, and shows its tremendous forces in volcanic eruptions and earthquakes. The heat of the sun, with its light, covers the earth with vegetable and animal life.

What, then, is heat? Not a substance streaming from the sun, and fires, and heated bodies; not an emanation; but the vibrations of an elastic fluid like the air, but immeasurably finer, and having very different qualities. The sun, and all sources of heat and light, excite vibratory movements of this ether, as sonorous bodies excite in the atmosphere vibrations of sound. These vibrations are communicated to the atoms of matter, and the movement produced gives the sensation of heat. This is the latest scientific explanation; but it is not very satisfactory. How can the expansive power of heat, as shown, for example, in the force of steam, come from the 
vibrations of a space-filling elastic medium? Can the vibrations of a substance, as much finer than air as that is finer than granite, melt granite itself, and keep the whole Earth molten? Yet it seems to be demonstrated that the light of the sun-all its rays, red, yellow, blue, and their combinations, heat rays, actinic rays, are but the varied perturbations of a medium filling all space, through which come the vibrations of stars so distant that they are centuries in coming. What, then, is this medium? Has it atoms, with their elastic forces of attraction and repulsion? We can conceive of no other kind-and this is past conception.

In such an ether, with vibrations corresponding to every shade of light and colour, there must be myriads of waves or impulsions in every second of time, transmitted at the rate of 375,000 miles in a second. These impulses pass through the most solid substances, as glass and crystals. Crystals of salt allow the passage of both light and heat. Seventy-five per cent. of heat is stopped by a plate of crown glass, but a second plate only stops ten per cent. of heat which passed through the first. Blue glass stops the red rays. Light passes freely where electricity can find no passage. Light and heat are both reflected from surfaces, as sounds are thrown back in echoes. Heat is also radiated from all bodies, so that there is a constant tendency to equilibrium. A convex lens brings the rays both of light and heat to a focus, and, with a large glass, the hardest metals may be melted by the vibrations caused by a body nearly a hundred millions of miles distant.

The sun, by its action upon the luminiferous ether which fills the universe, keeps the Earth, and all planets, no doubt, at the temperature required for vegetation and animal life. It is under the action of light that vegetables decompose the carbonic acid of the atmosphere. The light and heat of the sun raise the water into the atmosphere that makes life possible upon the earth. All force, all life, or the conditions of life, seem to come 
to us from the sun, through the medium whose vibrations give us all our sensations of comfort, and fill the earth and heavens with beauty and glory.

Of these vast forces of nature for ever active around us, man as yet has made but little use. The heat of the sun every day raises millions of tons of water into the air, which comes back in rain, rivers, cataracts; it every day fixes vast quantities of carbon in woody fibre, grass, grain, fruits, and vegetables; gives movement to the air and forms currents in the ocean. Gravitation raises tides that flow along our coasts and up our estuaries and rivers. We are day by day exhausting the forces of light and heat laid up in coal, but the winds, the descent of waters, and the flow of tides, will for ever furnish abundant force which can be transformed into heat and electricity, drive our machinery, and warm and light our dwellings and towns. When the coal is gone, every mountain stream, every slow running river, every tideway on the sea, and all the currents of the viewless air, will give us power, comfort, and light.

Whatever may be the constitution of matter, it is evident that it is with force that we have to do. It is that we see and feel. Force, exercised by an intelligence and a will equal to the creation and control of the whole universe, from the infinitely little to the infinitely great, fixes every atom, and defines every form. Let the force of repulsion in matter cease for one instant, and there would be a sudden collapse of matter. On the other hand, if the force of cohesive attraction were an instant suspended-if this power, whatever it may be, which grasps all matter and holds all forms were suddenly to cease to act, the entire universe and all it contains would explode-burst asunder like gunpowder, or nitro-glycerine, leaving infinity of space filled with unrelated atoms, empty air, without form and void, infinite silence, darkness, and death.

There are probably many kinds or modifications of force in nature unrecognised by science, though often seen in pheno- 
mena. No one, that I am aware of, has explained how vast quantities of water are sustained in clouds, often piled up on a level flooring in the sky, as if resting upon a stratum of repulsive force, until some change-probably electric or magnetic -allows it to fall in rain. No one knows by what force thousands of tons of water are carried up in waterspouts, spreading out in clouds, and sustained for days, contrary to gravitation. Quantities of fishes are sometimes carried up into the air, and come down in showers of rain far inland. Walking in a smart thunder shower, I have seen small frogs falling quite thick around me. They rebounded like india-rubber balls, and then hopped away. In India fishes have fallen weighing from one to three pounds. A shower of sticklebacks fell in Wales some years ago, near Merthyr Tydvil, over several square miles. Herrings rained down at Torrens, Isle of Mull. The force that sustains vast quantities of water, banks of clouds, immense masses of snow, could sustain any solid body. I have seen the deep snow blown from the top of a mountain, pass off as gorgeous clouds in the sunshine, at the same apparent elevation as the mountain-top, and not differing in appearance from other clouds, which, like it, were frozen-were in fact snow.

It is probable that birds of passage, which fly night and day hundreds of miles, and some of which almost live in the air, and sleep upon the wing, find strata in the atmosphere in which gravitation is counteracted by some force of repulsion, and in which they sail along as easily as fishes swim. It is not improbable that the discovery of such strata of repulsion, or balanced forces, may solve the problem of aërial navigation.

The roots of an oak growing near me, from the side of a ledge of very hard rock of the Malvern Hills, have separated and thrown out a mass of the rock like a heavy charge of gun. powder. A crop of fungus has lifted up a heavy flag stone. Consider the forces that have placed and sustain the weight 
of a great forest. And in animal life there are forces at work, still more mysterious and astonishing; forces of growth and reparation, nutrition, heat, secretion, motion, muscular action, nervous power, feeling, thought, will-animal and psychic forces, which we have scarcely begun to investigate. But these may best be treated of in future chapters.

\section{CHAPTER III.}

\section{LIFE.}

Organisation-What is Life?-A Guiding Intelligence-Life precedes Organisation-Necessity of a Self-existent Cause-Genesis of Species - The Darwinian Hypothesis-Characteristics of the Vegetable Kingdom-Variety of Products from the same Elements-Vital Chemistry -Sexual Life in Plants-Vital Mechanism-Nutritive ContrivancesSeed Distribution-Plant Aromas-Functions of Leaves-Contrivances for Reproduction-Protection-Mind.

WE have glanced at the phenomena of matter, and of the forces which make matter what it is, and which some hold to be all there is of matter. We have now to consider other forces which produce the phenomena, or constitute the condition, which we call Life. Vital Principle is a vague expression, but Life means something-it means all the phenomena of living things, and the cause or causes of the phenomena, so far as we can perceive them. The earth, waters, and air are full of organised, living things, which grow from minute germs, and propagate their kind.

Organised living beings are complex, having varying parts and organs; inorganic and lifeless substances are similar throughout. A block of stone or iron has no special form or organs. Vegetables and animals are composed of liquids and solids; and living things have a certain form, surface, or 
limiting boundary, defined by an inward cause, or the action of the forces which cause growth and organisation. This is seen in the peculiar forms of all plants and animals, and all their parts and organs.

In unorganised matter, beauty consists of straight lines and sharp angles, as in the beauty of crystals; but in all living things we delight in graceful curves. Inorganic bodies grow by the addition of atoms without. Crystals are built up like a mass of masonry; but all organised bodies grow by matter which is first prepared within.

Every living form has grown from a germ separated from another of which it is the counterpart or reproduction.

All organised beings have a limited term of existence-a diamond lasts for an indefinite period.

Vegetables expand from a germ, unfold or develop their various organs, feed upon the nutriment they need in the air around them, or the liquids they suck up by their roots, which they transform into woody fibre, starch, sugar, gum, delicious juices, odours, fruit, flowers, and the germs which produce similar organisations.

Animals do all this and more-they walk, swim, fly, see, hear, smell, feel, love, hate, and perform the most complex physical and intellectual operations. "The first office," says Lindley, "which all organised beings have to perform is feeding; for it is thus that existence is maintained. The second is that of propagating, by means of which the species is perpetuated."

That which gives those varied and wonderful powers to organised beings we call Life. But what is Life?

"Life," says Bichat, "is the sum total of the functions that resist death."

"Life," says Beclard, "is organisation in action."

Life is defined by another physiologist to be "the resistance opposed by organic bodies to the causes of destruction." 


\section{Human Physiology.}

These definitions define nothing. We are only told that iife is the opposite of death, as cold is the opposite of heat, or darkness of light; that life is the mysterious, the unknown cause of the phenomena of growth and reproduction in organised bodies; in short, that life is life.

In life, we have force governed or directed by intelligenceeverywhere a wonderful adaptation of means to ends. As force acts upon matter, life is something which contrives, designs, fashions, plans, orders, arranges, knows, foresees, desires, determines, directs the action of force. A man, with all his wonderful bodily organism, and his more wonderful intellectual powers, grows from a microscopic cell which contains all he is to be. In it is life; and in that life must be the spiritual force and guiding intelligence which presides over the material organisation.

Materialists contend that life, or the phenomena of existence, is the result of organisation. Spiritualists hold that organisation is an effect of life, not the cause of life. If organisation precedes life, what causes organisation? It is an effect, and must have a cause, which must be anterior and superior to itself.

An organ existing in a living animal is destroyed, as the leg. of a lobster; it is reproduced, showing that function, or life, governs matter; that the soul, or spirit, or intelligent force forms the body, and all parts of the body; and this, as I shall show hereafter, is the law of all formative and reparative processes. If it is said that in animals the nerve-cell secretes life; what, I ask, forms the nerve-cell, and gives to it its powers?

The universe is full of force--but blind force is commonly destructive. We require something above force-something to guide force. We need intelligence and will; and as nature is a grand system of harmonious parts, then must we have intelligence equal to the direction, and will or power equal to the control, of all the forces of the universe. Those forces, 
also, and the matter which they act upon, must also have their cause and source. And as the universe is one, every atom bound to every other atom, that Cause is One; being one. it must be Self-existent, Infinite, Eternal.

"In this wonderful order of the universe," says Richerand, "every being is perfect in itself; each being is best constructed for the purpose it is to fulfil; and all are equally admirable, in living and animated nature, from the lowest vegetation to the sublimity of thought."

As all plants and trees in their myriad varieties are developed from germ cells made of the same materials, surrounded by the same elements, it must be that they vary as the life-force, which presides over their growth, varies. For thousands of years we have had a constant reproduction of the same species of plants and animals. The grain of wheat found in the hand of an Egyptian mummy embalmed three thousand years ago is the wheat of to-day, and its life, sometimes, is not extinct. Cedars still grow on Mount Lebanon. The horse, the dog, the elephant, have not changed their specific characters. The races of four-handed animals have not grown more intelligent.

It is a law that like causes produce like effects. But in the same field, with the same soil, air, moisture, temperature, the same material conditions, we have growing, wheat, maize, beans, potatoes, a hundred beautiful and odorous flowers, each with different forms, colours and perfumes, medicinal plants, narcotics, violent and acrid poisons. Something more than inert matter and blind forces are required.

We cannot escape from recognising intelligence as directing force, by the notion of continuity - by saying that matter, force, and life are eternal. The mind cannot conceive of a train of effects with no cause. The earth gives abundant proofs that it was at one time without organic life-when its elements were melted with fervent heat, and when water existed only in its two elements, hydrogen and oxygen, or in a state of vapour. 


\section{Human Physiology.}

We find in the slow formed rocky strata of the earth, deposited under water, the fossil remains of the earliest plants and animals. Life on the earth had then its beginnings. If we say it came from another planet, we have the same process. to go through there, and so on.

It is believed by some that each species of plants and animals has been created upon the earth when it had come into the conditions necessary for its continuance-each having the power of producing the germs of future individuals of the same species.

It is held by others that all the species which exist and have existed upon the earth were developed gradually from the simplest forms of organised matter.

Mr. Darwin contends that this has been done by a process of natural selection aided by what he calls sexual selection. Beginning with the lowest forms of life, which were created with a liability to slight variations in form, and also with the power of transmitting those variations to the germs of future beings, some variations would be more favourable than others to the existence of the vegetable or animal. By the survival of the fittest, these changes would be perpetuated, and in this way, from one or a few germs, or very simple forms of living matter, we have all the varieties of vegetables and animals on our planet, with man to crown the visible creation. Sexual selection comes in aid of natural selection, or is a development of it, in the choice of mates for strength, or beauty, or some attractive peculiarity. But all varieties of character, instinct, intellect, and moral qualities, must, upon this hypothesis, be the result of chance variations, and the survival of the fittest. I have already alluded to this hypothesis in the first part of this work, and shall have occasion to speak of it hereafter.

The vegetable kingdom is the basis of the animal kingdom. On earth and sea all animals live primarily or secondarily upon plants, as plants live upon the elements of matter, carbon 
oxygen, hydrogen, nitrogen, lime, silica, potash, soda, iron, \&c Vast numbers of animals, it is true, live upon other animals, but the food of these is vegetables. The tiger eats the antelope, the antelope eats grass.

Plants differ from animals, excepting some of the lowest forms of animal life, in the fact that they are generally a congeries of individuals. Each leaf bud has its own life, draws its sustenance through special tubes, has its own organs of nutrition, is capable of an independent existence, and of producing other individuals of its own kind. Thus, a single bud of a plant may be cut away, grafted into another stock, or made to throw down roots, and live its separate life. There are animals which can be divided so that each part becomes -an animal, and some that live in clusters, like a bunch of grapes, with a common circulation, and others that multiply by division, or by producing buds which are thrown off and become individuals; but these are low forms of life on the confines of the vegetable and animal kingdoms.

There are plants, and reproductive portions of plants, which are provided with organs of locomotion, by means of which they move about with great rapidity, and are sometimes mistaken for animals. Even starch globules have a kind of quasi-spontaneous motion in their parent cells, acting under the microscope as if gifted with animal life and voluntary motion.

Spore, bud, seed, whatever begins the growth of a plant, must have life-a living germ. This may be preserved for thousands of years as in the mummy wheat, or longer, perhaps in seeds thrown up with sand from the bottoms of deep wells. Seeds are scattered everywhere by birds, by winds, by waters, flying with downy feathers, often so small as to be invisible. The atmosphere is full of invisible germs of vegetable and animal life.

Plants perform many acts which have the appearance o 


\section{Human Physiology.}

sensitiveness, choice, and intelligence. The mimosa closes its leaves at a touch. A sensitive Australian plant closes even at the approach of any one. Nearly all, without a mistake, send their roots downward and their stems towards the light. The roots of the rose grow toward water, curiously turning around obstacles. The hop and the tendrils of vines seem to reach out for support, and to be impelled or attracted towards objects near them. Some plants close their flowers against the heat of the sun; others carefully fold them up at night as if to guard against the cold.

The tendency of most plants toward the light is very striking. Some turn their leaves, some their flowers toward the point where it is strongest. A grape vine growing in the shade of tall trees climbs to their tops before it sends out its branches and leaves. Trees growing with others, for the same reason shoot up straight and slender. Bend down the stalk of the mullein at a sharp angle, and in a few days it will have made a graceful bend so as to point again to the zenith. If potatoes are allowed to sprout in a cellar, the sprouts grow toward the light, if it be from ever so small a crevice, in long slender stalks, which may be at an angle of 45 degrees or less from the horizontal. Plants bend toward white light and from red. Red keeps flowers and fruit from decay. I have seen a line of great trees by the road-side growing with three-fourths of the bulk of their branches over the road, apparently more for air than sun, and as if to avoid the neighbourhood of much smaller trees growing near them. So in a clump of larches, the branches are long only on the circumference of the group.

Plants have a skin and epidermis like animals; and this is, like theirs, converted into scales, hair, sharp spines for defence against climbers, as one sees on the acacia, \&c. On the leaf skin there are pores, in some cases 90,000 to the square inch, which regulate respiration and evaporation, open or close at weed, some being retractile-drawing in like a telescope. 
Plants perspire like men, hut seventeen times as much, and only in the light or a dry air in motion. They purify the atmosphere by absorbing carbonic acid which animals give out, and also enrich it with oxygen.

Every tree, by means of the spongioles at the extremities of its rootlets, selects from the earth the nutriment it requires. Wheat does not require the same as cabbage or clover, nor the peach the same as the fir tree. The leaves and flowers of plants also elaborate an extraordinary variety of substancessugar, acids, honey, caoutchouc, gum, turpentine, the most delicate flavours, the sweetest perfumes, the most nauseous drugs, the most virulent poisons-out of the same air, earth, and sunshine. This can only be done by organs adapted to such a wonderful chemistry, performing their functions by the influence of an intelligence guiding the forces of life. The rose and the poppy, the strawberry and the deadly hemlock, all grow in the same garden bed.

The growth of plants is sometimes wonderfully rapid. The leaf of the turnip increases at times fifteen times its weight in a minute-the root has grown 15,990 times its original weight in a day. And what a wonderful chemistry is involved in all vegetable growth. A plant can decompose water and carbonic acid; it takes hydrogen from the one, setting free its oxygen; it frees the oxygen and fixes the carbon of the other.

There can be little doubt that the circulation of the sap or juices in plants is as vital as that of the blood in animals. Neither can be explained by chemistry or mechanics. But the vitality of plants, and the action of what we must call intelligence, is shown most strikingly in the wonderful organs and processes of reproduction. In one day a whole tree is covered with blossoms; the world is filled with the beauty and perfume of flowers. Vital heat, a living property in all plants, rises in some cases to the extent of fifteen degrees, so that the flower is sensibly warm to the touch. The germ cells are formed in 
the ovaries of the plant, the fertilising pollen in the cells of the anther or male organ. By a great variety of special contrivances and vital movements, the pollen is brought in contact with the stigma, where it is retained by a viscid secretion. It sends a long slender tube-according to the length of the style - to the ovary, where it is met by a similar.tube from the germ cell. They are drawn together by a mutual attraction; a new centre of vitality is formed which grows into an embryo. If anything were wanting to the wonder of this vital process, most wonderful in all the forms of organic life, it is to be found in the fact, that when hybrids are produced by the union of different species, the mule offspring, as was proved by Dr. Herbert, Dean of Manchester, resembles the male parent in foliage and the female in flower.

Richerand says the plant is a being whose existence is limited to the phenomena of nutrition and reproduction; a machine constructed of a multitude of vessels through which the sap is filtered to be evaporated in the leaves. It shows, especially in its flowers, which are its organs of generation, a faint sensibility, a contractility by which its vessels contract and dilate, sometimes acting visibly; the stamina, or male organs, bow themselves over the female organs, or pistils, shake upon the stigma their fertilising dust, then retire from it and die with the flower, while the ovary lives on and produces seed or fruit.

The leaf is the most important organ of the plant, for it is by its changes of form that all the organs of flowers and thence fruit are produced. Leaves are composed of cells and bundles of spiral vessels, with skin and pores. A section of a leaf (Fig. 2), highly magnified, shows its structure.

It is in the leaf of the plant that its nutritive matter is formed. It is its lungs and stomach, its secreting and excreting organ. Water, filtered through the spongioles at the extremities of the rootlets, ascends the straight or spiral tubes to the leaf, carry- 
ing the mineral matters required and selected; in the leaf, this water is partly evaporated through its myriad pores, partly decomposed, the oxygen given off, and the hydrogen combined with carbon, which is obtained from

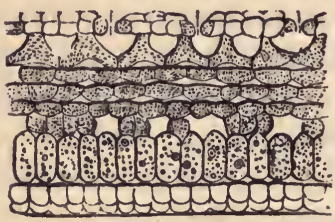

Fig. 2. the atmosphere, sucked in perhaps through erectile stomata, some of which draw in like the joints of a telescope. By the aid of light water and carbonic acid are both decornposed to make starch, oil, etc., and the air is thereby freed of carbonic acid and enriched with added oxygen. And in this wonderful laboratory of the leaf are prepared the flavours of sweet and sour apples, peaches, plums, grapes, strawberries, and all the products of the vegetable kingdom, under the influence anit direction of the unknown power or principle of life.

A proof that the leaves govern the functions

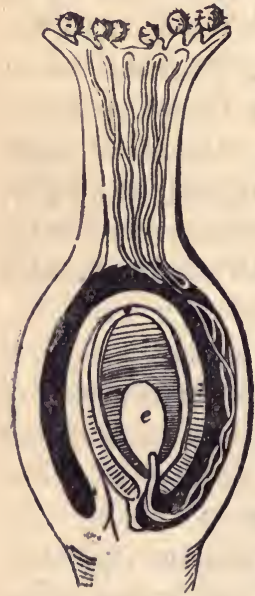

Fig. 3. of plants, rather than the roots or stalk, is shown by budding and grafting. A hundred varieties of roses may be grown upon wild briar bushes; a hundred kinds of apples upon crabs, and if you like to bud or graft so many, a hundred kinds upon one tree. Each bud has its own life, though all draw water from the earth and live upon the same air.

The pistil is the centre of most flowers, consisting of the stigma at the top of the style and at the bottom the germen, containing the ovary. Figure 3 is a magnified section of a pistil, showing the pollen grains resting on the stigma, and communicating through tubes thrown out for the purpose, with the ovule, egg, or seed germ of the plant.

The modes of vegetable formation illustrate the powers of 


\section{Human Physiology.}

life and the intelligence which directs them. A plant is made, lying folded up in its germ. A cluster of leaves is rolled up in a bud, as are the wondrous petals of a flower, with all their beauty of colours, exquisiteness of forms, and delicate odours. What mechanism to fashion them, all folded as they are, packed in the smallest space, protected by a warm, often a woolly envelope, while the outer shell is neatly varnished for additional protection! This has all been done months beforehand. In spring the buds open, and the trees are covered with leaves of tender green and a glory of flowers.

Life in the vegetable kingdom wars with the material forces that tend to dissolution. The plant grows and raises its sap contrary to the force of gravitation, and resists the action of oxygen and putrefactive agencies. Life resists heat and cold, dryness and moisture. Plants dry up and are blown about by the wind, but when they fall upon damp ground revive, and throw out roots. Trees maintain a warmth above that of the atmosphere, and flowers at maturity have a vital heat, sometimes sensible to the touch.

Some plants have peculiar contrivances for procuring food. The pitcher plant has some of its leaves transformed into beautifully-shaped pitchers, each with its well-fitted cover. The inner surface secretes a sweet liquid which attracts insects. When they enter this trap the door shuts down, and the plant feeds upon the ammonia set free by their putrefaction. So the Venus fly-trap closes upon the flies attracted by its honey.

The adaptations of vegetables to the wants and pleasures of men and animals are evident. Grass feeds sheep, cattle, horses; seeds and fruits are the natural food of man. Trees, plants, and flowers clothe the earth with beauty, purify the air and fill it with aromas not always perceptible to our blunted senses, but which make the atmosphere of a fertile country very different from that of a desert. Each tree and plant appears to 
find in the atmosphere the subtle element of its own life. When fruit trees are in blossom, it is said that fruits of the same kind, kept through the winter, lose their flavours, and even the stains of fruits can be bleached sut then as they can at no other period. If aromas do not exist, then they are manufactured in plants; and what a wonderful action of vital chemistry is it to make from the same elements all the odours, savours, honey, acids, gums, oils, turpentine, caoutchouc, camphor, opiates, poisons,-all the sharp, pungent, bitter, nauseous, delicious substances produced by the vegetable kingdom!

It is in the reproductive even more than the nutritive processes in vegetables we are to look for wonderful contrivances, because it is in them that life exerts its greatest force The thistle on the chalk downs cannot grow stalk or leaves; there is not soil enough for that; but it makes a perfect blossom, and abundant seeds, level with the fine herbage. Many plants depend upon insects to bring the two sexual elements together and make fertile germs. A drop of honey is formed by the flower and placed in a deep receptacle; bees or other insects scenting this, enter, brush off the pollen and carry it to the stigma of the same or another flower. Sometimes the insect sets free a spring by which the pollen is scattered.

The vallisneria is a water plant, male and female flowers growing on different stalks. The female flowers, those bearing pistils, grow on long stalks, spirally folded up at first, uncurling when the flower matures, so as to bloom at the surface. But the stamen flowers have short stalks. The buds form little bladders which detach themselves, rise to the surface, gather round the female flowers, expand, emit their pollen, perform their function, and die.

The arrangements for the distribution of the seeds of plants are very ingenious. Some seeds are provided with wings, or light down, by which they are wafted long distances by winds; some have hooks with which they fasten to animals; many are 
covered with a pulp, and are swallowed by birds, but protected by a hard covering from being digested, and so get distributed. Some seed capsules at maturity suddenly burst open, turn violently inside out, and scatter the seeds in every direction. In the spore cases of the liverworts are two spiral fibres coiled up like steel springs, and when the cases upen they scatter the germs.

The protective power of the life intelligence-or life instinct, if you prefer the term-is shown in flowers turning to the light; closing at night; closing to protect their pollen from rain. If you say that cold or moisture produces these effects, you must admit that certain flowers are made sensitive to cold and moisture. We are sensitive to cold and shut the doors, put on more clothing or build fires. The flowers fold up their petals.

Everywhere we see contrivance, design, adaptation of means to ends, artistic taste, and mechanical skill, which can only be attributed to a high intelligence joined to a power inconceivable. To fancy that such things are the result of the play of material forces, chemical affinities, and chance variations going on through millions of ages, seems to me absurd. My mind, by its very constitution, can conceive only of mind as the cause of such operations. 


\title{
CHAPTER IV.
}

\author{
ANIMAL LIFE.
}

Life in Animalculæ-Mollusca-Wonders of Insect Life-Insect Transformations-Flies-Bombardier Beetle-Honey Bee-Ants-Fire FliesSpiders-Fishes-Snails - The Rattlesnake-Birds, their Forms and Plumage-Butterflies-Beetles-Life in the Deep Sea.

LIFE, as manifested in the animal kingdom, is full of evidences of intelligence, adaptation, and design, of so varied, complex, beautiful, and surprising a character as to keep the mind of the naturalist in a perpetual admiration, and impress him more and more with the idea that an infinite wisdom, an omnipotent Mechanician and Artist, has willed and wrought. Let us, as the best introduction we can have to the study of the anatomy and physiology of man, glance at the structure and functions of a few of the lower animals, with special regard to the working of the Creative Element, or what we call.Life.

I find it difficult to group facts as I would wish, because the same animal or insect may combine in itself the most wonderful beauty, adaptation, mechanism, and strange instinctive faculties. I must leave, therefore, somewhat of the classification of facts to the memory and intelligence of the reader. What I wish to note specially, as bearing on the theory of development, is, that we find complex and perfect mechanism, wonderful beauty and perfection of apparatus, in the earliest, and what we call the lowest forms of animal life. A naturalist has said that he could spend his whole life in examining so much of the earth's surface as he could cover with his hand. I can therefore give but some hasty glances at the vast and wonderful world of animal life around us.

The myriads of animalculæ which we can only examine with 
the microscope have a great variety of organs by which they can move about, seize, entangle, and devour their prey, nourish their systems, and propagate their species. Some have ciliæ - little hairs which move with great velocity, propelling the animal like an engine, or forming little whirlpools which suck their food into their mouths. A bell-shaped animalcule is anchored by a spiral filament which enables it at will to push itself out for food or draw back from danger. Some glide through the water graceful as swans; some roll like wheels; some are provided with long threads which they shoot out suddenly like lassoos. These threads are armed at intervals with sharp spines which carry poison, or have some benumbing influence.

As if creative life revelled in its own special element-water, we find every sort of ingenious mechanism in the sea. The sea mouse is provided with a perfect harpoon with barbs, which is thrown out from a sheath formed to protect it from injury. The actiniæ, which, near the surface, are dusky and ugly, and covered with fragments of shell and gravel for protection, in the deep water are naked and beautiful. They have air-vessels to float them, and the power of throwing out such numbers of thread-like feelers, that they resemble skeins of cotton, or flowers. These tentacles are thirty or forty times as long as the sheath into which they are folded, and are armed with poisonous or benumbing spines, or poison darts, which are, in some cases, coiled up like a watch-spring in the tentacula, ready to be thrown out and strike their prey.

The Globe Baroe is a minute but most wonderful animal, which propels itself by some inconceivable nervous and muscular apparatus with paddles like those of a steamer, and throws out long cables from its body, and from these still other branching cables for food or anchorage.

Among the 15,000 recognised species of mollusca, there are some furnished with vulture-like heads constantly snapping- 
the disabled prey falling into the monster's mouth; some have instruments or solvent juices for boring in wood, or stone, or the shells of other species; some float near the surface of the water by means of air-bladders. The Portuguese Man-of-war floats with a large air-bladder, and throws out its cables, 12 to I 8 feet long, with which it entangles small fishes for its food. One ocean shell-fish floats by means of a raft of air vesicles attached to its foot, and to this raft its eggs are suspended. The sea urchin, whose orange-shaped shell is well known-so complex in its forms and full of minute holes-throws out from each of these pores a perfectly formed sucker, flexible and retractile like an elephant's trunk. By means of these 1,860 suckers, each a perfect machine, this round, hard-shelled animal can climb a smooth perpendicular rock, walk along the roof of a cavern, or bury itself in the sand.

The star-fishes are provided with elaborately-formed suckers for seizing food, climbing, and moving about. Some secrete poison, with which they kill the oysters they eat. When the brittle star-fish is alarmed it throws oft all its arms, breaking them in fragments, and then at its leisure grows a new set-a wonderful power of life which it has in common with crabs, lobsters, spiders, etc.

Among the lower orders of marine animals, no one, perhaps, has such strange, wonderful, and terrible powers as the Poulpe, a kind of cuttle-fish, which has been called the lion of the sea. This astounding beast grows in the tropic seas to a great size, weighing in some cases $4,000 \mathrm{lbs}$., 15 or 20 feet long, with eight arms 5 to 6 feet long; a strong and horrible creature who walks with his head down, swims rapidly backward, emits an inky secretion which darkens the water around him, and propels himself by a sort of hydrostatic engine, by ejecting water from a tube, a method of propulsion lately adapted to steamers, but found in many kinds of aquatic animals. The eight arms of this creature are each furnished with 120 pairs of elaborately- 


\section{Human Physiology.}

made suckers, or vacuum pumps, which fasten themselves to everything they touch, until the animal chooses to relax the muscles which control then. There does not probably exist an animal at once so hideous, so powerful, and so voracious.

Of the numerous tribes of crustaceans, the lobster may be taken as an example, with his protective coat of mail, strong, yet yielding to every motion, so that he can swim twenty feet backivard with one downward stroke of his tail. As he cannot move his head, his eyes are placed at the ends of two flexible tubes which he bends every way. He has also long, jointed feelers, and his great powerful claws, with which he seizes his prey, are furnished with teeth to cut it in pieces. When the lobster has outgrown his shell, he casts it off, pulling out his legs as from so many boots, and soon grows a new one. The cast shell contains the perfect mould of every part-the eyes, the teeth, every spike, every hair; and all are reformed again and again with the greatest perfection. Even crustaceans one sixteenth of an inch long shed their shells to the minutest parts.

Life in the insect world manifests a wonderful vigour of force and variety of manifestations, with an infinity of the most curious and astonishing contrivances. The nervous power and muscular strength of insects greatly surpass those of larger animals.

Insects have six legs, two antennæ or feelers, sometimes folded up in protecting cases; from two to six simple eyes, and two compound eyes, each composed of from 25 to 12,500 perfectly formed distinct organs of vision; a brain and double nervous system; a heart and circulatory system with numerous valves; air-tubes spread through the whole body, two trachæ with 236 tubes and r,004 branches; jaws armed with hooks, sharp shears for cutting vegetable substances, saws, files, augers, lancets, sucking tubes; stings in sheaths, spirting poison secreted by glands and kept in proper receptacles; liquid silk and the machinery for spinning it; eggs and instru- 
ments for depositing them, tubular and extensible like telescopes, and furnished with pincers, saws, or drills; glue to fix: the eggs, silk to cover them; in a word, a complex and wonderfully varied and perfect organisation. The secretions of insects are more numerous and varied than those of the higher orders of animals, among which are wax, honey, saliva, jelly, silk, gluten, varnish, scents, poisons, acids, smoke.

Man has 529 muscles; a caterpillar may have 4,06 I, each, of course, supplied with nerves and blood-vessels. An insect can leap 200 times its length, and drag fifteen times its weight.

The insect world is full of examples of the most wonderful. and beautiful mechanism, and of adaptation of means to ends. I have seldom seen anything which astonished me more than a case of leaf insects and walking-stick insects deposited at one time in the Crystal Palace. They looked precisely like a collection of dry brown stems of plants and bright green leaves, shaped, veined, and coloured in perfect imitation. It required a close examination to be convinced that they had once been. living insects. It is evident that they were so formed to protect them from enemies that would devour them. Was it by accident or done on purpose?

The sheep carefully selects a place to have her lamb someweeks before it is born; but insects make still more careful preparations for those they are never to see. They bore into trees, or the earth, or bodies of animals, and deposit their eggs; they put them in silken bags with a provision of food, and hang them up on trees, fasten in leaves, cover them with silk or varnish, always where the grub can find its proper food. Some lay 50 eggs, the queen bee lays 50,000 , some ants a much greater number.

The transformations of insects are infinitely curious. The gnat, or mosquito, lays its eggs on water, joining them together to form a boat which no storm can upset. The young. mosquito is an ugly and voracious swimmer, devouring animal-- 


\section{Human Physiology.}

culæ. At a certain stage of his growth he comes to the surface, bursts open his head, and out comes a delicate flying insect

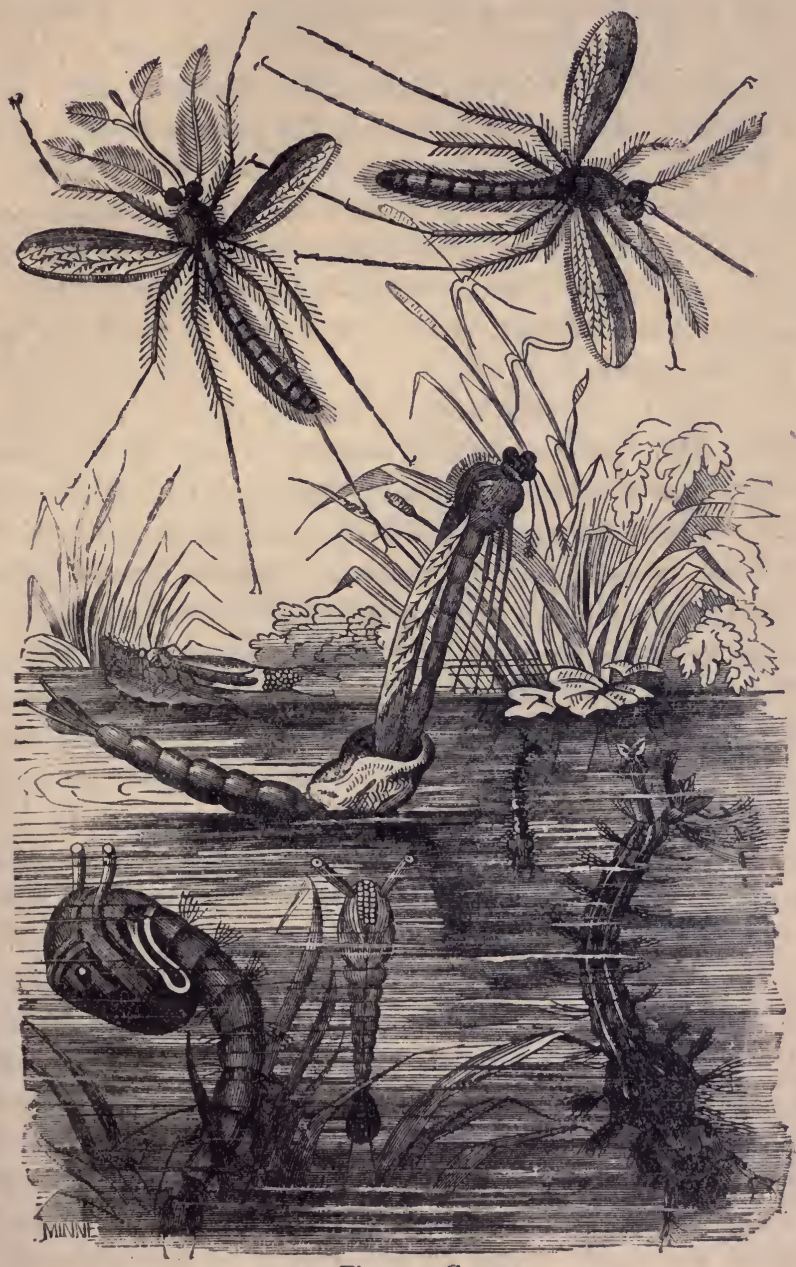

Fig. 4.-Gnats. 
with glittering wings and a long proboscis. Almost in the same manner is born the gorgeous dragon fly. In the water, its pupa moves itself by a hydraulic engine. When this phase of its life is completed it climbs upon a stalk, and by some hooks, provided for the purpose, hangs itself up to dry. In a little while its skin cracks open and the perfect insect comes out, its four great wings perfectly formed, only folded up carefully, like leaves or petals of flowers; these are spread out, dry in the sun, and then it flies off glittering with its splendid beauty-one of the most powerful and perfect of insectsflying backward, as well as forward, and even sideways with the greatest rapidity.

The wasp fly is also born in the water, and its larva is provided with a long breathing tube which rises to the surface and furnishes it with air. Some flies have the providential instinct to lay their eggs in the bodies of dead animals, which their larvæ, brought forth in immense numbers, devour, before they can fill the air with pestilential odours; and the progeny of a single fly consume more than a lion. Another fly lays its eggs on the hairs of living animals that they may be licked off, swallowed, and hatched in its bowels. The lace-wing fly hangs its eggs to the leaves of plants so as to produce the most delicate fringes.

These flies, when carefully examined, are found to have, in every way, the most remarkably constructed organs. They have feet with which they can walk up panes of glass, or upon the ceiling of a room; they eat loaf sugar by first dissolving it with their saliva, and then sucking it up with their trunks. The air-pipe of a fly is made of a special elastic thread between two membranes-the perfection of a mechanical contrivance combining strength, lightness, and elasticity. The wings of the fly are of the same character, and are moved by a nervous and muscular apparatus even more wonderful. The common house-fly moves its wings at the rate of 600 strokes in a 


\section{Human Physiology.}

second, flying 15 feet. If a horse had the speed of the fly, in proportion to size, it would move across the earth like lightning. One kind of fly has wide, branching eyes, like the hammerheaded shark, but far wider in proportion. The proboscis, with its lancets and suckers, is a most wonderful instrument, while the ovipositer-egg-placer-of the gadfly is rnade of four horny tubes, one shutting within the other like a telescope, the last ending in five points, of which three are long and hooked, by which the extended tube pierces the skin of animals and then holds fast until the eggs have been deposited. And this machine, and all these machines of myriads of insects with the instincts, of which they are instruments, we are told were casually developed by accidental variations, and continued upon the principle of natural selection! Upon this principle, the fly has also an eye with 4000 facets, each a distinct and perfect eye, while the butterfly has 17,000 , and the modella and dragon fly, 25,000!

One of the most curious instances of mechanical contrivances in insects is that of the bombardier beetle, by which it discharges from its abdomen, for defensive purposes, globules of an acrid, pungent fluid which explode like a shell when they come in contact with the air, the fluid acting upon the enemy like nitric acid. Some of these beetles can make a dozen successive discharges of this wonderful artillery. Open the receptacle and the matter effervesces and evaporates in an instant. This acrid explosive is secreted like the poison which bees and wasps send through their stings, and serpents through hollow or grooved fangs provided for the purpose-poisons secreted from the blood, made of most innocent food, and such as no chemist can produce. And we are expected to believe that these contrivances come by accidental variations, natural selection, and the survival of the fittest!

The Honey Bee, in its structure, and its instincts, which correspond everywhere to structure, is a wonderful illustration 
of the powers of insect life. The working bee has an extensible underlip, folded up when not in use, to reach the honey stored in flowers; a bag on his thigh for pollen; mandibles for cutting, tearing, etc. ; eyes looking forward and upward; antennæ to feel and fashion his work in the dark, talk with, give orders, and communicate intelligence; four wings, hind and forward hooking together; a very sharp, barbed sting in its sheath, with a secreting

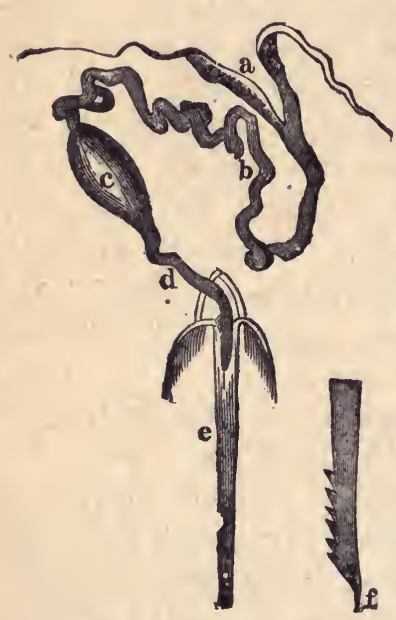

Fig. 5.-Bee Sting. organ, venom bag, and muscles to squirt the poison when the sting has penetrated. Need I speak of his skill in fashioning a comb of perfect six-sided cells of wax, hard in hot climates and softer in cold, of the provision of food for the grubs, of the cleanliness and ventilation of the hive, the carrying out or waxing over of nuisances, and all the wonders of its polity and government, the jealous mother queen, the industrious, provident, loyal neuters, the idle consort princes, who, their function accomplished, are taken out and put an end to?

The instincts and capacities of ants are, perhaps, more varied and wonderful than those of bees. They build cities and palaces, larger in proportion to their size than the pyramids of Egypt. They have males, females, neuters, labourers, soldiers, slaves, and keep other insects to supply them with food, as men keep cows. They make war, go on marauding expeditions, build covered ways to protect them from the sun, and tunnels under rivers.

The cockroach lays its eggs in a shell with a longitudinal slit, which the mother carefully closes and cements together, 
and the shell with its eggs are fastened to a place selected. When the larva is hatched it secretes a fluid which dissolves this cement, and so escapes from its prison.

Many insects, pursued by enemies, simulate death, as birds pretend to be lame, to lure people from their nests. The dung beetle pretends to be dead-but that is not his last dodge. He sticks out his legs and holds them rigid so as to seem more dead, and at the same time make himself an ugly object to swallow.

Similar to the electric apparatus in the electric eel and torpedo is the insect power of producing light. The glow-worm shines with a steady light, but the fire-fly gives out its light in a strong blaze at short intervals, and I do not know of a prettier sight than a meadow full of fire-flies or lightning-bugs. At intervals of two or three seconds the whole semi-transparent abdomen of the insect is a mass of pale bluish light. If crushed the matter retains its phosphorescence for some minutes.

The spider is a creature of marvellous structure and powers, spinning webs of great strength and mathematical beauty out of its own body by a complex and admirable apparatus. First it has glanas, which, under nervous influence, secrete from its blood, which is formed of its food, a viscid liquid which, the instant it comes to the air, hardens into silk. This liquid, by proper muscles, is pressed through minute orifices in from four to six spinarets, each spinaret in some instances having 4,000 orifices, so that 24,000 threads unite, woven together in zigzag lines, to produce one thread one-fiftieth the diameter of a hair.

The water spider lives in a bell-shaped house under water, lined with soft dry silk, and filled with air which the spider carries down in small bubbles. Others build houses in the ground, beautifully carpeted, and covered with a door which opens with silken hinges.

The mechanism of fishes for swimming; their propelling tails, so vastly beyond the power of any which have been 
adapted io steamers; the fins which keep them from rolling; air bladders which they expand when they wish to rise and compress to sink; and their wonderful armour of beautiful overlapping scales, are all familiar; but for special adaptations let me point to the hammer-headed shark, with its eyes so carried out that it can see in every direction, and those strange instruments of war furnished to the sword-fish and the saw-fish.

Fishes may seem stupid, cold-blooded creatures to us, but how perfectly are they adapted to their conditions; and their mental qualities are not to be despised. How does the salmon find his way through the pathless depths of the ocean back to his native river? Does the angler fish watch for his prey because nature has provided him with a line and bait above his head, or did line and bait grow there because he happened to have a taste for angling? How came the electric eel by a complete galvanic battery, and then to know how to use it to stun his enemies or his prey? Unlike other batteries, this is under the control of his will. He gives or withholds the shocks as he pleases. Who taught the goby and stickleback to build nests, watch over their eggs, and drive off intruders? Who contrived the sucker of the sucker-fish, so that he could make fast to a shark or other strong fleet swimmer and be carried about like a barnacle? And why should the barnacle, which at first swims about, lose his eyes when he has once made fast to ship or timber, and has no further use for them?

The common snail, with his house on his back, has telescopic eyes like a lobster, which he can draw back as one pushes in the finger of a glove, elaborately-formed ears with special auditory nerves, and in a cavity of each are minute crystalline bodies in constant motion, vibrating, turning on their axes, rushing with violent motion to the centre of their cell, from which they are violently repelled.

Serpents give us instances of design, or adaptation of means to ends beyond the powers of chance variation, similar in some 
cases to those displayed by insects. The rattlesnake is a remarkable instance. In his head is a gland which secretes a deadly venom, a bladder to hold it, a tube to carry it to a long curved, hollow, sharp fang, which is commonly folded out of the way, but which can be brought down at will. When an angry bite is inflicted, the venom is pressed through the tooth. This venom kills if it enters the circulation, but may

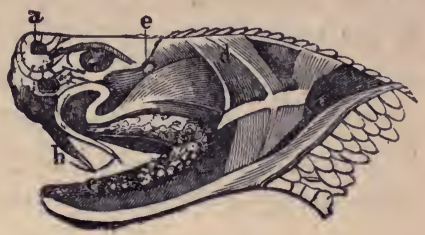

Fig. 6. be swallowed with impunity. But it is a gentle snake, and always gives warning before it strikes. To enable it to do this it has a rattle at the end of its tail, several joints of dried bone, which rattle together and give the intruder fair notice.

This world would be much less interesting and delightful than it is without the birds, who charm us with the beauty of their forms and plumage, and the sweetness of their songs. A world that has in it skylarks, mocking-birds, and nightingales is not so bad.

As mechanism, nothing could be nicer-light, strong skeletons, as well shaped for flying as a fish

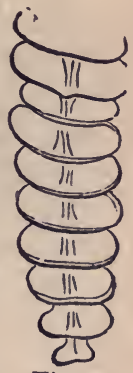

Fig. 7 . for swimming; muscles massed just where they are wanted; feathers, each a marvel of a light, strong, beautiful covering; broad, spreading wings unade for the air, as the air for them; legs with tendons bending the toes with the weight of the bird, so that it can sleep on its perch securely.

Little brains, but how wise! It needs no lessons to build its nest, and the first bird built as well as the bird of to-day. Some burrow in banks of earth, some hang their nests from boughs of trees The tailor bird sews up a leaf for his nest. They know when to migrate, where to go to in winter, and find their 
way over land and sea without chart or compass, coming back to the same tree.

I know not the use of the songs of the thrush and nighting lc. or the imitations of a whole forest of birds hy the mocking-bird. to the birds themselves. They make our dwelling-place more enjoyable for us. Mr. Darwin thinks the bright plumage anci curious ornaments of some male birds make them more attractive to their females, and so promote the good of the race; bus the sparrows manage with their dull grey colours, and the most

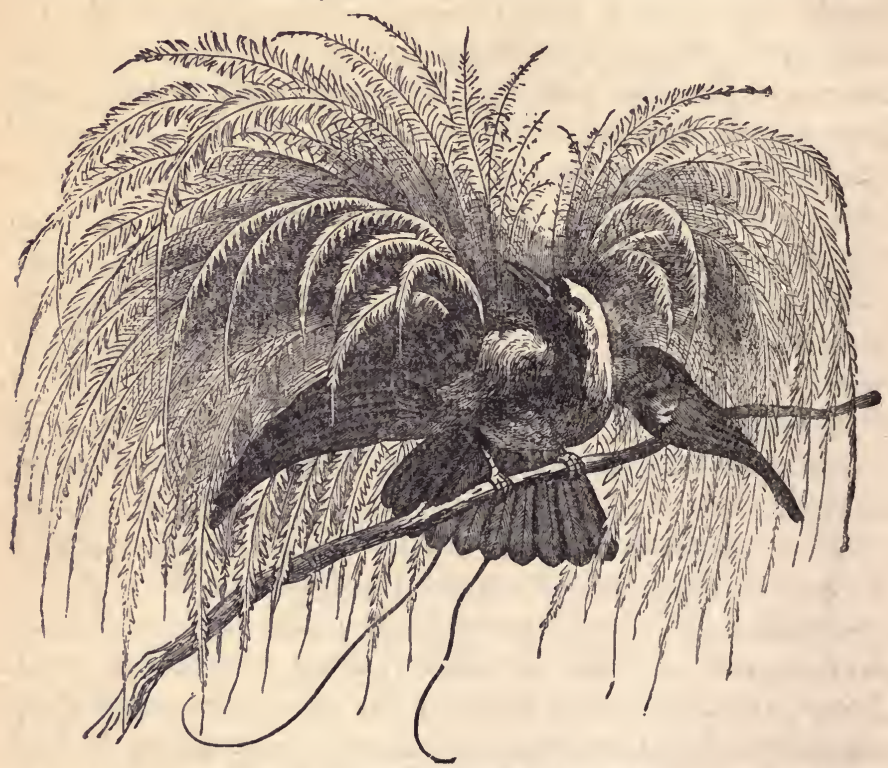

Fig. 8.-The Bird of Paradise.

beautiful birds are not otherwise the most charming nor the most prolific. The plumage of humming-birds, parrots, pheasants, the peacock, and great numbers of tropical birds, shows that the intelligence which governs life, does not despise the 
element of beauty. This is remarkably shown in gems, insects, flowers, and birds-shown in sea and sky, shown everywhere. The peacock seems proud of his tail, and ashamed of his ugly feet; the bird of paradise is said to spend a large part of his time in cleaning and arranging his beautiful feathers. Nor must we forget the beauty of those living flowers, the butterflies, nor the strange transformation from a ravenous caterpillar, eating many times its weight in a few hours, to the ethereal, winged creature, whose alimentary system is reduced to a thread, and whose only food is a drop of honey dew; nor the wonderful forms, finish, and colours of the beetles, who shine with diamonds and pearls, emeralds and rubies, whose splendours the highest powers of the microscope only make more effective. An insect with round lustrous eyes of twelve thousand lenses, in burnished armour of green, black, and gold, with four gorgeous wings like iridescent glass is a splendid combination of strength, lightness, and beauty. I do not know the object of its creation, nor the process; but I do not believe it is the result of a long series of accidental variations.

This wonderful beauty of life exists not only in the earth and heavens, but in the depths of the sea, in bright corals, luminous sea pens, and the wondrous living flowers to which beauty can be of no advantage in aid of sexual selection, any more than the lovely forms and delicate painting of shells. The microscopic world is as full of the beauty of exquisite forms as that we can see with our natural vision. The very worms of the seaannelida-are among the most wonderful and beautiful objects of which we have any knowledge, with their bright green rings, purple crests, and clouds of living cables, while every movement emits flashes of splendour, in which prismatic tints are blended with the brightest metallic reflections. One of these complex and gorgeous creatures moves forward with a thousand feet, is covered with beautiful vermillion plumes, protrudes a proboscis with three pairs of jaws. The colours of the brightest 
moth or humming-bird are not more beautifui. Some are armed with sharp scimetars and spears, harpoons, fishhooks, models of every kind of weapon that man has invented for offence or defence. The eunice gigantea, the largest annelid known, is four feet long-a gorgeous animal blazing with iridescent tints, rowing along with seventeen hundred oars so rapidly that the eye can scarcely follow its movements; a creature with three hundred brains or nervous centres, three thousand nerves, two hundred and fifty stomachs, five hundred and fifty branchiæ or lungs, six hundred hearts, and thirty thousand muscles!

\section{CHAPTER V.}

LIFE IN THE HIGHER ORDERS OF ANIMALS.

Mammalia-Resemblances and Diversities-Adaptations of Domestic Animals to the wants of Man-The Horse-The Dog-The Camel-The Elephant-Ready Submission to Man-Sagacity and HumanityCharacter expressed in Organism-The Manis-The Beaver-Monkeys-The Gorilla and Orang Outang-The Life of Man-Unity of Life-Infinite Power and Wisdom.

IN our rapid survey of life in the vegetable and animal kingdoms, we come now to the class of animals to which we, by our physical constitution, are most nearly related, and whose characters we can best understand, from similarity and a certain degree of sympathy. This is the class Mammalia-animals which suckle their young. This class has a wide range on land and water, from the elephant and whale to the mouse and bat; for our nearest animal relations not only walk on four legs, or climb with four hands, but swim and fly. They also differ from most of the lower orders of animals in bringing forth their young alive. To this class belong the animals most useful to 
man, and with which he is best acquainted; animals with the largest brains and most improvable by education; animals which seem to have been expressly created for man, and which are very useful, if not absolutely necessary, to his life on the earth. Their wool and skins have been inis clothing, their milk and flesh his food; they have been his friends, companions. and faithful servants, - watching, working, hunting, fighting $\mathrm{f} r \mathrm{r}$ him, and transporting him from place to place.

The body of man very nearly resembles the bodies of the higher orders of animals. All those with bony skeletons are made in the same fashion, as all nature seems formed upon the same plan and of the same materials; and it is probable that life in the most distant systems of the universe carries out this law of universal analogy. Everywhere there are the same elements of matter, the same forces in action, the same life and similar forms of its development and manifestation. If there are men, as I have no doubt there are, on Jupiter and Saturn, there are also birds, beasts, and creeping things, resembling him as our animals resemble us.

But remarkable as may be our resemblance in physical formation and corresponding mental character to many animals of our own class, how widely different from multitudes of others! What likeness, what relationship is there between man and the whole class of insects, with their curious forms, wonderful transformations, and strange modes of life? If man, in the progress of his foetal development ever resembles a grub, he certainly never comes to any striking similarity to a bee or a butterfly. Can we conceive of progressive development, under the same, conditions of matter and force, coming to such diverse results as, say, a whale and a dragon-fly? We must find something more than sunshine and electricity, or natural selection and sexual selection, to account for such diversities.

No one can look at a horse without being struck with his adaptation to the wants of man. His back was formed for a 
saddle; rather it is a saddle. His mouth has a space for a bit. $\mathrm{He}$ carries his rider with pride, or draws carriage, dray, or plough, as if it was the one thing he came into the world to do. How patient, and helpful, and intelligent! In the chase, the race, the battle, the horse is the sympathetic friend and ally of man; a creature made for him and curiously adapted to him. And when horses are well treated, they are very considerate and affectionate; loving each other, their human care-takers, and even other domestic animals. As far back as we know man, the horse was his compauion and servant.

The dog is possibly a still older friend of man than the horse; and his origin is a greater mystery. We see in dogs how far nature can go in the production of variety in the same species, and also the stern limits to that variation. Dogs through all the ages; but only dogs. All varieties breed with each other, but not with any other species; nor have they ever produced one. The horses and dogs of to-day are the same animals we see pictured in the remains of Nineveh and Egypt. The dog was made for man, and has adapted himself to man, becoming strong and fierce in the bull-dog and mastiff, slender and fleet in the greyhound, web-footed in the Newfoundland, hardy and wonderfully sagacious in the shepherd's dog, and running into curious eccentricities of delicacy in petted varieties. All this has been done by human care and intelligence presiding over their breeding and training; the same as in the varieties of horses, from the elephantine London dray horse to the winner of the Derby or the child's pony. Our own species, so distinct from every other, shows a still wider variety. Turn out dogs and horses wild to shift for themselves, and they would probably all come in a few generations to the same types.

The camel is another animal made for man, witt. special adaptations to a peculiar climate and conditions. Without him the great deserts of Asia and Africa would be impassable and uninhabitable. His feet seem expressly formed to carry 


\section{Human Physiology.}

him and his burthen over the shifting sands; he can live on the coarsest herbage; and his stomach is provided with a collection of cells in which he carries a store of water, as a ship carries it in her tanks or casks.

The elephant is one of the animals best worth studying, not only in his physical organisation, but his mental and emotional character. With his great bulk he has an almost monkey-like activity, climbing mountains, rushing down steeps; and he has been taught to stand on his head, walk on a rope like Blondin, and sit at a table and dine like a gentleman. The elephant's trunk is less complex than the trunks of some insects, but it is a marvel of construction and adaptation-wonderfully flexible, extensile, able to tear up a tree or pick up a needle. Its movements are made by 40,000 muscles, each having its arteries and veins, and each excited to contract, and controlled to a nicety in its movements by will, brain, and nerves.

In a state of nature elephants live in herds, each herd with a leader who directs its movements, and whose safety is guarded by the rest with great devotion. Some elephants, for unknown reasons, are banished from the herds, and do not seem able to get admission into others. Under these afflicting circumstances they grow morose and savage. A fine sense of justice, or regard for the rights of property, prevents a herd of elephants from breaking through the slightest fence when the rice fields are very tempting.

All domestic animals are so easily taned-so readily and naturally attach themselves to men, and submit to be governed by them-as to leave no doubt of the special design of their creation. A wild horse may be conquered in an hour, and be ever after submissive to his master's wishes. The elephant is perhaps still more tractable. He is captured with the aid of tame elephants, who engage in the work with zeal and intelligence. When driven into a corral, and fastened to a tree, two tame females caress, and, if necessary, discipline him with 
their trunks, which they put to his ears as if talking to him through whispering tubes. He submits, accepts a driver, and yields a ready and loyal obedience.

Elephants are employed in ploughing, clearing land, piling timber, which they do with great regularity, loading and unloading ships, drawing artillery, hunting and war, and they performed inportant parts in the earliest wars of which we read in history. Though not more ingenious than ants or beetles, their intellectual operations perhaps surprise us more, because more like our own. An elephant unloading a ship takes a cask to the shore, rolls it up the beach with his head and trunk, then holds it with his leg while he reaches out his trunk for a stone to prop it with. The first of a train of elephants, carrying an Indian potentate, found on a narrow causeway some sick people who had been brought out of a hospital to lie in the sun. $\mathrm{He}$ stopped, but was cruelly urged forward, when with his trunk he carefully removed the poor invalids out of danger. When elephants were drawing an artillery train of the British army in India, a soldier stumbled and fell, so that one of the hinder wheels of a gun carriage was about to crush him. The next elephant instantly seized the wheel with his trunk and raised it, so that it passed safely over the man, whom he then helped to his feet. A female elephant escaped from her keeper, and joined a wild herd. The man was severely punished, but some years later was employed to hunt elephants. He recognised the one he had lost, and went to her-alone. She joyfully welcomed him, knelt down, helped him to mount, and assisted in capturing and taming two young ones she had given birth to since she became a fugitive.

Dogs reason nearly as well as élephants, and are not less affectionate and faithful; and all domestic animals have the brains and physique, the mental and moral characters, which fit them for their evident destiny as the companions and servants of man. The law of their life, as of ours, and every 
creature's, is written in their constitutions; and their bodily organisation is the accurate expression of their mental and emotional character.

Natural history is full of example: of the adaptation of animals to their conditions, and curious fashioning of implements, arms, and armour. In the hedgehog and porcupine, the cuticle forms itself into long sharp spines; on the armadillo it becomes a coat of mail; on the manis, a South-American ant-eater (Fig. 9), the armour takes the more flexible form of scales, which are erectile; so that when the animal is attacked he rolls himself up, winds his tail around him, and presents on every side a chevaux de frise of sharp spear points.

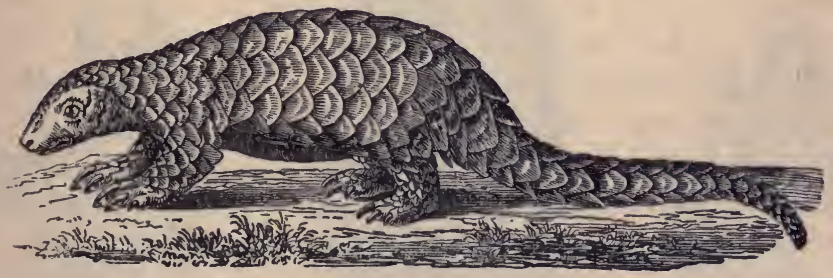

Fig. 9.-The Manis.

Of wild animals, the beaver presents one of the most remark able adaptations of form to instincts. In the skull of the beaver (Fig. Io) may be seen the four ever-sharp and ever-growing

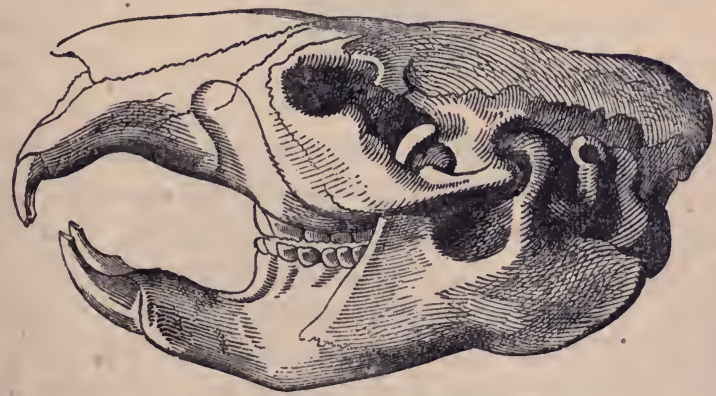

Fig. IO.-SkUll of Beaver. 
chisels, rodent front teeth, with which he cuts down trees, trims off their branches, and fashions stakes for his dam. With his fore-feet (Fig. II), which are as good hands as those of most monkeys, and adapted to more varied uses, he places his timbers, plants his stakes, mixes his. mortar, and builds his dam and dwelling. The hind-foot (Fig. I2) is also very flexible and useful, and he is web-footed here as an animal so aquatic in his habits should be. With his broad, heavy, scale-covered tail (Fig. 13) he drives his stakes, beats down his mortar, and

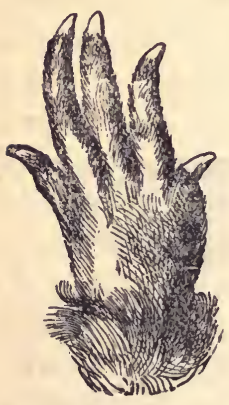

Fig. II.

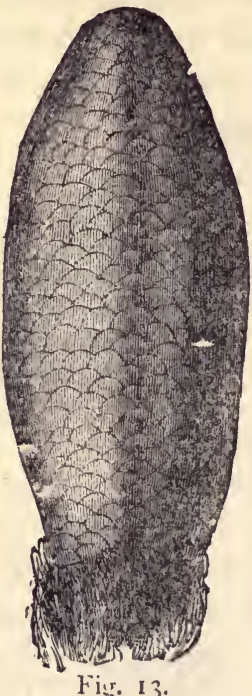

Fig. 13 .

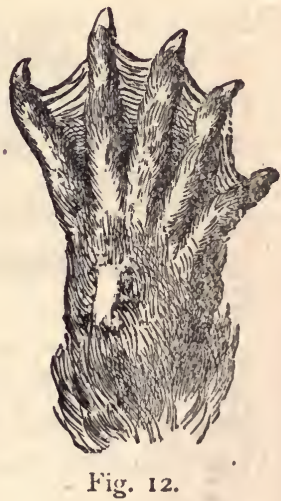

Fïg. 12.

gives signals to his comrades. The beavers live in communties and families. The pond created by the dam, and its wooded banks, are the common domain. Each family has a house of several apartments, proportioned to the number of its members. The site of the dam, and its mode of construction, show high powers of instinctive engineering. But the beaver does not cut down trees, and make dams, and build houses, 
because he has sharp teeth, hand-like fore-paws, and a tail like a trowel. These instruments have been formed by the brain and nerves of the animal; and it is in the brain that reside all the peculiarities of his character, as it is that which directs all his operations. This is not all. The brain is a collection of cells and fibres; matter which cannot act, but can be acted upon and with. The beaver life, beaver mind, beaver soul is back of brain and nerves, and works through them, first to fashion its body, and then to carry out the functions of its organisation. Head, feet, and tail point to the instincts, faculties, the most interior life which fashions and directs all.

The beaver is a gentle and affectionate as well as intelligent animal and easily tamed. When kept in a house he gathers all the materials around him, and does his best to construct a dam and house. A gentleman in Vermont, in the employ of the Hudson Bay Company, had a pet beaver that accompanied him in all his expeditions. When going by a river the beaver followed the boat, swimming, and though often not seen all day, he never failed at night to find his way to his master's feet. The steamers on Lake Champlain, a narrow lake nearly a hundred miles in length, make landings at several ports on either side. If this pet beaver were thrown overboard by day or night, he never failed to stop at the port at which his master had landed, and to find him quickly after. But how the beaver can follow his master by water and know where he had landed, they may tell us who know how the nightingales find their haunts, the salmon their streams, or the bees their hives, and who know much more than I do of life and its mysteries.

Monkeys are, intellectually, less like men than are dogs, or beavers, or elephants; in some things less like them than are ants or bees. But artists find strange resemblances to humanity in many birds and beasts. The higher classes of the fourhanded animals, the chimpanzee and the orang-outang, however, are in some of their external aspects curious caricatures of 
humanity, but they lack the constructive abilities of birds and insects; they cannot learn to talk like parrots. "The differences," says Professor Huxley, "between man and the highest apes are great and significant; every bone of a gorilla bears marks by which it may be distinguished from the corresponding bone of a man; and, in the present creation, no intermediate link bridges over the gap between homo and traglodytes." It would require twenty-four considerable alterations to make the body of the gorilla like that of a man. An English skull has a brain holding capacity of 96 cubic inches; that of a Hottentot 75 inches; the gorilla's, $34 \frac{1}{2}$ inches; the chimpanzee, $27 \frac{1}{2}$; the ourang, 26. Look at the stuffed specimen and skeleton of the gorilla at the British Museum, and see if it very much resem-

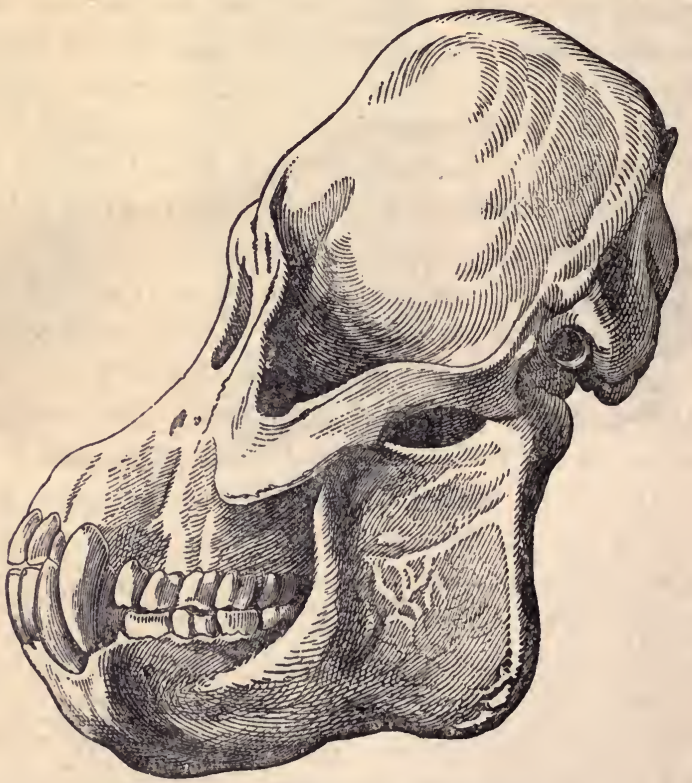

Fig. 14. - SKULL OF ORANG OUTANG. 
bles, or is likely to be any very near relation of, the lady you have invited to go with you and inspect it. The orang outang is a far more intelligent animal than the gorilla, but its skull (Fig. I4) does not give one a high idea of its intellectual character.

Man is two-handed, and his hands are capable of executing a great deal of what his mind can conceive. The four hands of the monkey are strong and flexible, good for climbing, picking fruit, and conveying it to his mouth. Man walks erect on two feet, with straight legs, and muscular developments on the back of the pelvis and leg to enable him to maintain the upright position. Monkeys have four hands, admirable for climbing, and they stand on their hind legs when trained to do so, but awkwardly, with bent knees, and resting on the outer edge of the posterior hands. The foot, or hinder hand, of the orang

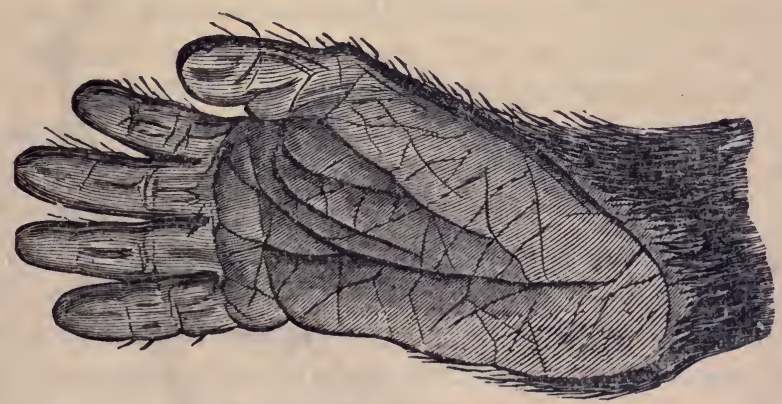

Fig. 15. - FOOT OF ORANG.

has very little resemblance to the foot of man. The head of man, balanced on its centre, with its eyes looking forward horizontally, as well as the form and comparative size of the head, make him strikingly different from all the animal creation. The human brain is mostly above the orbit of the eye, that of the gorilla is mostly below it; an average European child, four vears old, has a brain twice as large as that of the adult gorilla. 
And the life of man, in all its developments, is a life so infinitely higher, and more varied, than that of any member of the animal creation, that it is astonishing that the idea could ever have entered the mind of any cultivated and thoughtful man, that there was any near relationship between them. In whatever way the body of man may have been formed, it is evident that its animating soul cannot owe its origin to any animal which now exists, or of which we have any relics. Professor Huxley, who teaches that man's place in nature is that of a descendant of lower animal races, still says:- "No one is more strongly convinced than I am of the vastness of the gulf between civilised man and the brutes, or is more certain that, whether from them or not, he is assuredly not of them. No one is less disposed to think lightly of the present dignity, or despairingly of the future hopes of the only consciously intelligent denizen of this world."

"Missing link!" We want a thousand missing links to connect man with the brutes. I know that there are savages who do not count far, and perhaps have had little occasion for counting; but every race of man has a capacity for education and progress, that in a few generations will bring it up to the highest standards of civilisation. No animal shows any such capacity. There is a narrow range of improvement even in dogs and horses. Monkeys have shown no such capability. Does any one imagine that the most careful training of successive generations for a thousand, or a hundred thousand years, would enable dogs or elephants, or any race of monkeys to calculate an eclipse, or compose an opera-to paint a picture, or invent a locomotive-write a poem, or found a university?

Still we must not be unjust to our fellow-creatures, for they are all gifted with marvellous powers. Their organs of sensation are as perfectly formed as our own; and their senses in many cases, far more acute. Their eyes are adapted to the light by the same contrivances-a dark chamber, a convex lens, a pictured retina, nerves to convey the impression of the 
picture to the brain. Their ears have the same adaptation to the sound waves of the atmosphere. Their brains, as far as they go, are so like our own, that I doubt if the microscope can show any difference in the matter of which they are composed. They breathe, digest, circulate their blood, and carry on all the functions and processes of life in the same manner; and to a great extent they feel and think as we do. They remember, dream, perhaps meditate, and love. The affection, fidelity, and devotion of animals are sometimes very touching. The dog perceives that his master is about to die, and sheds tears of inconsolable grief. He follows him to the grave, and watches by it until his own life is ended.

The charm of Natural History is a sympathy we have with all life, recognising the similarities, as well as the diversities, of its manifestations. We get acquainted with our relationsthe near and more remote branches of our family ; and animals are interesting to us just in proportion as we find our own qualities in them, or theirs in ourselves. Recognising their superior powers, and even envying them-as the bird's power to fly, or the fish's to swim, or their mysterious instinctive faculties-we have a sense of intellectual and moral superiority, and capability of continued existence and progress, which makes us feel ourselves to be, with all our imperfections and depravities, monarchs of the visible creation.

We recognise a unity of life on the earth. The same Intelligence and Power has formed and sustains all things. Every creature shows the design and workmanship of the same Artis. The same plan and skill run through all. Matter and mina are governed by general laws, and universal analogy is the law of matter and of life.

I place under a microscope a dozen points of matter, cells filled with a liquid, all looking alike, and all composed of the same kind of matter-carbon, hydrogen, oxygen, nitrogen-all made of albumen and fibrine; all alive; but differing from each 
other, not in matter or form, but only in the quality of life. In that quality of life-in the subtle element which adheres to, or presides in, or over each giobule, is the directing force, the guiding intelligence, which will accomplish its development, and make it what it is to become. The material atoms do not differ, but each collection of atoms and molecules has in or around it a soul, a spirit, a living principle, an invisible, intan= gible mind-force, which contains the character and capabilities of the being into which each germ is to be developed.

And one of these microscopic globules, all so alike in form and matter, will become a rose-tree, and one a pine ; one will be an oyster, and one a dragon-fly; one will be a canary bird, and one an elephant; one will be an Englishman, with all his national peculiarities, another an Esquimaux. The same matter is moulded into a thousand forms, by the varying character of that which presides over matter, and directs form and manifestation. And this is what I have chosen to call Life, which is to force, what force is to matter.

The matter of our bodies is changing every hour. We constantly throw off the old, and constantly add new. At every breath we take in a new stock of oxygen, and give out a quantity of carbon. Hydrogen and nitrogen pass off continually by the millions of pores of our skin. The addition of each day's food is made needful by each day's waste. Our real life, then, is something superior to matter, and something which can order, control, and use material forces; a power that shapes every organ; that makes living blood, and then sends it through the system; which gives action to brain cells, nerve fibres, and muscle discs ; which is the real life of man, and of every living thing.

For matter can no more make of itself a leaf, than a lobe of brain. Dead brain and a dead leaf are much alike. It is life in both that works, and matter is worked with. The myriad shapes of leaves, and their myriad organs do not come from the 
attractions and repulsions of atoms or molecules of matter, but from other forces guided by intelligence, and working upon definite designs for special purposes. There is no chance work in life-no fortuitous concurrence of atoms. The insect, with its various organs, its multitudinous eyes, its wide-spreading wings, its nervous powers expressed in inconceivably rapid muscular action, and all the instincts of its varied existence, is a work of the most wonderful mechanism, the most perfect art, of an inconceivable intelligence. All we living things are "fearfully and wonderfully made." The mystery of life is the grandest and most terrible of all mysteries. But all the phenomena of life in the world around us, and in our own consciousness, lead to one result-the recognition of the Life which is the source of life-Infinite Power and Infinite Wisdom-a life which is to the whole universe of matter and of mind, what life is to every living thing in the world around us-the Life of Life.

\section{CHAPTER VI.}

HUMAN LIFE AND IMMORTALITY.

The Highest Powers of Life in Humanity-Sexual Life-Social Life-. Health and Disease-Health Forces Spiritual-Radiation of LifeSpiritual Attractions and Repulsions-Spiritual Powers of AnimalsClairvoyance, Dreams, Trance-The Spirit Life-Proofs of Immortality.

LIFE manifests to us its highest powers in humanity. There are, I doubt not, created intelligences surpassing us, and even our conceptions; but man stands at the head of the portion of nature subject to his cognition; he is the highest form of earthly life. The lower animals have in some respects faculties differing from his, some which he may envy, some which are incomprehensible to him. "O that I had the wings of a dovel" 
And one might say-O that $\mathrm{I}$ had the keen senses and infallible instincts of many animals. But the intellectual and moral powers of man are a thousand-fold compensation. One opera or oratorio surpasses all songs of birds since the creation; one picture, or statue, or poem, all works of insect, of animal.

Animals have some power of communicating with each other, by which one receives, probably in a very direct sympathetic way, the other's sensations. Man has himself this power of clairvoyant intuition very remarkably in some cases; but the animals have nothing to compare with human languages, embodying the thoughts and feelings of all peoples and ages. Nor can it be seen that animals, even the highest, possess any rudiments of human speech. The elephant understands his keeper, but he does not learn his language as we learn French or German, by slow degrees and with effort. He understands from the first, and without regard to the language in which his commands are given. Elephants, dogs, and horses, are not grammatical, but intuitional ; and understand men, when in sympathy with them, as they understand each other, by a consciousness of their thoughts or sensations.

The life of man has a still higher range. There is no indication that the most intelligent animal has any conception of God or immortality. Men, as far back as we know of them, have believed in Superior Beings, and expected to enjoy existence after death. The mind of man, his conceptions, his aspirations, his faith, and his hope, are satisfied with nothing less than belief in a Supreme Being and in his own immortality. Either those ideas were revealed to man by some higher intelligence, or they originated in himself-in either case they are a part of his life. His mind is so formed that he could accept such ideas when given to him, as we accept every truth, when it is adapted to our perceptions, or that he could conceive them vy his own intuitions, or admit them by his reasoning powers as logical necessities. In whatever way man came by the funda- 
mental ideas of religion, they must be natural to him-a part of, or in harmony with, his life.

It is true that all animals are alike in many things-in the matter of which they are formed, in the physical forces by which they are governed. All are related to the earth and to the sun. All live by water, air, and heat; all have that something - that forming, guiding intelligence which we call life. They are alike in the matter, and to some extent in the forms of bones, muscles, and organs of nutrition and reproduction, thought and volition. But they differ from each other, and all from man so widely that we can nowhere find the missing links between one species and another. The horse and ass may, if you please, have come from the zebra, but whence the zebra? Where is the progenitor of the giraffe, and in what geological strata are the remains of his gradually lengthening neck to be found? Where is the evidence of the progressive development of the food-strainer of the whale? Give us an idea of a trunkless elephant, or, for that matter, of a trunkless moscheto? Or, putting the cart before the horse, show us how atoms formed molecules, molecules made blood, blood formed heart and arteries, arteries created nerves, nerves expanded into brain, brain secreted thought, and love, and religion, and invented God and immortality. How matter, self-existent and eternal, begot force, and force and matter generated all forms of life in the universe. This is the problem for materialists to solve.

In considering the forms and operations of life in all the kingdoms of nature, we find it under three conditions-individual, sexual, and social; and no physiology can be complete which does not treat of plants, animals, and men in these three aspects. The male and female element must be considered in every life, for one is not complete without the other. We cannot comprehend the life of man, bird, or rose, if we do not know the functions, influences, and relations of sex; and we can scarcely give too much importance to that which completes 
the life of the individual, and is absolutely essential to the race.

Sex, it is evident to every observer, modifies not only the form and organs of the body, but fully as much the mind and character. The feminine instincts, passions, affections, and intellectual faculties differ from the masculine. We speak of masculine and feminine tastes and characteristics as we do of a masculine or feminine appearance. We are equally disgusted with masculine women and feminine men. There need be no question of superiority or inferiority here; but there is a question of fact and fitness. Among insects the female is generally the larger, stronger, and altogether superior creature. The working bees are undeveloped females; the queen-mother of the hive exercises the highest functions. The small minority of males are stingless, idle drones, who are put out of life when no longer needed. Their social position, while permitted to live, is not known. Throughout the insect world the females are far the most gifted and important portion of the community.

Among birds there is more equality. The males are generally larger, and excel in plumage and in song. The female does the chief work in making the nest, lays the eggs, hatches them, and, with or without the aid of the male, feeds and rears the young. Among the mammalia the males are generally larger and stronger than the females, and in some cases marked with striking peculiarities; as in the mane of the lion, the neck and horns of the bull, and the branching antlers of the stag.

In the human race we find size and strength of brain and body on the side of the male, while the female has most of delicacy and fineness of fibre, beauty, grace, charm, liveliness of imagination, purity of feeling, powers of intuition, or rapid and unconscious perception, which often give her a real superiority to the physically stronger male. And woman, as mother and chief educator of both sexes, exercises, and must ever exercise, the greatest influence upon the rare 
In his savage state, degraded or undeveloped, man, in many cases, has made woman his slave; and she continues to be so, in perhaps a majority of cases, in the highest civilisation, as I have shown in Part First. But what we call civilisation is a mixed condition, made up of a certain number of really educated, refined, civilised, and Christian people, mixed up with perhaps still larger numbers of rude savages and coarse barbarians. Among the really civilised members of society in every country woman reigns as mistress, wife, mother, and queen; the mistress of our youthful romantic aspirations, the wife of our affections, the mother of our children, the queen of society; to whom, in all these relations, we pay willing and devoted homage. The way in which men treat women is the true measure of their civilisation, and the higher the position of woman, in idea and in fact, in the literature, poetry, art, and life of any country, the higher is that country's moral and social condition.

It becomes, then, a matter of very high interest and grave importance that the relation of the sexes to each other should be understood, and its moralities regarded. Injustice to woman is an injury to the race. Degrade women, and all children, male and female, are degraded; elevate women, and the race, both men and women, is elevated. The child may receive an equal half of its mental and moral, as of its physical character, form, complexion, etc., from the father, but his direct influence may end with the procreative act, while the mother's continues through gestation, and, as a rule, through infancy and childhood; and every thought, every emotion, every act of the mother, has some influence, good or evil, on the character of her child. When women become what they should be, and are treated as they ought to be, our own salvation and the salvation of the race will be alike secured. Before a Saviour could be born into this world, there had to be a woman in it pure and toly enough to be His mother. And the pure life of God will 
come into this world when and in proportion as women are made or even permitted to be pure.

The life of society is as real a life and force, as the life of the individual. In marriage, it is said, the twain become one; in society many individuals partake of one life. This constitutes the character of societies, nations, or races. It is the spiritual basis of what we call public opinion and public sentiment. We see the action of this element at times very distinctly in a public audience warmed into a common enthusiasm, or a great excitement of rage or admiration; in the feeling and conduct of a mob when thousands of persons lose their own individuality, and act under a common impulse; in such vast popular movements as the Crusades; in the esprit de corps of armies, and in the strange panics to which they are liable; in religious revivals; in such united feeling and manifestations of pity and loyalty as attended the death of the Prince Consort, and the dangerous illness of the Prince of Wales. These are real phenomena, and they have a real cause and principle of action.

The individuals who compose a human society are all linked together in a common life, as are the organs and atoms that form our own bodies. When separated from our kindred and country, and cut off from their sustaining life, we suffer from nostalgia, or home-sickness, as real a disease as fever, and one which is not seldom fatal. Love of country, love of kindred and home, are not mere ideas, but facts of our physical life; a life that we feel sustaining us, as the circulation of the blood sustains our bodies. Sympathetic peoples, like the French, have this feeling more intense than more phlegmatic or mixed nations like the English, which is the reason why the latter make better emigrants and colonists. The Italians and Swiss scarcely emigrate at all, and always pine to return to their countries, or rather to their countrymen, or the strong element of sympathetic nationality in which they have their being. The 
science of this life of society-national life-or life of race, constitutes Social Physiology or Sociology.

The social life manifests itself as a sustaining force to every individual. Each one radiates his life, as all bodies radiate heat. All give and all receive of the life element; therefore no one can do anything to injure his health, and diminish the force of his own vitality without, at the same time, doing an injury to others. He wastes a portion of the common stock of life. When a weakly child is placed with robust companions, they strengthen him. A healthy child who sleeps with an aged and infirm person is seriously injured. The weak live upon the strong. In hospitals, where nearly all are weak, the whole life becomes feeble and exhausted, and there is often great mortality. This is one reason why small hospitals are better for patients than large ones; and why, even under great dis. advantages, it is better still to treat the poor in their own dwellings, where they are not subject to the drafts of the weaker patients around them, and where they have the benefit of a larger proportion of strong and healthy persons about them. There is also, no doubt, in hospitals an accumulation of the matter of disease. The emanations of diseased bodies adhere to the walls and are absorbed by other patients. Hospitals should be built with walls, floors, and ceilings as little porous as possible, and with facilities for perfect ventilation and purification.

A strong healthy man, full of the vigour of life, diffuses an atmosphere of health around him. His presence is a spring of life. The touch of his hand has an invigorating power. If he is friendly and sympathetic, and has the will as well as the power to help others, his influence is very marked. Physicians who have a vocation to heal the sick are successful, whatever their mode of practice. Allopathy or homœopathy, large doses or small doses, benefit the patient if only administered by a doctor in whom he has confidence-and this confidence is the perception of relief One doctnr can do more with a look, a 
smile, a tone of the voice, an encouraging word, with the com. munication of the subtle aroma of life to a patient, than another with any amount of medical science and skill. What is called mesmerism, or animal magnetism, is merely the conscious and definite voluntary direction of this life-force to a special end.

And all mental and moral power appertains not to matter, but to life. No matter, and no combination of matter, can feel, or think, or love. Love is life-a vital emotion. Take from the highest organisation we know - the human body-its life, and we have a mass of inert matter which quickly passes into decay. The force that presided over its formation and growth-the force and intelligence which placed every atom, shaped every organ, and presided over every function is there no longer. The matter, left to itself, yields to the ordinary material forces which life had held at bay, and the wonderful human body speedily becomes air and ashes. Life in its full power, presiding over the material organism, is health. Enfeebled life, struggling painfully against the tendencies of every material organism to change and decay, is disease. The defeat and banishment of life from the body is death.

A vigorous life-force, acting upon or through a fine and pure organisation, gives us the highest style of man. This force is radiated and apparent in his looks, actions, words; and still more, perhaps, is that subtle effluence which we liken to magnetism-that power by which the serpent fascinates the bird, and man awes and commands brutes and men. There are men "born to command"-men who have a wonderful power to control by their own wills the wills of others. They may not have physical power, or even high intellectual qualitiesbut they have a life-force which not only controls their own organism, but takes hold of the lives of others. They are the natural leaders of men. Women have this power over men, and men over women. A man so gifted with strong vitality, passionate, and unscrupulous, is one of the most dangerous 
of animals. A woman with no conscience, and great powers of seduction, may be more dangerous.

In the exercise of the mesmeric power the operator wills to use his life-force in a special direction and for a definite purpose. We all magnetise, or influence others unconsciously, but the experienced magnetiser uses his force consciously to quiet pain, to give strength, to produce insensibility, sleep, somnambulic trance, clairvoyance. The life-energy, aura, "fluid," or perhaps vibrations, is thrown off like electric or magnetic "currents" from the fingers, or radiates from the eyes. I have seen this act so powerfully as to produce a local paralysis, and many severe surgical operations have been performed upon patients magnetised into insensibility. The influence upon the mind and emotions is perhaps even more powerful than upon the body. The weak yield to the strong. People are controlled to good or evil. Love is, in a multitude of cases, only a magnetic fascination.

As every atom of matter has an atmosphere around it, a repulsive force, and a less comprehensible power of attraction, so animals and men have their spheres and forces. We speak of men and women being attractive or repulsive; and we attribute their power of attraction or repulsion to their looks, or manners, or conversation. These may correspond to the effect they produce upon us, but it is not these in many cases, if in any, which are the real forces which draw or repel us. An ugly man or woman may be very attractive and seductive-a handsome one may have no charm for us. There is something in either case beyond or interior to any manifestation to our senses. We feel the characters of people more than we judge of them by outward signs. A babe in arms will shrink away from one person, and go eagerly to another, when there is nothing in their looks or actions to justify the choice. There are persons whose mere presence is delightful to us or the reverse, and we can give no reason for our feeling. We feel 
ourselves drawn to some, and driven from others. The outward appearance corresponds to a great extent to the inner life or character; but not so much as to prevent our often being deceived in our judgment of persons; while the feeling of them in those who have such impressibility, is seldom mistaken. We all have, more or less, these sympathies and antipathies. There are names for them in all languages.

The lower animals have many of the most mysterious powers of life. They have clairvoyance, prevision, perception of character, powers of fascination, or magnetic influence, and intuition, or, as we call it in them, instinctive perception, or consciousness, of the most remarkable character. Bees, birds, fishes, beavers, and probably a great many animals we are less acquainted with, have interior, or what we call spiritual powers, which many find it hard to allow to man; as if he were less gifted than the lower orders of creation. That his gifts are marred and disordered is evident enough. What should be universal are exceptional and rare ; but they still exist in form, and sometimes in development. The bee, wherever you may carry it, goes in a straight line to its hive. There are men similarly guided. Migratory birds must be clairvoyant. Human beings have sometimes the power of seeing clearly what is going on hundreds or thousands of miles away. Animals adapt their dwellings to the temperature of a coming winter, and foresee calamities which endanger them. Some persons have the gift of prophecy, or the faculty of second-sight, though all the scientific men in the world cannot tell what weather it will be next Wednesday. A sealed letter, a lock of hair, or other relic, conveys to some very sensitive persons the revelation of the appearance, character, and even the events of the lives of those they have never seen, or even heard of. The somnambulist reveals the most secret thoughts and concealed propensities of persons. Knowledge of the distant, the future, and of that which cannot be known by ordinary methods, can 
come only in two ways. It must be the result of some power of the soul or life quite beyond our ordinary senses and means of knowledge, or it must come to us as a revelation from intelligent beings, gifted with higher powers, or more extensive means of observation. Both means may co-exist, but it is not, I think, unreasonable to believe that some persons may have faculties, which, however mysterious and inexplicable, are still possessed by the lower orders of the animal creation.

The Human Body, as I shall attempt to show in the succeeding chapters of this work, is a wondrous mechanism, moulded by the conscious soul to be its instrument during this primary stage of existence. The greater part of the body is merely an instrument of locomotion. If we cut off both legs and both arms, more than half the weight of the body, the life remains intact. Heine, one of the finest geniuses, lay on his bed for years with his whole body paralysed-but his spirit bright and strong. The decay of the body from disease and old age is not, in many instances, accompanied with decay of the moral and intellectual powers. Life retires to its citadel, and the spirit seems to gather vigour as the body dies. There are also a multitude of instances to prove that the force of the mind, its active powers, are not in proportion to the strength or the nourishment of the body. Blood goes to the brain, brain matter is renewed; but the brain can work on very small quantities of nutriment. And there is reason to believe that the nervous power is sometimes kept up by the absorption of finer elements of life than our common food supplies. There may be a nerve atmosphere or aromas of spirit nutriment of which we have little conception.

It is certain that the intellectual work of the world does not depend, either in quantity or quality, upon the quantity or quality of our food. The greatest thinkers have often been men of small appetites, living upon the simplest and sparest diet. And as to the quality of thought or intellectual work, it 
will not be pretended that works of the highest genius consume more blood and therefore require more food than those of the most ordinary character. Every one who has attended to his intellectual operations must be conscious that fasting even to bodily weakness is often accompanied with great clearness and vigour of the intellectual powers. Fasting has, from the remotest ages, been considered favourable to the activity of the spiritual life. There is abundant evidence that in some cases the soul has been able in some mysterious way to sustain the strength of the body. It is beyond a doubt that many persons have lived for months and years upon no more food than is required by hibernating animals; just as it is beyond a doubt that frogs and toads are sometimes found alive imbedded in solid rock-hard limestone or marble, where they must have remained, without nutrition or waste, for an unknown but immense period.

Remove the bones and muscles, the organs of nutrition, and the blood vessels and nerves that feed and govern themremove so much of the brain as presides over bodily functions, and how little matter of any kind remains to the soul! Destroy sight, hearing, taste, smell, and the whole sense of feeling; yet the soul or spirit, the real life of man, remains. The wonderful faculty of memory, all the powers of thought, imagination, will, love; all that constitutes the individual man, with all his faculties, remains, related, perhaps, to a few ounces of brain, 95 hundredths of which is water, and the rest albumen and fatdry, it is a pinch of grey dust. I must be excused from believing that such matter constitutes me what $I$ am conscious of being; and that when this matter is dust, or becomes part of a worm, a vegetable, or another human being, I shall exist no longer. I use this matter, but this matter is not ME.

If we can see without eyes, hear without ears, feel without contact or material proximity - and there is abundant evidence that we can, in some cases, do all this-it follows that the real 


\section{Human Physiology.}

life of man is not dependent upon, but quite superior to, his bodily organisation. Accordingly we have a vivid dream-life in sleep, and in the deepest trance and most perfect insensibility of the body, the mind sometimes exercises its highest powers. There is also abundant evidence that the spirit of man-the intelligent life-force which uses matter, or the forces which impress us as matter-exists after the death and decay of the body; exists with all its powers and faculties, and with some striking advantages, particularly in clearness and scope of vision, being all clairvoyant, and in a facility of locomotion which amounts almost to the annihilation of space, or a modified ubiquity. Spirits in the body sometimes have power to perceive the thoughts and feelings of others, and know the distant, the past, and the future. All spirits out of the body probably exercise these faculties habitually, and may have others of which we have no conception. Our life in the future, in its forms, actions, and senses, may differ as much from our present life as the butterflies or dragonflies differ from the caterpillars or grubs which produce them. The outer worm-a greedy, sensual, ugly, creeping thing-dies; and from this shell emerges a lovely winged creature, gorgeous as a rainbow, with thousands of eyes, and the most delicate appetites and senses.

The immortality of the life of man, and its frequent freedom from and final independence of the laws of material earthly existence, has been in the interior consciousness of all mankind, in all ages of the world. The only way of accounting for this, is that it is true, and a conscious truth-a fact implanted in the mind of man. It is also supported by abundant evidence, for in all ages of the world, in rare but still sufficiently frequent instances, those who had departed from the earthly existence have been able to give to their friends the assurance that they still lived, and that, therefore, we are not deceived by our prescience of a future existence, nor mocked with our

"Longing after immortality." 
In this, as in all things, attractions are proportional to destinies. Men desire, hope for, and believe in a life beyond the graveand this allone would prove its reality. But there are abundant proofs besides-proofs which have been sufficient to convince the most sceptical infidels, the most bigoted and fanatical of materialists.

The very nature of man-the scope of his intellectual powers - the utterly unsatisfying character of his earthly existencethe vast number of things he knows but in their beginnings, his ignorance of a thousand things he wishes to comprehend, his partial achievements and his boundless aspirations-all assure him that this is but the beginning, and is by no means the end of his conscious existence. Above all, man has proot of immortality in his wish to know more and more of that Infinite, All-Pervading Life in whom we live, and move, and have our being.

The universe is one. It comes from the same source, is governed by the same laws, and is pervaded by the same Infinite Life. I see no escape from this conclusion, and I cannot comprehend the condition of the mind which can come to any other. The whole universe, or all I know of it, seems to me the thought of a thinker, the design of an artist, the work of an architect, the creation of an Intelligent Power, of which I can only say it must be, as Cause, equal to the production of all $\mathrm{I}$ am and all $\mathrm{I}$ can see in the world around me. If you say this world, the whole universe, all I see, and admire, and love, is but an illusion of my senses; then I, who am capable of such illusions, am a being all the more wonderful, and I did not make myself. I can make admirable things, but life is far beyond me. I can make telescope, microscope, steam-engine; but not a fly, not even a worm. I and the worm equally require for our construction the wisdom and power of the Almighty.

Half the work for man is done when he can really believe- 
can distinctly realise-God and Immortality. Noblesse oblige. The son of a noble father -the daughter of a pure and highsouled mother-should be worthy of their parents. But men who derive their life from God should be God-like. The heir of a great estate feels its dignity and responsibility. What, then, should be the dignity of children of God and heirs of immortality? It is quite impossible that men who truly believe in such a relationship and such a destiny can lie and cheat, defraud and oppress, destroy themselves by low vices, or enslave their fellow-creatures, and produce all the evils and miseries I have shown to exist in the centre of the highest civilisation. When men come to have faith, all else will come to them. When men truly believe in God, they will practically recognise the brotherhood of humanity. When they really believe in an immortal existence, earth will become the vestibule of heaven.

Every view of the life of man is incomplete which does not include the phenomena of what we call the supernatural and the miraculous. It has been a fashion with some people who consider themselves educated and enlightened to deny that any event ever took place which was not in accordance with the laws, or usual operations, of nature. Others admit that such things occurred two or three thousand years ago, but have entirely ceased for some eighteen centuries. Really enlightened people know that what are called supernatural, or miraculous, events have been witnessed in every age of the world, and are at this day of frequent occurrence.

Under the constant action of gravitation all ponderous bodies fall to the earth; but heavy substances, and especially the bodies of men and women, have often been raised into the air, and sustained there by invisible agencies-forces of which we have no knowledge, and which we call super- or preter-natural. Of these phenomena there are scores, perhaps hundreds of well-authenticated instances, and many living witnesses. Gra- 
vitation is suspended; a man or woman is seen standing in the air, or gliding through it, as all, perhaps, sometimes dream of doing. Heavy articles of furniture rise, and are sustained in the same manner.

In all ages and nations of which we have records, the ghosts or spirits of the departed have appeared to the living. They have been seen, heard, and felt by so many persons, that the testimony to the reality of such appearances is overwhelming.

The power of spirit over matter has been shown in all miracles; in healing the sick, making the blind to see, the deaf to hear, and the sudden change of material conditions, as the instantaneous healing of abscess and cancer; and it has been shown no less, and in our own day, by the suspension of the action of heat, as well as gravitation. Many living persons in England, of the highest intelligence, have seen the human body take on a condition in which fire would not burn it; when an incandescent coal would not even singe the skin or burn a hair.

Facts that prove the power of spirit over matter and force are found not only in the Holy Scriptures, but in the history of the Church and the Lives of the Saints, and such facts, presented to the senses, or received upon the testimony of honest and intelligent witnesses, have converted great multitudes of people in Europe and America from materialism to a belief in immortality; and this seems to be the chief intention and use of all supernatural manifestations. Whether the spirits making these manifestations are good or evil, whether they speak truth or falsehood, they prove to us the great fact of a spiritual existence. 


\section{PART THIRD.}

THE HUMAN BODY.

\section{CHAPTER I.}

\section{BONES AND MUSCLES.}

The Human Form our highest Ideal-Symmetry - The Vital System-The Spine-Cranium - Thorax-Pelvis-Extremities-Mechanism of Joints -Protection of Brain and Organs of Sense-Muscles of the Neck, Face, Eye, Fore-arm - Tendons-Nervous Control of Muscular Action, Habitual Movements-Form of Muscular Contraction.

THE body of man is the sensible or material outgrowth of his soul or life. It is the visible and palpable extension and manifestation of his being, and the medium of his ordinary communication with the material world and his fellow-men.

Every faculty of the soul has its bodily organ, and the assemblage of these organs constitutes the human body. We call the brain the organ of the mind, but the brain, by its nervous extensions, pervades the whole body; and the mind, soul, or life, therefore, lives in every part. The whole form of man is therefore the form of his soul or spiritual essence.

And this form is, in its masculine and feminine types, the most noble and beautiful of which we have any conception, so that we readily believe that "God made man in his own image," for we have no higher ideal. The most beautiful objects in art are representations, in statues and paintings, of 
the "human form divine." No animal form approaches it in dignity and beauty. Compare the form of a beautiful woman with all beasts, birds, and insects; and all together, graceful and exquisite as they may be, fall far below its admirable proportions. For the beauty and expression of the human countenance there is no comparison. The finest and most intelligent animals fall infinitely short of it; and those animals supposed by some to be most nearly related to man are entirely wanting in the characteristic expression of humanity.

Every one has a more or less perfect ideal of the highest masculine or feminine beauty. Such ideas may be perverted by custom or fashion, as in respect to cramped feet in China, or flattened heads among some tribes of savages. Flat noses are said to be popular in Africa. These are exceptional eccentricities of taste. Men generally know a handsome man or a beautiful woman. In an assemblage of thousands there is scarcely a dissenting voice to such general recognition. This beauty consists of elegance of form and perfectness of proportion. The head must have its proper size as well as shape, and be well set upon a graceful neck, neither too large nor too small, too long nor too short. The arms and legs must also be of the exact length required to fit the body; tapering in graceful curves to hands and feet, which must also be of exquisite proportions. Each part must fit every other; and the standard is only to be found in nature, and our own conceptions of beauty and harmony in form.

The human body is symmetrical, as are the bodies of beasts, birds, and insects, but this symmetry does not extend to the nutritive organs. The bony skeleton of man, his brain, spinal chord, and the nerves which belong to it, and the muscles they control, have two halves. In Fig. I 6 the line may be seen which separates the brain, cerebrum, and cerebellum, into two hemispheres, and the same line divides the spinal column, and the two halves of the body. We have therefore the organs of 
sense as well as motion in pairs- two eyes, two ears, and the nose and tongue, organs of smell and taste, are divided in their centres, and served by pairs of nerves, so that a man may
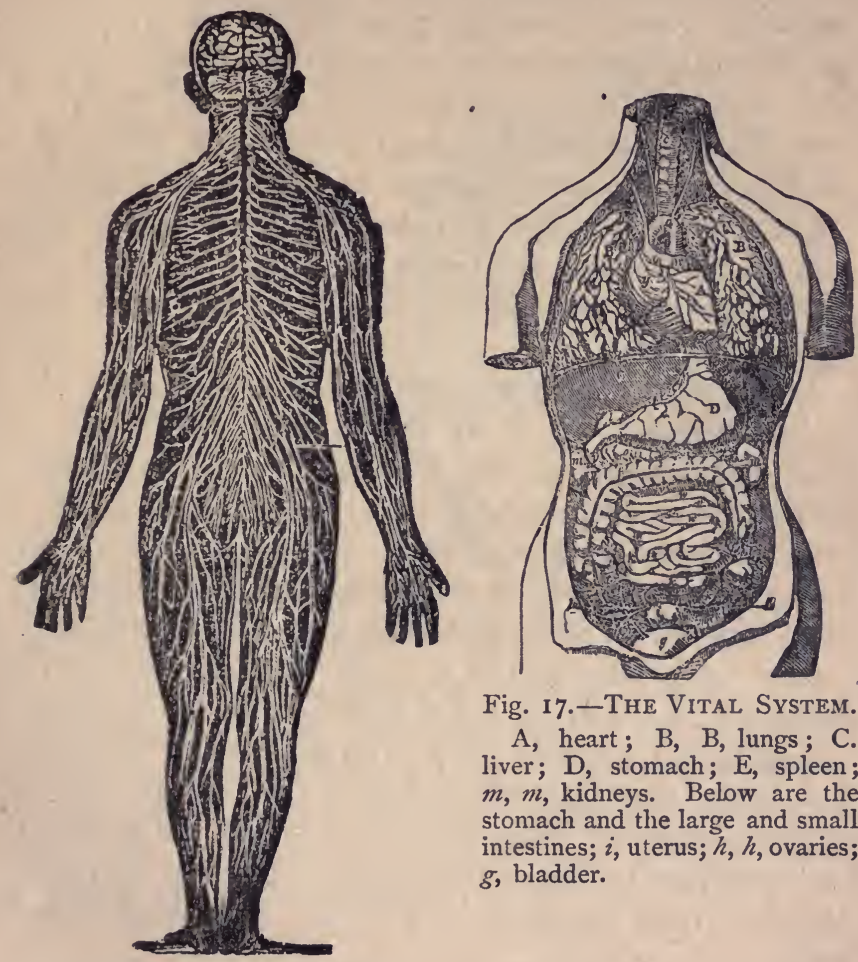

Fig. 17.-The Vital System.

$A$, heart ; $B, B$, lungs ; C. liver; $\mathrm{D}$, stomach; $\mathrm{E}$, spleen; $m, m$, kidneys. Below are the stomach and the large and small intestines; $i$, uterus; $h, h$, ovaries; $g$, bladder.

Fig. 16.-Nervous System.

be able to smell with only one side of his nose, and taste with only one side of his tongue, as he sees with one eye, or hears with one ear, or has the sense of feeling only in one half of his body. 
With most of the internal organs it is different. The symmetrical body is seen, in Fig. I 7 , to be filled with organs as unsymmetrical as an oyster. The heart lies across the centre of the body, and though it has its right and left auricle and ventricle, neither it nor the great arteries and veins within the body can be considered as having symmetry. The lungs have two lobes on one side, and one on the other. The liver fills a large irregular space on the right side, the spleen on the left, while the stomach, small or large, according as it is full or empty, lies across the centre, and the abdomen is filled with the convolutions of the small and large intestines. The kidneys, bladder, and the organs of generation are, however, symmetrical.

In the human body we have, first, a bony frame-work or skeleton, which gives it its general form, proportions, and strength. A spinal column of twenty-four cylindrical bones, with processes which make a bony canal for the spinal chord, or tail-like extension of the brain. This column is a marvel of strength and flexibility. Between the bones are elastic cushions of cartilage, which protect the brain from jar. These cushions are constantly lubricated by a glairy fluid secreted from the blood for that purpose. The bones are bound together by strong tendons, so as to allow a certain amount of motionhow much, those can tell who have seen the performances of gymnasts and "india-rubber men." And the movements of every bone in the spine are made by numerous muscles, placed with the nicest art to make one bone move upon the other.

At the top of the spine one of its bones and its processes have expanded into thin double plates so as to form the skull and protect the brain. Eight bones are formed into an eggshaped box, and, with hard and soft membranes, and the scalp and hair, protect the seat of sentient life. The brain as it lies in the skull is well shown in Fig. 18. The upper part of the 
skull is removed, and the dura mater, or tough membrane, raised to show the hemispheres and convolutions of the cerebrum. The brain fills the head to a line passing around it across the eyes and the opening of the ears. The face, it will be observed, occupies only an angle of the profile, and is made up of the nose, cheekbones, and upper and lower jaws.

Joined to twelve of the vertebræ, or spinal bones, are the ribs which, with the breast-bone, form the chest or thorax, which contains the heart and lungs, and which should expand and contract freely at every breath. At the lower end of the spine it forms, with two large, strong, thin bones, the basin or pelvis,

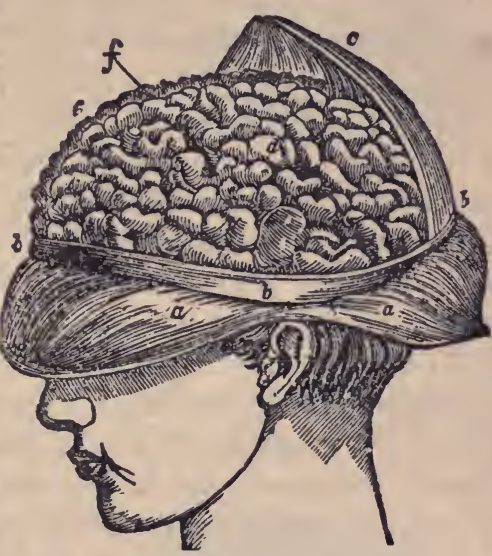

Fig. 18.-The Brain Exposed.

which contains the viscera of the lower abdomen. This is considerably larger in the female than in the male, which gives her greater breadth at the hips, a form very necessary to the processes of maternity. Shoulder blades are loosely attached to the upper ribs, which are braced by collar bones, joined to the breast-bone. The large bone of the arm is united by a shallow ball-and-socket joint to the shoulder blade, the two bones of the fore-arm join this, in a compound joint, at the elbow; eight small bones form a flexible wrist, and then come the nineteen bones of the hand, thumb, and fingers. Similarly, the thigh-bones are united by deep ball-and-socket joints to the pelvis; the leg-bones on each side by a hinge-joint to the thigh, and a more flexible one to the foot, which is an arch of bones, cartilages, tendons, admirably perfect in contrivance and mech- 
anism. The knee-joint is furnished with a bone unconnected with any other, the patella, which protects, strengthens, and beautifies the joint. There is also a disconnected bone at the root of the tongue.

I do not purpose to go fully into the anatomy of the human body, giving only so much as may be necessary to illustrate its physiology; but there are a few points of great interest in connection with the bony skeleton, with its cushions and stays, its light firm rods, broad strong plates, elastic arches, and general union of firmness and flexibility. Observe the number of movements that can be given to the lower jaw; the great sweep of the shoulder joint; the rotation of the arm notwithstanding the firm hinge-joint at the elbow; the flexible curvings of the wrist; the admirable hand, with all its capabilities. The brain is enclosed in a perfect box; the eyes have deep and very hard bony orbits to protect them; the nasal bones guard the organ of smell, and give to the face its most important feature; while the organ of hearing, not the external ear, is completely embedded in the centre of one of the hardest bones in the body. Consider then the hip-joint, where an almost round ball on the thigh-bone is bedded in a deep cup-like cavity, held there by a strong round ligament, held again by a strong covering capsule, and held and moved by a great mass of the strongest muscles. in the body; yet I have seen a girl of fifteen, standing gracefully erect on one foot, raise the other above her shoulder, till, without bending her body or touching her leg with her hand, she drank from a glass which she had placed upon the sole of her foot, and this performance, done apparently with perfect. ease, was as graceful as it was a wonderful exhibition of flexibility and trained muscular power.

The bones are moved by muscles. A muscle is a collection of small fibres of flesh in a sheath. Each fibre is made of numerous smaller fibres, which are composed of cells or disks, and it is the widening or contraction of these disks which 


\section{Human Physiology.}

shortens the whole muscle, which becomes thick in proportion as it shortens, as may be seen in the contraction of the biceps. Butchers' meat is composed of muscle, intermingled with fat, blood vessels, nerves, and connective tissue. There are about five hundred muscles in the human body, to carry on all its movements. A large number are employed to hold the head erect, and give it its various movements. A section of the neck (Fig. 20) shows all these muscles cut across, and sections of the fore-arm or calf of the leg would show a similar number.

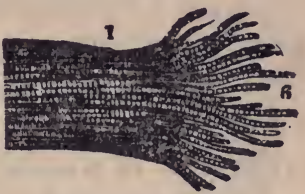

Fig. 19.-MUSCULAR FIBRE, dividing into fibrillæ, magnified 300 diameters.

Many of these muscles are in constant action, conscious or unconscious. The heart, a collection of very powerful muscles, beats on from the first signs of life in the foetus till death-no

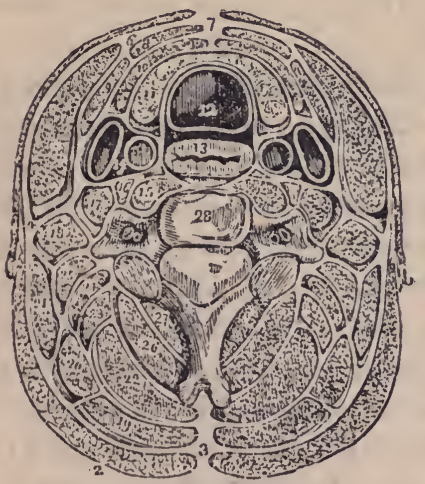

Fig. 20.-TRANSVERSE Section of THE NECK.

12. Trachea. 13. Esophagus.

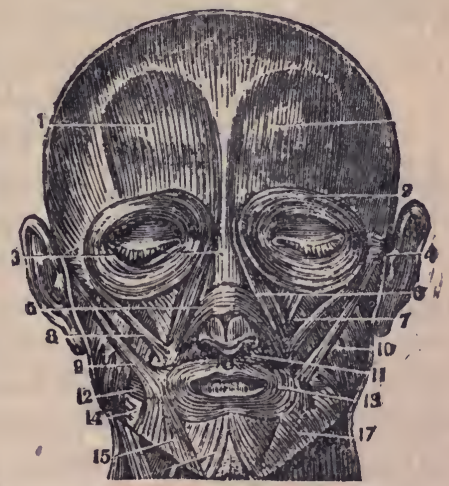

Fig 21. -Muscles of the Face.

pause, no rest. If the heart beat only sixty times a minute, its beats in a man of seventy count over two thousand millions. 
So with the muscles that expand the lungs. No rest for them. Day and night, waking and sleeping, the ribs must rise or the diaphragm be drawn down, or both, until the last breath has left the body. In sitting or standing many muscles are in constant motion, in our unconscious balancing.

Every movement, every expression of the countenance, is made by muscular action. Smile, frown, sneer, and every expression of hope, love, fear, or hate, is produced by the contraction of muscular fibres, under the influence of the nerves of motion, which receive their impulse from the brain, the immediate organ of the soul. This is the natural language of feeling and thought, and the same everywhere. There are ring-like constrictor muscles to close the mouth and eyes, muscles to open them, to elevate or depress the corners of the mouth, and compress the nose-to make all sorts of faces and grimaces. There are muscles to open and shut the jaws, and give them all their movements. The tongue is a mass of very active and powerful muscles.

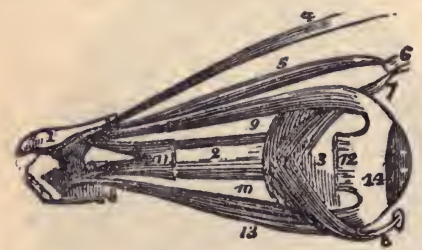

Within the orbit, or bony case, of the eye, are seven muscles. One raises the eye-lid, the other six give the ball of the eye all its movements. In Fig. 22, 9 turns the eye up, 13 draws it down, Fig. 22.-Muscles of THE Eye- 12, cut away, draws it to the BALL, from outer side of right orbit. right, 2 to the left; and their united action suffices to hold it in any position: but to perfectly adapt the eye to all the requirements of vision, it needs to be rotated a little on its own axis. The short muscle 8 draws it one way, but for the opposite movement a longer one is required; and here, as I once heard a lecturer say, "I will show you a very ingenious thing on the part of the Deity." The muscle 5 becomes tendinous and passes through a pulley at 6 , and, becoming again muscular, goes back and is attached to 
the hinder part of the eye-ball. There are dozens of adaptations in the eye itself far more wonderful than this; but we are struck with the simplicity of a contrivance so like what we should make ourselves.

The elbow-joint, as any one may observe, is a perfectly stiff hinge-joint, yet the hand can be turned more than half-way round. It is managed in this way. One of the two bones of the arm is fixed in the elbow-joint, the other equally fixed at the wrist-but each has a free end which revolves in a band on the other. Fig. 23 shows the two muscles by which the hand, which naturally lies on its back, can be turned over so as to lie on its palm.

It was necessary to the elegance and beauty of the body that the ankles and wrists should be small, and neither feet nor hands loaded with muscles; yet fingers and toes must have many powerful muscles to accomplish all their motionsmuscles for every joint of every finger. To accomplish this, the muscles are placed in the arm and

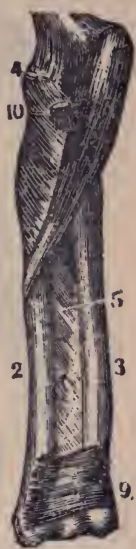

Fig. 23. Pronators OF THE Fore-ArM. leg, and they are connected with the bones they are to move by slender white cords, playing in sheaths, called tendons. These tendons at the ankle and wrist would pull up the skin, and spoil the shape of the limb, but that has been prevented by confining them with a strong tight band, as seen in Fig. 24. They also divide on the knuckles to avoid being pulled down on either side.

On the inside of the hand is a still more curious arrangement. The tendons of the muscles, which move the second joint of the fingers, divide to let the tendons of the flexors of the first joint pass through them, as shown in Fig. 25, where also may be seen the curious arterial arch, which gives off arteries for the four fingers. 
But the muscles have of themselves no power of motion. They can be made to contract only by some stimulus, or exciting cause. Every muscle is supplied with nerves of

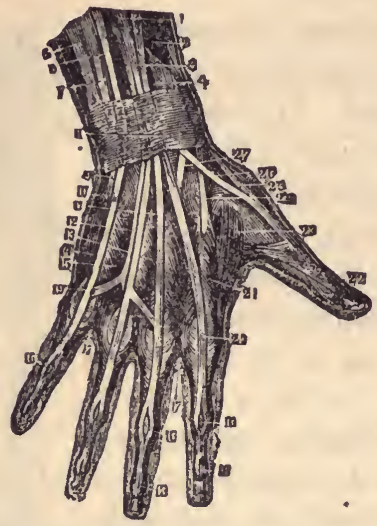

Fig. 24. -Tendons of the Back OF THE HAND.

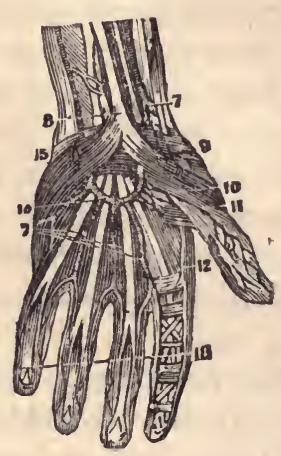

Fig. 25.-Tendons AND ARTERIES OF THE HAND.

several kinds-nerves of nutrition, which preside over the circulation of the blood, and the selection and deposition of the matter required to take the place of that destroyed by muscular action; nerves which direct the absorbents to remove waste matter; nerves which carry to the brain a sense of the muscular contraction-nerves which excite, direct, and govern that contraction.

Thus the body of every muscle is full of nerves, reaching. every fibre and every microscopic disk, giving off its brain influence apparently from the loops of nerve as shown in Fig. 26, among the muscular fibres. A nerve in my toe informs. my brain that a mosquito has inserted the lancet of his proboscis; another nerve carries an order to one or several muscles. of the foot to expel the intruder. Scores of these telegraphs are 
in constant operation, acting habitually, without effort, and often without our consciousness.

Electricity or galvanism, applied to the nerves of a man or animal, for a short time after death, will excite muscular contractions. Does it excite the nerves to action or the muscles? If the brain acts by vibrations propagated through the nerves, electricity may excite similar vibrations. The soulthe conscious $\mathrm{ME}$ - the man-wills to rise up and walk; and this will sets brain in motion, nerves, thousands of nerves, in action, and hundreds of muscles, and myriads of muscular

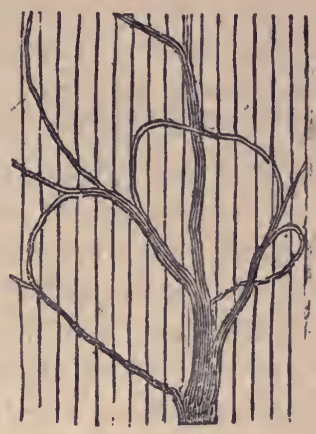

Fig. 26. - TERMination of Muscular Nerves. fibres contract, undergo a series of contractions, just the amount required to carry on all the complex movements of rising and walking. Or, take the case of a pianist performing a piece of music. The eyes receive the impression of the notes ; the melody and harmony are conveyed to the mind; brain, nerves, muscles of arms and hands. are brought into wonderfully rapid action; and the nerves of hearing carry back to the mind the result produced by all this complicated apparatus.

These actions of nerve upon muscle become habitual. We walk, work, play upon the pianoforte, without any conscious. effort. We can think, or listen to conversation, or read a book, and play, and even improvise music, at the same time. This power of habit is not in the muscles; they contract only as they are excited by the nerves to do so. The nerves are the telegraphs of the will-power. Will can no more be the act of the grey globules, or white fibres of the brain. Matter does not think. Cerebral matter-albumen, fat, and water,-does not secrete tragedies and operas. If it 
does, what is the force that determines and governs the serretion?

The power of muscular contraction is very great. Nearly all the muscles act at a great disadvantage. To raise twenty pounds with my hand, bending the elbow, the flexor muscles of the fore arm attached to the lever so near the fulcrum and so far from the weight, must exert a force of about $200 \mathrm{lbs}$. To hold a heavy weight out at arm's length, the muscles of the shoulder must contract with an immense force. Examine these muscles-you will find bits at the butcher's-and you see only a flabby mass of fibres, three-fourths water, with fat and membrane. The thickest muscle in the human body, the gluteus maximus, when perfectly dried, is like a sheet of paper. The whole force is in the attraction of microscopic disks for each other, excited by nervous action. That the intensity of this force is in proportion to the nervous or cerebral excitement is shown in the extraordinary strength of maniacs, or men acting under sudden excitement. In some cases of disease also, the spasmodic muscular action is long-continued and frightful. In these cases, it seems out of all proportion to the food eaten, or the bodily condition. The mind controls the body in ways utterly unaccountable by the chemical and materialistic physiologists. The force and rapidity of muscular action in insects has been noticed in Part II. A fly can keep up with a racehorse, but his muscular contractions must be thousands of times more rapid. 


\section{CHAPTER II.}

\section{BRAIN AND NERVES.}

The Brain-Form and Structure-The Ganglionic Nervous System-Modeof Nervous Action-Complexity and Mystery-Origin of NervesThe Brain the Organ of the Mind-Has each Faculty of the Mind a distinct Organ?

THE brain of man does not differ much in appearance from the brains of other animals. You have a soft substance, with little more consistence than cream; white in its interior, and gray, or ash colour, on the exterior. It is held in place by delicate membranes, and the surface is increased by convolutions, as shown in Fig. r8. The brain is a double symmetrical organ, each portion on one side of the head having its counterpart on the other, so that injury or paralysis of one side does not necessarily suspend its functions.

The best idea of the general structure of the human brain is given by a longitudinal section through its centre as shown in Fig. 27. The upper and whiter portion is the cerebrum, 2 I

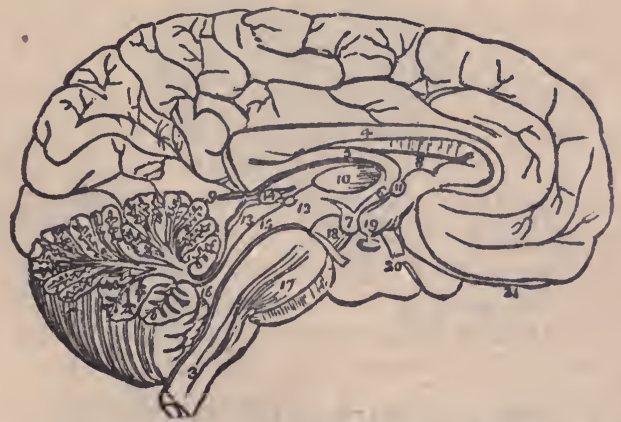

Fig. 27-Longitudinal Sećtion of the Brain.

Inner surface of left hemisphere and divided cerebellum, showing the arbor vitæ. 
marking the position of the optic nerves; the darker portion, with its fern-like form, is the cerebellum, or little brain, lying at the lower back part of the head; and the stalk-like portion from which the brain seems to expand like a fruit, is the medulla oblongata $\left(\mathrm{I}_{7}\right)$, and the beginning of the spinal chord (3).

No inspection of the brain could give us any idea of its functions. One can form no idea of the uses of any part of it from its form or appearance. There is no perceptible division into phrenological organs. We can trace the nerves of sight, hearing, smell, taste, feeling and motion, into the brain; we know that when this nervous connection is interrupted, sensation and motion are destroyed. The brain is proved to be the central organ of conscious life; but how it is so does not appear from its structure. A microscopic examination does not throw much light upon it. Brain matter may be seen in Fig. 28, a mixture of nerve tubes, blood-vessels, and cells or globules, cells of curious forms, but showing nothing which would give us any idea of the machinery of thought, will, memory, or imagination, in

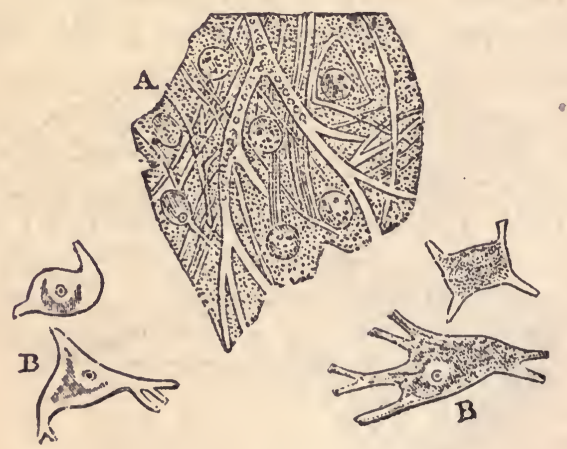

Fig. 28. - Brain and Nerve Matter.

A, ganglionic globules, nerve tubes, and blood vessels; B, B, globules from crus cerebri. 


\section{Human Physiology.}

this creamy stuff, which is 95 -1ooths pure water, and the rest tubes, membrane, cells.

The nerves, which seem to be but extensions of the brainnerve matter carried into the remotest parts of the body, are soft white tubes, às shown in Fig. 29, filled with cellular matter (3), and terminating in loops, both in the muscles, as already shown, and in the organs of sensation.

Press on a nerve or divide it and its function ceases, but a divided nerve may re-unite. It is sometimes necessary in surgical operations for neuralgia to cut out a piece of the nerve. A

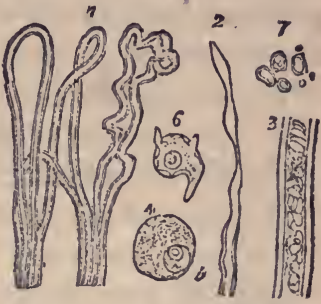

Fig. 29. -Minute NerVOUS STRUCTURE.* knock on the head will produce unconsciousness and general paralysis of the voluntary muscles. The heart continues to beat, the lungs expand, all the involuntary, vital functions go on, for they have a nervous system of their own in the body-the nervous system of organic life, or ganglionic system. The brain, though the seat of consciousness, thought, and volition, is not necessary to the life of the body. The bodies of infants are sometimes formed without brains. A turtle lives for days with its head cut off. The system is built up, and all its unconscious interior work-of nutrition, circulation, secretion, excretion-carried on by the

* Fig. 29 represents the microscopic elements of the nervous structure. I. Mode of termination of white nerve-fibres in loops ; three of these loops are simple, the fourth is convoluted. The latter is found in situations where a high degree of sensation exists. 2. A white nerve-fibre from the brain, showing the varicose or knotty appearance produced by traction or pressure. 3. A white nerve-fibre enlarged to show its structure, a tubular envelope and a contained substance. 4: A nerve-cell, showing its composition of a granular-looking capsule and granular contents. 5. Its nucleus containing a nucleolus. 6. A nerve-cell, from which several processes are given off; it contains also a nucleated nucleus. 7. Nerve-granules. 
nerves of organic life. The brain and its nerves of sensation and motion, and all its powers of thought and feeling, are built up. and nourished by, and rest upon, the nervous system of organic life, which has its ganglia, little brains, or vital centres near the heart, the stomach, in the pelvis, and along the spinal column, communicating everywhere with the nerves of the cerebrospinal system.

The nerves of organic life control all the more important processes of the bodily life. They preside over the

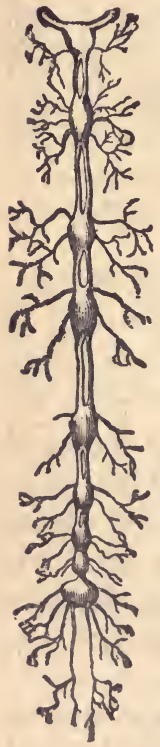
digestion of our food, the formation and circulation of the blood, its purification by the removal of the waste matter of the system, the action of liver, kidneys, and the myriad glands of the intestines, skin, and lymphatic system. The nervous systems of insects (Fig. 30) have a close resemblance to the human ganglionic system.

Prick the skin anywhere with the finest needle, and you touch nerves of sensation. The blood which follows the prick shows that you have pierced blood vessels, and the organic nerves everywhereaccompany these, and preside over their functions. It is the same in the whole interior of the body, only that nerves of sensation are not so fully distributed where they are not required; but the entire body is a mass or network of nerves, so that if all other matter were destroyed, the nerves would perfectly define the form of every organ. This is true also of the veins and arteries.

Fig. 30.

Nervous

SYSTEM oF

INSECTS.

The mode of action of brain and nerves is but little understood. We observe certain phenomena, but do not know how they are accomplished. The action of some force at the end of my finger makes an impression of pain, or roughness, hardness, smoothness, which impression is conveyed, somehow, by the nerves to the 


\section{Human Physology.}

brain; but how a very soft tube, filled with a milky fluid, can carry sensations of heat, cold, form, texture, pleasure, or pain, or how the brain can convert them into ideas of bodies, passes all comprehension. It is one of the mysteries of life. No more can we understand how the mind, through the medium of the brain, can play upon all the muscles of the body as an organist, pressing upon white and black keys, plays upon all the pipes of an organ. Another nervous action is also required. We must not only be able to contract a muscle, but to know how much it is contracted-to feel, and so limit and regulate, the action we produce. This may be a modified action of the nerves of sensation, and how nice this must be those know who have tried to walk on a rope or perform the more difficult feats of balancing and the lighter gymnastics.

In the complex nervous and muscular operations of speaking and singing, a great number of muscles are brought into action, and the nervous control of the small muscles of the glottis and vocal chords is so rapid and accurate as to enable singers to perform all the wonders of a cultivated vocalization, ind the mocking-bird to imitate all the birds of the forest, and all sorts of sounds beside, with unerring accuracy. And what are we to think of the composition and action of the nerves that carry to the brain and the mind every fine modulation of sound, quality of tone, intensity, pitch, and every shade of emotion or passion which the tones convey? What of the action of the optic nerve which conveys instantaneously the impressions of form, colour, light, shade, motion of the myriads of objects in a varied landscape? What of the sensitiveness of some olfactory nerves which distinguish all the scents of the gardens, kitchens, people, and animals of a large area? The shepherd's dog can pick out his master's sheep from other flocks; he can track his master, or even his master's horse; he knows the scent of every person and animal of his acquaintance.

In the distribution of the nerves of animal life, belonging to 
the cerebro-spinal system we have something like a reversed plant, its bulbous root the brain, its stalk the spinal chord, its branches given off at intervals and penetrating to every part of the body. But the spinal chord is formed before the brain, which may grow from it; or all may be formed together, by the inner life that directs the action of the nerves of the organic system. And if these nerves form, as they evidently nourish and sustain, the cerebro-spinal nerves, what forms them? We are at the end; we have no answer, except that they stand nearest to, and must have their origin from that mysterious force, property, essence, which we call Life. Here we cross the boundary line between matter and spirit, and we can have little doubt that spirit moulds matter, and acts upon it and through it. The action of spirit upon matter gives us all the phenomena of life.

It is not needful to point out the niceties of nervous distribution. Accurate anatomy is only needful for the surgeon. It is enough for us to have some general idea of the distribution and functions of the nervous system-and useful, perhaps, to know how little can be known of its mode of action.

There is no doubt that the brain is the seat of conscious sensation-that it is, in a certain sense, the organ of the mind. By it, and its antennæ, the nerves, we make all our observations, and receive all our sensations. We remember, we imagine, we combine our impressions and recollections, we think, calculate, contrive, invent. With the brain we love and hate; we believe, hope, reverence; we desire, dread, and have the emotions of pride, vanity, scorn, ridicule, joy, sorrow, conscience. But low a watery pulp, which people cook and eat, can become even the material instrument of all the faculties, sentiments, emotions, and passions of man, passes knowledge. We know, however, that a slight pressure on the brain will produce unconsciousness - that disease in the brain will produce loss of memory, loss of mental power, and every kind 
of mental derangement. In this life, in its ordinary phases, sensation, thought, memory, and will-all mental powers-depend upon the condition and action of the brain. The larger the brain, other things being equal, the greater the mental power. The finer the quality of the brain, the more delicate its organisation, the finer the quality of thought and feeling.

As the human mind is composed of a great variety of intellectual faculties, sentiments, propensities, it is natural to suppose that the brain is divided into as many distinct organs. There is no indication in the brain itself of such a division; but this does not prove that it does not exist. We refer our intellectual operations to the forehead; our higher sentiments to the upper part of the brain, our lower sentiments and propensities to the lower and back portion. If we can make any such division, there is no limit to it, and every distinct faculty must have its organ. If there is a portion of the brain devoted to the perception of form, and another to mathematical calculations, another to the perception of tones, etc., and if differences in the strength of these faculties correspond to the development of such portion of the brain, we have the basis of the science of Phrenology. If the brain, as a whole, is engaged in every mental operation, we can see why a man with a large brain should have more mental power than one with a small brain, but we cannot see why men should differ as widely as they do in character and intellect-why one should have a talent for music, another for mathematics, a third for painting, or poetry, or engineering. Division of labour, and a distinct organ for every distinct function, seems to be the law of life. But in almost everything we do, many faculties come into play, and there must be a combined action of many organs. There seems, therefore, to be a necessity for some combining and directing power-something which shall preside over, control, and direct, all the organs of the mind, as the mind or will controls the nerves and muscles-organs of voluntary motion. 
There must be a centre of consciousness, of the sense of personal identity, of will-of the unity of life which feels and governs our whole being.

It must be observed that the most intimate relations everywhere exist between the two great nervous systems - the cerebro-spinal and sympathetic, or the nerves of animal and

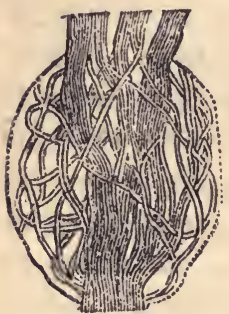

Fig. 3I. vegetative life. The latter are first in order, and build up the former. First, vegetative nerve matter; then blood and its circulation in vessels formed by these primitive nerves; then the formation of the nerves, spinal chord, and brain of the animal system. Fibres of spinal nerves mingle with the ganglia of the sympathetic; fibres are interwoven, and act upon each other. In this Ganglion of a way the emotions of the mind influence the Sympathetic action of the heart, the digestion, the action Nerve. of the liver, the secretion of saliva, milk, \&c., as we shall see further in considering the functions of nutrition, circulation, secretion, and excretion 
CHAPTER III.

THE FIVE SENSES.

Sense of Touch-Skin and Nerves of Sensation-Taste-Aided by SmellPapillæ of the Tongue-Uses of Taste-Smell-Odours-Powers of Smell in Men and Animals- Hearing-Phenomena of Sound-Structure of the Ear-Uses of Hearing-Sight-Structure of the EyeWonders of Vision.

THE soul of man, in this bodily life, holds its ordinary communication with the external world through the medium of five senses-touch, taste, smell, hearing, and sight. These are the usual, but not the only modes of receiving sensations or impressions of the objects around us.

By the sense of touch we receive sensations of heat, cold, and an agreeable, exhilarating, or uncomfortable and depressing state of the atmosphere, perhaps its electrical condition; of the qualities of the bodies with which we come into contact, as being gaseous, liquid, solid, hard, soft, rough, smooth, sticky, slimy; of the forms of bodies, and the texture and qualities which we cannot so well judge by sight. People judge of silk, woollen, and cotton textures, the edges of cutting instruments, and many things by feeling better than by sight.

Nerves of touch are thickly distributed in the skin over the whole body-in the true skin under its protecting scarf, the horny cuticle. 'There are thousands of nervous extremities in every square inch of skin over the entire surface, for the smallest prick causes pain; but the nerves are more numerous, and the touch more exquisite in some parts than in othersnotably on the end of the tongue, the lips, and the ends of the fingers. Take a pair of fine-pointed dividers, and you can distinguish the two points nearer together in such sensitive regions than on less sensitive portions of the body, as the arms or thighs. 
The ends of the fingers are most commonly used for touch. Here, to give a greater surface, or a better chance for objects to affect the nerves, the skin is thrown into minute ridges. Under these ridges of the cuticle the cutis vera, or true skin, rises in little cones or teats, papilla, which are alive with bloodvessels and nerves (Fig. 32). The nerves end in loops, as we have seen in the muscles, and they are so minute that the finest needle, or even the finest bee-sting, must pierce great numbers of them (Fig. 33). And every distinct fibre is capable of conveying an impression, or rather many kinds of impressions, to the brain, which has the power of forming, of these reports, a sensation and thence an idea of the qualities of the body examined. How delicate this sense may be, how many things can be done and enjoyed by the sense of feeling, they only can

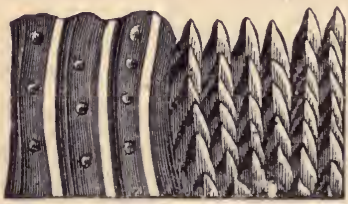

Fig. 32.-Pores and Papille OF THE SKIN.

On the left is a magnified view of the ridges of the cuticle, with the openings of the pores in their furrows. On the right, the cuticle has been removed, leaving corresponding rows of papillæ.

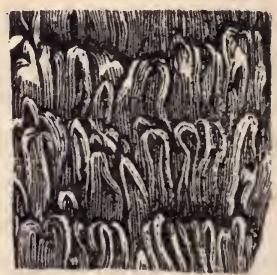

Fig. 33- - NERVES OF THE

Highly magnified view of the terminal loops of the sensitive nerves as they rise in the rows of papillæ.

know who have been deprived of other modes of sensation. The blind acquire a wonderful power of tact, and carry on trades, and accomplish processes which seem impossible. But bees build their cells and perform all the wonders of the interior of their hives in darkness-that is, they prefer dark- 
ness, and carefully wax over a window to the hive if it is left for any time uncovered.

Through the touch also we receive pleasures that seem to go much deeper than the forms and surfaces of objects. Our grasp- ings of hands, strokings, caresses, kisses, are all exercises of the sense of touch, or at least complicated with it. We show our affection, and we enjoy its manifestation, by contact with those who are pleasant to us; and the sense of touch rises to its highest power of sensation in the voluptuousness of amative embraces. But, in this case, there is something deeper than any ordinary exercise of the sense of touch. The entire nervous systems of animal and organic life participate when the lives of two individuals flow together in the most important function of physical life-the continuation of the species.

Touch is not only diffused over the whole surface of the body, but a sort of touch, or feeling of pleasure and pain, may be felt in the deep-seated regions of the viscera, for we feel not only in our mouths, but vaguely in our throats, stomachs, and intestines. And there seems to be no reason why we should not refer to this sense the comfortable and pleasant feeling we have in the use of our muscles when we exercise with vigour, and the languor of fatigue, or the pain of inward maladies. An inner ache of rheumatism, or gout, affects the nerves much like an external pinch or smart. If they do not belong to touch, we cannot exclude them from the sense of feeling.

Taste is a sense more special and circumscribed. It is confined to the mouth, throat, and nasal cavities, but centres specially on the tongue, and on the end and outer margin of that curious organ. A nauseous pill, placed on the centre of the tongue, and well back, may be washed down without being tasted. Still, I can often perceive a very distinct flavour in, and perhaps beyond the tonsils, or glandular bodies which help to form the hinder walls of the mouth.

The nose assists taste, or taste and smell are so blended 
that odours are perceived as flavours. If a man hold his nose tightly, and shut his eyes, he cannot, by tasting, distinguish brandy, gin, whiskey, and rum from each other. The moment the odour is permitted to enter the nose, the taste of each becomes perfectly distinct.

To enable the tongue to taste articles of food so quickly as to give pleasure in eating, or guard by disgust against swallowing acrid or impure substances, it is provided abundantly with

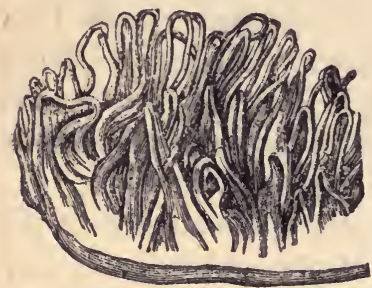

Fig. 34. - SMall Papille of

THE TONGUE; LOOPS OF BLOOD VeSSELS. nerves whose office it is to convey to the mind a sense of flavours. As a nerve of touch carries the sense of cold, heat, dryness, hardness, \&c., a nerve of taste carries a sense of sweetness, sourness, bitterness, and all the thousand modifications of flavour to be found in the vegetable and animal kingdom. These nerves are developed in papillæ on the tongue, as on the fingers, and the looped nerves, and looped blood-vessels attending and nourishing the nerves, make up the substance of these papillæ. The blood-vessels are shown in Fig. 34, as the nerves were in the preceding figure.

The uses of taste in warning us from danger are evident. But every natural function is attended with pleasure. All food natural and proper for man gives him delight through the sense of taste. Fruit, the most natural food of man, is the most delicious to the unperverted taste. The taste, however, in men, and even in some animals, may be educated and perverter. We learn to love things which were at first nauseous and disgusting to us. Men smoke and even chew tobacco. The excessive use of spices and condiments blunts the sensibility of the nerves of taste, and the corrupted sentinel lets the enemy pass into the stomach, and worry it into dyspepsia, while the 
whole current of the blood becomes tainted with the morbid products of an unnatural nutrition. All animals, in a state of nature, seem able to choose their proper food, and to avoid poisons.

Smell resides wholly in some large nerves spread over the inner surface of the nasal cavities. We draw in with our breath floating atoms of various bodies, odours; and a sense of their qualities are conveyed by these nerves to the brain and the mind. It is true that we also taste some strong odours; the molecules entering with the breath are caught by the tongue, and make their impression as a savour on the nerves of taste. But taste, smell, and all the senses are only modifications of the sense of touch or feeling. The atmosphere is filled with odorous substances-the vapour of the essential oils of plants and flowers, the various emanations of insects and animals, gases that rise from decaying vegetable and animal substances, the smoke of coal, wood, and burning refuse, or from metal and chemical works, and worst of all, the stench of human filth and disease. Most great towns are full of stenches; the country, on the contrary, when not infected with nuisances of human production, is full of delightful odours. What more charming than a ride or drive among flowering bean fields, lime trees, apple blossoms, and meadows of new mown hay!

The sense of smell not only guards the mouth and forbids the introduction of unfit food, putrid, nauseous, or acrid matters, but it guards still more, perhaps, the lungs from inhaling foul or poisoned air. It warns us against entering crowded and ill-ventilated rooms, breathing noxious gases, inhaling the odours of putrifying substances, and from remaining in the vicinity of those who are neglectful of personal cleanliness. Strong perfumes, snuff, and tobacco smoke, injure this sense and its protective powers. If our senses were in their natural condition, we should probably be able to avoid nearly all the causes of disease in malarias and contagions. 
Many animals have the sense of smell in great perfection. Many also, perhaps most, secrete odorous substances which attract to them animals of the same species. 'The strong scent of many insects must be for them a sort of language, and probably a means of defence. The skunk drives off his enemy with a discharge of a dreadful effluvia, which he has the power to secrete from blood as sweet and pure as a lamb's. This odour fills the atmosphere over a large area and lasts for weeks. Clothing, sprinkled with the secretion, can be freed from it only by burying it in the ground.

Every animal gives off its own peculiar odour. Dogs know the scent of the birds and beasts they hunt, and seldom mistake one for any other. But every person, also, has his own peculiar and characteristic smell. Those who are blind and deaf can tell all their friends by their smell; and some who are not blind are endowed with an extraordinary sensitiveness in this particular. I know a lady who, lying in her bedroom with the window open, can smell the plants trodden on by a horse in a neighbouring pasture, the various breakfasts of the villagers, the drinks at the public-house, the medicines people are taking, the qualities of smoking tobacco over a large area, and so on. She has a perception of the condition of persons she passes in the street, can tell whether they have taken baths, and the state of their clothing and often their diseases. Even moral character and conduct seem to come out at times, to persons so sensitive, as peculiar odours, as we read of the "odour of sanctity," and of the delightful odours that cling around the bodies of departed saints.

The natural smeli of the perfectly healthy human body is often as delightful as the perfume of a rose or violet. We notice this oftenest, perhaps, in the fresh health of a vigorous childhood. A sweet breath also indicates a satisfactory sanitary condition. On the other hand, every disease has its distinct, and generally disagreeable odour. Many even pleasant. 
odours act as poisons on the nervous system, and delicate persons should avoid strong and heavy perfumes. The rose cold and the hay fever are violent inflammations of the mucous membrane of the nose, caused by odours in some sensitive constitutions.

Smell gives us proof of the wonderful tenuity and diffusion of matter in the atmosphere; ancl we can see from the dispersion of matter as odours how the germs of such diseases as small-pox, yellow fever, intermittent fever, typhus, \&c., may fill the atmosphere without always producing a conscious impression on our senses.

Hearing differs from touch, taste, and smell, in that the sensation is produced by the vibrations of the atmosphere. A bell rung in a vacuum produces no sound. There is nothing to carry on its vibrations. Sound waves spread every way in the atmosphere, but are stronger, and move more rapidly with the wind than against it. In a rapid train on the railway the engine is nearly noiseless, while the last carriages are in the roar of the noise and echoes of all that have gone before. Sound also rises well, and is clearer in moderately high altitudes. When sound vibrations are confined in tubes, they go to great distances with little loss in intensity. Sound pipes might supply a whole village with music, turned on like gas in every dwelling. Sound is conveyed very rapidly and with great force in water, and by means of cords or woody fibre. A slight scratch on one end of the longest piece of timber can be distinctly heard by placing the ear at the other end. A poker, suspended by a double string with its two ends put in the ears, and then struck, sounds like a church bell.

Sound is reflected in echoes and can be concentrated by concave reflectors, as it is accidentally in whispering galleries. In the focus of the bellying sails of large ships at sea sounds are sometimes heard from the shore at great distances. Architects have yet to discover the mode of constructing the best shaped halls for public speaking and music. 
As the sound waves move with a velocity of about a mile in four seconds we see the flash of a gun before we hear the report, and can judge of the distance of lightning by noting the time it takes for the thunder to reach us. A long column of soldiers cannot all keep step at once to the music; and singers or players of instruments, far apart, cannot keep together.

The waves of sound, larger or smaller as the sounds are grave or acute, enter the opening of the ear. The long ears of the ass, horse, rabbit, \&c., seem to be useful in gathering and concentrating these vibrations, but the external ear of man is probably more ornamental than useful; and birds and many animals have very acute hearing without any external ear whatever. About an inch within the human ear is placed a membrane, like the head of a drum, which receives the vibrations of sound. Within this tympanum is an air chamber connected by a tube, the eustachian, with the mouth, and three small bones, joined to each other, aid in carrying the atmospheric impulses to the labyrinth or internal ear, which is the real organ of hearing, where the auditory nerve fills three semicircular canals and a very curiously formed cochlea, or shell-like spiral chamber

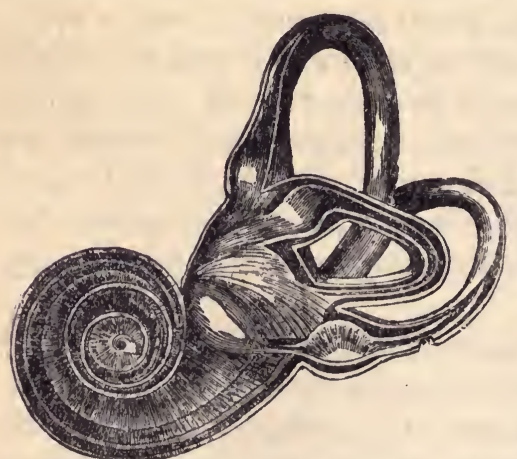

Fig 35.-LABYRINTH OF THE EAR, LAID open, MAGNified.
(Fig. 35), where its fibres may be seen spread out and gradually shortening like the strings of a harp or pianoforte, as if each sound from lowest pitch to highest had a separate nerve fibre to convey it to the sensorium; where atmospheric vibrationsare finally converted into all the wondrous modulations of music and speech. This true ear, the organ of hearing, is embedded in the bones of the 
skull, and receives vibrations through the air in the inner chamber, through the small bones, and through the bone of the skull. The semicircular canals, placed in three directions, are supposed to show us the direction of sounds, and the nerves of the spiral cochlea the pitch, of which we can distinguish, from the lowest note of the organ to the sharpest insect tone, nine octaves; but there must be sounds on either side beyond the reach of our sense of hearing.

And what a vast variety of sounds the ear transmits to the mind; for the quality of tones is as various as the pitch. No. two voices, no two instruments are alike. Violins so vary in quality, roundness, sweetness, loudness, or softness of tone that one may be worth a thousand pounds and another a few shillings. There are voices which bring large fortunes to their possessors; but all depends upon the power of the human ear to convey, and the human mind to feel, these differences. We cannot conceive of the nature of the differences in the vibrations which can make these varying qualities of sound. The waves or impulses may vary in size, or nearness, or intensity, but what can give all the varieties we hear in the notes of birds, the cries of animals, the instruments of an orchestra, or the modulations of the most perfect, wonderful, and delightful of all instruments, the human voice?

By our sense of hearing we have warning of danger, we are apprised of the action of the forces of nature, winds, waters, \&c., and we know much of what is going on in darkness. We hear in our sleep, for a sudden sound, or the cessation of an accustomed one, wakes us; we are guided in darkness, and we hold intercourse with our fellows in language. The blind acquire such use of the sense of hearing that they can tell the distance of a wall, the approach of any one, the nearness of a lamp-post or other obstacle, and a hundred things for which others depend upon vision. Hearing, in conveying to the mind a sense of the quality, tones, and modulations of the voice, gives us a. 
better idea of character than vision. Hearing goes more to the heart. We are far more impressed with what we hear than with what we read. The living voice has more power than all books or writings. We form an idea of persons from sight, but we never feel that we know them until we add the finer and deeper test of the sense of hearing.

While the structure of the ear is a mystery, that of the eye is a beautiful and wonderfully perfect piece of mechanism, of which we have some comprehension, and which we can never

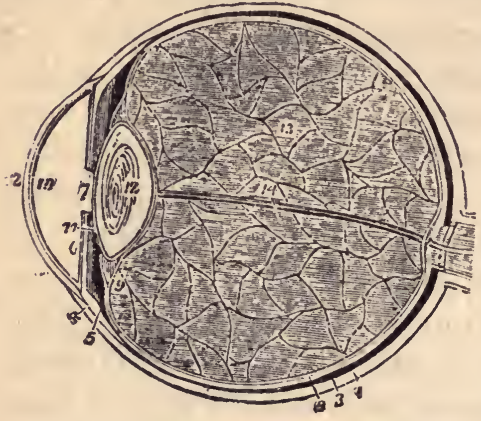

Fig. 36.-Section of THE Eye.* sufficiently admire. First, of all it is the most beautiful of our organs, in form, colour, position, movements and power of expression. It has been called the winclow of the soul, and it expresses, by wondrously slight changes, all our emotions-love, scorn, hate, pity, pleasure, pain, joy, misery.

The eye is a perfect

* 1. The sclerotic, thicker behind than in front. 2. The cornea, received within the anterior margin of the sclerotic, and connected with it by means of a beveled edge. 3. The choroid, connected anteriorly with (4) the ciliary ligament, and (5) the ciliary processes. 6 The iris. 7. The pupil. 8. The third layer of the eye, the retina, terminating anteriorly by an abrupt border at the commencement of the ciliary processes. 9. The canal of Petit, which encircles the lens (12). 10. The anterior chamber of the eye, containing the aqueous humour. 12. The lens, more convex behind than before, and enclosed in its proper capsule. 13. The vitreous humour enclosed in the hyaloid membrane, and in cells formed in its interior by that membrane. 14. A tubular sheath of the hyaloid membrane, which serves for the artery of the capsule of the lens. 16. The arteria centralis retinæ, embedded in the centre of the optic nerve. 


\section{Human Physiology.}

camera obscura-a dark chamber like the box used by the photographers. The pupil is the round tube pointed toward the sitter, but in the eye it grows larger or smaller with every change of light. The lens of the photographer is shaped like that of the eye, and moved backward and forward with a screw to secure a focus, but the soul within adjusts the lens of the eye from instant to instant to every object of vision. The rays of light from the sitter form a picture on a plate of ground glass, and then on the sensitive plate of the negative. In the eye pictures are continually formed upon the retina, upside down as in the camera, and of microscopic minuteness, but the nerve spread out to form the retina carries the impression erect and perfect to the mind. It has been imagined that the sense of touch was needed to correct the defects of vision, but there are no such defects. Chickens just out of the egg judge of distances perfectly. Ducklings hurry off to the nearest water. The butterfly sees as well the first hour of his life as the last. The whole mechanism is simply perfect, and of itself enough to convince any reasonable being that it must be the work of an Infinite Artist, a Mechanician all-wise and almighty.

I have spoken of the muscles that move the eye in a former chapter, one of which passes through a cartilaginous pulley to change the direction of the moving force; but the lovely curtain that forms the pupil of the eye, the iris, is drawn back and forward by a most complicate apparatus. The eye is washed every moment and kept clean and bright by a gland above it secreting a salt liquid and the involuntary opening and shutting of the lids, while the superfluous liquid passes off by a tube into the nose. Beautiful lashes shade the eye from glare and protect it from dust, and comely eyebrows guard it against the sweat of the brow. How beautiful as well as useful are brow and lashes any one may see who chooses to cut them off and do without them.

How wonderful is vision, and how wonderfully adapted is 
nature to satisfy the sense of sight! Before it is spread out all the beauty of the earth and all the glory of the firmament. Nature and art exist for the eye, and the eye makes nature visible to us and art possible. Through this sense we feel what is distant, we reach to the stars, and, assisted by the telescope, which is only an enlargement or extension of the eye itself, we see myriads of worlds which had else remained invisible. In a similar way, improving the scope of our eyes in another direction, we are able to scan new worlds of the infinitely little, and examine myriads of creatures of which but for the microscope we should never have known the existence.

Sight, in civilised man, though improved by his inventions, has lost much of the power it has in many animals and the more simple races of men. Birds of prey, and those that feed on carrion, from great heights in the air are able to'see small objects over a vast extent of territory. Let an animal fall dead on a tropic plain, and in a few moments vultures are seen flying from different directions, which were previously quite out of the range of human vision. Think of all the objects of such a vast area being painted upon the retina of a bird; so as to convey to his mind the distinct idea of a living or dead animal on any part of it! A sailor sees a ship at sea when a landsman sees nothing but the waste of waters. The Arab espies a camel when it is but a dot on the edge of the horizon, and on his retina must be of minuteness inconceivable.

Sight is the highest, the finest, the most perfect of the senses. We hear by atmospheric vibrations, but we see by infinitely finer vibrations of the luminiferous ether which pervades all space. We can hear only sounds coming from a moderate distance, a few miles; we see, or receive the impressions of light vibrations which come thousands of millions of miles. These vibrations, excited by the action of some force in sun and stars, reflected by all the objects around us, break in waves of light upon the spread out nerves of vision, as the atmospheric sound 


\section{Human Physiology.}

waves break upon the nerves of hearing. And by means of wonderfully designed and constructed instruments, and nerves, and brain, the sentinel soul within them all hears and sees. But who can doubt that there is a spiritual ear living in the material ear-a spiritual eye which has formed and makes use of the wonderful organ of vision?

\section{CHAPTER IV.}

THE ALIMENTARY SYSTEM.

Food Elements-Organs of the Oyster-Alimentary Canal of an InsectMucous Membrane-Teeth of Herbivorous, Carnivorous, and Frugivorous Animals-Saliva-The Stomach-Gastric Juice-Small Intestines-Cilıa-Pancreas - Bile-Villi and Follicles - LymphaticsConstipation-Relations of Food to Health.

THE bodies of men and all animals are built up, and their wastes repaired, by food, which is digested, or dissolved, reduced to a uniform creamy fluid, and under the influence of nervous action, converted into living blood, and circulated throughout the system. This blood furnishes the matter of bones, muscles, brain, nerves, and every organ and tissue, and continues to supply fresh matter to make up for the waste ordinarily going on in every part of the body. All animals receive food; they all have a circulating fluid-blood or its equivalent; all breathe air, or water containing air, so that the circulating fluid can be purified and vivified by the action of oxygen.

Even an animal so low down in the scale of being as the oyster has a complex and beautiful organism of digestion, circulation, respiration, with a nervous system suited to its mode of existence.

The animal kingdom depends for its food, the matter of 
- which all animal bodies are composed, upon the vegetable kingdom, which, in turn, draws its matter from the air and earth. The flesh, fish, and insect or animalculæ-eating animals, get their food at second-hand from the vegetable kingdom. The same elements enter into both-carbon, oxygen, hydrogen, nitrogen, chlorine, phosphorus, sulphur, sodium, calcium, potassium, magnesium, \&c.

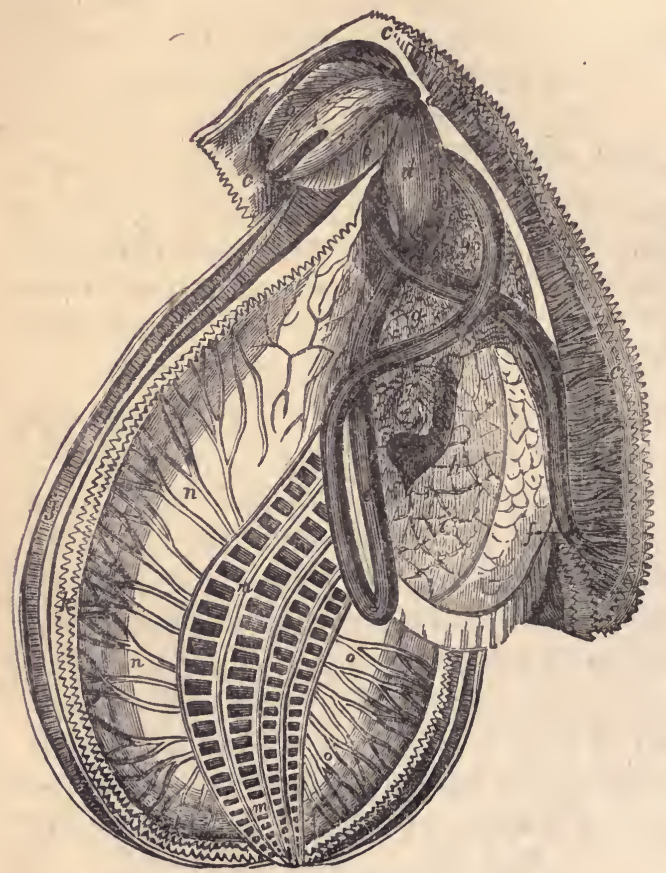

A, the mouth; $\mathrm{B}$, the lips; c c, the mantle; $\mathrm{D}$, the stomach; E, the intestine; $F$, its extremity; G, part of the liver; $H$, the heart; I, the adductor muscle; J, the margin of the breathing and feeding organs; $\mathrm{K}$, the right lobe of the mantle; $\mathrm{N}, \mathrm{N}, . \mathrm{O}$, $\mathrm{O}$, vessels distributed through the mantle ; $M$, the large canal containing the breathing and feeding organs.

Hig. 36.-ORGANS OF THE OYSTER.

Our muscular flesh is composed of the same elements as are found in most vegetables, grains, and fruits-carbon, hydrogen, oxygen and nitrogen. The fat is carbon, hydrogen, and oxygen. Bones have an addition of lime and phosphorus. The sheep 
and ox get all the matter of their bodies from grass; the lion and tiger get the same elements at second-hand from the carcases they devour.

The alimentary canal begins at the lips, and passes a length of about thirty feet through the body. This great length is required to give sufficient surface for the immense number of glands, absorbents, excreting ducts, arteries, veins, nerves, \&c., which line the intestinal canal; and this surface is perhaps quadrupled by the numerous folds of the intestines. The functions of the alimentary canal are thus evidently of great importance. The extent of the alimentary canal is much greater in man than in carnivorous animals.

Ir the lowest forms of life the alimentary canal is very simple. There is a mere sack or tube. A polype can be turned inside out, and seems to digest as well with what was his skin as with what was his stomach. The alimentary canal of the insect is considerably more complex, with elaborate glandular apparatus. We shall see that the alimentary system in man is complicated and perfect in proportion to the dignity and importance of the life it is made to nourish.

Within the lips we find the skin changed to a soft mucous membrane, lired with cells which are perpetually renewed, and kept moist by the exudation of a clear, and slightly slimy fluid. This membrane lines all portions of the interior of the body which have open communication with the external world. The interior cavities, as around the lungs and intestines, are lined with serous membranes. Fig. 37-Aliment-

Entering the mouth we first encounter the teeth, hard bone covered with a harder

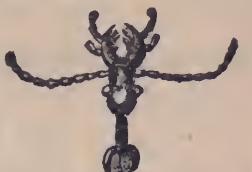
enamel; a set for childhood, and a larger and stronger set for 
maturity ; the front teeth, made for biting fruits, vegetables, and other comparatively soft substances; the side teeth for mashing and grinding seeds, nuts, and all matters which require to be reduced to pulp, and mingled with the saliva. The teeth of every animal point out its natural diet. The beaver lives on the bark and tender twigs of plants, and we have seen his teeth for cutting and grinding them (Fig. ro, Part Second).

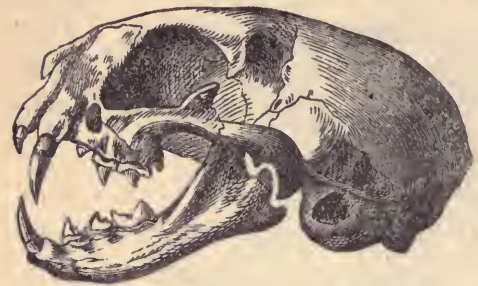

Fig. 38. -Sikull of CaRnivgra.

Here, in this skull of a carnivorous, or flesh-eating animal (Fig. 38), we have strong tusks for holding and tearing its prey, and at the sides of the jaws sharp cutting teeth for dividing flesh in pieces, which is then swallowed without further mastication. The teeth of men are similar to those of the fruiteating mammalia; and there can be no doubt that fruits, nuts, and grains, or the seeds of vegetables, are the most natural and therefore the most healthful food of the human species. 'This is the testimony of all the most distinguished anatomists and physiologists.

Beneath the under jaw, and near the ear, on each side of the face, are glands which separate from the blood the first fluid which aids the process of digestion-the saliva. The moment food touches the tongue-even when its odour penetrates the nostrils, and often at the sight, or even the thought of pleasant food, these glands are excited to unusual activity; the nerves increase the flow of blood to them, quite independent of any action of the heart; the nervous power, by some unknown chemistry, transforms a portion of the blood into a bland, slightly alkaline fluid, which is, or should be, thoroughly mingled with the food, and begins to dissolve it. The office of the tongue is to taste the food, and by this taste excite the 
nerves which preside over digestion; to bring every part between the mashing and grinding surfaces of the teeth; to feel if it is reduced to a soft pulp; and then to convey the food to the back part. of the mouth, where the action of involuntary muscles performs the act of swallowing. The food passes quickly down the channel of the esophagus into the stomach-passing over the opening of the windpipe, which is carefully closed by a valve constructed for that purpose- opening for every breath, closing tightly at every swallow.

When this pulp of food arrives in the stomach, which is a bag or pouch, small when empty, but expanding with its contents, it is turned over and over by the contractions of muscles along and around it. At the call of the nerves the bloodvessels swell and fill, and thousands of glands separate from the blood, or rather manufacture out of it, the gastric juice which dissolves food, and reduces it to a creamy whitish liquid called chyme.

Fig. 39 represents two glands in the coat of the stomach highly magnified. They are tubes expanding into cells, resembling vegetation. In all glands the forms give a great expanse of membranous surface, and in that surface, or in the nerves expanded on the surface, lies the power of taking the required elements from the blood, and making from them the required substance. Human gastric juice consists of 99.4.40 thousandths of water, a little of a nitrogenous element called pepsine, some

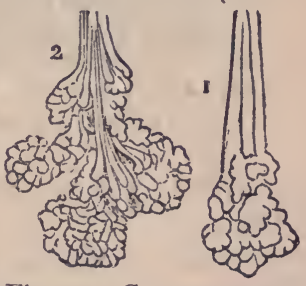

Fig. 39.-GLands IN THE COAT OF THESTOMACH Magnified 45 diameters. common salt, and a very small trace of hydrochloric acid. Of this gastric juice there is every day formed large quantities, as much, some observers have estimated, as twenty or thirty pounds, which, having performed its use, is again absorbed into the circulation. 
Liquids, and the liquid portions of our food are rapidly absorbed by the veins of the stomach and pass into the circulation. All intoxicating liquors are thus taken up and are in a few moments felt in the brain, and smelled in the breath and perspiration. But the greater part of the food dissolved in the stomach passes, as chyme, into the duodenum, or beginning of the small intestines.

These, like the stomach, are lined with a mucous membrane; and in it are multitudes of glands pouring secretions into them, and absorbents to take up and carry off the matter of nutrition. They have muscular contractions forming what is called their peristaltic action - a worm-like succession of contractions which force the contained matters downward. There are also on the interior of some animal intestines myriads of cilia, or little hair-like bodies, attached to the cells of the living membrane (Fig. 40), and these are ii

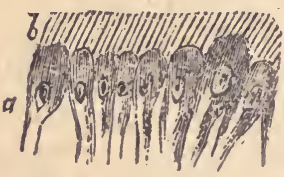
perpetual rapid motion, brushing or sweeping forward the fluid matter. The mode of their action is utterly inexplicable. The microscope gives us no clue to it. We know only that it is, and that similar Fig. 40.-Ciliated EPITHELium organs are found in all animals, down to the lowest forms of infusoria and even in vegetable spores. It is one of the millions of the mysteries of life.

When the chyme has left the stomach it soon encounters and is mingled with another secretion - that of a large gland called the pancreas-known in animals as the "sweet-bread"-similar to the salivary glands, and furnishing a large quantity, probably about ten pounds daily, of a clear, slightly viscid and alkaline fluid. Its office seems to be to convert starch into sugar, and oil or fat into soap, so that they can be dissolved. To form the gastric and pancreatic juices the chloride of soda has been decomposed, furnishing hydrochloric acid to one and 
soda to the other. In the duodenum these elements re-unite to form common salt, which is absorbed with the food into the circulation!

At the same point where the pancreatic duct brings its solvent juice into the intestines, the liver also pours in its supply of bile, which appears to promote the solution of fatty substances and.stimulate the action of the bowels. The bile, however, is an excretion, the result of a purifying process, but here is an instance of matter destined to be cast out of the system, still doing useful work on the way. By the action of these two agents the chyme is converted into chyle, and is ready to be absorbed and converted into blood.

In Figures 41 and 42 are shown the villi which line the

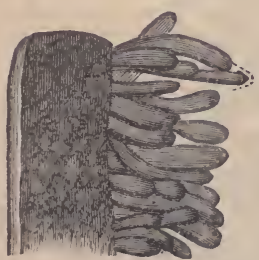

Fig. 41.-Longitudinal

Section of Small INTESTINES, SHOWING VILLI.

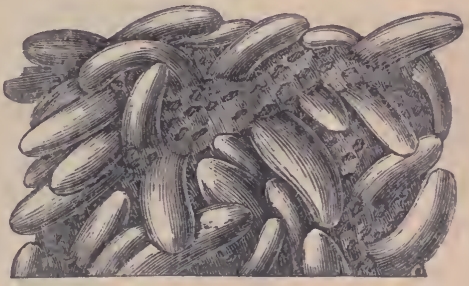

Fig. 42.-Villi and Follicles uf ILEUM, HIGHLY MAGNIFIEI)

intestines, and distinguish, choose, suck up, and, after what vital change we know not, pass over the nutritive matter to the capillaries and veins, by which it is carried into the circulation. Glands are at the same time pouring secretions into the intestines; and it is so managed that in a vigorous state of the nervous system these two opposite processes go on together without interference. The proper food elements are absorbed, and the refuse is passed on with the excreted waste matters of the system, until these latter, arriving at the end of the larger intestines, are stored there for a convenient time, and then 
expelled; containing, in the waste and refuse of the animal body, the richest food for the sustenance of the vegetable kingdom; which civilised men waste, polluting rivers, the sea, and the atmosphere with matter, which, restored to the soil from which it came, would yield them incalculable riches.

One portion of the nutritive matter which has become digested, and perhaps vitalised, in the stomach and small intestines, is absorbed by the veins; another portion is taken up by a system of minute, transparent tubes called lymphatics.

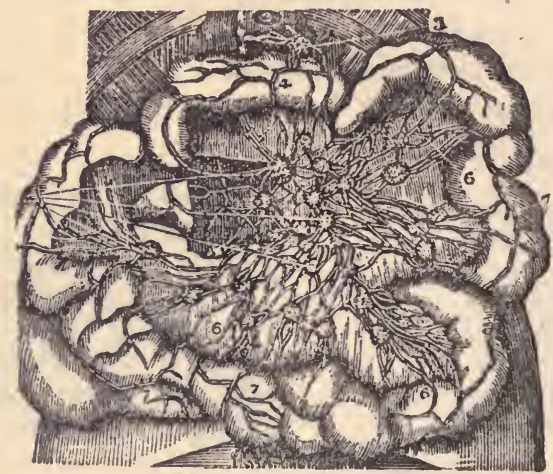

Fig. 43.-Lymphatics of Small Intestines.

The glands enlarged by disease.

These form a curious network, gathering in little knots which are called the lymphatic glands, and in these, under some action of the nerves of organic life, the matter of food appears to be transformed into blood; for these vessels unite in a duct which carries the lymph into a large vein, whence it goes directly to the heart, and after being subjected to the action of oxygen in the lungs, becomes red, arterial blood, and is circulated through the entire body.

Of the food received into the mouth, only a very small por- 


\section{Human Physiology.}

tion leaves the body at the lower extremity of the alimentary canal. Some indigestible matters, as the outer husk of grains, the skins of fruits, and some seeds pass through the body, and a certain amount of such matter appears to stimulate the action of the bowels and prevent constipation. Bread made of fine flour, pastry, and too large a proportion of concentrated food, as flesh, fish, eggs, etc., cause constipation. Bread of unbolted wheat, fruits which contain much woody fibre, figs with their numerous small seeds, coarse oatmeal, spinach, and other greens and vegetables, on the contrary, keep up a healthy action of the intestines.

It is evident that so extensive and complex an organism as that devoted to the digestion and absorption of the alimentary matters constantly required by the system may be liable to great derangements and disorders, and we have in the stomach and intestines the origin and centre of many diseases. If the digestive system is in good order, the health and vigour of the whole body are secured. If the action of the stomach and intestinal canal, and the glandular system connected with them is impaired, good blood cannot be formed, nervous power cannot be generated; without nervous power there cannot be healthy secretions or good digestion: thus we have a circle of evils, each intensifying the other. A man in ordinary health digests boiled rice in one hour-that is to say, it passes out of the stomach, dissolved into chyme. It may be two or three hours before it is absorbed from the intestines, and passes through the glands, and becomes blood. Wheat bread takes a little longer; cooked flesh requires from two to four hours; potatoes, cabbage, and other vegetables, from an hour and a-half to three hours; hard white of egg, four to six hours. But much depends upon thorough mastication and insalivation. More depends upon the energy of the nervous system. If that has been exhausted by excessive labour, or pleasure, or anxiety, digestion is slow, and may be entirely suspended. If, after a 
meal, the brain or the muscular system is suddenly called upon for great exertion, the vital forces are taken from the stomach, and digestion is impossible. The food is then only an irritating substance in the stomach, which we are better without.

For good digestion, mind and body should be at rest, or but moderately active. The hours taken for labour on a full stomach are stolen from life. When the process is well begun; in about an hour after eating, we can begin to work with brain or body with moderate activity. Those who take stimulants to enable brain and stomach to work at the same time, are burning life's candle at both ends.

It is evident that we require good food in sufficient but not excessive quantities; and that we have to avoid every cause of nervous exhaustion. These matters, however, will be more fully treated in the chapters on Health and Disease.

\section{CHAPTER V.}

THE BLOOD.

Matter taking on Life-Mechanism of the Heart-Aëration of the BloodCourse of the Circulation-Capillaries-Distribution of Arteries and Veins-Circulation in a Frog's Foot-Forces of the Circulation-Controlled by Nervous Power.

WHEN food has been mashed into pulp, and converted into chyme, and then into chyle, absorbed by venous capillaries and lymphatics, passed through the lymphatic glands, and the spleen, which may be a collection of such glands, it becomes a living fluid, the blood, or a fluid containing living organisms, the blood globules. We have no comprehension of the mode in which dead matter, the matter of our ordinary food; can become a part of the living matter of our systems-berome- 
imbued with life; but we see all round us, in the vegetative as well as the animal kingdom, this process going forward. Life lays hold of matter, trausforms it, performs incomprehensible feats of chemistry, and at length endows it with vitality. The food taken into the stomach, in from one to five or six hours, according to its digestibility, becomes living blood, and is sent circulating with great rapidity through the system.

There is in the body of an adult man about thirty pounds of blood, one fifth of the weight of the whole body. Add the weight of the heart, arteries and veins, and capillary system in which it circulates, and you have at least one quarter of the weight and bulk of the human body, filling every part of it.

The heart, the great regulating organ of the circulation, is. placed in the centre of the body, embedded in and sur-

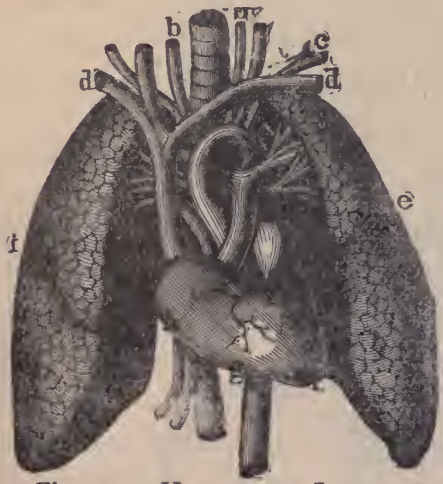

Fig. 44.-Heakt ANd Lungs.

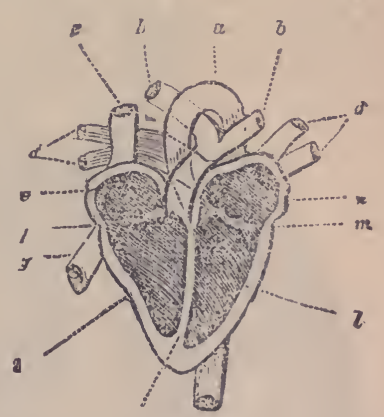

Fig. 45.-The Heart. Ideal Section.*

rounded by the lungs, because the first thing the living blood requires to do is to breathe-to be brought into contact

* $a$, arch of aorta ; $b, b$, pulmonary arteries; $\iota$, superior vena cava; $d, d$, pulmonary veins; $e$, right auricle; $f$, tricuspid valves ; $\varepsilon$, inferior vena cava; $h$, right ventricle ; $l$, left ventricle; $n$, mitral valve; $n$, left auricle. 
with abundance of pure air, from which it absorbs a large quantity of oxygen, parting, at the same time, with a quantity of carbonic acid and the various waste matters, often of a very unpleasant character, which are carried out of the system with the breath.

The heart is a very simple and very perfect machine-a double force-pump, whose action can be understood by the accompanying diagram (Fig. 45). There are, in fact, two pumps, or two hearts united. The blood, returning in the veins from all parts of the body, dark in colour, loaded with carbonic acid and other waste, with the new matter from the stomach and intestines, passes into the right auricle, by the muscular contraction of which it is thrown through valves which prevent its return, into the cavity below-the right ventricle. Instantly the right ventricle, or force-pump chamber of this side, contracts and forces it through the pulmonary arteries into every portion of the lungs, where every atom of blood is

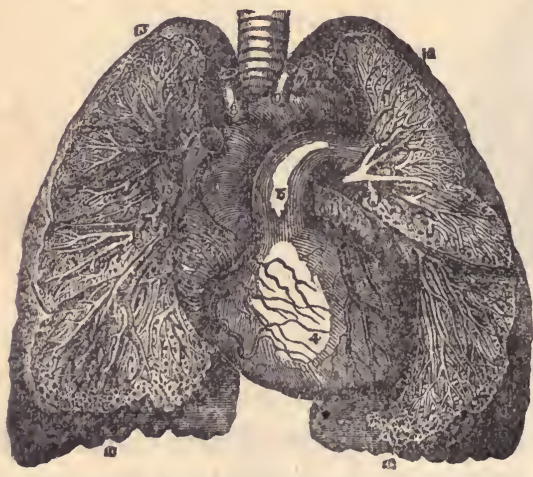

Fig. 46. - Heart and Lungs, SHowing BloOd ANd Air Vesseis. exposed to the action of the air, and absorbs oxygen and parts with its waste matter through membranes so thin as to offer no obstacle to these interchanges. In Fig. 46 the blood vessels and air vessels are shown intermingled-. but no engraving can show the minute ramifications of either. The air vessels are like leaves on a tree, or grapes on their stem, with an aggregate surface of 20,000 square feet; and the blood vessels are everywhere about them 


\section{Human Physiology.}

in a network so fine as to task the highest powers of the microscope to make them visible.

From every part of the lungs, the blood, which from its contact with air, from the absorption of oxygen, and loss of carbonic acid, etc., has, from a dark crimson hue, become a bright scarlet, is sent back to the heart, when it is received into the left auricle, passes to the left ventricle, and is expelled with

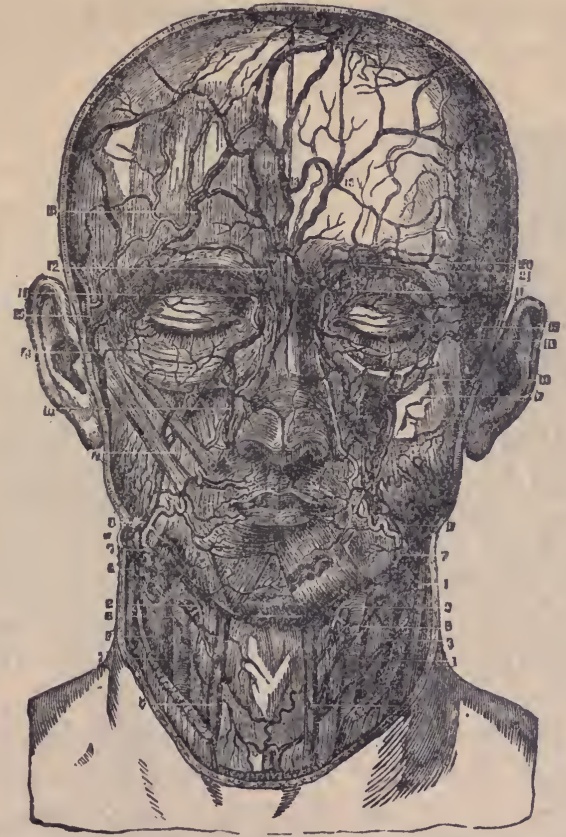

Fig. 47.-Arteries and Veins of the Head and Neck.

great force into the great aorta, or trunk of the arterial system, which branches out like a tree, carrying the blood to every part of the body-up into the head, where the brain gets a large supply; to all the organs of the body, to the upper and lower 
extremities, and wherever there is a gland to act or a tissue to be nourished; returning from every portion through the veins to the right side of the heart.

This circulation goes on with great rapidity. The heart beats 4,200 times an hour, day and night. At each beat two and a half ounces are thrown into the arteries, which is at the rate of six hundred and fifty-six pounds an hour, or seven and threefourth tons a-day. A quantity equal to all the blood in the body passes through the heart every three minutes.

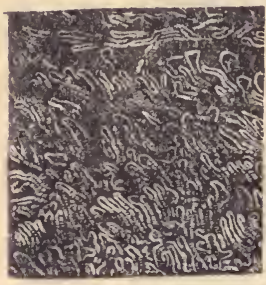

Fig. 48.

DISTRIBUTION OF

Capillary BloOd.

VESSELS IN THE SKIN

OF THE FINGER.

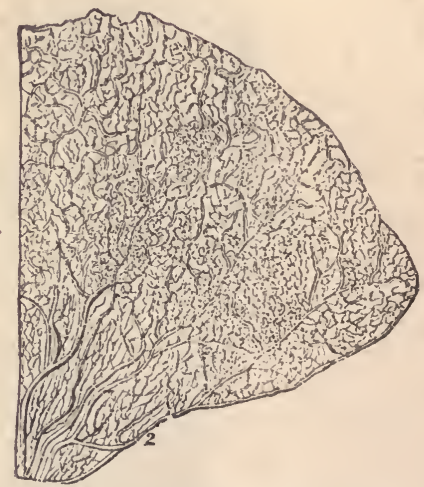

Fig. 49.-INJECTED VEINS FROM Cont of Intestine.

The arteries terminate in minute tubes, called capillaries, which carry the blood into very extensive ramifications in the muscles, glands, brain-in short into every tissue. Fig. 48 shows the distribution of capillaries in the skin of the finger, where there is a similar distribution of the nerves of sensation. The whole skin is pervaded with these minute bloodvessels, which are thicker in the more sensitive portions. Most are so small as only to carry white globules; in rosy 
cheeks they enlarge, so as to carry red globules, and give the glow of healthy blood to the face.

Fig. 49 gives an idea of the distribution of the venous capillaries and veins, gradually uniting into larger and larger trunks, and so gathering the blood and carrying it back to the heart.

The distribution of arteries and veins to the extremities is beautifully shown in Fig. 50, where the arteries, generally lying deeper, and better protected than the veins, can be seen branching off to the thumb and fingers; while the interlacing veins flow back nearer the surface. Perhaps the mode in which arteries and veins are distributed in their minutest ramifications has not been better shown than in Fig. 5I, copied from a preparation of Sir Astley Cooper, of the injected arteries and veins which enclose a villus of the intestines, magnified 45 diameters.

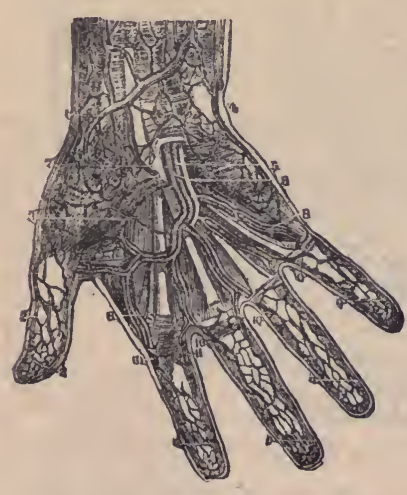

Fig. 50.-Circulation of the HAND.

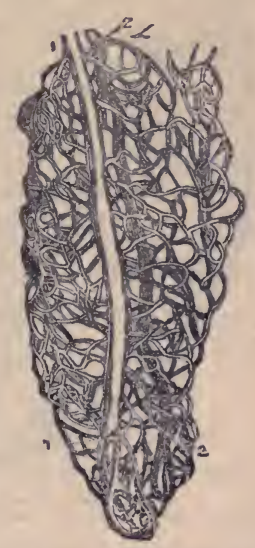

Fig. 51.-ARTERIES ANL VEINS OF AN INTESTINAL VILlUS, magnified 45 diameters: arteries dark.

Small as are the minute blood-vessels and capillaries, the blood rushes through them with great freedom and rapidity. 
I know of scarcely any spectacle more striking than a view of the circulation of blood in the capillaries of a frog's foot, as seen under a powerful microscope. The blood rushes through a net-work of sluices like mountain torrents, for the movement is magnified as well as the size; and the red and white blood globules look like oval cakes of ice in wintry streams. Fig. 52 gives a very good idea of the appearance of the vessels, but it wants the colour and movement that make the natural object so startling.

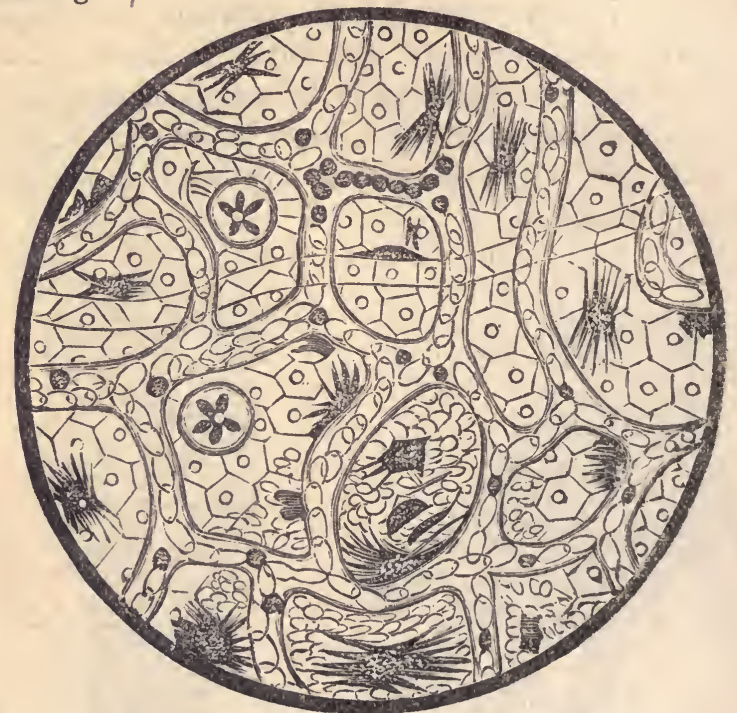

Fig. 52. -Circulation in a Frog's Foot.

Ihere are many interesting and important points about the circulation of the blood. The muscular force of the heart is sufficient, as is shown by the pulsations of our extremities, felt at times to the ends of our fingers and toes, to send the blood through the arteries, but not to force it through the capillaries, where it seems to be influenced by capillary attraction, or the 


\section{Human Physiology.}

curious force of membranous circulation called endosmose and exosmose. The heart cannot draw the blood back through the veins-their flabby structure would collapse at once. The blood must be pushed back to the heart by the capillary forces.

But the whole circulation is far from being entirely mechanical-it is far more nervous and vital. The heart is supplied with blood-vessels, arteries, and veins for its own nourishment. So are the arteries and veins. The nerves of organic life pervade them everywhere. When a draft is made upon the brain for an extraordinary effort, not only is the action of the heart quickened, but the arteries enlarge, and a fuller current goes to the head, and is seen in the flushed face, while the extremities become cold. Plood goes where it is most wanted. The heart can only pump away like a fire-engine-it has no power to direct the current; but the nervous power can send it, now to the brain for thought, now to the stomach for digestion, then to the muscles, then to heal a broken leg. When a leg is broken, the arteries and veins expand around the fracture; bony matter is deposited, first in a ring around and a plug in the hollow of the bone-then the ends are neatly joined together, and then the superfluous bony matter-the stagingis carried away; and all this is done by the nervous power controlling the small blood-vessels-by the intelligent powers of life.

If the circulation is governed by the organic nerves, they are subject to many influences from the cerebro-spinal system. Joy quickens the pulse-grief depresses it. A sudden emotion will fill the capillaries of the skin in the face and neck with red globules, as is seen in the lovely phenomenon of blushing. Under another emotion the arteries of the bosom fill, and the glands transform blood into milk. Anger sometimes colours the blood and thence the skin with bile. - Fear or anxiety will increase another secretion from the blood, and cause perspiration. If an arterial trunk supplying leg or arm be tied, nearly all 
the blood will be cut off, and the limb will grow weak and cold. But nature has provided against such accidents. Arteries run into each other. The branches above the ligature will enlarge, and in a few days the blood will flow freely in new channels enlarged by the influences of the nervous power, in obedience to the law of demand and supply. We shall see in our next chapter how far the circulation of the blood is from being a mere mechanical operation. It is, on the contrary, everywhere presided over by a masterly skill-a wonderful intelligence.

\section{CHAPTER VI.}

\section{SECRETIONS AND EXCRETIONS.}

Action of the Lungs-Ventilation-The Liver-The Spleen-The Kidneys -Effects of Animal Food-The Intestinal Glands-Action of Cathartics-The Skin-Pores-Sweat Glands-Chill-How to Strengthen the Skin.

In our view of the blood and its circulation, we have glanced at some of the organs in which certain matters are separated from it, or made out of the materials which it furnishes. Bone, muscle, nerve, cartilage, tendon, membrane, skin, cuticle, hair, nails, scales, feathers, \&c., are formed from the blood, and may all, therefore, be termed secretions. Matters cast out of the body as useless or hurtful, are also separated from the blood, for its purification, and these are termed excretions. Life is carried on by these two processes. The body is built up by secretion, and it is purified from its waste, diseased, and discasing-its really poisonous matters, by excretion. If one stop, the growth or nutrition of the body ceases, and it wastes away, as in consumption; if the other is hindered, the body quickly 
becomes a foul mass of disease and putretaction. Both are vital processes, and their being vigorously and perfectly carried on is a inatter of vital importance.

The action of the lungs in both the vivification and purification of :he blood has been already noticed. Every air-cell of the lungs is both a secreting and excreting organ. It secretes oxygen from the air for the blood; it excretes carbonic acid, and much other waste matter from the blood, which goes out to mingle with the atmosphere. The air should never be breathed twice, for two reasons. It is deprived of a part of its oxygen, and is thus rendered less fit for respiration; but it is also loaded with carbonic acid and other matter which should never be taken a second time into the system. It may be still worse to breathe over the breaths of other people. Our rooms should be so ventilated that every breath we draw should be as pure as the outer atmosphere. But our houses, our bedrooms, and still more our churches and theatres, schools and public rooms of all kinds, are often very imperfectly ventilated, and sometimes simply pestilential. The lungs themselves become diseased when required to act upon a foul atmosphere, and the blood may acquire more impurities through them than it is able to get rid of. The lungs, that so readily absorb ether or chloroform, probably take in, in the same way, the matter which causes typhus and cholera.

The liver, if we judge from its size, must be a purifying organ of great importance. It is the largest gland in the body, weighing three to four pounds, and is about twelve inches long, by six or seven wide. It is composed of an immense number of separate glands, each supplied with its nerves, its proper arteries and veins for its own nutriment, and also the vessels which bring the blood from the intestines containing the absorbed matter from the food, which the liver elaborates and perfects. The liver is a blood-making organ, and it appears also to form or secrete fatty matter. When the venous blood 
has been through the liver, it passes on to the heart and lungs. But it also purifies the blood of the bitter, resinous excretion, the bile, which, after performing a useful function in the digestive processes of the small intestines and stimulating the action of the larger, passes off with the fæcal

The spleen, a large gland opposite the liver on the right side of the body, appears to be rather a manufacturer than purifier of the blood. Large quantities of fibrin, which separates from the serum of blood in the act of clotting, are found in the spleen, and some physiologists hold that its action also increases the quantity of red globules. It has no excretory duct, and very little is really known about its functions.

The kidneys are very powerful secreting and excreting organs. They secrete urine from the blood-a function so important that if it ceases only for two or three days, death is often the result. The excretion of urine is the principal means of ridding the body of the waste matter of the system, mostly

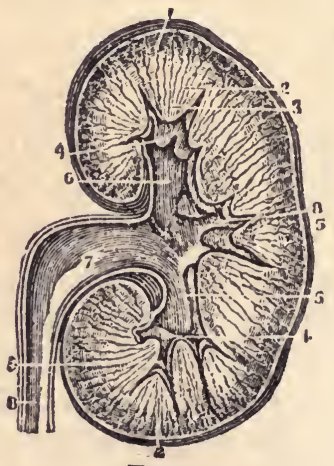

Fig. 53 .

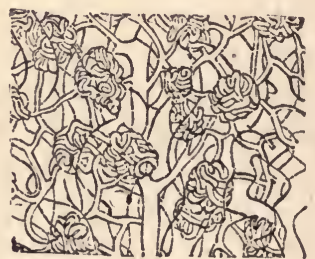

Fig. 54 .

A Portion OF Kidney MAGNIFIED 60 DIAMETERS.

Vertical Section of the LEFT KIDNEY.

urea, an ammoniacal compound. The waste of muscular tissue and brain matter is separated from the blood by the kidneys, 


\section{Human Physiology.}

which are placed in the course of the great arteries, and filter in a short time the whole current of the circulation. Passing into the kidneys by large arteries, the blood is distributed in minute vessels, wound into convolutions as shown in Fig. 54, mingled with organic nerve-fibres. The urine is drained from the blood and carried into a central receptacle, from which it passes by long tubes, the ureters, into the bladder, which these tubes enter in such a slanting direction that no liquid can flow backward-perfect valves, such as are found in the heart and veins, and wherever they are needed. People who eat flesh for food pass much more urea, or solid matter of urine, than vegetable feeders, because their blood contains the waste matter of the flesh they eat, as well as of their own tissues, and some of the severest forms of diseases of the kidneys may undoubtedly be attributed to the inordinate eating of animal food.

I have already mentioned in the chapter on the alimentary system, that the whole course of the intestines was a vast collection of glands of secretion and excretion. Some secrete blood-forming matter from the food; others secrete waste matter from the blood, which passes on and forms the great bulk of the fæces evacuation. This evacuation may become so large as to produce rapid waste-or the waste, beginning from some cause in the system, may seek this mode of evacuationas in diarrhœa and dysentery. Certain drugs excite these excretions from the bowels, or are most readily got rid of in that way. Purgative medicines are such as excite this action, some by entering the circulation and finding this outlet, others by simply stimulating or irritating the excretory glands of the intestines. In either case the habitual or frequent use of them is attended with great mischief, and they are seldom if ever needed, for a proper diet and injections of cool or cold water, and rubbing or kneading the bowels, are the only proper remedies.

The action of liver, spleen, kidneys, salivary glands, pancreas, 
and the tear-glands over our eye-balls we can influence, but only indirectly by the observance of the general conditions of health. Fresh pure air, exercise, and cheerfulness keep our lungs in order; pure food and other health conditions ensure the normal action of stomach and bowels; but the secreting and excreting organ, scarcely second to any other in importance.

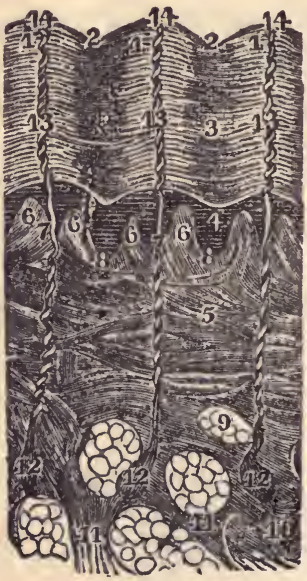

Fig. 55 .

MAgNified Section of THE SKIN OF THE Sole of THE FoOT.

3. Epidermis. , 4. Rete Mucosum. 5. Cutis Vera. 6. Papillæ. 9. Fat-Cells. 12. Sweat Glands. 13. Sweat Canals. 14. Pores.

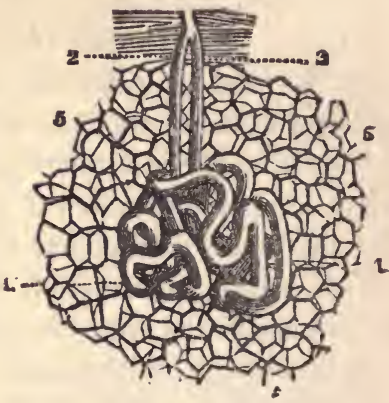

Fig. 56.

A Sweat Gland From the PALM OF THE HAND, magnified 40 diameters.

the skin, is more than any under our control. I have called the skin an organ, but it is in reality a wonderful collection of organs-glands of secretion and excretion, which are constantly 
pouring out the matter of perspiration separated from the blood. A square inch of the human skin contains 3,500 pores. Each pore is the mouth of a long twisted tube, a sort of drain pipe a quarter of an inch long, ending in a gland which secretes from the blood the matter of perspiration. These tubes are said to be in the aggregate forty miles long. Commonly the matter passes out in a state of vapour, or is immediately dissolved in the atmosphere. It is then called insensible perspiration. But let the circulation be quickened, and the action of the skin increased by exercise, or simply by a high temperature, and the fluid is poured out so fast as to gather in great drops over the whole surface of the body.

Take a single sweat gland more highly magnified, and we shall get a good idea of its structure. There it is (Fig. 56), a tube divided into a loop, and the loop rolled up into a ball. This is surrounded by a net-work of capillaries and nerves. When the nerves have the energy of health, they somehow compel the blood to part with that portion of its matter which it can best spare. They drain off the matter the system wishes to be rid of. If you have been drinking beer or brandy, it will pass into these glands by some force of attraction, and pass off at the pores; or eating onions, or herrings, or smoking tobacco. The clothing is soon tainted and made foul with the matter of perspiration.

In Fig. 57 a magnified section of skin shows a sweat gland and its tube, and also the roots of two hairs, which are also furnished with glands giving out an oily matter.

As some substances excite the action of the intestinal glands, others stimulate the action of the sweat glands, and excite to profuse perspiration. It would seem that in all these cases matter is taken into the body which it wishes to be rid of; and some kinds find one outlet and some another. The skin will absorb some things which pass out by the lungs or kidneys. Dip a finger in spirits of turpentine, and in a few 
minutes its odour can be smelled in the urine, and probably also in the breath. The odorous oil of onions comes out both by lungs and skin. Asparagus gives its strong odour to the urine.

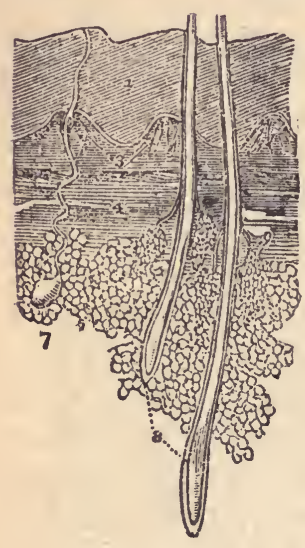

Fig. 57 .

Vertical Section of the

Skin Magnified.

The millions of pores of the skin ordinarily pour out two and a-half pints of water daily-water containing ail the matters of which I have spoken. If there is constipation, and therefore unusual foulness of the blood, more comes out by the breath and perspiration. If the perspiration is stopped by chill, there is an increased flow of urine. Chill may also cause diarrhœea, and is frequently the cause of a profuse watery discharge from the mucous membrane of the nose. A sudden check of perspiration gives us a cold. The natural remedy is to restore the action of the skin by a warm bath, a hot-air bath, a wet sheet-pack, or simply by such exercise as will bring on a full action of the skin.

And we can act on the skin so readily-we have all its millions of glands and pores so much at our command, that it is for us the most important of all the great purifying organs of the body. The cleanliness of a daily bath, at least of a thorough washing all over the body, is within the reach of all. All can strengthen the skin and promote its healthy action by friction with the hands, or coarse towels, or a flesh-brush; and a fourpenny brush is as good as any. Sea-bathing is within the reach of great numbers at times; hot-air baths have been opened in most large towns; and all these are useful; but the daily tubbing, or the morning sponge or towel bath, followed by 


\section{Human Physiology.}

a vigorous dry-rubbing, is what every one can practice, and those who do so, and live decently right in other respects, will seldom need doctors or medicine.

\section{CHAPTER VII.}

\section{IDIOSYNCRASIES.}

The Four Temperaments-Nature's Counterpoise to Variations-Causes of Idiosyncrasies-Singularities-Physical and Mental Diseases-Moral Responsibility-Manias-Good Souls in Diseased Bodies-SleepInstincts of Time, Locality, Number.

Constitutions differ. No two persons are exactly alike in form, features, complexion, thought, or feeling, or action. Children of the same family, and especially twin children, sometimes can scarcely be distinguished apart by strangers, but their own families have no such difficulty. It is said that a shepherd knows every sheep in a large flock-and men differ more than sheep. Where forms and faces are most alike, expressions differ with difference of emotions. Nature is infinite in variety.

Ancient observers of human nature classed constitutional peculiarities, idiocrasies or idiosyncrasies, in four temperaments - the sanguine, phlegmatic or lymphatic, nervous, and bilious or melancholic. Of course they grade into each other, and we have all varieties of compounds. Persons of the sanguine, or sanguineous temperament, have a predominance of blood-vessels and an active circulation, with white skin, fresh colour, light hair inclining to red, blue eyes, and the mind cheerful and volatile. The phlegmatic or lymphatic temperament is a modification of the sanguine, more soft and 
indolent, with a tendency to roundness and plumpness, and a paler blonde of hair and complexion. Such persons are calm and gentle, and not easily excited to violent exertion, or anger, or grief. Persons of the nervous temperament are generally thin and pale, with thin hair, large and active brains, and great force and quickness of nervous action-extreme sensibility, acute senses, active intellects, and vivid emotions. This is the temperament of fine talents, and great mental and bodily activity. The bilious temperament is characterised by firm muscles, dark, strong, thick hair, dark complexion and eyes, and great strength and firmness of character-a serious and sometimes severe and melancholic disposition. A fine combination is the sanguine, nervous, and bilious, in fair proportions. Some whole races of men are of one or two of these temperaments. In England and America we have all varieties, and by one law of generation there is a constant tendency to mingle these temperaments and efface individual idiosyncrasies. by the attraction of both sexes for their opposites. Dark men are fond of fair women, the tall are enamoured of the short, the lean admire the fat, and vice versa; so that there is a constant check to the propagation of varieties, or a directly opposite tendency to what has been termed natural selection. Sexual selection is therefore a counterpoise to any tendency to variation of species.

Unfortunately, the instincts of nature are often violated in this matter, and convenience, or interest, or some fashion or prejudice prevents the free action of individual taste in the selection of married partners. Men are induced to marry women of the same tribe, and even of the same family, so that peculiarities of character and constitution are rather intensified than neutralised, or combined with others.

It is not, perhaps, possible ever to find the reasons for individual idiosyncrasies - to know why one child in a family is very dull, and another a genius; why one is gifted with health 


\section{Human Physiology.}

and strength, and another suffers all his life from disease and pain; why one is gentle and conscientious, and another hard and dishonest. We should have to know the secret history of parents and ancestors, and to know the physical and moral conditions of both parents before, and of the mother during gestation. Peculiarities of features and even of habits, not only of the parents, but of grand and great-grand parents, come out in children; and if these, why not all sorts of mental and moral idiosyncrasies? Every effect must have its sufficient cause, and our constitutions and characters are modified by a great variety of circumstances, of many of which we have probably no idea whatever.

Some of these peculiarities are of a very curious and even whimsical character. Milk is the natural diet of every infant mammalian from bat to whale, and is a pleasant and healthful food for adults; but some find it disagreeable and hurtful. Cheese agrees with most persons, but on some it acts like poison. Some cannot eat eggs, even in small quantities in cakes and puddings, without violent illness. Honey produces in some persons an eruption on the skin. Some cannot endure the presence of a cat, even when it is not seen or heard, but only felt to be in the vicinity. People are born with extravagant likings or disgusts for certain fruits, or other articles of diet. Some children have from infancy a great fondness and urgent desire for animal food, and some such a disgust of it that it is with great difficulty that they can be made to eat it, and if left to their own tastes they never touch it through life. One child has a perfect ear for music, another can never learn to distinguish one tune from another. So of the power of judging of forms and colours, and all artistic tastes and capabilities.

It is but too evident that great numbers of persons are born with tendencies to disease, sometimes of the lungs, sometimes of the heart, stomach, liver, kidneys, brain, or portions of the 
nervous system. Consumption, gout, rheumatism, and many other painful and fatal affections are hereditary. Why should we not inherit the forms of our brains as well as the forms of our noses? Every one can see in us the features of our progenitors-if they could see deeper they would find their physical, mental, and moral characteristics as well. It must, however, be remembered that mental and moral idiosyncrasies modify, but do not therefore destroy moral responsibility, which is always conditional. There are sins of weakness as well as of ignorance. The force of temptation must be measured with the power to resist. Freedom to do or not to do certain things is attested by consciousness, and asserted in our feelings of love and hate, praise and blame, honour and dishonour, \&c. The languages of all peoples are full of words and phrases which express our sense of right and wrong in ourselves and others. We have the phrase "Moral responsibility," because we have the fact which it expresses. Such words as right, wrong, good, evil, can no more be blotted out of our dictionaries than what they express can be taken out of our natures.

Still, it must be recognised that some people are born with tendencies to evil so strong that they can only be properly treated as moral idiosyncrasies or insanities. A very common one is the tendency to theft, which is a mere intensification of the greed cultivated by the customs of a very selfish and largely dishonest society. Another form of this is the mania for gambling, from its outlawed phases of playing games for money to the tolerated and even fashionable gaming of the turf, or the highly respectable kind called speculation. Another is the mania for intoxicating liquors, which is so extensive and disastrous as to loudly call for the establishment of asylums for inebriates. Every vice may be so intensified by hereditary transmission as to become an idiosyncrasy, and so pass beyond the control of judgment, conscience, and will, as to be properly regarded as an insanity. 
Similar tendencies exist in our physical constitutions. In some men the bones, from a lack of a proper proportion of gelatine, break like pipe stems. In others, there is such a tendency to hemorrhage that slight wounds may cause death. The habit of obesity is the annoyance of many, and they grow fat in spite of the most meagre diet and the most active exercises. An opposite tendency converts men and women into living skeletons. Some shiver with cold in summer, some burn with fever in the depth of winter. Many are born with gluttonous appetites for food; others are naturally temperate. We have the extremes of beauty and ugliness, of extreme charm of appearance and fascination of manner, and awkwardness and repulsiveness. These are peculiarities of body and mind, but it is very difficult to say whether the body thus modifies the action of the mind, or the mind forms or deforms the body. As I believe the spirit moulds matter, and the spiritual body shapes as it governs the material, I must believe that these imperfections and deformities have a spiritual basis as well as a material expression and action. If the body forms or governs the mind, what forms or governs the body? If matter controls spirit, what controls matter?

We have, however, to observe, that a very fine and symmetrical brain may be joined to a very weak and diseased muscular or glandular system. Scrofulous children who die early of consumption or hip disease are often very sweet and intelligent. Great beauty and excellence of character often accompany feeble and diseased bodies. It was said- "They whom the gods love die young," and thousands of parents are made to feel that their brightest and best are soonest taken from them. But they must also feel that this is not in a true order of life. There is a harmony of soul and body when outward strength and beauty corresponds to high mental and morai endowments. And the true life of man, we all feel, is to pass healthily, happily, and usefully through all the stages of his earthly existence. The 
growth of the spirit requires a complete life, and all its experiences from infancy to age. The only natural death is that of the gradual decay of the body in old age. All death from disease is unnatural death and premature mortality.

Among the phenomena of our bodily life, one of the most remarkable is sleep. Young children sleep a large portion of the time. Before birth, the whole life is probably a sleep, with some disturbing dreams. Many animals sleep through the winter months, taking little or no nourishment. The dormouse and the bear alike sleep for months together, lying in a torpor, which has we know not how much of sensation. Men sleep from four to eight or ten hours out of the twenty-four. The aged sleep less than the young. But we do not know why men or animals require to sleep at all ; the heart never sleeps even in hybernating animals. The lungs never sleep. The secretions are kept up, as well as the circulation. The nervous system of organic life never rests. Why should the nerves, or any part of the nerves of animal life require the repose of sleep? It has been thought that their alimentation requires it, but why not the nerves, or the nervous centres that govern circulation and respiration? What we know is, that long wakefulness is very exhausting, and that a sleep of only five minutes' duration wonderfully refreshes and invigorates us. The requirement of much or little sleep, and the curious power wnich some persons possess of measuring time in sleep, and waking up at any moment fixed upon beforehand, may be classed with idiosyncrasies, impossible to explain.

The sense of time may be an instinct, or intuitive faculty, like the instincts of animals and insects. Savages have several which seem almost lost to man in civilisation, but which a purer and more natural life might restore to him. A civilised man gets lost in the forest, and even in an unknown city. He travels round and round in a circle, with a most uncomfortable 
feeling of being lost. The savage, on the contrary, strikes across a forest, or travels in darkness, or a dense fog, with perfect confidence, and is never wrong or lost. He goes like the bee to his hive; he may not be able to tell how he does it, but it is not by the observation of trees, or any indications of direction. He simply goes by a sort of consciousness of space in the way he does not see but feels to be right. It is the action of what phrenologists call the faculty of locality-an instinct of place.

A similar power seems to reside in the faculty of numbers. There are men, children sometimes, who çan give in a moment, almost before the question is asked, the result of very large arithmetical operations; such, for example, as the number of inches to the sun, or the number of seconds in a thousand years, or things more complex and inconceivable. Musical prodigies have displayed inexplicable powers of melody and harmony.

The amount or persistence of life in any individual may be properly classed as an idiosyncrasy. Some families are longlived, as others are the reverse. Longevity does not depend upon strength or vigour of constitution, as indicated by external signs. Persons small and weak at birth, ailing in infancy, and feeble in maturity, may yet be very long-lived-may outlive hundreds more hardy in their seeming. It does not depend entirely on healthy conditions or habits. We have aged, libertines and aged drunkards. Other things being equal, temperance and virtue prolong life. As a rule, vice and intemperance lead to disease and early death. When a man brings on disease and death at eighty by gluttony or drink, he probably might have lived twenty or thirty years longer. Artisans in towns are generally short-lived. In some trades it is rare to find a man of forty, and the average life is twenty or twentyfive. Such people give but a small stock of vitality to their offspring. In the middle and upper ranks of English life, and 
even among the more comfortable portion of the agricultural labourers, instances of great longevity are very common. With a good stock of vitality, freedom from care, and tolerably healthy habits and conditions, there need be no lack of centenarians.

Length of life seems to be in some proportion to slowness of development. Animals that come quickly to maturity are short lived. The horse, which is old at thirty, is in full maturity at four or five. Man, who lives from eighty to a hundred years, matures at twenty or twenty-five. Physical precocity is often a mark of shortness of life, as mental precocity is sometimes. In the rare instances of puberty at seven, old age has come on at thirty or forty.

We know but little of the human soul, or how it lives in, and acts upon and through the human body. We know little of the human body, or even of the matter of which it is composed, and the forces by which its functions are performed. What we can see is, that an Infinite Wisdom and Power has ordered all its parts, and that it is our duty to keep it, as far as in us lies, in perfect health, vigour, and in the uses for which it was designed by our Creator. 


\section{CHAPTER VIII.}

\section{LAWS OF THE BODILY LIFE.}

The Law of Exercise-Effects of Training-Musical and Artistic-Natural Talent-Early Training-Effects of Bodily Exercise-Laziness-the Curse of Childhood-Boys and Girls-the Law' of Habit-Physical. Habits-Moral and Religious Habits-Moral Responsibility.

Certain laws, or modes of being and doing, form the basis of bodily health, development, and training, or physical education. The distinction between physical and mental education is not a very clear one, since the mind has something, if not everything, to do with all the voluntary actions of the body.

The first of these laws is that of exercise. Every organ of voluntary motion intended for constant or frequent use, is strengthened by use. Every such organ which is not used loses its power. The right arm and hand are generally stronger than the left. The arm of an oarsman or blacksmith becomes very strong and brawny; the arms of dancers are thin and weak. All muscles gain in size and tone by use; those unused become soft and weak. The same is true of nerves, alike of motion and sensation. Every sense increases in power and acuteness by exercise. Every sense is wonderfully educable. All our talents and faculties are subject to this law. Regular use, or frequent exercise, invigorates and increases their power, and a strong: argument in favour of the fundamental principles of Phrenology is found in the fact, that the head actually increases in size when various faculties of the mind are brought into vigorous action in the process of education. The law has no exception in any portion of the voluntary system intended for constant use. From bone to nerve or brain, exercise increases the force and strength-exercise is the condition of health. 
It follows that the whole body, and all its parts and organs, with the exceptions already noted, can be brought by judicious training into their best form, highest condition, and healthiest, most harmonious, and most powerful action. The fingers can be trained to all kinds of skilful manipulations, notably to a wonderful power of execution in playing instrumental music. The eye can he trained or educated to the perception of form, light and shade, and the gradations and harmonies of colourto all that makes the artist, where some degree of artistic talent exists. So the mind can be exercised to reason logically, or to calculate accurately, or to strong, clear, and graceful expression in speech and writing; and mind and body can be trained together to grace and elegance of manners, and all that belongs to good behaviour.

It must not be forgotten, however, that the natural talent must first exist. There must be an ear for music-a natural power of perceiving the relations of sounds, or much effort may be wasted. There are great numbers whom no amount of training can ever make musicians, painters, or sculptors. Poets are born, not made; but where there is poetical talent, it can be greatly improved.

What we shall try to teach or learn is a question of economy. Will it pay? It will never pay to keep a child to music if ear, and taste, and the love of it be wanting. The time and talent for other things wasted in this way are incalculable. Not much is gained by efforts to make artists of those in whom the faculties of form, size, and colour are deficient. Boys are put to learn engineering or architecture who lack the necessary talents or gifts for these pursuits, and who painfully blunder through a series of failures during their whole lives, because they, or their parents or guardians, have mistaken their vocation. There is for every one some employment to which he is best suited. The first step in education should be to ascertain the talents, capacities, and aptitudes of the pupil, and then develop, train, 


\section{Human Physiology.}

exercise, strengthen, harmonise, adapt, and perfect all mental and physical powers for his or her vocation.

In some things it is necessary to begin young. The nerves and muscles have a suppleness, a pliancy, a power of forming habits of action in early childhood which they never have afterwards. Many teachers of music insist upon a child begin-' ning regular practice as early as six years of age. And every one sees how easily young children learn languages, and how hard it is for many to learn them after they have arrived at maturity. At Smyrna, a Babel of tongues, children five or six years old can speak as many languages. The parts of education which depend upon imitation and memory of words and things should begin early; and those which depend upon thought and judgment left until these faculties have developed. A child learns to dance, and to behave gracefully, with little effort. An adult learns with difficulty, with an intellectual effort, and never acquires the suppleness and unconscious ease of one trained in childhood.

And the same may be said of language. With a little trouble, chiefly in setting good examples, and the daily correction of slovenly habits, children can be trained to clear, distinct articulation, a refined pronunciation, simple and elegant forms of expression, and all that is nice and charming in conversation, and that most useful of all accomplishments, the art of reading aloud, which scarcely one person in a hundred now possesses in any satisfactory degree. A large proportion even of our professional readers read very badly. It is painful to hear them in the pulpit and on the platform. But it is certain that almost every person with the necessary understanding might learn to speak and read gracefully and effectively.

Exercise strengthens nerve and muscle, and by that means brings the vital organs of the body into more vigorous action. Exercise wastes the material of the tissues. The watchful nerves are cognisant of this waste, and call upon the heart and 
arteries for supplies of blood to furnish new matter. The heart and arteries and whole blood-forming organism are strengthened by this exercise. Food is needed for blood, and there is increase of appetite and digestive power; the blood is thrown. with a stronger current into the lungs, and the muscles of the chest and the diaphragm act with more vigour to increase the respiration. The chest expands, the lungs enlarge, the brain is furnished with more blood and better blood; good blood and nerves produce more perfect secretions, and the whole man -body, brain, soul, and spirit-is filled with a higher, purer, and more vigorous life.

In the opposite process, laziness leads to disease and stupidity; want of bodily exercise causes a languid action of the heart, poor blood, loss of appetite, dyspepsia, obesity, narrow chest, feeble respiration, imperfect secretions and excretions, retention of impurities in the body, and thence a train of diseases.

The condition of life is use. "Rust consumes faster than labour wears." This is said of metals; but it applies with tenfold force to the human organism. In idleness the body falls into languor, disease, decay, and the mind into imbecility. The musician out of practice cannot play-men forget languages and sciences. To be good we must do good. We need the daily exercise of the highest theological virtues. To keep us up to our best life we need every day to exercise a wide range of our moral, mental, and physical faculties. Every day we should try to learn and do something which will advance us to a higher level of life. In this requirement, and in this power of progress, we differ from the lower animals.

Happily the natural tendencies of childhood are to an abundance of vigorous exercise. What a wonderful intellectual and muscular activity is displayed by children from a year old in play. The monotony of most kinds of labour may tire and disgust them, but they can play from morning till night, and 


\section{Human Physiology.}

might work as well, if work could be found that was varied and amusing. Therefore, a child brought up in the freedom of an out-door life, with genial playfellows, grows up strong and healthy. The curse of childhood is to be shut up six hours a day in unventilated school-rooms, breathing bad air, and wearied with useless tasks, called education. Better a healthy brain, vigorous lungs, a pure blood and good circulation, and free action of the skin and all organs of purification, than ever so accurate a knowledge of the names, dates, and ages of the Kings of Israel and Judah, or even those of England, and all the other useless and quickly forgotten things which burden the mind of childhood.

Girls fare far worse than boys, and we see the result in the ignorance, the helplessness, and the wretchedly ill health of great numbers of women. From birth to seven or eight years of age girls and boys live and play together, and are much alike; but when the little Miss of the upper and middle classes becomes a young lady all is changed. While the boy is expanding his chest and hardening his muscles with football and cricket, and all the vigorous sports and pastimes of the English schoolboy, his sister is at her pianoforte, her needle work, her drawing, or walking out in boarding-school processions. A young female costermonger is as hardy and agile as a tigress, but a young lady is too often a bundle of nerves, and very unfit to become a wife and mother. The consequence is, that great numbers become a prey to consumption and nervous diseases.

Another principle of life is what may be called the Law of Habit. All acts required to be done frequently grow easy by repetition. Repeat a sentence a few times, and it is learned by heart. Perform any muscular act a certain number of times, and we do it withoust effort. It is the first step that costs Each repetition requires less effort, until we can perform the feat without difficulty, and finally without consciousness, and reven in our sleep. Nerves and muscles after a time become 
self-acting-work automatically, or without any apparent effort of the will. We walk, we sing, we play on instruments, we write, without any consciousness of effort. Habit fixes what: exercise has gained.

With a little trouble, we can form habits in our bodies of great importance to health. We can practice deep breathing. until it becomes a habit, and our blood is always well supplied with oxygen. We can habituate ourselves to the kinds and quantities of food, and times of eating, which are best for us, and to the proper period of sleep. Even the evacuations of thebody may be brought under the law of habit.

We are continually forming bad habits ; habits of using stimu-lants and intoxicants ; of taking brandy and tobacco ; of relying. on tea and coffee; of depending upon cathartic medicines; of eating high-seasoned food, or eating too much or too often. It costs much sometimes to break off a bad habit; but how easy not to form them! And it is easier to form good habits than. bad ones. The quantity of food is so much a matter of habit, that two persons of equal weight, and mental and bodily activity, will consume widely different quantities of food-one eating. four times as much as the other, the surplus being of no possible advantage, but the reverse. So habit makes five meals. a-day seem necessary to some persons; while others live equally well-perhaps, far better-on two meals a-day. It is a matter of habit whether a man sleep six hours or nine hours a-day; and three hours a-day is one-eighth of life. It is therefore of great importance that we form simple, natural, and healthful habits, and in all ways order our lives to the highest uses. There is. no tyranny so odious as that of a bad habit, no blessing so great. as that of having formed good ones.

And the law of habit applies to the moral and spiritual lifeof man as much as to his intellect and muscles. We can acquire habits of feeling as well as of thought and action. One has but to watch over impatience and irritability of temper to 
bring them under habitual control, and when a passion is not indulged it soon ceases to act. Men can become habitually good-natured. We have but to assume the natural language or manners of some virtues to come in a little while to possess them. We say rightly that men are habitually honest, truthful, and religious. We are instructed to acquire a habit of prayerfulness. We are told to make acts of faith, hope, and charity, and these acts become habitual. The importance of forming habits of temperance, self-restraint, patience, and the domestic manly and womanly virtues in ourselves, and, by our influence, in others, can scarcely be over-rated. Habits of chastity, of continence, of keeping perfect control of all passions liable to disorderly manifestations, are necessary to the peace of families and society. Education should consist very largely in the training or discipline which favours the formation of such habits. If common soldiers, recruited from the most disorderly members of the lower ranks of society, can be brought into habits of order, obedience, courage, and even heroism, surely everything is possible to a right system of training applied to the best materials of human society.

And why should we doubt that a perfect analogy runs through all the faculties of the mind, and all the organs of voluntary actions in the body. If what is true of a muscle, is true of an intellectual faculty or its brain-organ, music or number, for example, why should we stop there? Why does not the same law apply to all our emotions, and the highest acts of which we are capable. Why may not love, devotion, conscience be strengthened by exercise, and by habit become a second nature? What is moral and religious training but the strengthening of our highest faculties by exercise, and the formation of good habits?

If this principle be really universal in its application, then we have the key of human progress, human perfectibility, all reformation in the range of human possibilities in our hand. 
$\mathrm{W}^{\gamma}$, have to train men to good morals, honesty, and the love of brotherhood, as we train men to be soldiers, or rowers, or cricketers. We have to root out and repress what is evil, and develop, strengthen, and bring all his useful faculties and goor tendencies into vigorous and harmonious action. We can make good cricketers by a certain course of training, good dancers, good gymnasts, good soldiers. Why can we not as surely make good men. and women? good citizens, good statesmen, good Christians? I believe that we can and shall.

Judgment and conscience watch over the passions and emotions of man, and, by the aid of the will, have the power to bring some into more active exercise, and repress and regulate others. We can educate ourselves, control ourselves, form our habits of thought, feeling, and action, and therefore, and so far, we are morally responsible. We can influence the conduct of others by precept, by example, by approbation or condemnation-by all the motives that govern those to whom we are in any way related. Here, again, are high responsibilities. When we influence one person to good or evil, we may be a blessing or a curse to thousands now living, or to live hereafter. There is no limit to the good or evil which may come from our influence upon one human soul. One man may mould the character of a nation through centuries, and that nation may widely affect the destinies of the race. The character of that man may have been formed or strikingly modified, by parent, teacher, friend. There is both exultation and terror in the thought of the good or evil that may be done by one individual, and the responsibility that rests upon every one of using his power for good and not for evil 


\section{Human Physiology.}

\section{CHAPTER IX.}

LIFE AND DEATH.

Subjects postponed to Part Fourth-Vital Heat-Equality of Heat-Life in High and Low Temperatures-Origin of Animal Heat-Radiation and Evaporation-The Phenomena of Death--Possibility of the Resurrection-Conscious Identity-Pleasure and Pain.

IN Part Second I have considered at some length the phenomena of Life; but there are some of its incidents connected with the human body which may require more particular mention. I have also to speak of the relation of the body to the termination of this stage of our existence-of that change which we describe as Death.

I have adverted in a general way to differences of sex in vegetables, and through the animal kingdom. Sex varies the human body, and modifies the human soul. There is a striking difference in the thoughts and feelings, brains and nervous systems, forms and organs of men and women. Into this subject, and all that-belongs to the great function of generation, or the mode which the Creator has appointed for the continuation of all living beings upon the earth, I shall enter fully in Part Fourth: I have therefore omitted from this Part all account of sexual peculiarities, and of those portions of the human body engaged in the generative function. Some writers on Human Physiology have thought proper to omit all mention of the manner in which human beings are brought into the world-to ignore what is certainly not the least important portion of the human economy, in respect to health, duty; and happiness; to utterly neglect what it is of the greatest importance that all should know ; to leave people in ignorance, where ignorance is full of peril. I cannot follow their example. There is no fact in nature which it is not well to know. There is no fact in the 
natural life of man which may not be properly treated by a scientific and conscientious writer, who seeks only the highest. good of his readers. Leaving, then, the whole subject of sex, generation, and hereditary influences to a Part specially and entirely devoted to matters of such profound interest and importance, I close this Part with some words on Vital Heat, and. Death.

Heat is the accompaniment of life--some hold that heat is life. Plants and trees, while they live, are never so cold as the wintry air around them. All animals, even those called coldblooded, resist in some degree changes of temperature. They are never so hot or so cold as the extremes of temperature to which they may be exposed. Man has probably the maximum. of this vital power of maintaining an independent temperature. A dead body freezes as soon as the mercury falls below the freezing point, and roasts when exposed to a hot fire. A living. body resists heat and frost. In the polar regions and the tropics the blood remains at the same temperature. Whatever the condition of the skin or the extremities may be, the blood in the centre of the system keeps very nearly at the same degreeof warmth, about $98^{\circ}$ Fahrenheit. If there is any difference, it is warmer in winter than in summer, because respiration, circulation, and all vital processes are more active. Low animal organisms may be frozen to a certain degree, and still retain life; but in such cases there must be a centre of comparative warmth and vitality.

A man can remain in an oven while a beefsteak-flesh like his own flesh-is thoroughly cooked by his side. Many persons. have endured an atmosphere heated to $400^{\circ}$ or $500^{\circ}$. In the Turkish bath we can bear a temperature of $150^{\circ}$ to $200^{\circ}$, not only without injury, but often with great comfort and advantage. I have taken my morning bath with the thermometer at $20^{\circ}$ below zero, or in $52^{\circ}$ of frost, where every drop of water that fell upon the floor turned instantly to ice, without the least 
inconvenience, and with less feeling of chill than in an ordinary English temperature. And when one is out in a temperature of $40^{\circ}$ to $60^{\circ}$ of frost, he finds a healthy exhilaration, and a pleasant glow in such an atmosphere.

The production and maintenance of heat in the body is a vital process for which chemistry does not fully account. The union of carbon and hydrogen with oxygen, always going on in the system, is accompanied by the evolution of heat, but it cannot be shown that the heat developed in birds while hatching their eggs, or the external heat of fever, or that which is connected with the reproductive process in certain plants is the result of the destruction of tissue. The heat of inflammation has more resemblance to that of electricity, than that produced by combustion.

The human body, like all masses of matter, is constantly sending off heat by radiation. Clothing hinders this in some degree, and so aids us to husband our heat. When warnly clothed we waste less matter, and need less food to supply the waste. When the temperature rises above $70^{\circ}$ Fahrenheit, we need more than radiation. Then the action of the sweatforming glands is increased, and the body is cooled by evaporation. It is this profuse perspiration, and the rapid taking up of the heat of the skin by the conversion of water into vapour, that enables men to live near furnaces, and even in hot ovens. But these sudoriferous glands act under the influence of the nerves, which are the inmost organs of life. When the living power of the nerves of organic life is exhausted-when life is spent-the temperature can no longer be maintained. The extremities become cold and numbed; a clammy coldness overspreads the skin; the senses are dulled; the brain ceases to act; respiration becomes slow, slower, and stops; soon after the heart ceases to beat. The eyes lose their brightness, and assume a glassy stare; the whole body becomes rigid - the last. action of vegetative, or the mere bodily life; then comes relaxa- 
tion, softening, and the free action of the chemical forces which life had held in check. The body putrifies; gases are evolved, disgusting and noxious compounds are formed; and the body, so full of life and beauty, becomes a nuisance and a horror which we are glad to bury out of our sight. The body returns to its elements, and after a time only dust and ashes remaina little lime, magnesia, potash, soda. The carbon has united with oxygen to form carbonic acid; the nitrogen has passed off as ammonia, and the hydrogen has evaporated as water. A human body placed in an oven dries up to a weight of about twelve pounds; add more heat and it calcines into a few ounces. Its matter enters into the organisation of vegetables and animals. Egyptian mummies are ground up and sold as manure for English turnips and wheat, to make mutton and men, who in their turn will furnish food for more vegetables and animals. And what then, the reader may ask, becomes of the great Christian dogma of the Resurrection of the body.

St. Paul, writing to the Christians of Corinth, says-"Some man will say: How are the dead raised up? and with what body do they come? . . . . Thou sowest not that body which shall be; but God giveth it a body as it hath pleased him. It is sown a natural body, it is raised a spiritual body." It is evident that the matter which is constantly entering the body and leaving it is not the substantial body. The whole matter of our body changes, some physiologists reckon, as often as once in three months. The old matter is being continually wasted and carried away. We live, therefore, so far as this matter is concerned, in a constant succession of bodies; but there is an interior form which never loses its identity from first to last, which is in the minute germ, which expands to the maturity of life, which takes and uses all this constantly changing matter. A man who weighs at one period of his life 120 lbs. may grow to weigh $300 \mathrm{lbs}$., and then waste away again to a skeleton. "This changing and superfluous matter is not to be considered 


\section{Human Physiology.}

his proper body. The water which at all times constitutes fourfifths of our weight, is not our body. The lime embedded in our bones is not our body. What is our body? It may besomething quite apart from this changing matter-scarcely occupying space or having weight-something so identified with the life and soul of man as to be indestructible, but which shall have the power to again take on matter and form, and become "a glorious body." We know too little of matter or of what constitutes the individual identity of man, to say that the dogma of the Resurrection, as explained by St. Paul, is impossible. It may be as natural as the metamorphoses of insects; and the matter of which our outer bodies is composed at any period of life, or at the time of death, may have nothing to do with. it. The testimony to the fact that the spirits of the departed sometimes take visible and palpable forms-clothe themselves, so to speak, with matter, or with force which impresses our senses as matter, is overwhelming; and if we admit the immortality of the soul, we cannot reasonably deny the possibility and even the probability that it may resume, not the gross and corruptible body, changing from day to day; but its real, substantial, and identical body, of the true nature of which we may beable to form little conception.

Of the future life we know only what has been revealed to us. We are probably quite unable to comprehend the modes. and conditions of our future existence. What we most feel is, that we cannot lose our identity. In this life, though the matter of the body is constantly changing, we feel it to be the same body, and it is not improbable, and seems to be necessary to us, that this conscious identity should continue, and that we should for ever retain all that really makes a portion of our being.

The sensations of the bodily life of man, and probably of all animals, various as they may be, may be referred to two classes, those which give pleasure and those which give pain. The: 
sensations of health in all creatures are those of pleasure. There is a mild enjoyment-what we call comfort-in mere existence ; in living and breathing. - We hold to mere life with a strong clutch, and have an instinctive horror of annihilation. And it may be that we love life because we have, or hope to have, pleasure or happiness in it. All our senses give us pleasurable sensations. We enjoy beauty, music, odours, savours, and some phases of the sense of feeling, with an exquisite enjoyment. We have higher pleasures in the intellect and the emotions. Every achievement, success, approbation, above all, love, fills us with delight. Memory brings to us the accumulated pleasures of the past. Hope promises still more in the future. We have wonderful sources of happiness in nature, in ourselves, in our fellow creatures.

But there is also the liability to pain. Physical pain is evidently protective. It guards the body, in men and all animals, from danger. The fear and fact of pain is a perpetual warning. We protect our senses, our limbs, our lives, because every injury to the body is attended with pain. Pain warns us against too great fatigue of body or brain. We are compelled to rest by our sensations. But for pain we should burn or freeze ; or die of hunger or thirst. Our emotions are also painful, and this pain must also have its use and necessity. Simple deprivation of mental or emotional pleasure gives us pain, like that of hunger or thirst. We long for approbation, we long for love. We are deeply pained at scorn, contempt, hatred, or even indifference. We suffer from care, anxiety, the apprehension of future evils and sufferings. From these moral pains all the animal races seem to be quite free, and wanting also in the corresponding capacities for happiness. Some animals, however, suffer keenly from the loss of their mates, and persons to whom they have become attached, and dogs and birds are capable of a kind of jealousy. But it is not probable that any animal is troubled with the apprehension of future calamities. 
Man alone consciously reaches forward to the future, and enjoys the anticipation of a life of unending happiness. $\mathrm{He}$ alone, so far as we can judge, has the idea, the hope, the assurance of immortality.

Bodily pain is very terrible; but as every such pain comes from the violation of some natural law, it can be almost or entirely avoided. We are members one of another, all linked together in a common life, and so suffer by sympathy the pains of others, especially those near to us and those we love. Each man must keep himself in those conditions which give happiness and preserve from pain-but this is not enough. $\mathrm{He}$ cannot entirely save himself until others are saved. No one can be quite well or quite happy until the whole race is in the same condition. We must, for our own sakes, love our neighbour as ourselves. Our own highest, perfect good, rests in the good of others. Supreme selfishness forbids us to be selfish.

Physical pain, or the liability to it, and mental disorders are hereditary. We suffer for the sins of our progenitors. It is not easy to see how this is just, or why man should have been formed with such liabilities. It is, however, the fact; and we must believe that there is no mistake and no injustice in children suffering for the sins of their parents "to the third and fourth generation." It is one more of the mysteries of which life is so full. What we know is, that evil causes suffering, and not alone to the evil doer. Every day we see the suffering of wrong-doing fall upon an innocent victim, an injured woman or an innocent child. What we have to do is to live to the highest law we can see-to save ourselves from suffering by doing our duty, and so do all we can to save others from sin and its consequences. Nature is inexorable, but man is called to exercise the highest and purest love-the love of charityand that may possibly be a compensation at last for all physical and moral evils.

Health gives security from physical pain. In the highest 
health such incidents as dislocations, fractures of bones, and wounds are comparatively painless. Perfectly healthy women have very little pain in childbirth-some none whatever. Persons of good constitutions, who live upon a simple, perfectly healthful diet, never feel a disagreeable internal sensation. Who. does not know aged people who never had a day's illness, and do not feel a pain for years together? I have passed intervals of five years or more without a pain that I could remember. What is possible to one is possible to all in the same conditions. Even inherited disease can be, to a great extent, cast out of the system, and painless health, and a happy enjoyment of life, are in the power of most persons, who can or will comply with the required conditions.

Mind and body act reciprocally on each other. A pure, clean, unexhausted body is the tabernacle of a serene and cheerful spirit. A sound mind in a sound body is the condition of happiness. We can reduce disease to its minimum- whatever that may be-and I see no absolute obstacle to its being. stamped out altogether. We can raise the condition of man to. its maximum of health and enjoyment, and I do not see any limit to that maximum short of perfect health and a corresponding happiness. This can come now, as far as evil surroundings. will permit, to individuals - health, sanctity, peace. What comes to one, may come to all. If one man can be redeemed, the whole human race can be redeemed. If one man can be perfectly, or in a high degree, healthy and happy, all may be. Like causes produce like effects. I do not believe it impossible that the will of God should be "done on earth as it is in heaven." 


\section{PART FOURTH.}

TIIE LAWS OF GENERATION.

\section{CHAPTER I.}

\section{VEGETABLE REPRODUCTION.}

Vignity and Importance of the Function of Reproduction-Various Modes of Reproduction in Vegetables-Functions. of Flowers-Processes in Fertilisation-Pollen and Germ-True Generation-Formation of Bulbs-Tubers-Slips, Buds, and Grafts-Spores-Loves of the Plants.

From the simplest vegetable to the lighest animal we find life displaying its powers, forces, and organisms in the most wonderful and beautiful manner; but there is one power in all living things beyond all others wonderful - the power of reproduction. All life on the earth would soon perish if plants and animals of every kind were not provided with the means of producing similar organisations. A tree may live thousands of years, but it perishes at last. There are vegetables and animals that live but a few hours. The individual dies, but the race survives, because the individual is provided with a wondrous power of producing other individuals to carry on the life of the race or species. The function of reproduction is therefore of the highest importance and dignity. It is the work of creation for ever going forward. The production of a plant or animal, its development from a living germ, the gradual formation of all its organs, and its whole life processes are very wonderful; but the most wonderful thing any plant or animal can do is to 
reproduce itself - to pass on its life in similar organisms, so that its species may be continued for an indefinite period. It is this grandest of the functions of life that we have now to examine.

In the vegetable kingdom, where this phenomenon may be most conveniently examined, there are several modes of reproduction; even the same plant may have two or three distinct methods of propagating its kind. Let us look at our lovely friend of the earliest spring-time, the crocus. Each bulb sends up its flower, and each flower produces germs and pollen. The germ is formed in the ovary or female organ of the flower; the pollen is formed upon the anther, the top of the stamen or male organ. The pollen, a cell containing the masculine element, fertilises the germ-cell, or feminine element, and in some way, incomprehensible to us, the union of the two elements results in the formation of the living germ, which, under favourable circumstances, developes into the perfect plant, which in turn produces new flowers and seeds.

The flower of every plant, with its seed or fruit, is the consummation of its life. On flowers nature has lavished all her ingenuity of construction and adaptation, beauty, perfume, and sweetness. In most plants the masculine and feminine elements are in the same flower, stamens and pistils growing almost in contact. In upright flowers the stamens are longest so that the pollen can fall upon the pistil; in drooping flowers it is the reverse. The snow-drop at first holds up its pure petals to the sun, but when the period comes for the masculine and feminine elements to form the living germs of new beings, it modestly hangs down its head, and it is this change which makes that union possible. Professor Maury says:- "The snow-drop must at the period of fecundation bow its head and afterward raise it up again. There must be a certain relatior between its fibres and the earth's attraction to make possible the continuation of the species!" 
Many flowers are provided with organs which secrete honey; this honey is stored in deep vases, very deep sometimes, as in the Columbine. Bees and other insects, and even some birds, as the humming bird, attracted by the honey, and seeking it in its deep cells, unconsciously aid in the process of generation. The pollen adheres to their bodies or wings, and is brought in contact with the stigma of the same flower, or others of the same species, to which it is made to adhere by a viscid secretion. All flowers do not contain both male and female organs of generation. They may be on different parts of the same plant, as in the maize, or Indian corn, where the pollen is produced on the very top of the tall stalk, sometimes twenty feet high, while the long silky pistils grow from the cob which holds the germs in rows about the middle of the stalk. Sometimes the male and female flowers are on different trees or plants, and their propagation is entirely dependent upon insects or favouring breezes.

When the pollen cell, containing the fecundating element falls upon the stigma of a flower, adhering to its viscid secretion, a very beautiful vital process commences. The inner membrane of the pollen extends itself into a tube which penetrates into the style; which is sometimes two or three inches in length, until it reaches the germ in the ovary, where it penetrates the germ, or meets a corresponding tube thrown out by it. The two elements unite, the germ is fertilised and grows into a seed, the egg of the plant, in which is formed, and from which is developed the new plant which is to continue the species. The living germ of the plant is very small, quite microscopic in its dimen-

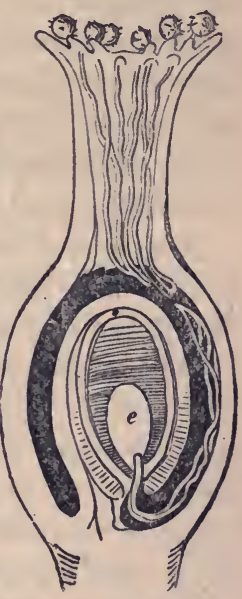

Fig. 58.

Section of PISTIL, with Pollen Grains, sending Tubes down to the Ovary. 
sions. The seeds of plants contain albuminous and oily matter, destined to be the first food of the young plant, and which also, in such seeds as those of wheat, barley, rice, peas, beans, \&c., furnish important stores of food for men and animals. If we examine such seeds, we shall find the real germ to be a mere speck, a microscopic cell, which must, however, contain potentially the future plant or tree, and all it is capable of producing; must contain form, character, colour, odour, and the directive or formative principle which governs its whole life and development. And this character of the plant, observe, resides in the two elements, male and female, which join to produce it, for by bringing together these elements, gardeners are able to produce all kinds of crosses, hybrids, and varieties.

The reproduction or continuation of the species of plants by this process is called true generation; but this is not the only mode by which vegetable life is continued or extended. The bulb of our crocus which sends up a stalk, leaves, and flower also throws out from its side fibres which form new bulbs, which the following season separate from the parent bulb, and themselves produce bulbs and flowers.

Take now a tuberous plant-the potato. It has its pretty flowers, and produces balls full of seeds which will produce new plants and varieties; but at the same time there grow out from the roots great tubers, and on these are buds which will grow into perfect plants, producing in turn seeds and tubers. The strawberry has also a double method of propagation. It produces flowers and seeds, but it also throws out long vines, which at intervals send down roots on which grow plants, and so on until a whole field is covered with them.

We imitate these processes of nature in multiplying plants and trees - of one making many. Ladies cut slips of geraniums, roses, and other plants, placing them in pots of moist sand or earth, when the covered buds send out roots, and those exposed to the light expand into leaves. The Chinese multiply fruit 
trees by moulding a ball of earth upon a twig, keeping it moist, and making a section in the bark below it. When roots have penetrated the earth they cut it off and plant it. Each bud of a tree has its distinct life, and in most cases can be transferred to another tree of an allied species and made to grow, producing, however, its own peculiar flowers and fruit. Each bud is a germ; the seed germs are similar, but differ at least in this, that they sometimes produce, as in potatoes and apples, new varieties. A bud or graft gives us the same fruit as its parent tree. A tree which grows from an apple seed may produce very different fruit. For this reason, when fruit trees are grown from seeds, gardeners bud or graft them; that is, transfer to them buds or twigs from trees producing a favourite variety, and let the transferred buds grow to form the future trees.

Low forms of vegetation, as the various kinds of fungi and ferns are produced from spores, which are germs or rudimental buds rather than seeds. They are very small, produced by myriads, as in the puff ball, and are so light as to be blown about by the winds, and almost fill the atmosphere. Whereever air can penetrate, it carries with it the germs of vegetation as well as those of the lower forms of animal life.

But it is in our lovely and odorous flowers that we have the highest types of the generation of vegetable life; and the favourite science of Botany largely consists of the study of the organs and processes of vegetable reproduction, or what the Elder Darwin in his curious poem calls the Loves of the Plants, which present us with the most delightful analogies to the higher processes of reproduction in animals and our own species. Botany is therefore a charming introduction to all other branches of natural history, and especially to that branch of human physiology which we are now considering. 


\section{CHAPTER II.}

\section{ANIMAL REPRODUCTION.}

Varieties of Modes of Reproduction in Animals-Gemmation-FissionRapid Multiplication-Artificial Reproduction-Production of EggsMasculine and Feminine Elements-The Propagation of Fishes, Insects, Birds, the Mammalia-Size of Eggs.

REPRODUCTION in animals is curiously analagous to the same process in the vegetable kingdom. There are the same varieties in the modes of multiplication and generation. The process of generation in some of the lower animal organisations is exactly like the throwing out of new bulbs in plants. The polypes throw out buds which in a little while grow mouths, fringed with cilia or tentacles, while they are still holding by stalks, and drawing part of their nourishment from their parents. When enough matured to get their own living they drop off, swim away, and shift for themselves. This is gemmation.

Fission is a common mode of propagation or multiplication among the infusoria. An animalcule is seen to contract in a ring around its centre; the fissure deepens, and it divides into two distinct beings, which also divide, and so on-multiplying with surprising rapidity. It has been estimated that one of these animalcules could produce by these successive divisions in eight weeks a progeny of two hundred and sixty-eight millions. This reproductive power is, however, almost rivalled by some fishes and insects. The carp lays seven hundred thousand eggs in a season, and lives two hundred years. The possible progeny of a pair of these fishes is almost beyond computation. The cod is said to produce from four to nine millions of eggs. The female termite lays sixty thousand eggs a-day for a considerable period.

Some of the lower animals may be multiplied artificially like vegetables. Thus, if some species of the polypus are cut in 


\section{Human Physiology.}

pieces, each piece produces the missing parts, so as to become a perfect animal, as cuttings of a geranium produce geraniums. But perhaps the most curious mode of multiplication takes place in some sea-worms. They divide into sections by constricting rings, and each section forms for itself head, eyes, \&c., at one extremity, and tail at the other, while yet the sections are united; but when all is ready each section sets up its own independent life, and then produces in its body germs of similar worms, by the more usual process-just as some vegetables propagate by seeds, as well as by bulbs or tubers.

These modes of multiplication-fission, gemmation, \&c., such as I have described are, however, not the rule in nature, but the exception, or variation-a ruder method of the extension of life, which is confined to the lower forms of animal existence. As vegetables are generally produced from seeds, animals are generally produced from eggs. There is no good reason, so far as we now know, to believe that there is any spontaneous generation of vegetables or animals-that is, that any vegetable or animal ever of itself is formed from matter without a spore or germ which has been produced by a similar organisation. At some time, and in some way, every kind of living form had its beginning; but no one has seen such beginning. Creation is a mystery. Every living thing upon the earth has at some time, somewhere, and somehow been created; but we do not know the when, the where, or the how. Human science reveals to us something of the phenomena of naturenothing of its causes or beginnings.

As in vegetables we find the beginning of new organisations in the formation by the generative organs of a plant, which are in most cases portions of its flower, of a germ cell in the ovary or female organ, and of a pollen cell by the anther or male organ, which unite to form the living germ, which develops into the perfect plant-so in all the higher forms of animal life, in oysters, fishes, insects, birds, beasts, and men, we have 
germs or eggs formed in the ovaries of the female, which at a certain stage of development are impregnated, or fecundated, by union with a similar germ, produced in a somewhat similar organ of the male-the male and female elements uniting to produce the perfect being. The unfertilised, unimpregnated, or unfecundated ovum or egg quickly perishes. The one to which has been added the masculine element is from that moment endowed with life, and, with favouring conditions, developes with a wonderful rapidity.

Fishes produce a vast number of eggs, as may be seen in the hard roe of herring, which, when they have arrived at a certain stage, are spawned-that is, expelled from the body in places which the fish instinctively find for that purpose. Salmon come hundreds, perhips thousands of miles through the deep ocean to lay their eggs in the shallow fresh water streams in which they themselves were hatched. The male herring and salmon produce, in organs not unlike the ovaries, myriads of sperm cells, destined to fertilise the germ cells of the female. This is the soft roe- a brain-like substance, chiefly composed of these cells. The male fishes attend the females, and fill the water where their eggs are laid with what seems a milky fluid. The two elements come into contact, perhaps by a mutual attraction, fecundation takes place, and, in due time, swarms of young fishes are the result.

With insects and birds, the process is a little varied. The eggs are formed, as with the fishes, in the ovaries of the females, but at a certain stage they are fecundated before leaving the body, by the male element being conveyed to them by a process similar to that which takes place in flowers. The seminal fluid of the male, corresponding to the pollen of the plant, is conveyed to the germ in the ovary by means specially adapted to that purpose. After the egg has grown to its full size-in insects covered with a tough menbrane, and in birds with a hard shell-it is placed in som 
proper nest, and hatched either by solar heat or the warmth of one or both of the parents. Animals so born are called oviparous-born from eggs. A few fishes, as the shark and skate, lay fecundated eggs like birds, with curiously formed horny shells, and cables for mooring.

With the mammalia, the higher orders of animals, including the human species, there is still another process. The egg or germ is formed in the ovary of the female. When fully formed it bursts from its containing membranes, with a certain degree of excitement of the generative system, and passes through tubes provided for that purpose into a receptacle called the uterus, or womb. If here met by the seminal fluid, or fertilising masculine element, tecundation takes place, a perfect germ is produced, fotal life begins, and the animal is, so to speak, hatched in the womb of its mother, nourished by her blood, and grows until it is ready to come into the world and live its independent life. Animals so produced are called viviparous, or born alive.

The young of the kangaroo, and other marsupials, are born in a very immature condition, and carried in a kind of bag formed upon the abdomen of the mother; within which are the teats from which the little ones draw their nourishment.

The eggs of birds, from those of the humming-bird, like peas, to the great eggs of the ostrich, which will furnish a dinner for six men, contain not only the germ, which is very minute, but its supply of food-the materials from which its body, bones, feathers, \&c., are formed, during the process of incubation or hatching. The white of the egg, almost pure albumen, is not essential to it, but useful as food. The eggs of many animals are without it. The yolk, consisting of albumen and oil, contains the matter first taken into the organisation. The germinal spot, a point of matter, is the real germ, and can only be seen under the microscope. The eggs of viviparous animals are of extreme minuteness. That of a dog is the $\mathbf{I - 1} 3$ oth of an inch 
in diameter including yolk, germinal vesicle, and germina, spot. The human ovum is still smaller, about I-I 4 oth of an inch in diameter; and in the circumference of that small diameter lies, what a world of character and power!-lies all that shall distinguish the highest example of human civilisation and culture from the lowest savage-poet, philosopher, hero, idiot, ruffian, lunatic -all the possibilities and potentialities of humanity.

\section{CHAPTER III.}

\section{GERMINATION AND FECUNDATION.}

Production of Germs in Vegetables, Insects, and Animals-Varying Powers of Reproduction-Office of the Ovaries-Anatomy of the TestesEvolution of Spermatozoa-Results of Impregnation-Changes at Puberty-Peculiarities and Mission of Woman.

AT a certain period in the life of a plant, in organs prepared for that important function, are formed the germs of new plants. The germ producing organ, frond or flower, does its work and dies. The tree lives on, but each individual bud, producing flower and seed or fruit, perishes. This is the law of vegetative generation. Such is also, to. a great extent, the law of insect life. The insect produces one crop of germs; they are fertilised by one conjunction of the sexes; the eggs are deposited, sometimes in immense numbers, where they can be hatched in safety, and where its proper food can be found for the new being in the earliest stage of its development; and then, as if the whole purpose of life had been accomplished, the male and female alike perish. In some cases the male insect sacrifices his life in the very act of tecundation. 
In the higher orders of animals, fishes, reptiles, birds, and manmals, the production of germs goes on year after year in varying periods. The guinea pig begins to breed at two months old, and the higher the type, the later is the period of germ formation, until in man the period of puberty, or the beginning of the generative function, is at about fifteen years, varying from twelve to eighteen; but the natural powers are scarcely at their full strength and fitness until some years later.

The power of reproduction as to numbers seems to be in the inverse ratio as to development. The lowest forms of life multiply with amazing rapidity; some insects produce myriads, fishes spawn eggs by millions, hens lay an egg a-day for months together, rabbits, cats, dogs breed every few months, and have at each birth a numerous progeny, while the higher orders of mammalia produce their young but once a-year, and have but one, or, in rare cases, two at a birth. When the human germ has been slowly formed in the ovary, and perfected up to the period when it bursts forth in its first birth, fit for impregnation, it is nine months in arriving at the development which fits it for birth and independent existence. For twelve months more it draws its supply of nutriment from the mother, and two years may be considered the normal interval from birth to birth. It should never be less with a proper regard to the health of the mother, and the proper development of her children; and the practice of shortening this period by hiring wet nurses is a. violation of nature which is avenged on parents and their offspring. The mother is exhausted by too frequent child bearing, and children are deprived of the love, the magnetism, the life of the mother, which comes to them from her blood transformed into the most delicious food for them, and the nervous and spiritual food which no money can buy, and no one but the mother can give.

The human germ cell, or egg, is formed from the blood in a 
gland-like organ, about an inch and a-half long, oval shaped, placed in the lower part of the abdomen, in the groin, and represented (7) on each side of the uterus, or womb (Fig. 59). In each ovary, from the period of puberty, in a healthy female, there is a constant formation and growth of germs, or ova, which goes on for thirty or forty years. When the first perfect germs

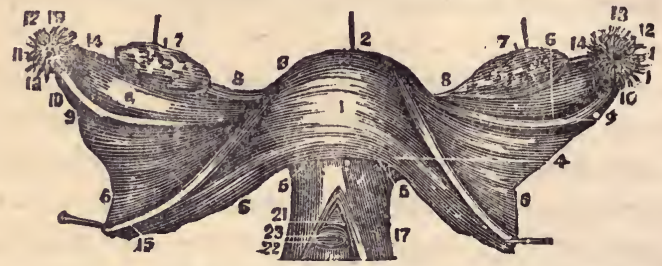

Fig. 59.-Uterus, Ovaries, Fallopian Tubes, etc.

have ripened, one or more, they come to the surface of the ovary, burst from their sacs, sometimes with considerable force, attended by a nervous excitement, a congestion of the blood vessels of ovaries and womb, and, when impregnation does not take place, the freed germ passes into the mouth (I 2) of the Fallopian tube, through which it passes into the uterus (I), from which it passes, with the menstrual evacuation, a secretion from the mucous surfaces of these organs, reddened more or less by some exudation from the congested vessels, through the mouth of the womb (23), into the vagina. This menstrual, or monthly flow, marking the production of germs, and their expulsion when not fecundated by the presence of the masculine element, goes on monthly, from its commencement at the age of puberty, normally at fourteen to sixteen years of age, to the period of the cessation of the menses, or "turn of life," from forty-five to sixty, when no more germs are formed, and the capacity for shild-bearing ceases. 
Corresponding to the ovaries or egg-forming organs of the female, are two similar glandular bodies, called the testes, in the male, which produce the spermatic or seminal fluid, corresponding to the pollen of plants, by which the germs are fertilised, or fecundated; by means of these germ cells and sperm cells the masculine and feminine elements are brought together so that they can unite in the body and soul, the material and spiritual life, of a new being. The human testes are formed within the body, near the kidneys, but some time before birth they descend, pass out of the abdomen by the inguinal canal, and take their place in an external sac prepared for them, called the scrotum.

These testes, or testicles, show the importance of their function by a wonderfully elaborate organisation, of which some idea is given in Fig. 60; though a very imperfect one, in an ideal section intended to give an outline of the structure. The oval body ( $\mathrm{I}$ ) is composed of a vast number of lobules, formed of very fine tubes closely folded, and everywhere in contact with blood vessels and nerves. There are in each testicle about four hundred and fifty of these lobules. The matter secreted by them passes through a vast number of tubes, I-1 7 oth of an inch in diameter, ending in a convoluted tubular structure $(8,9)$, measuring twenty-one feet in length, ending in a single tube, which carries the masculine generative matter to the urethra, whence, in the sexual congress, it is ejected into the vagina, enters the mouth of the womb, and, either there or in the Fallopian tubes, meets and impregnates

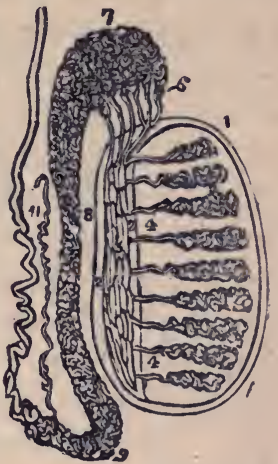

Fig. 60.-ANATOMY OP THE TESTES. the germ coming from the ovaries.

The seminal fluid is as complex and vital a substance as we should expect to have formed by so remarkable an apparatus. 
Floating in a liquid are minute cells, in which other cells, or

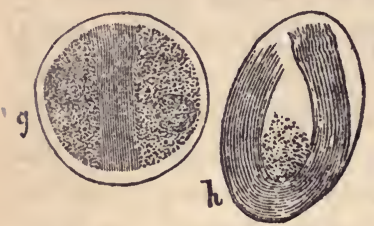

Fig. 61.-Evolution of SPERMATOZOA. corpuscles may be discovered, and in these are formed, as shown in Fig. 6r, bundles of spermatozoa, curiously shaped living cells, $\mathrm{r}-600$ to $\mathrm{I}-800$ of a line in length, each one of which is furnished with a single cilium, or long slender tail; which propels it with a constant vibrative motion, as if it were a

living animalcule. This spermatozoon is believed to be the true agent of fertilisation, corresponding to the pollen grain of the flower. It has been discovered in the womb, in the Fallopian tubes, and in contact with the germ just leaving the ovary. There can be little doubt that the cells, furnished with long propellers, as shown in Fig. 62, carry in them the male principle which gives to the female germ all

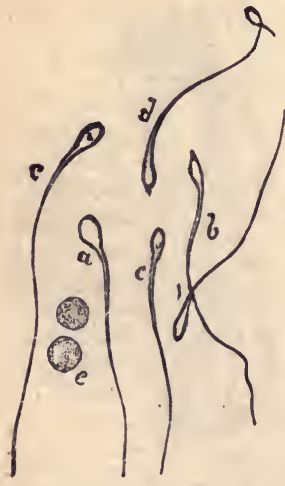
that makes the child resemble its father, all that it inherits from him of bodily form, features, complexion, temperament, constitution, mental power, and moral character-health, disease, idiosyncrasy ; that which may make his happiness or misery in this life-and who can say how much also in the life to come?

The germs of human, as of all life, are produced in immense numbers. Even in childhood imperfect germs are formed and discharged, and conception may take

Fig. 62.-HUMAN Spermatozoa.* place before menstruation begins. Idle. ness, luxury, the use of rich, highly sea soned food, condiments, and stimulants.

* These are magnified from nine hundred to one thousand diameters *. Spermatozoon presenting the flat surface. $b$. One viewed in profile 


\section{Human Physiology.}

and the excitement of the passions hasten puberty, and exag. gerate and disorder the corresponding masculine function.

The microscope does not reveal to us what takes place in the act of impregnation or conception, or what change is produced by the contact of the spermatozoon with the ovum. The egg of the maiden hen contains the rudiments of the chick, but it can never be hatched. The warnth that brings life and development to the impregnated egg, only hastens the putrifaction of the unimpregnated. The unimpregnated eggs of the frog quickly putrify; but if the male element be soon brought to them they expand into living creatures. In this case the spermatozoa can be seen to become buried in the gelatinous covering of the eggs, they pass through the membranes which cover them, and are probably absorbed into the ovum.

The blood goes to the testes in long, slender, tortuous arteries, presenting an extensive surface for the action of nervous energy, and there is no doubt that the best blood of the body is selected to form the semen, and that it is changed and perfected, first in these arteries and then in the wonderfully fine and convoluted tubes of the testes. The same arteries that supply blood to the testes in the male, furnish the circulation of the ovaries in the female; and the same nervous centres furnish the nerve energy and directing intelligence; but what makes the difference in action-forming germ cells in one sex, and sperm cells in the other-or what makes sex, must probably remain among life's inscrutable mysteries. "Arrest of development" will not account for it, and if it did, what causes arrest of development? "Male and female created He them."

At the age of puberty remarkable changes take place in both sexes. Boys and girls differ indeed from their tenderest years.

c. Showing a circular spot on the surface, which some suppose to be a sucker. $d$. Shows an elongation from the head, like a proboscis. e. Granules, or cells, in which other zoosperms are preparing. 
As a rule boys are more boisterous, girls more gentle; whue the girl chooses a doll for her plaything, the boy prefers a drum, a sword, or whip. But at puberty the sexual instincts become stronger, and there is in each a more pronounced development of masculine or feminine appearances and qualities. In the boy the voice deepens in tone, and the face begins to be covered with a beard. Where the testes have been removed, destroyed, or imperfectly developed, the voice remains treble, and the beard light or wanting. There is an enlargement of the throat, the "Adam's apple" corresponding to the full development of the masculine organs. On the other hand the girl becomes at puberty more decidedly feminine, by the enlargement of the pelvis, the broadening of the hips, and the development of the mammary or milk-forming glands in the bosom. There is no beard to mar the delicacy and feminine beauty of the face, but in both sexes alike, at this period, hair appears upon the pubes. The most striking difference, however, is that already mentioned-the occurrence of the monthly period, marking the ripening and expulsion of germs capable of becoming living men and women.

Woman differs from man in her entire organisation-mental, emotional, physical. She is more rounded, graceful, soft, sensitive, mobile. Her nervous system is finer and more delicate; she has quicker sensibilities and finer powers of instinct and intuition. Even the bony skeleton of a woman can be distinguished at a glance from that of a man by its longer head and broader pelvis, and generally by its smaller hands and feet. Richerand has, perhaps, exaggerated in saying that "the reproduction of the species is, in woman, the most important object in life-almost the only destination to which nature has called her, and the only duty she has to fulfil in human society;" but Madame de Stael went nearly as far in saying, "Love is but an episode in the life of man; it is the whole history of the life of woman." Lord Byron has said, almost in the same words, 


\section{Human Physiology.}

"Love is of man's life a thing apart;

'Tis woman's whole existence."

I think, however, that there are women who have brains as well as ovaries; and that even the faculties which make women most charming as wives and most excellent as mothers, may have a much broader scope than the production, care, and education of their own offspring. Hundreds of women who have never borne children have been more than mothers to great multitudes. In the actual condition of humanity there may be a higher work for many women in saving the children of others, than in having children of their own.

\section{CHAPTER IV.}

EMBRYOLOGY.

Changes at Conception-Fœtus in Utero-Size and Development of the Human Ovum-The Hen's Egg-Development of Chick in the Process of Incubation-Development of Fishes-Growth of the Human Fœtus-Peculiarities of Fœtal Life-Phenomena of Birth-Lactation.

WhEN conception, or the fertilisation of the germ, has been accomplished, a great change takes place in the system of the female, in which arises a series of functions totally unknown in the male. The ovary is quiescent. No germs are developed and expelled during the nine months of gestation; nor, normally, during the whole period of nursing. The mammary glands become active, and, in many cases, the breasts are filled with milk at an early period of pregnancy. Life flows to the bosom instead of the ovaries. As the ovarian action is suspended, there is no occasion for the menstrual excitement and evacuation. Its cessation is therefore the earliest, and, in the healthy female, the surest sign that conception has taken place. And where there is health, and the entire absence of amative excitement, as there always should be during the whole period 
of gestation and lactation-from the beginning of pregnancy until the child is weaned-the menses are suspended.

It is upon the womb, and the embryo it protects and nourishes, that the nervous power, the most interior life of the mother, is chiefly expended; and she needs every atom of that life for the wonderful processes there to be accomplished. The womb, or uterus, as shown in Fig. 59, p. 252, is shaped like a flattened pear, with its neck downward, opening into the vagina, and is scarcely larger than a small hen's egg. When the germ becomes fecundated at or before its entrance into the womb, as it passes out of the Fallopian tube, there is a nervous shock of which women are sometimes conscious. The womb suddenly expands; its arteries enlarge and are filled

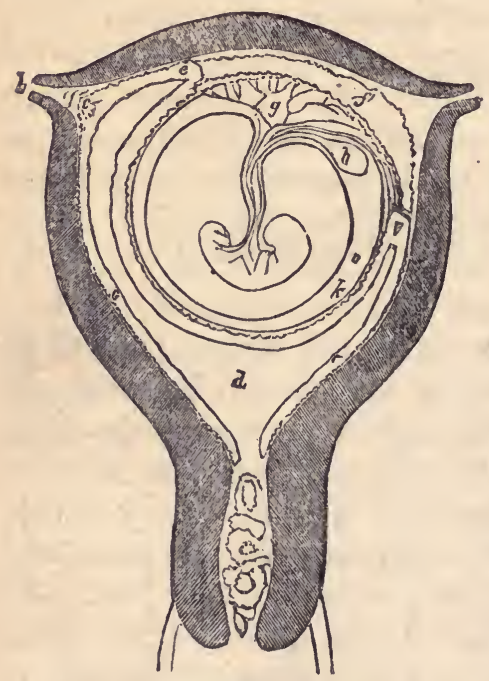

Fig. 63-Fatus in Utero.* with blood; an exudation from the inner or mucous surface of the womb forms a strong rough membrane, which the germ pushes before it, so that it forms a double envelopment for its protection. A clot or plug is formed to close the mouth of the womb. A mass of blood-vessels and nerves forms upon the inside of the womb, called the placenta; a double organ, with two complete sets of vessels, one set communicating with the mother, through the walls, arteries, and veins of the womb; the other set with the child,

* Sectional view of the uterus with the ovum; the cervix uteri is plugged up with a gelatinous mass, $a$. The decidua vera, $c$, sends a process, $c^{2}$, into 


\section{Human Physiology.}

by means of the umbilical artery and veins. Through this admirable organism the blood of the mother furnishes the material from which is formed the blood of the child, and by which it is nourished and built up.

The human ovum, at its impregnation, is very small-smaller than the naked eye can distinguish. It is from the $\mathrm{I}-\mathrm{I} 20$ th to the I-I 4oth of an inch in diameter. But from the moment of fecundation, it grows with great energy. In a fortnight it is of the size represented in Fig. 64. The foetus of one month is an inch long; two months, two inches and a half long; three months, five inches; five months, six or seven inches; seven months, eleven inches; eight months, fourteen inches; nine months, eighteen inches.

The interior structure of the ovum, and the

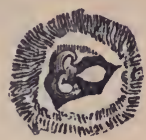

Fig. 64 .

HuMAN OVum

LAID OPEN. gradual development of the germ, embryo, and foetus, are best explained and illustrated by reference to the larger eggs of fishes and birds. The hen's egg may be taken as a model, and when a hen is setting, or, more humanely, when eggs are being hatched by artificial heat, if one be broken every.second or third day, the whole development may be watched with great facility. Nature, it will be seen, has prepared everything, forgotten nothing, and goes on in the formation of a

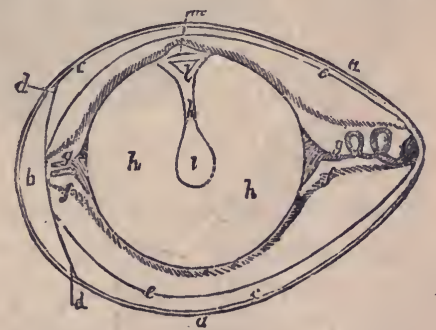

Fig. 65.-IdeAl Section of A IIEN'S EGG.*

the right Fallopian tube; the cavity of the uterus is almost completely occupied by the ovum. e, e. Points of reflection of the decidua reflexa. $f$. Decidua scrotina. $g$. Allantois. $h$. Umbilical vesicle, with its pedicle in the urnbilical cord. $i$. Amnion. $k$. Chorion; between the two, the space for the albumen.

* The egg of the fowl is the type of all ova, and from its large size is easy to study, $a, a$. Shell, $b$. Space filled with air to supply oxygen. c. Mem- 
new being, insect, bird, or man, with the same wisdom and power that creates a universe.

The first step in development in the yolk of the egg must be the vitalisation of its matter-further vitalisation, I should say, for it is already alive-an organised existence. But the entrance

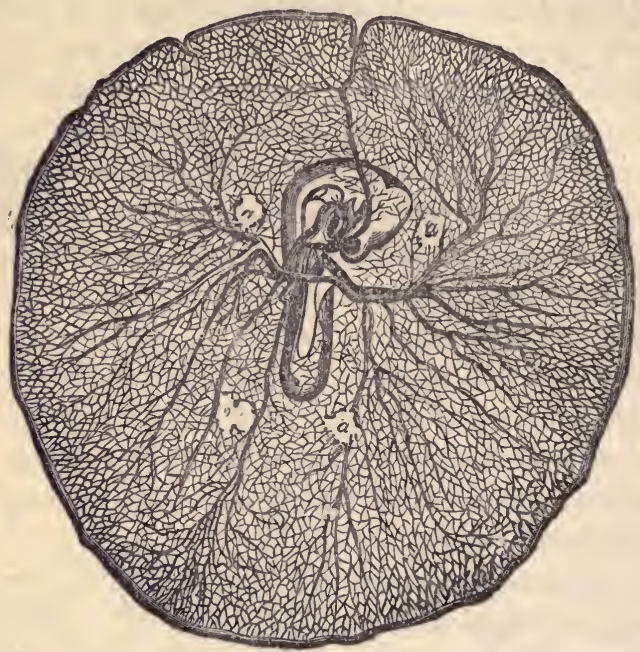

Fig. 66.-Chicken's EgG, Third Day of Incubation.

of the masculine element-or its union with the feminine element, whatever they may be-gives a new and very intense life. There is a diffusion, perhaps a rapid spreading growth of fibres of the nerves of organic life. Under their influence cells

brane of the shell, which, at $d, d$, splits into two layers. e, c. Limits of the second and thicker albumen. $f$. Limits of the third and thickest albumen, the white being in three layers. $g, g$. Chalaze, or ropes of twisted fibres from the yolk, which hold it in its place. $h$. Yolk. $i$. Central cavity in the yolk, from which a duct, $k$, leads to the cicatricula, or tread. l. Cumulus proligerous, or germinal cumulus. $m$. Germ, or blastos. The egg is so formed that the yolk floats high in the white, and the germ is always uppermost. 
are formed of matter already fitted for such structures. These cells undergo rapid transformations, and become the blood, muscle, bone, all the tissues of the young animal. In the egg, these cells are seen to become more opaque in some parts, more transparent in others; they divide and subdivide, until the yolk forms what is called a mulberry mass. A germ gathers upon the surface, and separates into three layers. In the eggs of fishes, which are so transparent as to be easily watched through the process of development, may be seen an upper or nervous layer, in which are formed the organs of animal lifebones, muscles, brain and nerves, \&c. The lower layer gives origin to the organs of vegetative life-the abdominal viscera, intestines, or alimentary system; the intermediate layer produces the heart, arteries, veins, \&c., of the system of circulation.

At a very early period, the general form of the insect or animal is manifested. In insects and crustaceans, the germ is divided into sections. In the germs of vertebrate animals, there are seen the rudiments of a spinal canal, which, when formed, is filled with a fluid, from which is formed the brain and spinal cord. The embryo rests upon the yolk, and covers it like a cap, vertebrates enclosing it by the edges uniting at the navel.

In fishes, whose embryonic development has been carefully observed by Professor Agassiz, the first lines of the embryo appear on the tenth day - a canal, which becomes a tube-the spine, and an enlargement at one end, the rudimentary head, in which may soon be seen a division of the brain for the organs of sight, hearing, and smell; and soon after the rudiments of eye and ear are apparent. About the seventeenth day the heart is seen as a simple cavity, and, as soon as it is closed, there are regular contractions and a movement of blood corpuscles. On the thirtieth day there is a regular circulation of blood; the tail gets free, and moves in violent jerks, and the head is soon liberated. The fish has a brain, an intestine, a pulsating heart, and a limited amount of spontaneous 
motion; but its form is not clearly defined. By the fortieth day, the shape of the fish is evident, the remains of the yolk hang in a bag to its belly, but it soon becomes absorbed, and then the fish is obliged to seek its own food, having exhausted its embryonic provision.

The condition of the fish about the thirtieth day is shown in the embryo of the fowl as early as the eighth day-Fig. 67 ,

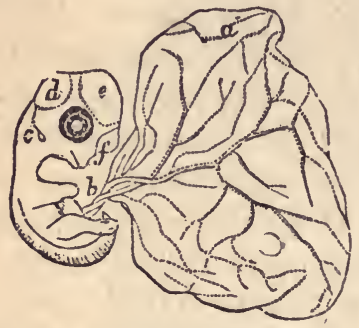

Fig. 67.-Embryo Fowl of EIGHT DAYS.*

where the head forms more than halt the animal, and the eye is out of all proportion to the head. The yolk is being absorbed through a membrane and vessels, which unite to form the umbilicus, the yolk of the egg being to the embryo-chicken what the placenta and blood of the mother are to the human fœtus.

The appearance of the rudimental spine in the mammal embryo at an early' stage of development is shown in Fig. 68, where the germ is seen, shaped almost liked a grub or worm in the centre of the egg, or matter from which it is to be organised

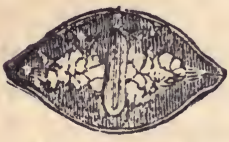

Fig. 68.-Mammal Ovum. before the placenta is sufficiently developed for its nutriment.

The inner membrane of the embryo secretes the liquid in which it is suspended during its fœtal life, protecting it from injury by violence. These waters escape by the rupture of the membranes a little before birth.

* A further advanced embryo, with an apparatus of nutrition, called the allantois, $a$, with the umbilical vessels, $b$, branching over it. $c$. The external ear. $d$. Cerebellum. $f$. Hemispheres. The eye is very large, and far advanced; the mouth begins to take the shape of a bill, and the legs and wings are sprouting. 


\section{Human Physiology.}

The human ovum is too minute for observation, and the opportunities for such observation are necessarily rare. Up to the seventh day after impregnation nothing is visible to the naked eye; on the tenth a semi-transparent greyish flake; on the twelfth a vesicle, size of a small pea, filled with fluid, in which swims an opaque spot, the embryo, which with its two membranes, waters, \&c., weighs about one grain; on the thirteenth day it resembles a worm bent together, and stretched out is nearly half-an-inch long. In the seventh week bone begins to form in the lower jaw and clavicle; the brain, eye, and ear are growing more perfect; the heart is getting its proper form; the liver is very large, and an active organ; but the lungs, which are not needed until birth, are mere sacs, and the tracheæ delicate threads. At from sixty to seventy days all parts are rapidly growing; the eyes enlarge, the lids are visible, the nose prominent, the external ear formed, and the heart fully developed. At three months the eye-lids are distinct, the lips drawn together, the larger vessels carry red blood, fingers and toes well defined, and muscles begin to be formed. At four months the intestines are covered in by the abdominal muscles, the lungs have grown and are even susceptible of a slight dilatation. The skin begins to form, and the place of the nails is visible. There is also some excretory action in the intestines. At six months down appears on the head, fat begins to be deposited. At seven months the foetus is fully formed, and, if born, is capable of independent life; but the size increases up to the normal period of birth, nine months, when it weighs from five to nine pounds, or an average of about seven, varying between the extremes of three and a-quarter up to twelve and even more in some rare instances.

Fœtal life has some remarkable peculiarities, which we may well consider. The formation of germs in the ovaries, their periodical development and expulsion, their impregnation or fecundation by spermatozoa formed in corresponding male 
organs; their extreme minuteness and rapid development into all the complexities of our wondrous organisation, constitute a series of mysteries. But the mode of fœtal existence is strangely different from that of the infant from the moment it comes into the world The fotus cannot breathe. Its lungs are useless-no blood is thrown into them except what is necessary for their growth, and no air penetrates them, for the fœtus swims in a liquid. The fotal heart has an open communication between the two auricles which is closed at birth. The blood of the infant gets its supply of oxygen from the blood of the mother by means of the placenta, or afterbirth. The lungs of the mother breathe for herself and her offspring during pregnancy, so that pure air is then more than ever needed. The blood of the child, fed and purified by that of the mother, passes from the placenta through the umbilical vein to its liver, and thence into the right auricle of the heart, and from that into the left auricle through the fotal opening between them, and then to the left ventricle, and is expelled into the arteries which supply the head and upper extremities with the purest blood for their more rapid development. From the head and arms the blood returns into the right auricle, from which it passes to the right ventricle. In the adult it would now pass into the lungs, but in the fœtus it is carried by a special artery, afterwards obliterated, into the descending aorta, and sent partly to the lower extremities, and partly to the placenta, to be purified by contact, through thin membranes, with the blood of the mother.

Here we have a special machinery, an opening in the heart which is closed at birth, lungs solid and useless, arteries and veins most important in the fœtus, but at birth obliterated, and an organ expelied at birth after the infant, which in its fœtal life performs the function of both stomach and lungs, furnishing the matter of blood, and also the oxygen for its purification and vivification.

The average duration of gestation or fœtal life is nine months, 
or from the thirty-eighth to the fortieth week after conception, but the period varies from 260 days to 293 . A child may be born alive at six months; it may live at seven months; and natural gestation, in the opinion of high authorities, may continue for ten months and possibly longer. But in the vast majority of cases, and, it may be supposed, in all really normal ones, the period is very close upon nine months.

The phenomena of birth are as surprising as those of conception and the evolution of the foetus. The uterus, which has gradually expanded so as to hold a full-grown child, waters, inembranes, and afterbirth, now begins to contract by the involuntary action of its own powerful muscular fibres. These contractions continue at short intervals for hours and even days until the child is born. The insensibility produced by chloroform does not suspend them. The mouth of the womb which will with difficulty admit a goose quill, and which during gestation is sealed up by a dense membranous substance, suddenly begins to expand until it will admit the passage of the child; even the sutures which unite the bones of the pelvis soften, and allow a degree of expansion. In almost every case the fotus presents the back of its head, the natural and of course the best possible presentation. The whole process is so entirely natural that there is needed no interference of art. All the animals in the world are born by natural law; and only a few, demoralised by man, ever require his assistance. Women would require it as little if their lives were as natural as those of the wild or only partially domesticated animals, or as the better sort of savages. Child-birth without pain or danger is entirely natural and

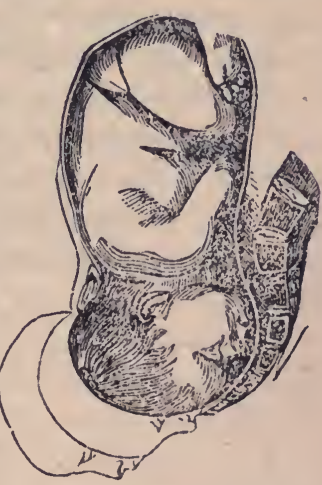

Fig, 69. Natural Birth. 
perfectly possible to natural and healthy women. Pain and danger come from artificial and diseasing habits and conditions.

When the womb returns to its usual size and condition, the mammary glands take on their full action, and secrete from the blood the natural food of the infant,

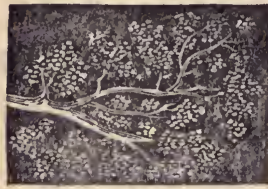

Fig. 70.

Mammary Glands. which it instinctively seeks with eagerness. These glands vary but little from the others. There is a large surface in a small space; a full supply of blood and strong nervous action. The red arterial blood is somehow, by nature's subtle chemistry, converted into a white sweet fluid, which contains all the elements of nutrition required by the infant, in just the right proportionsprovided that the blood of the mother is pure, her nervous powers unexhausted, her system free from the poisons of drugs, or of disease.

But the mother must be pure and healthful, or she cannot give pure blood or pure milk to her child. The miscroscopic cell generated by the father, and his contribution to the life of the child, may carry with it fatal and terrible diseases. It may have in it the seeds of sensuality or insanity, gout or scrofula, moral and physical deterioration and death. What then must we think of the influence of the mother who not only furnishes the germ, but nourishes it for nine months with her blood, and then a year longer with milk formed from the blood of her bosom! 


\title{
CHAPTER V.
}

\author{
PHYSICAL LOVE.
}

Sexual Attractions-Blind and Regulated Instinct-Phenomena of Impregnation-Law of Sexual Union among Animals-Normal Period of Conception-The Natural Law of Human Sexual Relations-The Law of Exercise--The Law of Chastity-Dangers of Childhood and Youth.

THE continuation of life on the earth by the successive reproduction of individuals of all species of vegetables and animals requires special organs, processes, and adaptations. The union of the masculine and feminine elements requires strong attractions between them, and means and contrivances for bringing. them together. Some of these have been already noticed in the sexual organs of plants, the beautiful and odorous flowers which make the vegetable kingdom so delightful. In most flowers the organs of the two sexual elements are in proximity and attract each other. The stamens are seen, one after the other, to bend toward the stigma, embrace, leave some grains of fertilising pollen, and retire. In other cases the intervention of insects, or of the winds, produces the desired result. In every case some wise provision of nature has ensured the continuation of the species. A plant may be dwarfed and starved, but all the life it has is expended in the reproductive process.

Insects, and all the animal creation, are moved to the performance of the procreative function by the most powerful instincts. The lives of many creatures seem to consist entirely in two operations, nutrition and reproduction. Insect life is, in most species, divided into two stages, one occupied with voracious eating, the other devoted to the production and care of offspring.

In all cases there comes at the proper time that attraction of the sexes for each other which results in the bringing together of the two elements required, as already explained, in the 
reproductive process. Male and female are drawn or driven together by an inward impulse, which, in the lower orders of animals, is simply irresistible, but which in man is placed under the government of reason and sentiment. Man differs from all other creatures in having the power to order, regulate, and adapt the instinct of reproduction to the highest uses; to keep it under the control of reason, and make it subservient to the demands of morality and religion. Vegetables and animals obey a blind instinct which urges them to do what is necessary for the continuation of their species. Man feels the powerful promptings of the same instinct, but he also feels a higher and purer sentiment of spiritual love dominating and controlling it ; and he is able also to choose the proper time, and the best conditions for offspring; or, if reason and duty demand, to refrain altogether from the gratification of his natural desires.

It is probable that all sentient beings have a degree of pleasure in the exercise of every natural function, and the strongest feeling of sensual delight may probably be connected with the most important of the voluntary vital processes. Eating, which is necessary to sustain life, appears in all animals to bring enjoyment; and the sexual congress, necessary to reproduction, is, as far as we can judge, also connected with pleasure. Even with fishes, and lower organisations, where fertilisation is produced without contact, the expulsion of ova and the seminal element may give a sensible pleasure, in some proportion to the force of the instinct which urges to the act.

The higher orders of animals are furnished with tissues and organs, and nerves of sensation and motion, specially formed for the generative act and its accompaniments. The erectile tissue, as it is called, a substance which under nervous excitement changes in form, increases in size, and from being soft and flexible becomes rigid and erect, is one of the most curious of all the wonderful provisions and contrivances of nature. This action is seen in the glandular system, on a minute scale, in 
the processes of digestion, when the flaccid villi of the stomach and intestines, under the stimulus of food, become enlarged, erect, and active. It is observable in the fulness of the pouting lips, and the sudden enlargement of the nipples; parts connected by an intimate sympathy with the reproductive system.

The sudden enlargement of erectile organs, produced by an impression of the senses, by memory, or an emotion, or however excited, is, like the act of blushing, or that of coughing, sneezing, etc., produced by nervous action, and in this case the nerves seem to act upon the blood vessels, enlarging the arteries, and at the same time constricting the veins, so that the blood is forced into the part, and is permitted to return only in diminished quantities, producing a temporary congestion. The changes of this kind, both ways, are very rapid. One emotion produces a sudden increase, and a different emotion as sudden a diminution. A local irritation may, however, keep up a continuous engorgement of the erectile tissues ; but this is a morbid condition.

When a mutual attraction, and an animal instinct, have brought the sexual organs into the relation to each other necessary for procreation, there arises an excitement of the senses, generally highly pleasurable. This is the natural and healthful condition; but where the nervous power has been exhausted, the sensibility blunted, by early excitement of the amative organism, by sexual excesses, by any cause, there may be little sensibility and no pleasure, or even pain. A great many women, especially, never have pleasure in the sexual embrace; and to some it is always a cause of suffering. This insensibility or pain may be hereditary, or caused by an early excitement of the amative faculty, of which so many children of both sexes are through their own ignorance, or the errors of others, the unhappy victims.

The sexual congress terminates in an orgasm, or powerful nervous shock, in which, by a series of spasmodic contractions, 
the seminal fluid is thrown upon the mouth of the womb, which probably opens by a similar action to receive it. The spermatozoa which this fluid contains ascend by their own vital propelling power, through the womb, and even penetrate through the Fallopian tubes, against the ciliary action of the mucous membranes, until they meet a germ or germs ready for impregnation.

In vegetables and most insects this act of generation takes place but once. As soon as the seed is formed the flower perishes. The pea grows in its pod, which is its protecting womb, hanging by a little stalk, which is its umbilical cord, through which it draws its nourishment. So all seeds are produced and nourished. The male insect performs his function in impregnating the one crop of germs produced by the female, and then dies, in many cases in the very act. Among the higher animals, where there are repeated births, through a series of years, the sexual congress never takes place except when the instinct of the female demands it for the impregnation of ripened germs. Life is never wasted in infertile and merely sensual embraces.

When germ's are ripened but once a-year, the male organs are quiescent, except at the period of use, and in some cases, as in the various kinds of deer, they are shrunken and impotent at all other times. Among elephants sexual union occurs, it is said, only once in five years. The female carries her young two years, and nurses them two years more; and among animals living in a state of nature there is never sexual union during pregnancy or nursing, nor, in fact, at any time except when naturally required for the purpose of generation. Every male animal, however he may express his readiness or his desire to perform his part of the reproductive act, awaits the call of the female, and as soon as her requirement is satisfied, that is, as soon as conception has taken place, she refuses further connection, which, so far as I know, among animals living in natural conditions is never forced upon an unwilling female. 
She has only to signify her wish to have it perfectly respected by the most powerful and savage of beasts. Among the more natural and instinctive races of men, also, this great law of nature is respected; and it is only among very artificial or perverted races that sexualunion takes place during pregnancy, when every atom of the strength of the mother is needed for her child, or during lactation, when she needs all her force for its proper nourishment, and not for mere sensual gratification without regard to the natural uses of the generative function. In this respect, also, man differs from, and some races of men at least, have fallen far below the standard of healthy and instinctive animal life.

It is probably true that domestic animals, and animals kept in confinement, and in unnatural conditions as to food and exercise, may in some cases suffer from some degree of disorder or perversion of this function, but the law is as above stated.

It follows that sexual union can only normally take place at the period when conception is possible. In the human species germs are matured in the ovaries of the female every month, and thrown off at the menstrual period. As a rule, conception may take place from sexual union from six days before the beginning, to ten days after the cessation of the menstrual evacuation. During pregnancy and lactation, the production of germs, and the corresponding evacuation, are suspended; or occur unnaturally, and in consequence of some hurtful excitement. During these periods no woman is naturally fit for amative excitement or indulgence, and, for her own sake and the sake of her child, should never be subjected to it; and every man who truly loves his wife and his children, will most carefully protect them from the excitement, nervous exhaustion, and serious injury which come from such useless and merely sensual intercourse. It often causes abortion and miscarriage. It stamps sensuality upon the nature of the child. It is a drain upon the life of father, mother, and child. A large 
proportion of the diseases of women, and their early decay, and of the premature mortality of children, and the habits or vices which injure or destroy them, are caused by the sensuality and ignorant, thoughtless, or much worse than brutal selfishness of men, who stimulate lust by gluttony, and other sensual excitements, and then sate it in murder. The civilised world is full of these sins and crimes-sins against nature, and crimes against ourselves and our species; and the recognised teachers of men are often as deeply in fault as the rest. Clergymen wrest the Scriptures to their own destruction, and the destruction of those who rely upon their authority; and physicians give sensuality the sanction of pretended science, where the law of God and the law of nature is one of purity, of chastity, of pleasure only in use, and the avoidance of any useless or hurtful sensual gratification.

It has been stated that every faculty of man, and every organ, demands its proper exercise and use. All nerves and muscles subject to the will are strengthened by exercise; but this law has no application to the nerves and organs of organic life. The heart beats on from birth to death, but it cannot be said to fall under the law of exercise. The liver, kidneys, spleen, \&c., perform their natural functions from first to last in their own times and ways, and the only way we can influence them is by keeping ourselves in healthy conditions. Continued use, or exercise, have nothing to do with the production of germs in the ovary, with the phenomena of menstruation, with conception, the nourishment and growth of the fœtus, or the secretion of milk for its support. These things are not learned or done better by practice; nor are the organs and their functions strengthened by use, though they are so often weakened by abuse. It is the same with the male as the female. There is no analogy between the strengthening and education of the hands and arms, or the intellectual faculties, by exercise, and the production of the seminal fluid. Every physiologist will 
admit that the amative feelings and organs should remain in the most perfect quiescence up to the age of puberty, while the mind and muscles are receiving vigorous training. It is not less certain that it is better for men and women to arrive at inaturity-which comes at from twenty-one to twenty-eight years of age-before marriage, and the birth of offspring, than to enter prematurely upon those functions. Every physician knows that women best recover their health and energy by long periods of rest; and that amative excesses and frequent childbirth destroy health and shorten life. Every one knows that men can live in perfect continence for years, and all their lives, in full bodily and mental vigour, all the more strong and vigorous for the disuse of the amative function. The law of exercise, therefore, has no application to the involuntary and instinctive powers, and all such analogies are utterly false and misleading.

For animals we have the law of instinct, and we have seen how wise, and pure, and moderate they are; and how we libel brutes when we talk of the brutal passions and behaviour of men. For men we have the law of chastity, which is in perfect accordance with the higher nature of man. During childhood, there should be free activity of body and mind; but perfect freedom from any excitement of the amative or sensual life. When children are born of chaste parents, they have no tendency to such excitement; but when the mother has been obliged to submit to the embraces of her husband during pregnancy, what can be expected but premature development of sensuality in the child?

Innocent children are also liable to be corrupted by depraved nurses; by adults with whom they are allowed to sleep; and especially by playfellows and schoolmates, who have in any way fallen into habits of unnatural and terribly hurtful indulgence. Whole schools of boys have been found corrupted, and even boarding-schools of girls plunged into the most 
destructive sensuality. In these cases, it is the strongest natures that most easily fall a prey, and are soonest destroyed. And children fall into these vices in perfect ignorance of any evil consequences-and innocent, because they have never been instructed or warned. Parents are too squeamish to teach their children the laws of nature and the commands of God. Teachers are possibly ignorant, or they are merely unfaithful, like the parents, who commonly have the excuse of fondly believing that, though other people's children may fall into destructive vices, which may curse their whole lives, or prematurely end them, their children are too pure, too good, ever to be drawn, even by the evil example of others, into such deplorable evils.

Many are wrecked in childhood, many are destroyed or greatly injured in early youth. The period of puberty is full of perii. The system is excited, and full of expansion and change. With the deepening and strengthening of the love-life come feelings of the poetic, the romantic, the chivalric. Young men become shy, girls more modest and retiring. This should be the season of mental and artistic culture, and physical training. If the forces of life are turned into the studies and exercises suitable for youth; if the nervous power generated in the evolution of the reproductive organism is absorbed and distributed over the body, the youth passes on to the full development and vigour of mature manhood and womanhood, fitted to perform their duties. But if the strength at this early period is wasted in sensual indulgence, either in a too early marriage, with excess and waste, or in unlawful pleasures, the effect will be seen in failing health and enfeebled offspring. 


\section{Human Physiology.}

\section{CHAPTER VI.}

\section{LOVE AND MARRIAGE.}

Sexual Attraction-Various Kinds of Love-Attraction of Opposites-First Love-Spiritual Loves-Loves that should not End in MarriageVarious Forms of Marriage-Sexual Relations of Animals-Reasons for Monogamy-Celibacy-Who Have a Right to Marry-Should Marriage be for Life?-Divorce.

THE attraction of the sexes for each other, though based upon the dual principle of generation which pervades the living world, and which has its analogies in the attractive forces of matter, yet pervades the whole being. Love is not merely the instinctive desire of physical union, which has for its object the continuation of the species; it belongs to the mind as well as the body ; it warms, invigorates, and elevates every sentiment, every feeling, and in its highest, purest, most diffusive form, unites us to God, and all creatures in Him.

All love is essentially the same, but modified according to its objects, and by the character of the one who loves. The love of children for their parents, of parents for offspring, brotherly and sisterly love, the love of friendship, of charity, and the fervour of religious love, are modifications of the same sentiment-the attraction that draws us to our kindred, our kindthat binds together all races, and humanity itself, resting on the Fatherhood of God, and the brotherhood of man. It is but natural that this love should vary in degrees. Attractions are proportional to proximity. Family is nearer than country; we prefer our own nation to the rest of the race.

Each individual also has his own special attractions and repulsions. There is love at first sight, and friendship at first sight. We feel some persons pleasant to us; to be near them is a delight. Generally, such feelings are mutual-like flows 
to like; or, as often, perhaps, differences fit into each other. We seek sympathy with our own tastes and habits; or we find in others what we lack. Thus the weak rest upon the strong, the timid are fond of the courageous, the reckless seek guidance of the prudent, and so on.

In the attractions of the sexes, this love of opposites constantly tends to neutralise those variations which are supposed by $\mathrm{Mr}$. Darwin to result in the generation of species. If it were not for this law of the attraction of opposites, we might have varieties perpetuated; but there is now a constant tendency to correct variations, and maintain the general character of the species. It is, therefore, very rarely that, where there is freedom of choice, two very tall or very short persons, very lean or fat, very dark or fair, are mated together. One has but to look about him in the classes where there is most freedom and opportunity of choice, to see how admirably nature manages to keep the balance of all such extremes. And this extends to peculiarities of mental and moral character. It is notorious that most men of genius marry pretty simpletons; and the sweetest and best women seem to have a perverse fondness for scamps. How many hard, bad men do we see and read of, whose wives were models of saintly purity! We expect Socrates to have his Xantippe.

The sentiment of love for the opposite sex-tender, romantic, passionate-begins very early in life. Fathers and daughters, mothers and sons, have a special fondness for each other, as also have brothers and sisters; but the boy soon comes to admire some one, generally older than himself, who is not a relation. Very little girls find a hero in some friend of an elder brother. Fondness for cousins generally comes more from opportunity than natural attraction, though a cousin may have very little appearance of family relation. The law appears to be, that free choice seeks the diverse and distant. A stranger has always a better chance with the young ladies of any dis- 


\section{Human Physiology.}

trict than the young men with whom they have always been acquainted. Savages seek their wives out of their own tribe.

The first love of boys and girls is a romantic idealisation, which is pure, chaste, and of a refining influence upon the character and manners. In most cases it runs its course, dies out, and exists but as a memory. Differences of age and social position often make marriage undesirable. And it sometimes happens that the first love of a romantic boy or girl is already married. Where there is no obstacle of age or condition, the second love-the grand and serious passion-may fix upon the same object, and endure for life. This, however, is not the rule. The single, life-long passion is the rare exception. Most men and women who can be said to love at all have a capacity for loving a succession of objects; and some, perhaps many, one for loving, in various degrees, several objects at the same time. It is difficult to say how far such idiosyncrasies are disorderly or abnormal. We must, I think, admit that there are many phases of affection, which are not very closely related to the love which should exist between the partners of an indissoluble marriage. It becomes, therefore, a matter of very serious importance to distinguish a true and lasting love, which justifies union for life and the rearing of a family, from the attachments of friendship, romantic interest, or poetic sentiment, which may be both diffusive and evanescent.

It is my belief that, naturally-I mean in a state of pure and unperverted nature, but developed, cultivated and refined by education-every man loves womanhood itself, and all women so far as they approximate to his ideal; and that, in the same way, every woman loves manhood, and is attracted and charmed by all its gentle, noble, and heroic manifestations. By such a man, every woman he meets is reverenced as a woman, accepted as a friend, loved as a mother, sister, daughter, or, it may be, cherished in a more tender relation, which should be at first, end may always remain, pure and free from any sensual desire. 
Such love may have many objects, each attracting the kind and degree of affection which it is able to inspire. Such love of men for women, and women for men, may be free, and will be free, just in the degree in which it is freed from the bondage of sensual passion. Such love has a direct tendency to raise men above the control of their senses. The more such love one has, and the more it is diffused, the less the liability to sink into the lower and disorderly loves of the sensual life.

The idea that every attraction, every attachment, every love between the sexes, must lead to marriage-that no love can be tolerated but with that end in view, is a very false and mischievous one. It deprives men and women of the strength and happiness they might have in pure friendships and pure loves, and it leads to a multitude of false and bad marriages. Two persons are drawn together by strong attractions and tender sentiments for each other, who have no more right to be married than if they were brother and sister, but who have the same right to love each other. But their true sentiments for each other, and consequent relation to each other, are not understood by those around them, and perhaps not by themselves. They are urged, by the misapprehension of others, by their expectation, by ignorant gossip, by the prejudice of society based upon low and sensual estimates of life, to marry; they find often that they must either marry or lose the happiness they have in each other's society, and they make the irrevocable mistake.

When it is understood that there are other loves than that of marriage-when the special attraction that justifies union for life, and the begetting of offspring, is discriminated from all the other attractions that may bring two souls into very near and tender relations to each other, there will be more happiness in the world, and fewer incomplete, imperfect, and therefore more or less unhappy marriages. Nothing can be more detestable than that playing with fire, which goes by the name 
of flirtation; but there are men and women who have the happiness of loving, and of being tenderly and devotedly loved, by persons of the opposite sex-loved purely, nobly, and happily, without injury, and with great good. Where such loves are accompanied by perfect trust in the goodness, purity, truth, and honour of the beloved, there can be no jealousy-no desire for selfish absorption-no fear of deprivation of any right. There is no reason why a husband or a wife should limit the range of pure and spiritual affections to near relatives. The man who can love a sister as sisters are often loved, may love in the same way, or as purely, any woman who might be his sister. As men and women learn to purify their lives, the world will grow more tolerant, and love will become more universal. The tender and fervent exhortations to mutual love, to be found in the Gospels and Epistles of the New Testament, are now almost without a meaning. But they had a meaning to those to whom they were addressed, and when we are better Christians, and bring our lives to the purity of Christian morality, they will have a meaning to us, and we shall learn that, in a sense we have not dreamed of, God is Love.

Marriage, as it has existed in the world, has in most cases fallen far short of our idea of what such an institution should be. During the historic period, over a large portion of the earth, polygamy-or the marriage of one man to several women-has prevailed. And this custom is now prevalent among more than two-thirds of the inhabitants of the British Empire. Polyandry, or the marriage of several men - usually, several brothers - to one woman, is the custom in some savage tribes, and some districts of India and Thibet. Monogamy, or the marriage of one man to one woman, prevails over Europe, with the exception of Turkey, and in America, except among the Mormors, Chinese immigrants, Indians, and Esquimaux. But in both Europe and America, in spite of religion and law, polygamy exists as really as in 
Mahomedan countries, in the common practice of married men keeping mistresses, or engaging in amours ; and polyandry is a formal institution in the prostitution tolerated, and more or less regulated, in almost every Christian country.

Among insects and animals, we have the types of all kinds of human sexual relations, under the law of instinct, and without depravities or disorders. Polygamy prevails extensively among gregarious birds, horses, cattle, sheep, sea-lions, seabears, seals, \&c. Polyandry is found among insects, notably among bees where a single female in a hive has several hundred males to choose from; but it does not appear that she ever calls upon more than one of them to perform the act of impregnation. Monogamy, or the mating of single pairs, is the law among a vast number of birds and animals, sometimes for a single season, sometimes for life. There are also insects and animals which meet casually, and seem to have no permanent relations.

The relations of the sexes among animals seem to be determined chiefly by the requirements of their offspring. Where a nest is to be built and a young family fed for a considerable period, the male and female mate, work, watch, and care for them together. Where the young brood is able, on coming from the shell, to go about like chickens or swim like ducks, the female is able to take care of her young without assistance. Where the proportion of females to males is very large polygamy is the evident law.

In the human race all circumstances point to monogamy as the law, or natural condition. Males and females are born in almost exactly equal numbers. If there are two or three per cent. more of males than females, the risks of life with males soon make the number even. Therefore, as a rule, no man can have more than one wife without robbing his neighbour Polygamy is therefore a manifest injustice, and may become the most grievous of all monopolies. 
Children are the most helpless of all young creatures, anci require the care of parents for the longest period. The care of a husband for his wife, and of a father for his child, is an evident necessity. The proper care and education of a single child should extend over at least fifteen years, and that of a family may reach to thirty years, or throughout the greater part of an ordinary life. During all periods of pregnancy, child-bearing, nursing, and the education and care of a family, every woman has a right to the sympathy, sustaining love, and constant aid of her husband. No man has the right to desert or leave helpless, or even dependent upon others, except in extraordinary cases, the mother of his children. For this reason soldiers, who may be sent to distant countries, are not usually allowed to marry, and sailors who are absent on long voyages can very imperfectly perform the duties of husbands, and the fathers of families. And many men and women who are called to important social and religious functions, priests, educators, and those who devote their lives to the service of the sick in hospitals, or to the succour of the poor, renounce, like soldiers and sailors, the pleasures of marriage, devoting their whole lives and all their strength to the performance of what they consider higher or more urgent duties. Celibacy, which exists to a large extent, from choice or necessity, in most civilised countries, certainly does not become wrong, as some seem to imagine, when it is adopted as a vocation and from a sense of religious duty, and celibate priests, and monks, and nuns, have surely as good a right to refrain from marriage as selfish bachelors who prefer the comforts of their clubs to the cares of a family.

Marriage, like celibacy, should be a matter of vocation. The special object of marriage is to have children-the co-operating motive is that two persons, drawn to each other by a mutual affection, may live helpfully and happily together. A selfish marriage for its merely animal gratifications-a marriage in which strength, health, usefulness, often life itself, are sacrificed 
to sensuality and lust-is a desecration of a holy institution, and somewhat worse in its consequences than promiscuous profligacy, for the consequences of that may not fall upon one's children and posterity.

There are many persons who have no right to marry. There should be a kind and amount of love that will justify and sanctify such a relation. There should be a pure motive, and a fixed intention of making the relation what it ought to be to husband, wife, and children. There should be a reasonable assurance of the power to provide for a family. There should be that amount of health - that freedom from bodily and mental disease-that physical and moral constitution which will give a reasonable prospect of children whose lives will be a blessing to themselves and to society.

Where there is deformity of body or an unhappy peculiarity of mind or temper liable to be inherited, people should not marry, or if they live together, should resign the uses of marriage. People should conscientiously refrain from propagating hereditary diseases. Persons near of kin are wisely forbidden to marry, for there is in such cases the liability of imperfect generation - the production of blind, deaf, idiotic or insane offspring. The laws and ecclesiastical regulations respecting marriages have in almost every case a scientific basis. And in respect to second marriages, it is undoubtedly true that a man may have acquired by the close intimacy of marriage such a near relationship to his wife that it is best, as a general rule, that he should not marry her sister, or other near relation.

Should marriage be for life? As a rule, undoubtedly. Every real, proper, true marriage must be. It takes a lifetime for a husband and wife to make a home, and rear, and educate, and provide for a family of children. But how if people make mistakes and find that thev are not suitably married? These are mistakes very difficult to remedy. If a man, after deliberately making his choice of a woman, ceases to love her, how can he 


\section{Human Physiology.}

honourably withdraw from his relation to her, and enter upon another, when she still loves him, and is ready to fulfil her part of the contract? Laws cannot very well provide for mistakes. If the distaste for each other be mutual, and both parties desire to separate, a separation may of course be permitted, but it is a serious question whether two such persons can go into the world and find new partners, with justice to the rest. The law which permits of no divorce certainly bears hard upon individual cases, but if it leads to greater seriousness and care in forming such relations, it may be, on the whole, the best thing for society that it should be strictly observed. Those who have made a mistake, by their own fault, or misfortune, and are obliged to separate, are no worse off than the millions who are never able to marry at all; and when marriage is regarded as a religious rite, a real sacrament, it is evident that it cannot be lightly dealt with. The deatl of one party alone can terninate the mystical relationship.

But considered merely as a civil institution or contract, it is not desirable that there should be facility of divorce. Free divorce means legalised adultery. Free divorce is simply giving the sanction of the law to licentious promiscuity or a modified polygamy and polyandry, and neither of these can be tolerated in a well ordered society, since they are opposed to the interests of parents and children and destructive of families; and we have but to imagine the effect of such a state of things in any community-men and women meeting their ex-wives and exhusbands in society; young people forming the acquaintance of their half brothers and half sisters, and the incestuous relationships that would be sure to follow. We have only to imagine the social and moral consequences of such freedom of divorce as some of our philosophers and reformers are advocating to see how abhorrent they would be to the instincts of morality. 


\section{CHAPTER VII.}

\section{HEREDITARY TRANSMISSION.}

I.aws of Breeding- Plants and Animals-Darwin on Marriage-Hereditary Transmission of Peculiarities of Race-Mixed Characters Transmitted - Law of Hereditary Vices-Qualities given by each Parent-Influences during Gestation-Blood or Race-Inherited Diseases and Moral Predispositions-Fruitfulness and Longevity -Ante-Natal Impressions.

THE farmer who wishes to improve the quality of his wheat carefully selects, year after year, the earliest, heaviest, finest heads for seed, and is equally careful in the choice and preparation of soil, time and mode of sowing, and all the conditions that aid in making a good crop. The gardener gathers his seeds from the choicest varieties of plants, year after year, and so brings them to perfection. He grafts or buds the most beautiful roses, or the most delicious fruits into the most vigorous stocks, and a wise agriculturist will not waste time, soil, manure, and labour on poor seed, or ugly flowers, or harsh and undeveloped fruits.

In the same way breeders of birds, dogs, sheep, horses, select the choicest specimens of every variety, and bring together males and females which have the qualities most desired. By this means we have all varieties of dogs, horses, sheep, and cattle brought to the highest perfection. Setter, pointer, retriever, foxhound, greyhound, inherit not only the forms and colours, but the dispositions and educated or modified instincts of their progenitors. What an animal has gained by training is instinctive in its descendants. Sheep are bred for wool or for mutton; or the two, by proper crossing of stocks, may be united. Wise breeders leave nothing to chance in these matters. Ten guineas are paid to secure the breed of a favourite greyhound, and twenty to fifty for the use of favourite stallions. 
Throughout the vegetable and animal world the law of hereditary descent is clear. It is not less clear-it is, indeed, more evident with regard to the human race, but it is only with respect to the breeding of men that it is almost entirely disregarded.

Mr. Darwin, in his work on "The Descent of Man," has well said:- "Man scans with scrupulous care the character and pedigree or his horses, cattle, and dogs before he matches them; but when he comes to his own marriage he rarely, or never, takes any such care. . . Yet he might, by selection, do something, not only for the bodily constitution and frame of his offspring, but for their intellectual and moral qualities. Both sexes ought to refrain from marriage, if in any marked degree inferior in body or mind. . . When the principles of breeding and of inheritance are better understood, we shall not hear ignorant members of our legislature rejecting with scorn a plan for ascertaining by an easy method whether or not consanguineous marriages are injurious to man."

The fact that physical, mental, and moral qualities are hereditary is shown on the large scale in the persistent characteristics. of races and nations. The Jewish and Negro types as they exist to-day are to be seen engraven or painted on the monuments of Nineveh and Egypt. The Chinese and Japanese have had the same characteristics for thousands of years. The descendants of the ancient Greeks and Romans may still be recognised in Greece and Italy. We see in old English families the same form of nose coming down through galleries of family portraits; and we have everywhere inherited peculiarities. of form, feature, and complexion, intellect, disposition, even little tricks of manner, habits, eccentricities, idiosyncrasies, and diseases. It is notorious that the tendency to gout, to consumption, or to insanity exists in certain families, and lasts for generations. The peculiar features of the Jewish physiognomy are not more marked than certain traits of character, as indisposition to agriculture, fondness of trade and finance, and the 
desire and ability to "make money." These traits have grown out of their conditions for many centuries. The peculiarities of the Saxon, Celtic, Scandinavian, and Sclavonic races are handed down from parents to children. Climates, conditions, and crossing of races modify these characteristics of race as we see to-day in America, or even in Australia; but the law of hereditary transmission remains one of the most potent of all the influences that mould and govern our humanity.

It is one of the most astounding marvels of physiology, that the whole character, exterior and interior, of an animal or a man should lie in its germ-lie within the compass of $1-2400$ th of an inch diameter-lie in a microscopic cell. It is incomprehensible that all the life of man-his bodily organisation, his intellect, genius, sentiments-his whole character, and all his peculiarities of temper and temperament, habits and propensities, humours and diseases, should lie in so narrow a compass as the sperm cell, or germ cell, of either parent. The fact, however, cannot be doubted. The child of a white father and black mother is a mulatto, partaking of the character of each. The child of a well-marked Frenchman and Englishwoman shows the same admixture of peculiarities. We can often pick out of a group of children of the lower classes the chance offspring, or "love-child" of a father of gentle birth and breeding. Special aptitudes, as for music, painting, poetry, or the mechanic arts, are inherited as surely as the qualities of dogs and horses. Whole races are musical or poetical as a rule, or the reverse. Intellectual educability is found to depend on blood, or on the education of progenitors. Hence the work of educating a long-neglected people must always be a slow one, and extend over several generations. Mr. Herbert Spencer says, "The capacity of a germ of unfolding into a complex adult, which repeats ancestral traits in the minutest details, is one we cannot understand. That a microscopic globule should become a man -gouty at fifty-is a truth, incredible, if not daily illustrated." 


\section{Human Physiology.}

There is a proverb, "Every part rnakes a part." Mr. Darwin has adopted this saying, and named it Pangenesis. He fancies that the germ cells and sperm cells are composed of atoms which come from every portion of the body-every organ, every tissue-blood, brain, muscle, bone, and every part of every minutest organ; and that these atoms have the power to build up an organisation, by each reproducing the part from which it has been derived. It is difficult to conceive of such a mode of reproduction; difficult to imagine in a microscopic cell the myriads of atoms required; those which must come from all parts of the nervous systems, for example, and the complex and delicate machinery of eyes and ears, the immense number of glands in the skin and mucous membrane, etc. Still, in some way, it must be that each organ has something to do with reproducing itself, else how have we the very shape of fingers, features of the face, form of head and body, and minute reproduction of organs even to brows and eye-lids, hair and nails, with all kinds of peculiarities and diseases. There is pangenesis; but possibly not of the material character Mr. Darwin has imagined. The formative force may come from every part-the presiding and directing power which orders matter and gives form. In some way germ cell and sperm cell contain the future insect, bird, horse, man, and not only $a$ man, but the man, with all he inherits from all the generations of his progenitors. More, and more wonderful, the germ cells and sperm cells of the first pair of human beings must have contained the furmative power which has produced all their posterity that have been, are, and shall be. Is there a limit to that original, all containing, procreative energy? If there be, when it is reached the race must die out, just as animal races have died out, and the human race will have its end, as it had its beginning.

The main facts of the transmission of qualities by descent are evident and well understood with regard to animals. No one 
expects that two common hacks will produce a racehorse; or that two mongrels will produce a pure hound; nor can it be more reasonably expected that two scrofulous parents can have a strong healthy child; two irascible, excitable parents, a gentle, placid child ; or two parents of small intellect and little culture can have a child of genius. When children are "born thieves," or "born liars," we expect to find the cause in one or both of their parents or their progenitors.

For the correction of many physical, mental, and moral peculiarities, we have the law of the attraction of opposites; but this law does not apply to vices and diseases. In this case "birds of a feather flock together." The ignorant and the vicious, people of low organisations and habits, herd together, intermarry with each other, and beget their kind. Drunkards beget drunkards; dishonesty and lust are hereditary vices. Sensual parents beget sensual children. Diseased parents transmit weakened constitutions and diseased tendencies to their offspring. But nature has provided a terrible remedy. "The wages of $\sin$ is death." Hereditary vices cause disease and hereditary diseases shorten life. The process cannot go onward, because those who violate the laws of health soon lose the power of transmitting their evils to their posterity. Their children die too young to continue the evil stock. Every community living in bad sanitary conditions and habits tends to its own extermination. All large towns are peopled by a constant immigration from the country districts.

The part which each parent has in giving physical and moral qualities to its offspring is a question of curious, if not important interest. Abd el-Kadir said the essential forms of the horse were derived from the stallion. The mule of the mare resembles its donkey father, while the mule of the stallion is much more like the horse. Hybrid plants resemble the male parent in foliage and the female in flower. Breeders are very careful in regard to both males and females; but greater pains 


\section{Human Physiology.}

are usually taken with respect to males. In human families we find some children strongly resembling the father, some looking more like the mother, while some mingle the traits of both. A child also not unfrequently bears more resemblance to one of its grandparents, or uncles, or aunts, than to either of its parents.

Celebrated men, it is held, are more often indebted to their mothers than their fathers for the qualities that make them famous. We have no sufficient collection of facts to enable us to say that special qualities are inherited from either parent; and it may be that their respective and relative conditions at the period of conception determine the character or extent of their influence upon the child. The resemblance of the offspring to the male is said to be more striking in proportion to the state of his health, or the energy of his vitality. Certain'y, a man of exhausted nervous power cannot expect to give to his offspring what he does not possess.

But we must go beyond the parents to find the causes of the difference in the children of the same family. Remote peculiarities crop out; and the varying relations of the parents to each other, and their relations to other persons, undoubtedly have an influence.

Sometimes the children of a woman by a second husband resemble her first husband. It is seen in animals that one male gives the type to the future progeny sired by others. So a man who is only the friend of a lady-may, as it is said, "mark" her offspring. Even pictures or statues are believed to have an influence upon the forms and features of children; and we may well believe that the mother who is surrounded by beauty and music is more likely than another to have beautiful and musical, or at least tasteful and cultivated children. One child of a family may have a musical ear, and others be deficient-one may be a genius, and the others very common mortals, and this where there can be no suspicion of varying paternity. Still, every effect must have its sufficient cause. 
When a man is to buy a horse-say, a hunter-he is earnestly counselled to look for breed. Without what is called "blood"-that is, a particular line of parentage-a hunter is of no use. "Blood gives stamina, emulation, and intelligence; and when the under-bred, lumbering beast is licked to a stand-still, the wiry, well-bred 'weed' will be going on, which shows how even a weak specimen of the thoroughbred will often give the 'go by' to an animal possessing more muscular development, but lacking in aristocratic descent."

But when a man is to "take a wife," or a woman to "accept a husband" - when it is a question of the paternity and maternity of a family and a race, what is the consideration? "Good family" is, in some sense, certainly considered by most people of a certain position, but not by the greater number; and even by the middle and upper classes, money, or the position that money can purchase, often goes for more than health or charac:ter. Yet physiologists assure us, that "predisposition to any form of disease, or any malformation, may become an inheritance. Thus disease of the heart is hereditary; so are tubercles in the lungs; so also are diseases of the brain, of the liver, and of the kidneys; so are diseases of the eye and of the ear. General maladies are equally inheritable, as gout and madness. Longevity on the one hand, and premature deaths on the other, go by descent. If we consider cases of peculiarities, more recondite in their origin than these, we shall still find the law of inheritance to hold good. A morbid susceptibility to contagious disease, or to the poisonous effects of opium, or of calomel, and an aversion to the taste of meat-are all found to be inherited. So is a craving for drink, or for gambling, strong sexual passion, a proclivity to pauperism, to crimes of violence, and to crimes of fraud."

Scrofula, consumption, cancer, and syphilitic diseases are so notoriously hereditary, that it is a serious moral question whether any marriage ought ever to take place by which these 
diseases may be propagated, and passed on, even in modified forms, to posterity. Gout is, beyond doubt, transmissible, and from its origin is looked upon as an aristocratic disease. It is, however, often fatal, and is allied to apoplexy, the tendency to which is shown in clearly inherited bodily configuration. Weakness of sight, near-sightedness, and other defects of vision, are hereditary, as are blindness, deafness, and similar deficiencies; so of tendency to fatal hemorrhages. Legal authorities recognise the hereditary character of various forms of insanity, and they should equally recognise hereditary tendencies of an equally strong and ungovernable character to various crimes, especially to those of theft and murder. The tendency to suicide is very decidedly hereditary, arising, perhaps, in the mental condition of the mother at the period of conception, or during pregnancy, and then handed down to posterity. 'Suicide, it is well known, prevails in some families for several generations, as one of several kinds of transmitted manias.

In men, as among breeds of animals, the prolific character is hereditary in some families, as in others the reverse. There are families in which almost every member for several generations has had from twelve to twenty children. Longevity is equally remarkable as belonging to certain families. In considering the probable length of the life of any person, or even the probability of his recovery from any disease, we wish to know whether his parents and ancestors were long or short-lived people.

When both parents come of long-lived families, or strong, or prolific, or intellectual, the peculiarity will be intensified in the children. This law provides for the strengthening and increase of all good qualities; while the like effect is produced by the conjunction of evil influences: only many of these, being of a destructive character, are naturally self-limiting.

The effect produced upon the character of the child by 
the condition of either parent at the period of conception, or of the mother during gestation, is very remarkable, and should be universally known and heeded. A child begotten by an intoxicated father may be insane or idiotic. Any remarkable disorder, mental or physical, in either parent, may show itself in the whole life of the child. In one case, where the union which resulted in the birth of a child was an outrage on the mother, her indignation produced such an effect upon the child that it was never able to speak to the father. Many children have inherited a strong repugnance to their male parents. The children of mutual love are affectionate to both parents. They inherit the love of father to mother and mother to father-a happy inheritance. They may also inherit indifference or hatred.

Any shock to the mother during the period of pregnancy may produce very striking effects upon the child. It is recorded that in a famous siege, which ended in blowing up the arsenal of the city, a large number of the children born subsequently were maimed, had their bones broken, or were rendered idiotic. Mother's marks-an impression upon the child of something the mother longed for-are common; and tastes for particular fruits or kinds of food are often impressed upon children by the desires of the mother during this period. One of the most unfortunate of inherited tastes is that for intoxicating drinks which may be given by either parent, before birth, or acquired from the mother or nurse after birth. Drunkenness and sensuality are the sad inheritance of a vast multitude of children, as well as exhausted nervous systems and many bodily and mental diseases.

When men and women are free to select their mates solely by their instinctive and intuitional powers - by the free play of their attractions and repulsions, presided over by reason and religion, or the sense of truth and right, the law of hereditary transmission of qualities will carry the human race to its highest 


\section{Human Physiology.}

possible perfection. Men have but to carry reason and conscience into the domain of love, to make marriage one of the highest and most sacred duties of life, in order to ensure a healthy, highly developed, and happy posterity.

\section{CHAPTER VIII.}

THE LAWS OF SEXUAL MORALITY.

All Laws founded in Nature-The Law for Childhood-The Law for Youth-Equality of the Sexes-Opinion of Dr. Carpenter-Waste of Life-The Law of Chastity-The Law of Marriage-Worldly Morality - "Sexual Religion"-An Abhorrent Doctrine-The Christian Doctrine of Marriage-The Law of Progress.

ALL laws affecting the wellfare of man are written in his constitution. All rules of conduct, to be of any value in promoting his happiness, must be in harmony with his unperverted nature. No law, or social custom can have any reality to us, if it is not in accord with our highest sense of right-if we do not recognise its fitness to our physical, moral, and intellectual nature, and its correspondence to our highest ideal of truth, duty, and enjoyment.

The laws of sexual morality must have this basis. The unperverted instincts of all animals living in a state of nature are the law of their life. The instincts of man are so perverted by his unnatural conditions, that they can seldom be trusted to guide him in the path of virtue, health, and happiness. Men inherit perverted natures, diseased constitutions, disordered propensities, from their progenitors. Their education and habits of life often increase these evils of birth. Air, clothing, food, drinks, narcotics. and intoxicants, employments and 
amusements, literature and art-all tend more or less to increase these false conditions. We are driven therefore to study the real nature of man rather than his habits in a false society; to consider his physiology rather than his pathology; that we may ascertain what modes of life and action tend to health and happiness, and how he may avoid such as lead to disease and misery.

The law of sexual morality for childhood is one of utter negation of sex. Every child should be kept pure and free from amative excitement, and the least amative indulgence, which is unnatural and doubly hurtful. No language is strong enough to express the evils of amative excitement and unnatural indulgence before the age of puberty; and the dangers are so great that I see no way so safe as thorough instruction regarding them at the earliest age. A child may be taught, simply as a matter of science, as one learns botany, all that is needful to know, and such knowledge may protect it from the most terrible evils.

The law for childhood is perfect purity, which cannot be too carefully guarded and protected by parents, teachers, and all caretakers. The law for youth is perfect continence-a pure vestalate, alike in both sexes. No indulgence is required by one more than the other-for both Nature has made the same provision. The natures of both are alike, and any-the least -exercise of the amative function is an injury to one as to the other. Men expect that women shall come to them in marriage chaste and pure from the least defilement. Women have a right to expect the same of their husbands. Here the sexes are upon a perfect equality. The exercise argument is just as good for one as for the other-and, as a matter of fact, the medical men who outrage science and morality by prescribing sensual indulgence to young men, do not hesitate to do the same for young women, and for the same fallacious reasons.

On this subject, Dr. Carpenter, in his physiological works, 
has written like a man of true science, and therefore of true morality. He lays it down as an axiom that the development of the individual, and the reproduction of the species, stand in an inverse ratio to cach other. He says:- "The augmented development of the generative organs at puberty can only be rightly regarded as preparatory to the exercise of the organs. The development of the individual must be completed before the procreative power can properly be exercised for the continuance of the race." And in the following extract from his "Principles of Human Physiology," he confirms my statement respecting the unscientific and libertine advice of too many physicians:- "The author would say to those of his younger readers, who urge the wants of nature as an excuse for the illicit gratification of the sexual passions, "Try the effects of close mental application to some of those ennobling pursuits to which your profession introduces you, in combination with vigorous bodily exercise, before you assert that appetite is unrestrainable, and act upon that assertion.' Nothing tends so much to increase the desire as the continual direction of the mind toward the objects of its gratification, whilst nothing so effectually represses it as a determined exercise of the mental faculties upon other objects, and the expenditure of nervous energy in other channels. Some works which have issued from the medical press contain much that is calculated to excite, rather than to repress, the propensity; and the advice sometimes given by practitioners to their patients is immoral, as well as unscientific."

It is a medical-a physiological fact, that the-best blood in the body goes to form the elements of reproduction in both sexes. The nervous power which we expend in this process is probably more important than the matter over which it presides. In a pure and orderly life this matter is reabsorbed-it goes back into the circulation, ready to form the finest brain, nerve, and muscular tissue. By its aid a man can become the 
most powerful athlete, or exercise the highest intellectual power of which he is capable. He can use his life to the last atom, instead of wasting it. This life of man, carried back and diffused through his system, makes him manly, strong, brave, heroic. If wasted, it leaves him effeminate, weak, and irresolute-intellectually and physically debilitated, and a prey to sexual irritation, disordered function, morbid sensation, disordered muscular movement, a wrecked nervous system, epilepsy, insanity, and death.

I need not dwell further upon the consequences of diseased amativeness, or the waste of life in sensual excess, in this place, as they will be further treated of in Part Fifth; here I wish only to enforce the law of chastity, and to show that a sound physiology is in perfect unity with the requirements of Christian morality. Every man and every woman, living simply, purely, and temperately-respecting the laws of health in regard to air, food, dress, exercise, and habits of life, not only can live in the continence of a pure virgin life when single, and in the chastity which should be observed by all married partners-but be stronger, happier, every way better by so living.

And it is well to know this. In a country where there is a surplus female population of a million or more, it is not pleasant to believe that chastity is not a natural as well as a spiritual virtue. In a country where a vast number of men, for one reason or other, do not find it convenient to marry-where thousands of brave, and self-denying, and religious men renounce the pleasures of marriage-it is well to know that they may not only do so with safety, but often with advantage, and that, though marriage is honourable, a virgin life is not only possible, but may be to many the highest and best, if they have for it a true vocation.

If men and women can live in continence from the age of fifteen to twenty-five-if ten years of purity in the heyday of youth are no injury, but. rather a good to them, how absurd to 
think that they cannot live as purely in any after time-in marriage when required or rendered advisable-in absence-in widowhood. The opposite doctrine seems to me not only utterly false, and opposed to all nature and the highest human experience, but most shameful and degrading - an insult to our manhood and our womanhood-a libel on daughters, sisters, wives, and mothers.

Chastity is the conservation of life and the consecration of its forces to the highest use. Sensuality is the waste of life and the degradation of its forces to pleasure divorced from use. Chastity is life-sensuality is death.

From the age of puberty to marriage the law is the same for both sexes. Full employment of mind and body, temperance, purity, and perfect chastity in thought, word, and deed. The law is one of perfect equality. There is no license for the male which is not equally the right of the female. There is no physiological ground for any indulgence in one case more than in the other. No man has any more right to require or expect purity in the woman who is to be his wife, than the woman has to require and expect purity in her husband. It is a simple matter of justice and right. No man can enter upon an amative relation with a woman except in marriage, without manifest injustice to his future wife, unless he allow her the same liberty; and also without a great wrong to the woman, and to her possible husband.

It is contended that the sins of men against chastity are more venial than those of women, because of the liability of women to have children. But men are also liable to be the fathers of children; and they are deeply wronged by the absence of paternal care. The child has its rights, and every child has the right to be born in honest, respectable wedlock, of parents able to give it a sound constitution and the nurture and education it requires. The child who lacks these conditions is grievously wronged by both father and mother. 
The law of marriage is, that a mature man and woman, with sound health, pure lives, and a reasonable prospect of comfortably educating a family, when drawn to each other by the attraction of a mutual love, should chastely and temperately unite for offspring. The sexual relation has this chief and controlling purpose. The law of nature is intercourse for repro duction. Throughout the vegetable and animal world there is no other. Pleasure is a secondary consideration. "Marriage," says St. Francis de Sales, a wise and holy man who speaks the law of the Church, "is for progeny; mere sensual pleasure is not a sufficient motive. It is the same as with regard to food. The motive to eat is not to gratify the appetite, but to nourish the body. The sin in both cases is in seeking sensual delight apart from natural use." The use of marriage for any other purpose is never allowed, except as a concession to human infirmity, or as a preventive of greater evils, as polygamy was permitted under the earlier dispensation. Under the Christian law, marriage is the symbol of the union of Christ with the Church; husband and wife are one in the Lord; they are to live in marriage chastity, not in lust and uncleanness ; and there cannot be a more hideous violation of Christian morals than for a husband to wreak his sensuality upon a feeble wife against her wishes, and when she has no desire for offspring, and no power to give them the healthy constitutions and maternal care which is their right.

The law of Christian morality is very clear. It is the sexual union first and chiefly for its principal object. It is for the husband to refrain from it whenever it is not desired; whenever it would be hurtful to either; whenever it would be a waste of life ; whenever it would injure mother and child, as during pregnancy and lactation. A man who truly loves a woman, must respect and reverence her, and cannot make her the victim of his inordinate and unbridled, selfish and sensual nature. He will be ever, from the first moment of joyful pos- 
session, to the last of his life, tender, delicate, considerate, deferent, yielding to her slightest wishes in the domain of love, and never encroaching, never trespassing upon, never victimising the wife of his bosom, and the mother of his babes. We have romance before marriage-we want more chivalry in marriage.

This is not the world's morality-yet it seems to me the world must respect it. This high and pure Christian morality is not always enforced by Christian ministers, some of whom yield too much to human sensuality and depravity, instead of maintaining the higher law of Christian purity-which is but nature restored, or freed from its stains of sin. The world requires that unmarried women should be chaste, while it gives almost unbridled license to men. A girl detected in amours is disgraced and often made an outcast. In young men such irregularities are freely tolerated. They are "a little wild;" they "sow their wild oats;" but open profligacy, the seduction of innocence, the ruin of poor girls, adultery, harlotry and its diseases, do not hinder men from marrying, nor from requiring that those they marry should have spotless reputations. It is not for a moment permitted that women in these matters should behave like men; and a pure girl is given to the arms of a wasted debauchee, and her babes are perhaps born dead, or suffer through life with syphilitic diseases, while she endures a long martyrdom from disordered, diseased, and unrestrained sensuality: For the unmarried, young men, soldiers, sailors, and all who do not choose to bear the burdens of a family, society has its armies of prostitutes-women like others, and more than others, or in less reputable fashion, the victims of the unbridled lusts of man. These are everywhere tolerated as "necessary evils," and, in some places, protected or regulated, and from economical or philanthropic considerations, or both combined, efforts are made to free them from the contagious diseases, which for some centuries have been a curse attend- 
ing this form of the violation of the laws of nature-one of the consequences of lust, which is the divorce of the sexual instinct from its natural use and purpose.

There is another theory of sexual morals, worse, if possible, than this, but more logical and consistent. It is the one widely taught by a large and very active school of social reformers in England and elsewhere, under the name of Free Love, by which the names of freedom and love are both perverted; or Sexual Religion; or Social Science.

The doctrine is that sexual union, from the age of puberty, is the natural requirement and right of every person, male and female, and that nothing ought to prevent its free and frequent exercise; and that to avoid too great an increase of population, the inconvenience of children to the unmarried, and too many to the married, means should be used to prevent conception. The generative organs, it is said, are subject, like all other organs, to the law of exercise, and "it is a duty and necessity to give them this exercise from the age of puberty, till their decline." I quote from a book which boasts ten editions. This doctrine is simply one of unrestrained, universal, promiscuous intercourse, extending to every person of both sexes; and it is at open war with the conventional morality of society, which tries to guard the purity of some women before marriage, by the sacrifice of others to the Moloch of masculine lust, and the morality of religion, which insists on chastity both of men and women, in and out of marriage.

I have already shown that the basis of this horrible demand for universal prostitution and license is utterly unscientific. The generative organs differ from all others in being adapted to long periods of perfect repose. We have seen that in vegetables and many insects they are used but once in a life time; and that in all the higher animals they come into use only at long intervals, in many, intervals of years, and for one specific purpose. We know that with thousands of men, and millions of 
women, such use never occurs, or is suspended through long years, with no bad effects upon body or mind, but rather with a notable increase of bodily and mental vigour and spiritual life. The assertion, therefore, that such a theory of morals, or of immorality, is natural is the result either of very gross ignorance or of great impudence. It is, however, the shameful fact that the book from which I quote professes to have been written by "a graduate of medicine," and that its principles have been adopted by not a few of the more ignorant or unprincipled members of the medical profession. This work prescribes for most of the diseases of men and women, and most of the evils of society, unrestrained sexual indulgence in both sexes, of all persons, in all conditions, from the age of puberty to the decline of the bodily powers.

Abhorrent as this theory is, it is yet consistent. Based upon a fallacy, it is yet more reputable than the partial and absurd conventional morality of society, which has one law for men and another for women, and sacrifices thousands of women to provide for the vices of one sex and protect the virtue of the other.

The Christian law of marriage, as set down in the Holy Scriptures, and defined by the best writers on moral theology, is in harmony with nature-in consonance with the higher nature of man. "God hath set the earth in tammies." Adultery is a sin, because it disorders that divine arrangement. Selfish lust is a sin, because it mars it. Fornication is a sin, because it prevents pure marriages. Prostitution is a sin, because it is a sacrifice of women, who might be wives and mothers, to the selfish lusts of men. All useless indulgence is a waste of life, and a kind of suicide. In a pure marriage union men and women unite themselves with God in acts of creative power.

The progress of humanity depends upon individual development, and the conditions of generation and gestation. With culture, and a harmonised development, we acquire a higher 
and more integral life. When two parents are in their highest condition, and in a true union with each other, the child combines the best qualities of both parents. When parents are not in the unity of a mutual love, the child may be inferior to either parent. The intensity of mutual love tends to the reproduction of the best faculties of both parents in the child. When men or women are exhausted or diseased the race deteriorates. Health is therefore one of the conditions of progress. Freedom of choice-and a wide range of choice may be a condition of freedom-is necessary to the formation of true marriage unities.

The force and material used in the evolution of germ and fotus, are the same that develop the individual. In the physical, moral, and intellectual development of the individual, this force and matter-this material of life-may be used up to the last particle; but there is a compensating reaction when every faculty gives of its material for the generation and formation of the new being. Amative waste comes from suspension of individual development; therefore chastity is the condition of individual progress, and the development which it makes possible is the condition of the progress of the race. In a true society reproduction will be the result of high individual development, integral loves, and the desire to combine the sum of such development. It will be the conscious integrality of life, and its resulting happiness, which will seek perpetuation in new beings. In such a society the greatest crime would be the reproduction of partial and discordant beings. The love life is first to produce, and then reproduce. Where waste, or reproduction, precede production, or individual development, there is no progression in the individual or the race. Both are wasted, deteriorated, and destroyed.

"It is all very fine," I shall be told, " to talk of purity and chastity; but we must take men as they are. How are you going to make men pure and chaste, and respectful of the 
purity of women? How can you get men with strong amative propensities to live like anchorites?"

How can you get men to do any right thing or refrain from any wrong thing? There are three motives-fear of punishment, hope of reward, and sense of right, or the principle of duty. The first of these is the lowest, but often the most effectual; the second is higher, and appeals to hope and the love of happiness; the third, the highest of all motives, pure and unselfish as the love of truth, as in mathematics, acts on noble minds with great power. Men of real conscientiousness love the right for its own sake. They are just from love of justice-pure from a sense and love of purity. They love good, and God as the source of all good; and do right, not from fear or hope, but from pure love.

We must appeal to all motives. Men refrain from theft and other dishonest conduct from the dread of disgrace and punishment ; because they see that "honesty is the best policy," and from a sense of justice and regard to the rights of property, or a sense of honour which makes a mean action impossible. By similar motives great numbers are restrained from drunkenness and other vices. Children are to be restrained from impurity by the fear of the terrible consequences of unnatural indulgence in causing disease and pain, by the hope of a pure, healthy, and happy life of love in manhood and womanhood, and by a sense of the beauty and holiness of chastity, and the sacredness of the functions by which the race is re-created and preserved. The religious feeling that our bodies are to be kept pure, healthy, and holy in every way as "the temples of the Holy Ghost," cannot be too early instilled into the infant mind, which is open to the highest sentiments of veneration, devotion, and heroic religion. In youth there are the same motives. Indulgence in solitary vice is self-destructive of all that youth most values-a profanation of his own body. Seduction is a desecration of what he should hold in the most tender reverence. To the young man 
womanhood should be sacred, and no woman, mother, sister, the beloved of the present or the future, should ever be wronged by one thought of impurity. In this matter instinct goes with right. The inward voice supports the outer law of morality. Before men can become bad, their instinctive modesty must be broken down. Unless very badly born, with disordered amativeness hereditary from a diseased and lustful parentage, they must be perverted and corrupted before they can act immodestly and impurely.

Women are protected by a strong public sentiment around them. They have the dread of disgrace. For them to yield to their own affectionate desires, or the solicitations of a lover, is a fall, is ruin. They have the hope of a loving husband, a happy home, and the respect of society. And in women passion has commonly less force, and the sentiment of modesty and purity more power. Women are weak in yielding to solicitation, giving everything for love; but we see how protective of female virtue are these motives to vast numbers. Add a strong sense of religious duty, and we have women generally, almost unexceptionably virtuous, in the middle and upper classes of England and Scotland, and in Ireland almost universally. In the lower classes of England, Scotland, and Wales there is more laxity, as the statistics of illegitimacy manifest.

Men can perfectly restrain the sensual part of their natures whenever and wherever they have a strong motive to do so. A child would be simply mad who was not controlled by the presence of father, mother, and persons he respected or feared. Young men have no difficulty when they are in the company of pure women. They are in no trouble where their lives are full of mental and muscular activity, and particularly if their habits of eating simply and temperately, of refraining from heating and exciting stimulants, and sleeping in cool beds and fresh air are such as health requires. There needs but the strong will to live purely in any one, and at any age-the will that comes 
from the high motives of conscience and religion, or all motives combined. A strong sense of what is just and right controls even the motions of our bodies, and actions which seem to be involuntary. A man who has a vivid sense of the right and duty of refraining from sensuality, and preserving his own purity of mind and body, and the chastity of all women, will do so even in his dreams. When the will is right, all things are soon brought into its subjection. The mind controls the organisation, and the life forces are directed into other channels. A strong man, full of life and love, can safely hold a virgin in his arms and respect her virginity, if he have but the motives and the will to do so. If he be pure in his will, how can he commit impurity? If a woman be sacred in his eyes, how can he profane her? It is not that men have not the power of selfrestraint, the power to do right-it is that they lack the motive. They have lost the sense of right; they are even impelled to do wrong by the pressure of opinion around them. Boys and young men are driven into libertinage by the ridicule of their companions. Vice is considered manly. They seek sensuality in an evil emulation, as they learn to smoke, or game, or drink. And, later on, vanity has often more to do with excess than the force of lust. Young men seduce girls that they may boast of it. They keep mistresses because it is the fashion. They exhaust themselves, because they wish to give a high idea of their manly prowess. Even in marriage women are injured, and have their health destroyed, yielding weakly, or from a false sense of duty, to a husband, whose own motive is the desire to acquit himself manfully in what he considers his marital duties. Men and women are, in thousands of cases, wretched victims to what they innagine to be the wants or expectations of each other. A man, ignorant of the nature of woman, and the laws of the generative function, goes on in a process of miserable exhaustion to please his wife; she submits, sometimes in pain, often in 
disgust, weariness, and weakness, to what she dare not from love or fear refuse.

For evils of ignorance we want knowledge; for those of false notions we want truth. When the great law of nature-which is the law of God-respecting the reproductive function is clearly known, and the consequences of its disorders and abuses, and the health and happiness that may come from purity and holiness of heart and life, men and women will aid each other in avoiding the evil and enjoying the good. Men will no longer injure themselves and destroy women; women will no longer give the sanction of their tolerance, and even approval, to men of profligate and dishonest lives, wasting their own energies, and making women the wretched slaves of their lusts.

Drunkenness has ceased to a great extent among the higher classes in England, because women will no longer tolerate tipsy men in their drawing-rooms. Drunkenness has gone out of fashion. If the women of England would cease to tolerate libertines, sensuality would also become unfashionable. If the mothers of England cared more for honesty and virtue in the husbands of their daughters than wealth and position-if the daughters themselves, instead of simpering "Oh, you naughty man!" shrank with a true woman's horror of impurity, with all its consequences, from men of evil lives, who have wasted themselves, destroying others, there would be a different state of things; and if the religious sentiments so many profess had any reality, they would govern the opinions, influence the feelings, and control the lives of a great many more in the world about us.

Men have to know what is right, and to will to be right. This will is omnipotent. God helps those who have the will, who have even the desire, to do right.

If the presence of those we fear or reverence, respect or love, restrain us from sin, and stimulate us to right action, faith in the existence and presence of God, and angels, and the spirits 


\section{Human Physiology.}

of the departed, must have a more powerful and pervading influence. No one who really believes in the existence of a Supreme Being: no one who is strongly impressed with the reality of a Spiritual life, can go on doing what he knows to be wrong. A religious faith is therefore the most powerful of all restraints from evil, and incitements to good.

It has also to be understood that every sin, every wrong action, is a violation of the law of God, written in the physical or moral nature of man. It is a sin, a wrong, an evil, because it is contrary to the nature of man-because it is, in one word, unnatural. Every sin is therefore a sin against nature. Every law of God for man is founded upon the fact that to do otherwise than it commands is an injury to himself. We are to do justice, and avoid injustice to others, because in hurting them we do ourselves an injury. We are to love ourselves-this feeling is implanted in us; and we are to love our neighbour as ourselves, because his well-being and happiness are bound up with ours. Our higher nature requires that we love God, as the condition of our own peace and happiness. The law of nature, written in our minds and hearts - the law of judgment and conscience-is the one constantly appealed to, and it is necessarily the only one we can comprehend or be influenced by. This principle is embodied in the great rule of conduct"Whatsoever ye would that men should do to you, do ye even so to them." This rule is based upon the fact that the law of God is written in the constitution of man. It is impossible for a man to do any wrong to another which is not a great wrong and evil to himself. Therefore, it is better to suffer wrong than to do wrong. A fraud upon us, a theft, or a calumny, may be a very slight injury to us-one of which we may be almost or quite unconscious, but not so to the evil doer.

We have therefore the powerful motive of self love given to urge us to right action, and to restrain us from wrong action. And when men can clearly see what is right, and therefore best 
for them, it cannot be that they will perversely do wrong against every motive to do right. There are, no doubt, cases of exceptional, perhaps insane, depravity, but we educate our children, and we try to influence, in various ways, the conduct of those around us, preach sermons, write books, because we believe men can be instructed, can be helped, can be influenced by motives to shun vice and practice virtue. If some can be taught and influenced, more can. If some can be induced to "cease to do evil and learn to do well," where can we limit the possible reformation?

\section{CHAPTER IX.}

PROBLEMS OF THE SEXUAL RELATION.

Of the True Marriage-The Relation of Marriage to Love-Limitation of the Number of Offspring-Marital Rights-Woman's Rights and Wrongs-The Religious Rule-The Population Question-Food Resources of Great Britain and Ireland-The Physiological SolutionOught the Sexes to be Educated together-Dangers of SeductionJealousy.

Many questions arise in an artificial social condition respecting the relations of the sexes to each other, which are difficult to answer. The highest good is not always attainable-we are sometimes driven to a choice of evils.

It is held by many persons almost as an article of religious faith, that there is for each person one love, and one object of love. Marriages are made in heaven, and when the two persons who belong to each other are joined there is no separation in time or eternity. It is a spiritual as well as a material relationship which death cannot sever, and for the survivor to marry another is spiritual adultery. To persons of 
great constancy and persistency of affection this is a fascinating theory, and such love and consequent marriage may accord with individual idiosyncrasies; but I have seen no reason to believe that any considerable number are constituted for such exclusive fidelity. It seems more probable that for each individual there must be many persons, perhaps great numbers, suitable for conjugal union. In a large society, with freedom of choice, few men or women find any difficulty in getting congenial partners. Love may follow marriage, as it is said to do in most cases in countries where matches are made by the parents. Even in England there is more management among the middle and upper classes than young people imagine. Those who are considered suitable for each other are thrown together, and matches are made by match-makers, who exist in every grade of society.

Is love necessary to marriage? I cannot see that any man is justified in marrying a woman he does not love or that a woman can be truly joined to a man except in such a love as husband and wife promise to have for each other till death do them part. But even where love exists at the beginning it does not always last; and if mutual love were the essence and necessary condition of marriage, when it ceased on either side the marriage would be null and void. But the law does not so regard it. There are those who believe that love alone can justify the most intimate relation of the sexes. Without mutual love, they say, marriage is but legalised prostitution. They would justify a husband in denying conjugal rights to his wife, or a wife in refusing herself to her husband, if either ceased to love the other. If mutual love be the sole justification of sexual unionif it be false, unnatural, abhorrent, where such love does not exist, then the cessation of love on the part of either would be the end of marriage-a divorce, or at least a separation. But the interests of children, families, and society, as it is now constituted, do not permit of divorce for sentimental grievances. The 
intimate relations of two married partners must be regulated by themselves, and in this, and in all that pertains to marriage, they must follow the law of charity, do as they would be done by, and what, all things considered, seems to them best for all concerned. Where there is no positive sin, no violation of conscience, we must seek the greatest good, even in a choice of evils; and we are not to seek our own good merely, but to make sacrifices, if need be, for the good of others.

Have we the right to prevent conception, to limit the number of children, to regulate families and population? Every one has the right, for good reasons, not to marry. It is a question of fitness, inclination, or vocation. A man who has a constitutional disease which he may communicate to his wife or child has no right to marry. It is doubtful if persons with strong tendencies to consumption, or epilepsy, or insanity should marry. They have the right at least to refrain from so doing. If people have the right not to marry, they must have the right to live in continence in marriage, and to refrain from sexual union when the health of the husband, or the wife, or the interests of their children require it. It is a duty not to have children with such frequency as to destroy the health of the mother; and it may be a duty not to have more than the parents can properly care for; but this is a more doubtful case, for no one can tell what may be his means and ability. With health, children are a blessing; and the world is wide, and can easily maintain ten times its present population. Continence, a mutual refraining from the sexual embrace, is, however, the only natural, and ordinarily, the only justifiable mode of preventing pregnancy. Pleasure comes of marriage, but marriage was not instituted for pleasure. This is sensuality and gluttony. God has not instituted marriage for health-I am quoting theologians-but for offspring. To select for union the period when conciption is least likely to occur, or to use any means whereby the masculine and feminine elements cannot unite, are 
unnatural practices, closely akin to the solitary vices which are so abhorrent and so destructive; and there is no doubt that every practice of this kind is a physical injury. We cannot interfere with natural functions with impunity. We can refrain altogether, by mutual agreement, with mutual advantage. Against purity, continence, chastity, the apostle says there is no law.

But what can be done when lustful men, who care for nothing but the gratification of their sensual appetites, compel their wives to submit to their embraces, when they are utterly unfit to bear children, and are so un-brutal as to make these demands during pregnancy, at the risk of producing abortion, and during nursing, to the great injury of mother and child?

First of all, there should be no such unnatural husbands. But it is hard to say how wives can protect themselves from them, where they exist, any more than they can from being abused or outraged in any way. In such cases, it would seem that the wife ought to have a right to protect herself and her offspring. No man has a right to force a child upon a woman against her. wishes : and for every wrong there should be a remedy. Women have a partial remedy against the injuries of compulsory embraces, in the fact that the nervous excitement of the organs is to a considerable extent under the control of the will. Women have the power of refraining from participation in the pleasure, and therefore, to some extent, of avoiding the exhaustion, of the sexual embrace. The unfortunate women who sell their bodies to gratify the disorderly lusts of men, commonly yield themselves passively, without pleasure, often with disgust, while they enjoy the embraces of men they love.

There is some misapprehension as to the requirements of marriage, or what is called the marriage debt, or marital rights, which can be sued for in our courts, and the duties which religious teachers, directors, and confessors enjoin. In the Holy Scriptures married partners are exhorted to act justly and charitably 
to each other, and wives are to obey their husbands in the Lora. The best writers on moral theology teach that the use of marriage is not for appetite, nor for pleasure merely, or chiefly; that excess is like gluttony ; that marriage requires the consent of both parties, and must be interior, exterior, free, absolute, and made with knowledge, and it is inferrable that the payment of the marriage debt should be accompanied with the same conditions; that the demand must be serious, at suitable periods, and for proper motives. If dangerous to the health of the wife or child, as during pregnancy and nursing, it cannot be demanded, nor in drunkenness, as it may inflict a hereditary predisposition, or even idiocy upon the offspring. In a word, the rules of religion are always those of sound cummon sense, and a true science. No law of God in His Word can ever contradict the law of God in His Works. What we have to do is to rightly read both revelations.

The population question has agitated the minds of Englishnien since the days of Malthus; but population has increased in its .customary ratio notwithstanding, and England is less crowded, compared with its means of subsistence, than it was twenty years ago. A manufacturing and commercial country, drawing its supplies from other, and even very distant regions, may sustain an almost unlimited population. In an agricultural country like Ireland the population has a limit, but such limit has probably never been reached. A large portion of the produce of Ireland is exported to pay the rent. If the land were owned by those who cultivated it, or if the owners lived and spent their incomes in Ireland, the country could sustain a much larger population. If England and Ireland were cultivated in the best manner, and the land devoted to hops, barley for malt, and grains for distillation were used for raising food for men, the population might be largely increased, without food imports. If the land used to feed cattle were used to feed men - that is, if the population lived on a vegetable and 
fish, instead of a flesh, diet-it might be trebled. Then population increases the fertility of a country, if its waste is put upon the land, instead of being turned into the rivers and the sea. The checks to population in a low state of development are war, pestilence, and famine, and all the causes of infantile and premature mortality; but in a higher development we shall have the operation of two checks of a very different character. With high mental and moral culture there will come the love of chastity; and we shall have the operation of the physiological law that the higher the development of any race becomes, the less is the number of individuals it produces. This law holds throughout the vegetable and animal kingdom. The lowest forms of life multiply with the greatest rapidity. In the higher progeny grows more and more scanty. The educated and refined classes, as a rule, have few children, and many are childless. Among the poor and ignorant children swarm. An aristocracy is always dying out, and requires to be continually strengthened by new blood. We have but to read the peerage to see how many families have become extinct. The higher we can raise the standard of intellectual and moral culture the less will become the danger of over-population. Then, for centuries to come, there will be the resource of emigration. In this matter, as in so many others, we may be sure that ample provision has been made for all needs. Nature is not an accident or a blunder. The destiny of man on the earth is guided by Intelligence and governed by Law. We have simply to conform to the order of Nature, and we need not fear for our own fate or the fate of our posterity.

The question respecting the amount of freedom that may be safely given to young men and women in their intercourse with each other, is one of the most important connected with the regulation of sexual morality. The customs of different countries and races differ very widely in this respect. In most oriental countries, all women of the middle and upper classes are strictly 
secluded. In Southern Europe, in the higher ranks of life, girls, from the age of puberty, are kept from all mase society but that of near relations until they are married. In England, though there is more freedom of intercourse-a freedom which sometimes astonishes foreigners-boys and girls, and young gentlemen and young ladies, are educated in separate schools. In America there are large schools and colleges where young men and women are educated together, eating at the same tables, reciting in the same classes, and joining in the same amusements. English girls are none the worse for the freedom they enjoy, greater than can be found in France, Spain, or Italy. And, so far as I can judge, the American young ladies, educated in colleges with young men, are in no way inferior to their English sisters who have had the seclusion of fashionable boardingschools. I am assured by those who have had the best opportunities for experience and observation, that the influence of the sexes upon each other, at such colleges, is highly favourable to intellectual and moral improvement, giving refinement of manners and stability of character. The young men are kept from low associations and vices, and compelled, by the force of female opinion around them, to be on their good behaviour. The young ladies have, perhaps, an equal advantage in masculine society.

The model of a school, one would suppose, must be the family, where boys and girls are born and educated together. The separation that usually takes place at the age of ten or twelve years, is not wholly an advantage to either sex. Boys do not become more manly, in the true sense of the word, when deprived of female society; nor do girls become more womanly in seclusion. Both are deprived of an element of social life, education, and development, and both suffer from its lackboys becoming rude and bearish, or sinking into a sickly sentimentalism; and girls equally tending to the two extremes of a morbid misanthropy, or an equally morbid romanticism. I. 


\section{Human Plyysiology.}

cannot but think it would be better, during the years in which the character is formed, if the two sexes were more in each other's society.

But how, it will be asked, can they be protected from the dangers of such associations? How are they protected now? Boys and young men have very little protection of any sort. At school, boys fall into the most deplorable and destructive vices. Young men, deprived of virtuous female society, find such as can only demoralise and deprave them. Severed from the friendship and sentiment, elevation and refinement, of such female society as all young men naturally desire, they too often sink into mere animal sensuality, and waste the force of life in the low vices and profligacy which utterly ruin vast numbers of young men of the highest promise. Are young ladies better protected? Those who know what may sometimes be found in boarding-schools of the highest reputation can answer. I prefer not to enter upon particulars. Suffice it to say that there are real evils in the separation of the sexes, which are possibly greater than would be likely to arise from their education together in well-ordered and properly regulated institutions, while there are considerable advantages to manners, morals, and intellectual development, in the influence which each sex has upon the other.

The real objection-the one that would have most weight in English society-is the dread that young men and women of different social rank-different caste-might form attachments to each other which would end in marriage. To avoid such a social scandal, there would have to be schools and colleges for every grade. The young nobleman, who forms a friendship for a plebeian tuft-hunter, can easily shake him off when he leaves the university-in the other case, the mischief might be irreparable. It must, however, be considered that young people are not free from the prejudices of caste, and that if young men aspire to those above them, young ladies are not very likely to 
give too much encouragement to their humble admirers. There would be in every such society a public opinion that would go far to regulate all its affairs and relations. If this difficulty could be removed, I can have no doubt that mixed education would be found to have great advantages for both sexes over the present system. If we ever come to a social state in which the real character and worth of a man or woman will be more valued than rank, or fortune, or artificial position, there will be a real advantage in the free association of the sexes, and no harm if the friendships formed in childhood and youth from genuine attraction should ripen into love, and be consummated in marriage.

The question of safety from sexual peril is wider than that of a choice of the mode of education. Absolute seclusion, or constant oversight of women up to the period of marriage, is the rule in many countries. Then the wife is handed over to her husband, and he takes his own measures for securing her fidelity. This care, however, is bestowed only on women. The purity of men is in no danger, or it is of no consequence. But in countries of freer manners-in England, where girls have a great deal of liberty, and in America, where they are the queens of society and rule with undisputed empire--how guard against the dangers of seduction? In England a seducer can be sued by the father or husband, and juries sometimes give heavy damages; but in ninety-nine cases in a hundred the aggrieved parties avoid the disgrace of a public law-suit. If seduction were a penal offence, it would be the same. Not in one case in a hundred would the crime be prosecuted. Where girls and women are not protected by their parents, or relatives, or the laws, I see but one way left. They must be taught to protect themselves. And this self-protection may be in all cases the best remedy.

It is well for the young of both sexes to know the nature, and the perils, of the sexual relation. It is well for young men 
to know that there are still in the world such women as are described in the Proverbs of Solomon; women whuse strong sensual natures have a magnetic power to inflame the desires of those who come near them; women who are really dangerous to men of a certain susceptibility to such impressions. An atmosphere of lust is spread around them. It is real and palpable. They can charm like serpents; throwing off magnetic currents, which come from and act upon the amative nature. It requires a certain force of character and strength of resolution to resist this fascination of the senses, which many women delight to produce; some for mere amusement, or the triumph of exercising power, as men in riding or hunting, in what they call innocent flirtations; some in abandoned voluptuousness. Generally it is best to run away. The better part of valour is discretion. Many such women seem to have a heightened pleasure, whether of ambition or lust, in the mischief they do. They like to take a husband from his wife, or a lover from his betrothed.

The male flirt and the male seducer, are far more dangerous, not, perhaps, as having more fascinating or magnetic power than women, but in the more terrible social consequences that may fall upon their victims. It is no disgrace to a man to get in love with a woman, or to be seduced. Either may be ruin to a girl or woman. And there are many men who want but opportunity to make almost any woman they choose to act upon love them, and any weak and loving woman yield to their desires. Such men are the terror of families. Fathers, mothers, chaperons, husbands, are in constant dread of them. In the days of duelling they could be called out-but it was at a strong risk of the challenger being shot, for wicked men are not always cowards.

Such a man, dangerous to female-reputations and virtue as the man-eating tigers of India to the poor inhabitants, need not be handsome. Very ugly men are often very successful. They 
need not be clever or elegant; though brains and manners are certainly an advantage. They need only to have in a strong degree the sexual magnetism of which I have spoken-the quality of fascination-a physical or nervous power, exercised by many animals, and multitudes of men, with or without consciousness, to do the greatest possible mischief. They put a spell upon a woman, which many find it difficult, perhaps impossible, to resist. It used to be supposed that the power they exercised resided in some philter or love-potion. A gift, a keepsake, may no doubt carry it, so may a billet-doux, which may be imbued with a subtle influence, which is not in the written words. It is in the strong will of the magnetiser. $\mathrm{He}$ interests his victim in some way-in a conversation, in music, in art, in religion-and not a few clergymen are adepts-and then wills her to love him. When a woman loves ever so innocently, ever so purely, she is no longer quite mistress of herself. She wishes generously to bestow herself on him she loves. It is an effort and a pain to refuse him anything he asks. But what if he bring to bear upon her the same will that has already charmed and fascinated, bewildered and taken possession of her? She is lost.

Forewarned is forearmed. It is the first step that costs. When a girl, a very young girl, knows that there are such dangers-and some, and, I hope, many, know it instinctively - they can watch against the first approaches, the first interest, the first feeling, that may lead them into danger. It is useless to say that no man should be trusted-it is themselves they are to watch, and safely keep; they must stand firmly against, or, if need be, fly from, the first symptom of a tender, and what may become an amative feeling, towards any man-any feeling which may give him the least bit of this dangerous power over them. Other safeguards are of little use. Men and women must possess themselves, know what is right, feel what is right, and resolve to do what is right, and resist what is wrong. A sense 
of purity, a devotion to purity, and flying from the first insidious approaches of evil are the remedies to be relied on. And when religion is a real, earnest, practical faith, entering into the whole life, living in good works of piety and charity-not a mere sentimentalism, or trying to feel good, but rather a trying to do good-and the whole life is one consistent prayer for the highest and purest love, bad men, living in sensuality, will have no power to injure.

What is jealousy, and what are its uses? Every passion thwarted gives us pain. Every object of desire wrested from us is a cause of grief, which may be accompanied by feelings of hatred and revenge. The loss of what we prize, what we have a property in, or a right to, is painful. We are jealous of our property, our position, our reputation, and most of all jealous of those we love. But the element of selfishness shows itself most strongly in our sexual relations. We are willing to, share our friends, our fortune, our common pleasures with others. The enjoyment of others heightens our own. A man likes to have his dinners relished, his pictures enjoyed, his music applauded, his children praised, his wife admired; but whatever a man wants exclusive possession of - whatever he loves with a selfish and exclusive love, he will be jealous of. If we grant the right of exclusive love and possession, we must admit the utility of the pain and passion that guard it. We have love and honour as our guarantees on one side; on the other, pain and fear. Perfect love casteth out fear-casteth out jealousy.

People say, where there is reason for love, there can be no reason for jealousy, and vice versa. But love itself is not always reasonable. With entire trust there can, of course, be no distrust; but perfect trust can come only of perfection-the sense of perfection in ourselves, and the recognition of perfection in another. A high estimation of one's self is a great protection from jealousy, which often comes from morbid humility and morbid approbativeness. We feel unworthy to be loved; 
we fear that we are not, or shall cease to be. In our pain and fear, distrust and suspicion, we make ourselves unlovely, and bring upon us the very calanity we dread. Distrust destroys friendship, and jealousy may kill out in time the tenderest affection.

No doubt jealousy, or the tendency or disposition to jealousy, has its uses. In the lower stages of development, it is the watch-dog, sentinel, safeguard of marriage and the family. The husband or the wife, ever so faultless, may suffer deeply from the fault of another; and a prudent watchfulness and wise care may prevent many evils. When both husband and wife are bonest and pure, no such protection is needed. Jealousy is like physical pain; the healthy do not suffer from it. We do, however, suffer deeply from the real or imaginary wrongdoing of those we love.

Bearing the infirmities of the weak, we must aspire to the health that has no pain, and the pure unselfish love that has no torment of jealousy; for jealousy dishonours its subject and its object. People feel it to be a humiliation, and do not like to confess it; and they are also unwilling to admit, that those they love enough to be jealous of can ever give them cause for such an emotion. We must therefore consider jealousy a morbid passion, the result of morbid conditions, and strive to attain to a higher and purer phase of life and love.

There are many other questions connected with the generative function and sexual relations, some of which will be more properly treated in Part Fifth, in the chapters on the Conditions of Health, and Causes of Disease; while others will naturally be discussed in Part Sixth among the elements of morals and society. 


\section{PART FIFTH.}

HEALTH, DISEASE, AND CURE.

\section{CHA P T E I.}

HEALTH.

What is Heaith?-Beauty-A Picture of Health-Harmony of LifeActivity-A Condition of Happiness-Exceptional Happiness in Disease-Health Natural-Health of Plants and Animals-Natural Life and Natural Death-The Attainment of Health a moral and religious Duty.

Health is Saxon for whole, akin to holy and to heal. To heal is to make whole, or to make holy. Health or wholeness, completeness, perfection of the body and mind, corresponds to holiness, wholeness, and purity of heart. It means completeness and perfection of organisation, fulness of life, freedom of action, purity from all stain or corruption, harmony of functions - "a sound mind in a sound body."

Health is a condition of perfect development-the wholeness of the harmonious growth and adaptation of part to part, organ to organ, where none are stunted and none in excess. . In this we have the perfection of symmetry and beauty, which are merely the result of wholeness or health. For it can be shown that the forms and proportions of man and of every animal which are the most useful, are the most beautiful. When every bone is of the best form and size, there is perfect proportion; when every muscle has its proper development, with just enough of fat in the cellular tissue, we have the highest beauty 
of form; when the texture of the skin is finest, the circulation most vigorous, the blood most pure, we have the glow and charm of the finest complexion. Beauty is therefore more than a sign of health ; it is its expression; and perfect beauty can only come of perfect health. Partial beauty, fading beauty, decaying beauty there may be, with partial, fading, decaying health; but it is unsatisfactory and painful. The artist and poet imagine beauty glowing with health, and cannot separate these ideals. No painter or sculptor would represent a Venus, a Diana, a Hebe, other than as in the perfection of health, and therefore beautiful and glowing with life.

"A picture of health." What is this picture? A form of perfect proportion and symmetry; skin smooth, clean, semitransparent, with the red blood shining through, especially in the cheeks and ends of the fingers and toes; hair glossy and lively, or full of life ; eyes clear, bright, full of expression, and dancing with life; lips rosy, full, pouting, and smiling; teeth sound, even, and of a pearly white; breath sweet as the breath of a healthy cow ; the body free from any disagreeable odour, and, where health is perfect, giving out a pleasant perfume; activity of body, with a love of exercise and work; activity of mind; courage, hope, cheerfulness, mirthfulness, buoyant spirits, and a happy disposition; enjoyment of life, and constant desire and efforts to promote the happiness of others. This is a picture of health, which comes only from the orderly, regular, and perfect performance of all the functions of life. This is the state at which we should all aim to make the most of the great gift of life for ourselves and others.

Health is the energy of life in harmonious action. It is, in the human being, the perfect combination of bodily organisation, intellectual energy, and moral power, all in harmony with each other. The brain and nerves must be as perfectly organised, and as finely proportioned, as the bony and muscular systems. There must be a symmetrical head as well as a 
harmonious body. And the nutritive system must be perfectly adapted to the requirements of brain and body. No organ can be spared. The smallest instrument out of tune brings discord into the harmony of life.

The energy of life displays itself in a constant activity. We see this in the rapid growth of vegetables, in the restless movements of young animals and children in all their waking hours, and in the movements of the bodily organs. A healthy child is full of play, a healthy man is equally full of work either of brain or body. Indolence is a sign of a low original vitality, or a symptom of disease. Health is the cause, and also the result, of activity of life. The vital energy needs to expend its force in action, and it is renewed by exercise. The action of the brain promotes the circulation of the blood by which it is nourished.

Health is to every creature a condition of happiness. No one who watches the sports of insects, birds, and animals can doubt that they have great enjoyment of life. Healthy children are very happy. When the body is free from pain, and the mind is also free from anxiety or remorse, mere existence is a pleasure, and we enjoy all the beauties of nature with an exquisite enjoyment. Sunshine, a fresh breeze, green grass, waving trees, the beauty and odours of flowers, the flight and songs of birds, the glory of the ever changing sky, fill the healthy mind with ecstasy. Add to these the pleasures of the intellect and the heart, and, if we could shut out the sense of the evil, and sorrow, and $\sin$ around us, the earth would be a paradise. There can be no perfect happiness for any until all are happy; still, health is the condition of such as we can attain; health of body for physical enjoyment; health of mind for intellectual pleasures; health of heart-health of soul-for the highest spiritual enjoyments. Health of mind is to a considerable degree dependent upon health of body; especially upon that of the nutritive and purifying organs. Some diseases are a cause 
of melancholy. Others, as gout and other painful affections, leave the mind free, or in some cases seem to promote mental activity and enjoyment. Every physician has observed the sweetness of character which often accompanies scrofulous affections, and the happy hopefulness in tubercular consumption. Health of body is, however, the usual condition of mental and moral well-being and consequent happiness; but the mind and the soul often assert their superiority to all material conditions, and we see serenity, hope, and happiness in the midst of bodily disease, decay, and dissolution.

Health is the natural condition of every organised being. This point is very important. It is not something to be attained by effort or artifice. It is a normal state; a natural condition; the rule of life to which disease is the exception. We see this to be the case throughout the vegetable and animal kingdoms. Not one blade of grass in a million suffers from disease-not one plant or tree of millions. In a state of nature plants and trees of all kinds germinate, grow, produce leaves, flowers, seeds, fruit, and live out their natural lives without a sign of disease. They die at last of old age, in one season, or hundreds, or thousands of years; but when they have reached the natural term of their existence. When brought under culture and exposed to unnatural conditions we see signs of disease and premature decay. Plants may be crowded like men, deprived of wholesome air, supplied with improper, or insufficient, or redundant, nutriment; but in their natural state their almost universal condition is one of pure, beautiful, and vigorous health.

The same is true of the whole animal creation. In crowded and overfed flocks, among pampered horses and stall-fed cattle deprived of light and air, we find disease, contagion, epidemics, and great mortality, the same as among human beings exposed to similarly unnatural conditions. But who would expect to find sick fishes in the open sea, or in lake or river, unless it had 
been tainted by human impurities? Birds in cages may pine and die; crowded together they may be swept off by an epidemic; but how seldom do we find any disease among the free birds of our forests. "Hearty and rugged as a bear," we say. Does the fox have the measles? Do wolves die of scarlet fever? Has any one seen a leopard laid up with rheumatism? or a tiger down with typhus? or a gouty gorilla? Animals may perish of hunger or by violence; but in natural conditions they do not suffer from diseases. It is only our domestic animals which are liable to disease, because we deprive them of some of the conditions of health, or expose them to the same or similar conditions which produce our own diseases.

When we consider how closely we resemble the higher animals in our bodily constitution; how similar are our bones, muscles, nutritive and excreting organs, blood-vessels, nerves and senses, we must see that health is as natural a condition to us as to them. If an animal lives the life for which it is constituted-to which its organisation is adapted-it cannot have disease. Its only natural death is one of gradual decay in old age. And such is the only natural death of man. There is no reason why he should not be as healthy as any plant, or fish, or bird, or animal ; and it is probable that man is, by the nature of his organisation, the most healthful and longest lived of all the animal creation.

In the Zoological Gardens some effort is made to place every bird and animal in its natural and therefore healthy. conditions; but we see how imperfectly it is done. Birds that in a state of nature would fly fifty or a hundred miles every day, using all their energies to gather their food, are shut up in cages and fed. The eagle and condor, sea gulls and Mother Carey's chickens, born to range the mountain peaks and the wide ocean, must pine in such an indolent captivity. A sick monkey may be seen in a menagerie, but never, I believe, in its native forest haunts, where it can spring from tree to tree 
and live on nuts and fruits of its own gathering. Nature has made no provision for sick animals unless it be water cure in baths and showers, and the use of such plants as instinct may prompt them to eat, as cats eat catnip. But animals have no doctors or surgeons, no chemists or druggists, no dispensaries or hospitals. The whole animal kingdom does not afford the spectacle of a crowd of patients waiting for a doctor with their guinea fees in readiness, or the larger crowd of out-patients to a hospital with no fees to give.

That health, pure and perfect from the cradle to the grave, is as natural to man as it is to plants and animals is evident from the healthy condition of those who come nearest to living in natural conditions. The natives of many of the South Sea islands were found by their discoverers almost entirely tree from disease and deformity. The ordinary diseases of civilised men were unknown to them. Those who were not killed in battle aied of old age. Even in the midst of civilised life we find individuals whose instincts have preserved them from its unnatural habits and diseases-men and women who never know a day's illness and die of old age. Such exceptions may become the rule. If one person in ten can escape disease and premature death, more may do so. Like causes produce like effects. All men may become healthy and happy simply by adopting the means and conditions of health and happiness.

If health be the condition of vigour, activity, usefulness, and happiness-the condition of the best performance of all our duties-its preservation when we have it, and its attainment as far as possible when it has been lost, becomes a high moral and religious duty. To lose health by neglect of any of its conditions; to waste it by bad habits and vices is a violation of the law which says "thou shalt not kill." To diminish health is to lessen the amount of life, and generally to shorten its duration. To injure one's health, or neglect the means for its preservation; ut restoration is, therefore, a sort of suicide. If we would offer 
our lives to God, let us do nothing to diminish the value of the offering. If we would devote our lives to the service of man how careful should we be not to diminish in any way the value of that service. If we look only to ou own enjoyment, health is the necessary condition of happiness. Life is a trust-the talent committed to our care-and we are held responsible not to waste it. It is our duty to make the most of it. We have no right to squander, to shorten, to paralyse, to destroy it. It is our duty to preserve, cherish, and in every way make the most of, and do the best with, every power and faculty of body and mind.

Health is the condition of the highest use and happiness. I do not undervalue the heroism that struggles with pain and disease, nor their purifying and elevating influences. Where they are inherited, or blamelessly incurred, they are to be endured with faith and patience, and it is beautiful to see the moral nature triumph over disease and death. But disease and pain are no more to be sought than death itself. If it be a duty to preserve life, it is no less a duty to keep life in its integrity; to preserve our bodies in purity, and vigour, and fulness of life, and to treasure health, strength, and physical, mental, and moral power for their highest uses.

The virtues enjoined upon us by our religion are all healthy virtues: cleanliness, moral purity, chastity, temperance, industry, cheerfulness, hope, faith, charity, in a word, HolinessWholeness-Health. 


\section{CHAPTER II.}

THE CONDITIONS OF HEALTH.

Birth-The Care of Infancy-Diet of Infancy and Childhood-Temperature and Clothing-Influence of Light-Pure Air-Ventilation-Size of Rooms - Ventilation of Towns - Duty of Architects - Sanitary Police-The Natural Food of Man-Stimulants and IntoxicantsClothing and Shelter-Bathing-Sleeping-Work-Society-Chastity -Religion-Righteousness.

THE first condition of health, is to be well-born. It is the inheritance of a good constitution, moral, mental, and physical. Health and longevity, as I have shown, are hereditary; and many parents give a low vitality, or weakened nervous power, to their offspring. Children are also born with the seeds of death in their constitutions, in the inheritance of depraving and exhausting passions, or in the various modifications of scrofula. By good birth we have the rich inheritance of health of body, health of mind, and that moral constitution which is the best guarantee of a peaceful, happy, healthful, whole, or holy life; a sound, pure, firm constitution from our progenitors, which it is our duty to hand down unimpaired to our posterity.

Next to a good birth is the proper care of infancy and childhood. The babe requires absolute cleanliness, so that no atom of the waste matter of its body can be inhaled or re-absorbed to poison it-for all our excretions are poisons to ourselves and others. It needs also pure fresh air, an abundance of light, and pure, nourishing food. It should never be smothered in close rooms, nor in clothing. When the face of an infant is covered ever so lightly it is compelled to breathe its own breath over again, like people in crowded or unventilated rooms, for 
a room without free ventilation is only a larger covering. At the first breathing, air is deprived of part of its oxygen and loaded with carbonic acid and waste matter. Every breathing diminishes its oxygen and increases its impurity. A child needs light as much as a plant needs it. The more open air and indirect sunshine the better; when not in the open air, then airy rooms, large unshaded windows, and a sunny exposure.

The best food for an infant is the milk of a healthy mother. The mother's love strengthens her babe; and their lives mingle in the act of nursing. A mother gives much more nourishment than her milk. She gives of her nervous power, her vital force, her heart, and mind, and soul. A good healthy wet-nurse is the best substitute for the mother, but very difficult to obtain. If she put away her own babe to nurse another, there is a great wrong. She may not be able to do justice to both. The milk of a healthy cow is better than that of an unhealthy mother, or a doubtful nurse. The milk of either mother or nurse may be injured by the relation of marriage, by bad diet, by drinking, by any exhausting or diseasing habit. Cow's milk, pure and healthy, diluted with one-fourth part water, and sweetened to the taste of mother's milk, is very good food for the first six months, after which bland ripe fruit and farinaceous substances may be given in addition. The food of childhood should consist chiefly of brown bread, wheat, oatmeal, rice, milk, fruit, and vegetables-substantially, a bread, milk, and fruit dief with an avoidance of fine flour, pastry, especially that made by bakers and confectioners, and concentrated sweets. An agreeable proportion of sugar in food is better than confectionary.

Children do not need any kind of flesh or fish, and are much better without it. Flesh, especially, is a stimulating form of food, often impure and unhealthy in itself, causing fever of the blood, and exciting sensual feelings, which are among the chief perils of childhood. For the same reasons, children should never have pepper, spices, hot sauces, heavy wines, beer, or 
spirits, and their delicate nerves are always injured by tea or coffee. Chocolate is too heavy, heating, stimulating, and bilious, and even the mildest cocoa is doubtful. Milk, water, and the juices of fruit are the proper drinks of childhood; and soft pure water, drank when they are thirsty, is the most grateful to an unperverted taste, and all that is really required. 'To avoid an unnatural thirst, the food of children should be almost entirely free from salt. Fresh butter and mild cheese in moderation.

Temperature is important. The infant should never chill, and never be kept too warm. There is a golden mean of absolute comfort and vigorous health. Its daily baths, tepid at first, may be cooled according to its reactive power, until a quick cold bath, with vigorous friction after it, will be a luxury. Through childhood, the clothing should be light in colour and very porous, so as to admit light and air to the skin; just enough protection against chill, but never "coddling" or oppressive. Let warmth be supplied rather by exercise than extra covering. Clean clothing, especially that next the skin, by night and day; daily bathing in cold water, or in warm water followed by cold, with brisk friction; sleeping on hard elastic beds with cool, light, porous covering; active and varied employment, and not too much reading or study, or confinement in hot close rooms; natural conditions, and gentle, affectionate companionship, and the religion which teaches the Divine Fatherhood and the great blessing of Immortalitythese are the conditions of a healthy and happy childhood, which lay the foundation for a long and useful and therefore happy life.

What I have said of infancy and childhood applies, in its principles, to every age. Health is natural to man, as to every organised being; and the conditions of health are found in a simple conformity to nature. Through life we need the light of the sun, for light is the great element of life to plants and- 
animals. Shut up a plant in darkness, and see what comes of it. Only the fungi can so flourish. In partial darkness there may be a pale weak growth, but no flowers or fruit. Shut up the strongest man in a dark dungeon, and he becomes pale like a corpse, his blood loses its vitality, and he is liable to scrofulous diseases. He loses the power of resisting diseasing influences. The cholera finds its greatest proportion of victims in the narrowest and darkest lanes and courts. There are great differences in its mortality between the sunny and shady sides of the same streets. Sunshine strengthens all, and is a powertul medicine for many diseases. A sunny exposure, plenty of large windows, and no blinds or curtains, are important conditions of health. Early rising is healthful, chiefly because by that means we live more in the light. Night is the time for rest and sleep, because we can then best spare the invigorating influences of the day. The fashion that turns night into day, diminishes health and shortens life.

Air is the first condition of independent life. There is no life without air. During gestation, the mother breathes for her child; her lungs receive the oxygen that reddens its blood; but from birth to death we breathe every moment, and our health depends very largely upon the quantity of the air we breathe, and upon its purity. When the air is impure we breathe less. In the foetid air of crowded assemblies, in unventilated churches, theatres, or school-rooms, we instinctively limit our breathing to the least quantity that will keep us alive. We take in poison. with every breath, and yet we must breathe. When we come out, what expansion of the lungs, what draughts of pure fresh air! The result of our bad-air poisoning may be a cold, or diminished health for days. What we need for health is a full and constant supply of pure air at all times-sleeping and waking-by night and by day. Night is the time to sleep; and in sleep we do not need the stimulus of light-but we need pure air as much as by day. The blood demands its oxygen- 
the body to be freed from its waste matter. We cannot breathe the same air over and over with impunity.

Every sleeping-room should be so freely ventilated that a person entering it in the morning from the fresh air can detect no closeness by the smell. This can easily be done by having no blinds to the windows, or setting them three inches below the top, and lowering the upper sash the same distance. This will keep up a double current of air all night-the warm air of the room passing out at the top of the opening, the cooler air from without entering below. Such an opening of two or three inches can occasion no hurtful draught, and it secures a perfect ventilation. The amount should be increased with the number of persons in the room.

And here I must expose another vulgar error of scientific men. It is held, and the error enters into the legislation of the country, that every room in which people live should contain a certain number of cubic feet-that so many cubic feet of space are necessary for each person. Some medical authorities require $I 200$ feet, or a space of twelve feet long, ten wide, and ten high. A certain amount of space is convenient, but a man can live better in a well-ventilated room containing 400 cubic feet, than in an unventilated one containing 1200 , or one of treble its dimensions; better in a hogshead with good breathing holes, than a tightly-closed room of any size. It is not the size of a room, but the perfection of ventilation-the constant supply of fresh air-that is in question. And what every man wants is to draw his individual supply from the great reservoir of the entire atmosphere, and to have the air he breathes uncontaminated with the breath of any other person, or with his own. The size of the room is of little consequence; the quality of the air it contains is of the greatest importance. This should change with every breath, and every breath of man should come fresh from the outer air.

In the crowded parts of London, the whole air is deadened 
and tainted with impurities, but it also becomes heated and rises, while there is pouring down into the great parks, squares, broad streets, and all open places cataracts of fresh air out of the sky - great downward currents, which then spread out and take the place of the impure air of the upward currents. The air in the centre of Hyde Park, on a still day, differs but little from that of the country. Every open square is a fountain of health. Above the Thames is a great river of pure air flowing up all the streets and alleys on either side. The principle of ventilation is very simple-it is to provide a constant and full supply of pure air for every person. But when some hundreds or thousands of persons are crowded into one room, there are practical difficulties. The vitiated air, which naturally rises toward the ceiling, must be allowed to pass out, and for this there is required only a sufficient opening in or near the roof. But fresh air must come in to fill its place; and during the greater part of the year such air, if admitted in heavy draughts, produces chill, discomfort, and disease. There are two remedies-one to warm the air in a large lower apartment by proper furnaces, before it is admitted into the room in which it is to be breathed; the other to admit the fresh air by a great number of small openings.

Whatever means are employed to ventilate public edifices, schools, railway carriages, cabins of steamboats, most of which are now almost or entirely deficient in proper ventilation, nothing can be safely left to the choice or will of the persons most concerned. People would not breathe at all if it depended upon their volition. The bad air should flow out of, and fresh air into, every place in which people are to breathe, without their having any care or thought about it ; and the first care of an architect should be to adapt every room to its most important requirement, the health of its occupants. As it is, we are stifled and poisoned wherever we go. Ten persons in a railway carriage, are at the mercy of those who sit next the 
windows. A window, which is the only entrance of air for twenty persons, may be closed by any draught-dreading hypochondriac. We get our amusements, or say our prayers, in a state of semiasphyxia. Meanwhile, nature asserts her sovereignty, and, as the first condition of health, demands pure air for every creature.

Every dwelling should be built upon clean dry soil, or protected from dampness, well drained, and free from any filth or nuisance. It is the right of every man, living in a village or town, not to be poisoned by the bad air of filthy people, or animals, or manufactories. What right has a soap-boiler to fill whole populations around him, as the wind shifts from hour to hour, with the stench of his abominations? Every district should have its sanitary inspector, who should watch for foul air as carefully as policemen ought to watch for burglars, pickpockets, and adulterators. With such cleanliness we might defy all epidemic diseases.

Food comes next to air; and I have already spoken of the proper food of infancy and childhood. The natural food of man is abundantly furnished in the vegetable kingdom. Threefourths of the human race live on grains, fruits, bulbs. tubers, and the leaves and stalks of plants. Wheat, rice, Indian corn, rye, oats, barley, sago, tapioca, arrowroot, potatoes, yams, onions, cabbages, bread-fruit, plantains, bananas, are the great staples of food for man. Add to these grapes, apples, pears, peaches, plums, olives, melons, berries, \&c., and we have a vast variety of the most healthful and delicious articles of food, abundant for all our needs. To these provisions of a bountiful nature we have added the milk of cows, goats, camels, sheep, and, in some cases, mares and asses, with butter and cheese; and as milk is the natural food of infancy, milk and its products seem not a very unnatural addition to our common stock of nutriment. In the same way we appropriate the eggs of fowls, finding in them a pure form of albuminous nutriment, which harmonises with bread and milk. 


\section{Human Physiology.}

Can we naturally go farther? Ought we to deprive any animal of life that we may feed npon its body? Oysters, and other shell-fish have so little apparent sensibility, that we feast upon them without much compunction. We have not much sympathy with fishes. They do not come very near us, and they seem to be a clean and tolerably healthy form of food. Yet a man might well have some scruple about needlessly depriving a trout or salmon of its vigorous and active life. When we come to the warm, red-blooded animals, the birds and beasts which seem to be more nearly related to us, we may well doubt of our right to deprive them of life, and eat their flesh for food. I have already expressed the opinion that man is naturally a fruit-eating animal, and that he finds his most natural and most healthful food in the vegetable kingdom-that though the use of fish and flesh may be justifiable as a necessity, it is not the original, or the best food of man, and that the most perfect health, and therefore the highest use and enjoyment of life, may be attained on a purely vegetable diet; and where a mixed diet is used, I can have no doubt that the smaller the quantity of flesh, and the larger the proportion of fruit and vegetable substances, the better will be the health of the great majority of persons.

The food should be pure, free from all diseased and diseasing matters. We can never be sure of the healthfulness of the animal whose flesh we are eating; with grains and fruits we have a much greater security. And all flesh must contain waste matter not yet cast out. The flesh of stall-fed animals, and especially of offal-fattened swine, is often diseased. We want food that will give us the purest matter of nutrition, at proper times and in proper quantities. When our appetites are stimulated by exciting food, the artifices of cookery, and by exciting and irritating condiments, we are tempted to gluttony-which is a sin against nature, and a violation of the laws of health; we overtask our powers of digestion and assimilation by eating too large a 
quantity of food, and thereby destroy health and snorten life. Temperance in regard to quantity, and a wise choice in the quality of food, are among the most important of the conditions of health.

Man can live from the cradle to the grave in perfect health, and the full use of all his faculties, without resorting to any stimulant, any narcotic, any intoxicant. Yet stimulating beverages, as wine and beer, which have alcohol for their basis, have been used from the remotest periods of human history - and in Eastern Asia, tea. Later, the distillation of alcohol was discovered in Europe, coffee came from Arabia, and the tobaccoplant of America has spread around the world. It is hard to see that the world is in any way the better for the common use of its intoxicants and narcotics. Even the mildest of them are of doubtful benefit; and where pure water can be obtained, it is the best, as it is the most natural drink of man.

It must be admitted, however, that the experience of the southern nations of Europe does not seem to be unfavourable to the common use of light pure wines, which are seldom drunk to intoxication, and do not produce the disease and demoralisation caused by the use of heavy and drugged beers and spirits in this country.

Tea, coffee, tobacco, opium, \&c., are not necessary to health. They contain no element of nutrition in any quantity which makes them of the least importance as food. If they diminish waste, or the signs of waste, such action is injurious; for they keep matter in the body which ought to be cast out of it. They all, like alcohol, excite, and thereby weaken the nervous system, and may therefore more properly be treated of in the chapter on the causes of disease.

Clothing, and that larger clothing, the shelter of our houses, I have already alluded to. In our houses we want shelter from cold, heat, high winds, and moisture-a genial temperature, absence of damp, plenty of light, free ventilation, and all that 
belongs to comfort-all the conveniences, and what we can command of the elegancies of home. No show apartments, no rooms kept for company, ostentation, and vanity ; every room and every article of furniture for use. Every window should let in plenty of light and air. It is an economy and comfort, if a well-constructed furnace in the basement can furnis's soft, pure air in winter to the whole house. No one should rest content until every one is provided with a clean and comfortable and proper dwelling.

For clothing, the same healthy rule. Comfort first, and then as much elegance as we can or care to add; but no elegance or decoration at the expense of comfort and health; and always cleanliness as the first condition. No garment should be wor at night that is worn in the day. Frequent changes of und $s$ clothing, and thorough ventilation of every article. The clothing becomes filled with the emanations of the body, the waste matter of insensible and sensible perspiration. The accumulation of this matter becomes foul, offensive, poisonous. Every garment when removed should be shaken, and hung up to air-. not huddled up in a heap; and the oftener all underclothing is changed the better. In cold, damp climates, woollen underclothing is preferred to cotton or linen, as more porous, and allowing the waste to pass off more freely, giving also more protection from the effects of rapid changes of temperature.

The cleanliness of bathing has come to be recognised as a luxury and fashion in the higher classes in England, and it would be a blessed thing if it could spread as rapidly as fashions in bonnets. But one has only to use his nose to perceive that it has not gone far down in the ranks of society. One may not see that his neighbour does not take a daily bath, but one can smell. It would be a curious, and not the least useful, bit of sanitary statistics-an official return of the number of persons in the United Kingdom who are washed all over even once a week. A daily bath might be made compulsory by Act of Par- 
liament more justifiably than the always doubtful and often injurious practice of vaccination; for the daily bath is a safeguard against, as well as a remedy for, most diseases.

The highest health and full vigour of the skin, and its vast number of nerves, blood-vessels, and glands, requires a daily washing of the whole body, preferably as a rule, in cold water; or, if warm water be used for cleaning, a dash of cold, for its tonic and invigorating effect should follow. And it need not be a very elaborate or expensive process. A broad shallow tub to stand in is convenient, but not indispensable. Two towels will do at a pinch, and a basin of water. Fold your huckabuck along the middle lengthwise, and then in four; and dip it in the water, and if you have no tub to stand in, give it a moderate squeeze. Wash face, neck, hea.d, and arms. Dip again, and wash front of body and lower limbs. Open out its length, dip the centre, and, beginning at the neck, saw down the back to the knees. Fold and dip again, and wash the front of the body and feet. Wipe thoroughly, and polish off with a rough crash, or Turk. There is a solid good bath, which may be taken anywhere in five minutes. And such a bath every morning, taken by every inhabitant of these islands, would do more to increase the public health, and lessen the bills of mortality, than all the doctors and drug-shops. Cleanliness in our persons, our clothing, our dwellings, the food we eat, the beverages we drink, in our whole lives-including physical and moral purity-is one of the most comprehensive of health conditions.

We sleep from six to eight or nine hours out of every twentyfour. More than a third of our lives, on an average, is passed in bed. The character of the bed, as well as the ventilation of the bed-room, is therefore a matter of some importance. A moderately hard, firm, elastic bed is not only more healthful, but pleasanter than a soft one. A feather bed heats the body, buries it in a bath of perspiration, weakens the skin, enfeebles the nerves, causes spinal disease, and amative irritation. It absorbs the 
matter of perspiration and the emanations of diseased bodies, so that an old feather bed becomes a mass of abominations. Among the comforts of the Continent, or the portions of it nearest to England, are the excellent hair or woollen mattresses, frequently made over, and always clean and in good order. Better sleep on a bed of straw or hay than one of feathers. The covering should be of blankets, clean, and porous; and health requires a light and cool covering, rather than one too heavy or too warm. Sheets to be well aired daily, and changed weekly.

A health condition of high importance is work. When idleness is not the result, it is the cause of disease. Body and mind-the whole system of voluntary life-are paralysed by lack of use. We talk of the dignity of labour; we must recognise its necessity. Laborare est orare. Man was made to labour, and health requires that every one should fulfil the objects of his existence. The proper performance of the functions of the nutritive, secreting, and excreting organs, requires the daily exercise of the brain, the nerves, and the muscles of voluntary motion. But mere useless exercise-that which produces nothing-cannot satisfy the conscience. Selfish sports are not sufficient. No man can feel at ease in himself-can enjoy the wholeness of health-who consumes the result of the labour of others, and renders them no equivalent. Honest productive labour of body or mind, or both, is the need of every one, and there can be no integral health without it.

And there can be no full and perfect health without the satisfaction of man's social nature. Man cannot truly live in the free play of all his faculties without campanionship, friendship, fraternity, and the exercise of the affections of the heart. It is not enough to love mankind in general; we need to love some of them in particular. Love comforts, strengthens, invigorates, sustains. There is a circulation of life among friends, comrades, companions, and those who live together in mutual affection, in which each gives to all, and all to each. Love is 
life, and life-giving. The spiritual sustenance we derive from the relations of domestic love and friendship is so important to health, that all suffer, and many pine and perish without it.

I scarcely need here repeat what I have written in Part Fourth on Chastity as a condition of health. Sensual indulgence is the most fatal waste of life. The health of thousands is destroyed in childhood and youth, and civilisation is full of miserable wrecks of manhood and womanhood from unnatural or excessive amative indulgence. There is no more important health injunction than the emphatic command of the apostle, "Keep thyself chaste." "Keep thy heart with all diligence, for out of it are the issues of life."

Harmony with pature is the condition of health for every creature ; and man requires also the higher harmonies of union and communion with the invisible and spiritual. His body must be in the order of the natural life; but his soul must be no less in the order of the spiritual life; and his highest faculties, by which he recognises and feels his relation to the spiritual and eternal, demand their use and satisfaction, no less than those which minister to his earthly wants.

Freedom in order, obedience to law, that only liberty which is the right to do right, are the conditions of health. Anger, hatred, remorse, anxiety, all disturbing passions, are foes to health. Every exhortation to the exercise of the Christian virtues of faith, hope, and charity, is an exhortation to health. Finally, before universal health be possible, there must be the reign of justice, of right, or what the common version of the Scriptures calls righteousness, upon the earth. If men were banded together in the love of God and humanity, not contending against each other in selfish competition, but generously labouring together for the good of all-if, in a word, man loved his neighbour as himself, there would be no more wasting anxiety, no care that kills, none of that mental misery which is the most terrible result of our discordant and wretched social 
conditions. Vice, crime, and misery fill the world with disease and death. When men are honest and wise, in the highest sense of honesty and wisdom, they will be healthy and happy. Be sure that righteousness, justice, equity, truth in all relations, exalteth a nation, and that sin, iniquity, injustice, falsehood, is a reproach and a misery to any people.

\section{CHAPTER III.}

DISEASE.

What is Discase?-The Mystery of Pain-Theories of Pathology-Classification of Diseases: Zymotic, Constitutional, and Local-Most Diseases Preventable-Efforts of Nature to Expel Matter or Remedy Disordered Action - Two Elements in Zymotic Diseases-Cancer, Scrofula, Consumption-Brain, Digestive Organs, Kidneys-Phenomena and Seat of Diseased Action.

DISEASE is want of ease, want of comfort, lack of the sensations which belong to the energy of life. It may be a mere sense of weakness, or a feeling of disorder, discomfort, irritation, and so on to positive pain, increasing from the slightest degrees to the most acute and agonising torments. The mind has its diseases as well as the body, and in like degrees; and all our sentiments and passions give us pleasure in their normal action, and when thwarted or disordered bring us pain and misery.

Pain of mind or body is the regulator of life-the alarum of nature-the warning voice that tells us when we are going wrong - the effective punishment of wrong-doing. Pain is always the sign of evil, physical or moral, in ourselves, or acting upon ourselves-present evil, or past, or future. Our present or past misdeeds bring us the pain of disease, or the remorse which follows moral wrong-doing, or both combined. 
We suffer physical pain, and also moral disorder and its pain, from the mistakes and wrong-doings of our progenitors. The dread, or anticipation, or prophetic intuition of coming evil gives us pain. A thorny hedge of pain and misery surrounds us, and its purpose can only be to keep us in the path of peace. All pain must be for the general good-and there may be compensations which will make all pain a blessing to the individual sufferer; but pain and evil are mysteries which, in this life, we cannot penetrate, but which, we may hope, will be clear to us in the future. The mysteries of life, insoluble here, prove that there must be a hereafter.

Disease, we are told, is a unit. It is a diminution of the vital force, or nervous power of the system, one school of Pathologists contends. Another holds that the blood is the life, and impurity in the blood is the cause of all diseased action. But good blood cannot be formed without sufficient vital force or nervous power; and good blood is necessary to the healthy action of the brain and nervous system. Here is reciprocal action, each depending upon the other. Must there not be something higher than either behind them both? The humoral pathologists who find matter of disease, or diseasing matter, in the system, poisoning the blood, deranging nervous action, and producing morbid conditions in all the organs of the body, are certainly right. Waste matter, retained in the system, is a materies morbi, and there are many kinds of bloodpoisoning. As health is force, activity, the harmonious action of all the functions, giving pleasure and enjoyment of life, disease is weakness, languor, disordered functions, excessive or diminished action, giving pain and misery. Health is the orderly growth and maintenance of the physical and mental powers; disease is their disorderly action, or paralysis, or decay.

The nosology, or classification and naming of diseases, now in vogue, is convenient, and relates them to their causes. The 
distinction between organic and functional diseases is scarcely necessary. Every organic disease must be also functional; every functional disease must be really organic, though there may be no perceptible lesion or change in the part. And no so-called functional disease can long exist without becoming organic, and, in most cases, perceptibly so-though changes in the brain and nerves are often difficult and sometimes impossible to detect.

In the system of Dr. Farr, adopted by the Registrar-General, diseases are divided into four classes, each including several orders. Under Class I.-Zymotic Diseases (zymé, a ferment,) are included epidemic, endemic, and contagious diseases, and those caused by specific poisons, and food or want of food. The four orders are-r. Miasmatic Diseases (tainted), as smallpox, measles, scarlet fever, diphtheria, typhus and typhơid fevers, cholera, ague, \&c. Order 2. Enthetic Diseases (implanted), as syphilis, gonorrhœa, glanders, hydrophobia, malignant pustule, \&c. Order 3. Dietic Diseases, as famine-fever, scurvy, purpura, rickets, delirium tremens, and all the effects of stimulants and narcotics. Order 4. Parasitic Diseases, as itch, worms, ring-worm, scald-head, \&c.

Class II.-Constitutional Diseases, containing two orders. I. Diathetic Diseases, as gout, anemia, cancer, \&c. ; and 2. Tubercular Diseases, as scrofula, phthisis (tubercular consumption), mesenteric disease, \&c. These are, for the most part, hereditary.

Class III.-Local Diseases, contains, order I. Diseases of the Brain or Nervous System, as apoplexy, paralysis, epilepsy, chorea (St. Vitus' dance), hysteria, mania, \&c. 2. Diseases of the Heart and Blood-Vesseis. 3. Lung Diseases, as bronchitis, pneumonia, pleurisy, asthma, \&c. 4. Diseases of the Digestive System, as inflammations of the stomach or intestines, jaundice, \&c.; and orders 5, 6, and 7 are diseases of the kidneys, generative organs, bones, muscles, and skin. Class 
IV. includes Developmental Diseases. I. In children, as malformations, idiocy, teething; 2. Of women, relating to menstruation and childbirth; 3. Of old age; 4. Of nutrition, as atrophy, debility, \&c.

It is evident, in looking over this formidable classification of the infirmities and diseases of humanity, that nearly the whole of them are clearly, readily, and easily preventable; that they are inherited, caught, or produced by avoidable conditions, as we shall see more fully when treating of the causes of disease. The miasmatic diseases, which are caused by some taint, germ, or poison in the atmosphere, acting upon an impure blood and weakened nervous power, have all a similar character. What we call the disease-the fever, the pain, the hurried circulation, the hot skin, the eruptive action-is a process set up by nature to expel the morbid matter from the system. When that matter comes to the surface, and is cast out, or when the body is purified by the skin, lungs, the action of the bowels, in whatever way, the disease is cured. When that action fails, and the poison falls upon the brain, or paralyses the action of the nerves of organic life, the result is death.

The same effort is set up, and the same struggle takes place in the enthetic or implanted diseases. Syphilis, it is almost universally admitted, is the reaction of the system against a specific poison of unknown origin. No one has ever seen it arise spontaneously - as far as we know, it is always communicated by one person to another-inherited, tainting the germ of life, or taken by absorption into the circulation. After a certain period of what has been called incubation, a diseased action-really an effort to expel the poison-is set up. If only partially successful a second effort is made at a later period over a larger surface in eruptions on the skin; later still there may be suppurations and abscesses; but in weakened constitutions all these efforts may fail; and the poison, in modified forms, may exiot towough several generations Some animal 
poisons, as glanders and hydrophobia, are almost inevitably fatal. They do not fasten upon every constitution; every poison of this kind seems to need some kindred element on which to act; but when they declare themselves, the power to combat them is lost. The poison of hydrophobia may lie inert for months, then suddenly burst forth and kill.

The other diseases of this class, dietic and parasitic, are evidently avoidable. They are diseases of poverty, vice, and dirt; and it is the shame of civilisation and Christianity that hundreds of persons should die every year in London of hunger, of drunkenness, and of filth. It may be doubted if parasites ever fasten upon vegetables or animals in full health. And health is, in fact, the best preventive remedy for all diseases.

It is important to remark that two elements enter into the production of most, if not all kinds of zymotic, contagious, or epidemic diseases. There is the malaria, miasm, or contagious matter, or the influence, whatever it may be, which determines the specific form of disease, as the contagion of small-pox or scarlatina, typhus or cholera; and there must also be the physical condition which predisposes the patient to be acted upon by the diseasing agent. Only a certain, and generally a small, proportion of persons suffer from epidemics. The greater number are protected by the purity of their systems, or the vital force which gives the energy of health. In every case the germ must find something to nourish it - the poison, something which cannot resist its action. A healthy man, with unexhausted nervous power and pure blood-one who breathes pure air, lives upon a pure diet, and refrains from all diseasing habits, may pass unscathed through small-pox contagion, yellow-fever, cholera, and defy the influences of deadly malarias. Persons who live upon a simple vegetable diet, and whose habits in other respects are healthful, are very little susceptible to the influence of epidemics. Some cannot be vaccinated successfully until they go through a course of flesh-eating. In every 
epidemic, nine-tenths of the mortality is among the classes who enjoy least of the conditions of health, and are most exposed to the general causes of disease; and it is observed that the most fatal epidemics but slightly disturb the general averages of mortality - that those who are carried off by them are mostly such as would have soon died of other diseases.

Constitutional diseases are generally hereditary, and hereditary diseases are preventable. Gout and cancer, scrofula and consumption, run in families; but why one should have painful swellings of the joints, liable to be transferred to the stomach or the heart-why the breast, or stomach, or womb of another should take on the morbid and malignant growth of cancerwhy tubercules should form in the lungs or the glands of the mesentery and destroy the power of forming blood or ærating it, and so produce a slow and wasting death, human science is powerless to explain. The causes, in most cases, are evident enough; the phenomena we know too well-but of the nature of the diseased action we know very little. And in some cases nature seems at fault in her efforts to expel disease or the causes of disease. In cancer it seems as if all the bad matter of the system gathered to one point, and there set up a false and destructive action. This action may be mudified, suspended, sometimes reversed. Surgery cuts away the diseased part, but where the diseased tendency exists it is very liable to recommence its action. In consumption of the lungs, where the matter of disease gathers in lumps called tubercles, there is an effort to cast out the diseased matter. The tubercles suppurate, and are discharged. In rare cases, where small portions of the lungs are involved, this is a process of cure. Generally the strength is insufficient, and vital organs fail to relieve themselves because of their vitality. This class of diseases, and especially those of the second order, cause a great mortality. In 1865 the deaths from constitutional diseases in England were 88,504 ; from consumption, 53,734. And tubercular 
diseases can be communicated by inoculation, and apparently by contagion, or by the inhalation of expectorated and dried tuberculous matter.

Local diseases, enumerated in the five orders of Class III., include many of the most severe and fatal. Men die suddenly of apoplexy, or pressure upon the brain from the effusion of blood or serum; they perish slowly of paralysis, or a failure of nervous action; and epilepsy, mania, and other disorders of the brain and nerves have many unhappy victims. The heart, arteries, and veins are weakened in action by the loss of nervous energy, or of the tone of their own tissues. The heart is a collection of muscles, and these may become weak or fall into a fatty degeneration. The valves of the heart may be affected by disease, and unable to perform their functions. Weakened veins may fail to carry the blood back to the heart. Great arteries may distend and burst. The mucous membrane of the throat and bronchial tubes, the substance of the lungs and its lining membrane, the pleura, are liable to inflammation, congestion, and change or destruction of substance. Spasmodic constrictions produce distressing difficulty of breathing. The stomach and bowels are subject to inflammations and congestions, chiefly of the mucous membrane and its glands, with excessive and morbid action, as in diarrhœa and dysentery. The liver may be inflamed-come into a state of local fever and congestion, or become torpid. The kidneys, organs of the most vital importance, are liable to disordered action and violent and painful disease, or gradual decay, as are also the bladder, testes, ovaries, and womb. Disease attacks also bones, muscles, cartilages, and the skin. The eye, the ear, the teeth-every organ of the body is liable to irritation, weakness, inflammation, and painful diseases.

But of the real nature of all these diseases, or forms of disease, we know very little. We can but describe symptoms, or the observable phenomena-the quickened pulse, the height- 
ened colour, the burning heat, the anxiety, distress and pain, the furred tongue, the thirst, the weakness, and all the struggle, as if the forces of life were contending with the forces of death. There are. pains in the bones and muscles, a cold shivering, a hot flush with suffused eyes and reddened cheeks, perhaps delirium, parched lips, no appetite, fœtid exhalations, profuse sweats, and this goes on for days, until nature or the disease triumphs. The fever ends, the patient is as weak as an infant; and slowly recovers. Of the action of the nervous system of organic life we know no more in disease than we know in health. All the phenomena, however, point to the probability of a contest between the vital forces of the organic nerves and something which was clogging, oppressing, or poisoning the sources of life. And in every disease there is more or less of this contest-an effort, more or less painful, for cure.

As the body is formed, built up from its primitive cell, and reformed from day to day by the action of the nerves of organic life, we must look upon this primary and underlying system of nerves as the centre of diseased condition and action. As health is the result of the purity and vigour of this central vitality, all disease must be a weakened condition of these nerves, or their invasion and oppression by what, for the lack of more definite knowledge, we must call morbific agencies. These nerves, gathering in great centres, as around the heart, stomach, and pelvic viscera, carry on all vital processes. But, in proportion to their complexity and delicacy is their susceptibility to injury, paralysis, and death. A blow at the pit of the stomach may suddenly kill, by the shock given to one of these nervous centres. A stroke of lightning kills in the same manner. A drop of certain poisons will do the same. The danger in taking chloroform is that these nerves may be paralysed, as well as the brain and nerves of sensation. Sudden emotions of joy and grief kill by the shock communicated from the animal to the organic nervous system. And painful and 
depressing emotions of the mind weaken, disorder, and destroy the body. The nerves of organic life, liable to have their action suspended by violent shocks or poisons, may of course be weakened, exhausted, and deranged in action by less violent causes; and here we have gone as far, perhaps, as we can go in our pathology. We know that there is something beyond. Matter does not plan, or organise, or carry on intelligent action; but the intelligence and force that act upon, with, and through matter, we have little power to investigate. As with all the forces that govern the material world, we can only judge . of them by their results.

\section{CHAPTER IV.}

\section{THE CAUSES OF DISEASE.}

Hereditary Taint and Predisposition-Darkness-Malaria--ContagionImpure Air-Food, Famine, Excess-Condiments-Impure and Hard Water-Stimulants-Clothing and Shelter-Mortality from ColdDiseasing Fashions-Excessive Labour and Unhealthy Employments -Amative Excess-Solitary Vice-Moral Causes of DiseaseDouble Origin of Contagious Diseases-Scrofula-ConsumptionSyphilis-Brain and Nervous System-Effects of Narcotics-Heart and Circulation-Dyspepsia-Constipation-Vegetable, Animal, and. Mineral Poisons-Drugs as Causes of Disease.

If the first condition of health is to be well-born, the first cause of disease must be to be born badly-born with a feeble or, worse, a diseased constitution, or with hereditary tendencies to disease or the causes of disease. Children are born deeply diseased with the taint of syphilis; they are scrofulous from birth; born with tubercles in their lungs, certain to develop into pulmonary consumption; born with hereditary tendency to gout, or cancer, or apoplexy, or insanity. Children are born 
deaf, blind, idiotic, deformed. Worse, they are born with hereditary predispositions to vice and crime. So that birth, or hereditary predisposition, is one of the most fertile and fatal of all the causes of disease. Whole families die of consumption, inherited from consumptive parents. Diseased parents beget diseased offspring. Short-lived parents have short-lived children. A certain portion of our diseases are thus made for us by our progenitors. We have therefore not only to struggle against and endeavour to subdue the diseasing conditions around us, but to combat and, if possible, eradicate these hereditary taints, predispositions, and idiosyncrasies.

Reverse the conditions of health, and we have the causes of disease. For light, have darkness or deep shade and gloom, and you shall see palor, a feeble circulation, a low vitality, tuberculous disease, scurvy, goitre, blindness, deafness, deformities, idiocy, a miserable life, and a premature death. Thick curtains will give a fashionable palor to the complexion, and they will also give many fashionable diseases.

If pure air, fresh and vital, electric and ozonic, be necessary to health, air impure, stagnant, dead, exhausted of oxygen, loaded with carbonic acid, or noxious gases, or vegetable or animal impurities, must be a cause of disease. The blood demands a certain amount of oxygen every moment; and the nerves of organic life demand also in a pure and vital air their natural food and stimulus. What it is, chemistry does not tell us; but we feel a glow, an exhilaration, in the fresh air of the mountains or the sea-shore that we never find in the effete, dead, loaded, and often noxious air of towns.

What the air may be as a cause of disease-what it may carry of diseasing matter or diseasing force we know in malarious and contagious diseases. A few days' exposure to the atmosphere of a fever and ague district will produce an intermittent fever that may last for months or years. One night in an American rice swamp, or an East Indian or African jungle, 
may cost a white man his life, though the acclimated negro may breathe the same air with impunity; as one habituated to them may take what to others would be fatal doses of opium, tobacco, or arsenic. A ship with yellow-fever on board, lying at quarantine, has her hatches open when the wind is blowing on shore, and in a few days twenty or thirty cases of yellowfever break out in a healthy sea-side village. The small-pox contagion fills the air of a whole district, and the air carries the diseasing influence, or vaporous virus, across wide rivers. Scarlet-fever spreads by such virus, germs, or diseasing emanations, floating in the atmosphere. There can be little doubt that the exciting and determining cause of cholera is atmospheric. It rests like a cloud over certain localities, and affects all who are susceptible to its influence.

But ordinarily impure air-air unaffected by the virus of any special pestilence-is an abundant cause of disease. As health consists of vigour and purity, weakness and impurity are the conditions of disease; and foul air fails to invigorate, and at the same time fills the system with its impurities. And when the vital force is lowered by the lack of pure air, and the blood filled with the impurities of foul air, the filth and abominations of decaying vegetation, putrifying animal matter, reeking gut-. ters, sewers, and cesspools, and the foul emanations of the lungs and skins of a crowded population in all stages of filth and disease, the person in such a condition is ready to be affected by any kind of contagious matter-that of scarlet-fever, small-pox, yellow-fever, typhus, or cholera. These atmospheric poisons do not produce their effects upon all. The strong resist, the weaker fall before them. In pure bodies the germs of disease find no lodgment-they find their nidus or condition of propagation in bodies already diseased. We see that in a great city like London or New York, the cholera or other epidemic may attack one person in a hundred in the cleaner, more airy districts, while it destroys one in ten in the more 
crowded and filthy quarters. For one rich man who dies of cholera, there are a hundred of the poor-simply because the rich can command the conditions of health, and have, therefore, the power to resist diseasing influences. Impure air, whether that of close, unventilated rooms, or of close and crowded districts, or that loaded with noxious effluvia, is not only a predisposing cause of zymotic diseases, such as measles, scarlet-fever, diptheria, small-pox, typhus and typhoid fevers, but a direct cause of a great many local diseases, especially those of the lungs, and those depending directly upon the condition of the blood, for blood-poisoning comes chiefly from the atmosphere; and the accumulation of matter of disease in the system is caused by the lack of vital force, which prevents the removal by excretion of waste and noxious matter.

As food, suitable in quality and sufficient but not in excess in quantity, is a condition of health, it follows of necessity that bad food, insufficient food, or too much food must be a cause of disease. No plant, and no animal--consequently no mancan maintain perfect health without a perfect nutrition. Man can live on a wider range of food than most animals; but as some kinds of food are better adapted to him than others, are therefore more natural for him, there must be some diet most natural and best adapted to the human constitution; and every variation from that, in quality or quantity, must be a cause of imperfect health, which is disease. Man has great power of adaptation. The Esquimaux live on blubber, and some Europeans feed on the almost equally greasy and less pure flesh of the fattened swine. Blubber or bacon? The blubber must be the least harmful. All animals living in unnatural conditions are liable to disease. Pigs, penned in sties, become scrofulous (scrofa, a sow); the livers and lungs of fattened hogs and cattle are often filled with tubercles, and their flesh may give tuberculous disease to those who eat it; the hog is also specially liable to one form of tape-worm. as the sheep is to another, and the 


\section{Human Physiology.}

whole body of a measly hog is filled with cysticerci, or undeveloped tape-worms, as various animals are filled with trichinæ. These parasites may, indeed, be destroyed by thorough cooking, but animal flesh filled with parasites must be diseased, and cannot be nice or healthy eating. It must be noticed, also, that dead flesh of diseased men, and of equally diseased animals, developes in itself most virulent poisons. How many surgeons have been poisoned severely, and often fatally, by the mere prick of a scalpel, when engaged in a dissection or postmortem examination! And we must not forget the vast quantities of meat and fish seized every year in the markets in Londonflesh of diseased animals, or too far gone in putrefaction to be fit for human food. Is it probable that a tenth is seized that ought to be? If it were, such food would cease to be offered. And what is the probable condition of the great quantities of animal carcasses made up into meat pies, head cheese, collared beef, potted meats, and sausages? There can be no doubt that the consumption of unwholesome flesh, the flesh of diseased animals, or the flesh of healthy animals undergoing putrefaction, is a very fertile source of disease. Unripe, bad-conditioned and decaying grains, fruits, and vegetables, are not healthy; but they have no such virulence of disease, and no such abominations of nastiness, as belong to the masses of flesh exposed for sale, and eagerly bought by the poorer classes of our population.

Men die of famine. We know it too well, when at some seasons there are coroners' inquests every day in the metropolis with the verdict, "Died of starvation." But where one dies of such actual and immediate want, many slowly sink of disease brought on by insufficient and improper nutrition. The common food of the very poor in England is bread--the dry, alumy, adulterated bread of the bakers for the poorer classes, who make large loaves by over raising, destroying the nutritive properties of the flour. The bran, which is the richest part of 
the wheat in flesh-forming nutriment, is reserved for cattle. This bread is eaten, perhaps with a little grease (dripping), or cheap-manufactured butter, made of horse fat, or bone fat, or better dry, with a weak infusion of something called tea, sometimes coloured with a white liquid, which one may see retailed in the streets of East London as milk at a penny a quart! Refuse potatoes, stale cabbages and turnips, and staler herrings, form the usual diet of hundreds of thousands. Only the more prosperous achieve the luxury of a bit of pork and some potatoes for a Sunday dinner. There is always the temptation to buy what is cheap, and in animal food cheap generally means nasty. Extravagant as may be the prices of West End tradesmen, the poor actually pay for rent, food, and clothing, more in proportion to what they get than the rich. Their rents are higher, their food, even to pennyworths of tea and sugar, pays a larger profit. And the stuff they get, after being robbed in price, weight, and measure, is not fitted to maintain them in health-is, on the contrary, a fertile source of disease and premature mortality, producing low types of fevers, bowel diseases, and scrofula.

But in the middle or comfortable classes, and among the rich, excess is a greater source of disease than famine among the poor. An ounce too much of even good food needlessly tasks the whole nutritive system, giving extra work to the nerves, and muscles, and glands. Too much blood is nearly as bad as too little. Over feeding has its dyspepsia, gout, inflammations, fevers, constipation, piles, obesity, nightmares, blues, and horrors. A hundred doctors and druggists are employed by those who eat too much, where there is one of either for those who eat too little, and while men are digging their graves with their teeth, the butcher shovels guineas into the doctor's pockets. Five meals a-day are three more than health requires, and these three are in most cases causes of disease-in rnost cases, because five very simple and moderate 


\section{Human Physiology.}

meals may be eaten without injury by a few persons with quick digestions; but, as a rule, there should be five or six hours between our meals, and few persons can eat within six hours of bedtime without being the worse for it. A late meal disturbs the whole alimentary system, when it ought to be at rest. It produces irregular action of the brain, with unpleasant dreams and nightmare; causes amative excitement, loss, and exhaustion; after a troubled sleep a weary wakening, with fever and thirst, headache, languor, loss of appetite, and various dyspeptic symptoms; tendencies to heart disease and apoplexy. Bad feeding and over-feeding are the direct causes of most of the diseases of the stomach, intestinal canal, liver, and kidneys, and the indirect cause of many diseases of the heart and circulation, and of the brain and nervous system.

Condiments of a heating and stimulating character, as peppers, spices, sauces, relishes, are causes of disease by stimulating to excess. They excite appetite and digestion; but all stimulants weaken and destroy the nervous power they excite. We must take more and more, and finally they fail to act, and leave us helpless and wretched. "Hunger is the best sauce." A healthy appetite needs no stimulation.

Bad water, and bad drinks taken in the place of water, which are, in fact, water with more or less noxious additions, are causes of disease. There are some striking facts which illustrate the influence of pure water in preserving health, and of impure water in generating disease. Typhoid fevers are traced to wells near leaking sewers or cesspools. Many cases of cholera in London were believed to have been caused by drinking the water of particular wells, which was found to be tainted with sewage. In one attack of cholera, mostly confined to a district of East London, the population had been supplied for a time with water largely mixed with sewage. But the river Thames itself, which supplies a large part of the metropolis, is the common sewer of hundreds of thousands of people 
and much cattle living in the towns above. It is true that light and air, and living vegetables and animals, are constantly at work purifying this water, and it undergoes a certain amount of beneficial filtration before being served out to the inhabitants. In 1858 , a ship, with 500 men on board, lay in the river Hooghly for six weeks, in the hottest weather, without losing a man, while the cholera raged on all the vessels around her. The chief difference was that while the crews of the other vessels drank the river water, the crew of the unscathed vessel had an unlimited supply of distilled water. Impure water, containing foul vegetable and animal matter, fills the blood with its impurities, and may be a direct cause of diarrhœe, dysentery, typhoid fevers, and all the diseases of impurity. Hard water, water containing lime and other mineral substances, may be a cause of glandular disease, gravel, stone, ossifications, \&c., while a pure soft water, rain water filtered through clean sand, or the gravel of insoluble. rocks, or distilled water which has absorbed its quota of oxygen, dissolves such concretions, washes every globule of the blood, aids the free action of the skin and all the excreting organs, and keeps the whole system in a state of healthful purity.

Alcoholic and other narcotic drinks often carry diseasing drugs, used for flavouring and adulteration, into the system, and so cause disease; they excite the nervous system, and deaden it, as the reactive result of such excitement. This effect is seen in the increased dose required to produce a certain effect. Alcohol, long continued, or taken in large quantities, brings on unsteadiness, irregular action, or partial paralysis of the nerves, and a morbid excitement and disorder of the brain, culminating in delirium tremens. There is no doubt also that, used in any but the smallest and almost inappreciable quantities, its tendency is to disorder and weaken the whole nervous system, diminish the activity of the purifying 
organs, lessen the power to resist morbific agencies, and so leave the system a prey to other diseasing influences and conditions. The intemperate, and those whose vital powers have been lowered by the use of stimulants, are the first and most numerous victims of many epidemic diseases, and are especially liable to fevers and several forms of local-disease. The difference between the action of alcohol and other narcotics in common use, such as opium, tobacco, coffee, tea, \&c. is not, in all respects, unfavourable to alcohol, which, in small quantities, passes more rapidly out of the system than the others, and, strength for strength, makes a less injurious impression on the nervous system. It is, however, a point in favour of the others that they do not so readily produce mania, or violent and debasing excitement. Opium, however, in a quieter way, seems as demoralising as alcohol; and tobacco, I am satisfied, has a stupefying effect upon the higher moral faculties. Tea and coffee, which are said to "cheer but not inebriate," have a very bad influence upon the nervous systems of many persons, and are the undoubted causes of a great deal of nervous disease. One of the principal causes of the breaking-down, nervous exhaustion, brain softening, and heart disease of men of great intellectual activity, is their working upon stimulants, chiefly tea, coffee, and tobacco. If they worked simply upon their own unstimulated strength, and stopped when they were tired, they would rest and recover; but when the normal nervous power, the natural capacity for work, is exhausted, they stimulate, spur up their brains to more effort, and it is this extra effort which exhausts them and brings on apoplexy, paralysis, \&c. And it must be remembered that whatever exhausts, directly or indirectly, the nervous power-the vital force that is manifest in the nervous system of organic lifemust be a cause of disease. The man who does physical or mental work upon the stimulation of alcoholic drinks, or the finer and more subtle stimulation of other narcotics, sooner or 
later breaks down the power of his stimulated brain and nervous system, and is always liable to neuralgia, dyspepsia, and a. train of dispiriting and painful diseases.

Insufficient clothing, and the lack of comfortable shelter from the inclemencies of climate, are frequent causes of disease. A cold week in winter raises the mortality of London hundreds above the average. In a church or chapel crowded with poor, in winter, one can scarcely hear the preacher for thecoughing. Bronchitis, and inflammations of the lungs, or its: lining membrane, carry off great numbers., Children die of croup, hooping cough, and congestive diseases. Then cold makes people huddle together and shut out the air, so that, if they do not perish of chill, they are weakened and filled with impurities for lack of ventilation. Cleanliness is neglected for a similar reason. The skin is clogged with dirt, and its horny surface is less sensitive to cold-- but its functions are suspender, and the body thereby diseased. A "cold" is the suspension of the action of the skin, and a thereby increased and disordered action of the mucous membrane. And so poverty, in its lack of the necessaries and comforts of life, is a very serious cause of disease, which disease intensifies poverty and its miseries.

In the higher classes, or better classes, as they are termed, dress is often a cause of disease. Fashion demands that the upper portion of the female body-the arms and a large part of the bust, which are carefully covered by day, should be as. carefully uncovered at night, whatever may be the weather. And if thick shoes and stockings are worn in the morning, they must give place to thin ones at night. Waists are compressed by corsets into the form of wasp or hour-glass, to the serious detriment of lungs and heart, stomach and liver. It is. not wonderful that women, otherwise in the most favourableconditions for health, should sometimes catch colds, have coughs, glide into consumption, and fall a prey to a train 
of nervous disorders. The weight of clothes bearing and pressing upon the lower part of the spine, and heating and compressing the delicate organs of the pelvis, causes painful diseases of the womb and ovaries. The bulk and weight of false hair now worn upon the back of the head and neck cannot fail to produce disorders of the cerebellum. Men's hats burthen and compress their brains. Infants and young children are sometimes half-smothered in clothing, sometimes their lower extremities are exposed without covering to the bitterest wintry blasts.

Excessive labour, especially protracted labour in unhealthy conditions, in heated shops and factories, in bad air, in cramped positions, and exposed to irritating dust or poisonous vapours, is a fruitful cause of disease. Steel-filers, brass-workers, workers in mercury, arsenic, lead, and antimony, workers in shoddy factories and bakeries, are short-lived, and suffer from special diseases. Lead causes constipation and paralysis; the makers of lucifer matches are liable to a horrible necrosis of the jaws; metallic dust, and even the flour of mills and bakeries, clogs the lungs and causes consumption. But shoemakers, tailors, milliners, artificial flowermakers, suffer scarcely less from the bad air of crowded and unventilated shops and factories. Among all our manufactures there goes on the manufacture of disease and death. The agricultural labourer is laid up with rheumatism from hard work, exposure, and too much cyder. The town artizan dies of bad air, dust, and beer. Literary men break down early with sedentary brain-work and stimulants. There is no healthful order of industry; but a great disorderly battle of life, with its wounded, disabled, dying victims.

Whatever exhausts the nervous power, whatever is a drain upon the material of life, must be a cause of disease. In excessive amative indulgence, we have both causes in action. There is a great expenditure of nervous force in the sexual orgasm. 
There is also in one sex the loss of a highly vitalised fluid formed from the blood, and containing its finest essence-a fluid which seems, indeed, to be a concentration of the nerveforce of organic and animal life. In the other sex a disordered ovarian action and menstruation may produce similar exhaustion. Nature calls for this expenditure only at maturity, and at rare intervals, and for a specific purpose. When amative waste begins in early life with unnatural indulgence, when it is continued by excess of what nature intended, it must always be a cause of disease; and it is one of the most common causes of many of the most distressing diseases. It affects the nervous system and all the vital functions, weakens digestion, impoverishes the blood, paralyses the skin, wastes the muscles, weakens the intellect and memory, and is a frequent cause of palsy or apoplexy, insanity or dementia.

On the painful subject of secret amative indulgence in both sexes, I cannot quote a higher, a more respectable authority than Copland's Dictionary of Practical Medicine. "It is," says this work, "the Moloch of the species," and is "far more prevalent in very young children of both sexes than is generally supposed," and is a cause of hysteria and of insanity, of which it is "a most influential predisposing and exciting cause." - "It is, I believe, a growing evil, with the diffusion of luxury, of precocious knowledge, and of the vices of civilisation, and is even more prevalent in the female than in the male sex, and occasions many of the disorders connected with the sexual organs." And similar to this is the testimony of many English, European, and American medical writers.

I cannot neglect here to mention the moral causes of disease. Every violent emotion, even hope and joy, may be, in certain cases, a cause of insanity or death; but there are depressing emotions which develop tendencies to disease, and remarkably favour the action of other causes of disease. Dread, fear, terror, seem to have a very direct influence upon the spread of 


\section{Human Physiology.}

epidemic diseases, while courage resists them. Those who attempt to fly from plague or cholera fall victims; those who manfully face them, and help to nurse the sick, commonly escape. Care, the anxiety of the poor about their means of living, reduces their vitality, and makes them an easy prey to the physical causes of disease. Sorrow, grief, jealousy, remorse, thwarted love, or disappointed ambition, all favour the development of disease, if they do not actually produce it; even the bird pines to death at losing its mate, and the dog dies on the grave of his master. A broken heart from grief is by no means an imaginary disaster.

Besides this general view of the causes of disease, it may be well to consider the special causes of particular diseases, and classes of diseases, enumerated in the previous chapter, beginning with the first-class, or zymotic diseases. Epidemic, endemic, and contagious diseases have a double origin; first, in the exhaustion and impurity which make the liability to disease; and, secondly, in the contagious matter or determining cause of the particular form of disease.

Small-pox, for example, is a disease of filth, spreading chiefly in the poorer quarters of large towns, in bad air, and where unhealthy conditions offer the predisposing causes. Such a population is liable to become the victims of any miasma; but there is a special kind of poison or virus which produces the febrile eruptive disease called small-pox. It can be communicated by inoculation, by contact, and through the atmosphere. We know nothing of the nature of this determining causewhether it is a vegetable germ, a living animalcule, or something quite different from either. What we know is, that small-pox matter, however carried or blown about, produces small-pox in those who are susceptible to its influence; that measly matter produces measles; that the matter of scarlet-fever produces its kind; and that one will not produce the other. As the clean and healthy, the pure and strong, often entirely escape these 
diseases, or have them so lightly that they are scarcely perceptible, we know that some predisposition must unite with the determining cause. As most persons have these diseases but. once, it would seem that some element of predisposition is, by the action of the disease itself, eliminated from the system. It would appear also that one who has had any of these diseases is less liable to have the others ; that they purify the system so as to make it less susceptible to disease in general.

We are sometimes told that small-pox and cholera can begenerated at any time, and anywhere, by the conditions of filth that favour their spread as an epidemic, but there is no good. ground for this assertion. Most of the great towns of Europeand America had been in bad sanitary conditions for a long. period, but the Asiatic cholera never was known among them until it was brought from Asia. When small-pox broke out as. an epidemic in so many English and American towns in $187 \mathrm{r}-2$, these towns were in no worse sanitary condition than they had been for twenty years, and many of them had greatly improved; nor had vaccination been more neglected.

In the enthetic or implanted diseases, and especially themost widely spread, and, as many think, the most virulent and mischievous of them, syphilis, we have similar conditionsa constitutional liability and a specific poison. Some personsdo not take syphilis, and cannot even be inoculated with its virus. In some it is a comparatively mild disease; in others it produces the most terrible ravages. Some throw it off readily; others can never get free from it, and transmit it in various modified forms to their posterity. But of the real, determining cause of syphilis we know almost nothing. We do not know the time or manner of its origin, or its first "appearance in Europe. It cannot be shown that it has been caused by excessive or promiscuous intercourse of the sexes: for in periods of the greatest and most wide-spread profligacy, it was, so far as we can judge, unknown. And now it is never known 


\section{Human Physiology.}

to arise spontaneously, but is propagated as a special virus or distinct contagion.

Tubercular diseases, as scrofula and consumption, though to some extent hereditary in their character, seem less mysterious in their origin, or determining causes, than those generally recognised as contagious. They prevail in some climates, countries, and races more than in others. The purer races - like the French, Spanish, and Italians-are less liable toscrofula and consumption than the mixed races of Germany, England, and America. The people of cold and damp climates: suffer more than those of warm and dry ones. Consumption is more frequent in the North-eastern States of America than in the South-western, while the dry, equable climates of Texas, New Mexico, and California, are almost free from it. Spongy, or clayey soils, with their cold and dampness, favour its development. Bad air and the absence of light are evident causes of tuberculous diseases. Insufficient nutrition, and the milk and flesh of tuberculous animals, are also probable causes. Scrofula, king's evil, white swelling, and consumption, are undoubtedly hereditary, whether original diseases or modifications of syphilis. Consumption of the lungs seems to be a direct consequence of this protean poison. In the regiments of the British army most exposed to syphilis, half the men die of consumption. There is also much reason to believe that the tuberculous predisposition to the disease itself may be propagated by contagion. Animals inoculated with tuberculous matter have developed tubercles, and consumption has prevailed in camps and barracks to such a degree that the surgeons were forced to the belief that it was communicated from man to man, probably by the inhalation of the matter of the disease. Consumption is a common disease of habitual drunkards, and of persons of disorderly lives and-exhausted vitality. It therefore seems probable that when the impurities of the body, from any cause, cannot be cast out, they gather in 
the lungs, the mesenteric glands, and other organs, and form tuberculous deposits.

The diseases of the brain and nervous system are generally diseases of nervous disorder and exhaustion. The brain is worn with labour and care, excited and therefore weakened by stimulants, exhausted by amative irregularity and excess. Hysteria, chorea, and epilepsy are generally connected with excitement and exhaustion of the generative system, with amative passion and unnatural or e:"cessive gratification. Tobacco poisons the nerves of organic and animal life; tea and coffee excite and disorder them; alcohol, absorbed into the circulation, penetrates the brain, and disorders and impairs all its functions. Drunkenness is a mania, and the habitual drunkard has little more power of self-control than any other lunatic, and as much needs restraint and proper treatment. Drunkenness should, in fact, be considered and treated as a disease, and the drunkard kept out of the temptation and the possibility of indulging his morbid appetite, either by removing him from drink or drink from him.

The diseases of the heart and circulation are those of nervous exhaustion and bad nutrition. 'The latter may depend upon the former in a diminished power of digestion and assimilation, or upon unhealthy food, or deficiency, or excess. The use of stimulants acts very directly upon the blood and the organs which contain it; while the more virulent poisons of strong coffee, tea, and tobacco excite, and then paralyse the nerves which control the action of the heart.

The distinguished German chemists, Dr. Aubert and Dr. Haase, obtained 8 or 9 per cent. of caffein from coffee, and from 2 to $2 \frac{1}{2}$ per cent. of an almost identical element from the best Pekoe tea. It causes reflex nervous excitability and tetanus, acting on the nerve centres, and producing effects resembling those of strychnia. A frog is tetanised by the fivethousandth part of a gramme, and a cat or dog by one-fifth 


\section{Human Physiology.}

of a gramme. It accelerates the action of the heart, and at the same time diminishes the force of the circulation by paralysing the ganglionic nerves of the heart. The violent muscular exertion of the now fashionable athletic contests havea similar effect in producing nervous disorder and exhaustion. Nothing can be better for either sex than a moderate amount of daily exercise, and the fatigue from which one perfectly recovers with a night's sleep is no harm to any one; but thetraining that takes the whole force of the body, and tine violent efforts of struggles for victory, are not consistent with health, with an even development of mind and body, or high intellectual achievement.

No one who does much work with his brain can safely exhaust his powers with muscular exercise. Even long walks are not favourable to mental application. The more passive kinds of exercise, as riding on horseback, are best for brain work. We think best in the morning after a night's rest and sleep. Four or six hours of intellectual labour a-day are as much as is consistent with the health of brain and body. From six to eight hours a-day is time enough for any kind of severe or monotonous toil; but where work is light, varied, and interesting, as all work ought to be; where we can turn from one kind of employment to another, and find interest and recreation in it, we may work pleasantly and healthfully most of our waking hours.

Dyspepsia and constipation are two diseases or disordered conditions of the nutritive system, which are the causes of numerous maladies. As nutrition builds up the body and sustains it in all its parts and functions, every kind of disorder may come from; or be coincident with, a disordered nutrition. If the stomach will not perform its function death is inevitable. If it performs it imperfectly life is. feeble, painful, and will probably be of short duration. With a diseased stomach, disordered bowels, and imperfect excretion, what can there be 
but general disease? The whole nervous system must suffer, and its suffering is expressed in weakness, pain, ringing in the ears, weakness and disorder of the eyes, toothaches, neuralgias, imperfect action of the skin, and many local maladies. With dyspepsia the body cannot be properly nourished; with constipation it is not properly cleansed; and the waste matter which should pass off freely every day is retained in the system, thrown upon the lungs, skin, and kidneys, to disease them, and clogs and disorders the whole economy. The current of life is filled with impurities and the matter of disease.

The causes of dyspepsia are bad diet, bad air, and nervous exhaustion. By bad diet I mean too much food, unhealthy, diseased and diseasing food, and stimulants. Bad air makes bad blood, and bad blood makes bad nerves and bad secretion of the digestive fluids. Nervous exhaustion saps the forces of life. When amative excess has weakened the nervous power, and stimulants are taken to excite the system, and the stomach is loaded with the abominations of a luxurious table, with its sauces, and pastries, its grease and condiments, what can be expected but exhaustion and disorder in the entire digestive apparatus? When the stomach is fevered, overtasked, its tone weakened, and its secretions disordered, what can be expected of the small and large intestines which must sympathise with this disorder? If the nutritive matter be not digested, and absorbed, and converted into good blood, health is impossible. If the waste matter of the body cannot find its way out, if the sewers are clogged, the pumps cease to act, and the whole machinery of purification lies torpid, very serious consequences must follow. There is in many cases a direct cause of constipation, which seems to be partly of a mechanical character, in the nature of the diet. Certain kinds of food are constipating, others are relaxing-that is, they promote the action of the bowels. Concentrated aliment, as eggs, cheese, ifine flour bread, and pastry, are constipating, not from what 


\section{Human Physiology.}

chey contain, but from what they lack. Fruit, greens, like spinach, brown bread, and especially coarsely ground wheat mush or porridge, produce a full, easy, and regular action of the bowels. The cause of constipation would, therefore, seem to be in many cases the lack of a certain proportion of innutritious matter, or woody fibre, which is contained in the natural food of man eaten in its natural condition. When horses are deprived of hay, straw, husks, \&c., they become constipated, and instinctively eat their mangers, wood shavings, and even their blankets, to get the coarse matter they require.

Poisons, vegetable, animal, and mineral, are causes of disease. Some vegetable poisons, eaten by accident, sicken or kill. All the narcotics are poisons, killing in large doses; injuring, assuredly, when taken habitually even in moderate doses. It will not be pretended that opium-eating is not injurious. Tobacco is as poisonous as opium. A concentrated dose kills as surely. The same is true of tea and coffee. The injury all of them do to the nervous system is evident in many cases; but the fact remains that they are all, even including opium, habitually used by many through a course of years with no very marked injurious result. Habit is a second nature, and enables people to tolerate, and seem to thrive, on arsenic. And we have this difficulty in regard to all drugging and medication: we cannot compare the actual case of the patient with what it would have been under other conditions. We can only judge by experience and general principles.

Of animal poisons we have examples in stings, the bites of poisonous reptiles, poisons developed in putrifying flesh, glanders in horses, with which men are sometimes fatally inoculated, hydrophobic virus, gonorrhœa, syphilis, small-pox, and vaccine matter, which sometimes carries with it the matter of other contagious diseases. All these poisons may be the causes of annoying, severe, and fatal diseases, and for some of them medicine has found no remedy. 
Mineral poisons, to some of which I have referred as producing the diseases of certain trades, have been' used as. medicines, when they act prinarily as poisons, but secondarily as alteratives or evacuants. Thus, mercury is given as an alterative and cathartic; antimony as an expectorant and emetic. Nearly all the drugs, vegetable or mineral, used as medicines, are of the nature of poisons, and may be, and often are, causes of disease. One irritant poison taken into the stomach produces a spasmodic reversed action by which it is thrown up, with the other matters the organ contains; another, of a less suddenly irritative character, is expelled more slowly by the bowels, which are at the same time excited to throw off other matter. In each case good may be done, but in each there may also be more or less injury to the nervous system and the irritated organs. The habitual use of purgative medi. cines is often a serious cause of disease; and nearly all medication must be considered a choice of evils.

In short, every deprivation of the conditions or violation of the laws of health is a cause of disease. Whatever overtaxes or diminishes the nervous energy, the inner life, or what some have called the vital force, or vital principle, is a cause of disease. Whatever introduces foul, noxious, or poisonous matter into the system, or prevents the waste and morbific matter from being thrown out of it, causes disease. Whatever lessens the normal action of any of the vital organs, is a cause of disease. Whatever diminishes the energy or disturbs the harmonious action of this wonderful machine, or organ of the divine lifethe body and soul of man-is a cause of disease. 


\section{Human Physiology.}

\section{CHAP'TER V.}

THE PREVENTION OF DISEASE.

Sanitary Legislation-Testimony of Dr. Playfair-Status of the Medical Profession-Case of the Murdered Convicts-Sanitary EducationEffects of Disinfectants-Quinine-Vaccination-Sanitary Inspection.

Prevention is better than cure, and the more advanced countries in the world are doing something in the way of sanitary education and legislation.

The prevention of disease is comprised in securing to every individual the conditions of health, and protecting him from the causes of disease. Sanitary legislation may give light and comfortable shelter, by compelling the construction of proper dwellings; pure air, by general cleanliness and ventilation; pure food, by intelligent and honest inspection, and prevention of frauds and adulterations; pure water; and other health conditions by suitable hours for work, fair wages, public recreations, baths and wash-houses, and the diffusion of a general knowledge of the laws of health.

Dr. Playfair, one of the most enlightened of physicians and legislators, has said:-

"Just as in war, while 20 per cent. of its victims perish on the field or die of wounds, 80 per cent. die of diseases which follow a camp life, so in peaceful occupations, the preventable deaths by violence are small in comparison with the preventable deaths which follow as infringements of sanitary laws. They are as definite and inexorable as any law in physics. You go to the top of a precipice and topple over it, and the law of gravitation most surely pulls you down with increasing swiftness, till it dashes you to pieces on the ground. You brought yourself under the law of gravitation, and never dreamt that it 
would alter its action, by a hairbreadth, to save you from your folly or ignorance. So is it with sanitary laws. Swift, stern, inexorable, and invariable in their action, they punish all violations. Yet man was not born into the world that he might pine and die, but that he might grow in vigour, and live his allotted period. Health is the normal state of obedience to law, disease the penalty of its infringement. In consequence of this disobedience, our kingdom has $\mathrm{I} 10,000$ lives ruthlessly sacrificed every year, while 220,000 people are needlessly sick all the year round. And why? Because neither our rulers nor our people will become acquainted with and obey simple sanitary laws. No epidemic can resist thorough cleanliness and ventilation. There was a period of a thousand years, during the dark middle ages, when not a man or woman in Europe ever took a bath, and during a century of that time it lost forty millions of its population by plague, the disease of excessive filth. Now plenty of good air, good water, and the removal of all garbage from the interior and exterior of dwellings, forms the conditions of public as well as of private health -in one word, cleanliness in our towns and in our persons. It is a law simple to learn and simple to apply, but our pride revolts against it, as did the leper of old, when he was told to 'wash himself in the Jordan. 'If a prophet had bid us do some great thing, 'would we not have done it; how much rather, when he saith unto us, Wash and be clean.'"

It has long seemed to me that one of the most important measures for the prevention of disease would be an entire change in the status of the medical profession. Doctors may be the best of men, but they are still men, and they are directly interested in the prevalence and spread of diseases. Glaziers do not, as a rule, go about breaking windows; but can we reasonably expect the average glazier to hope that no windows will be broken, or that he will enter very heartily into any extensive scheme for the prevention of such accidents? 
If there were any true science of medicine, undoubted and infallible, in which all could agree, and which all might trust, then physicians might be appointed like clergymen, and receive proper salaries from the State; but while there are so many medical sects, opposed in theory and practice,- and doctors proverbially disagree-no such arrangement, which would make public health the direct interest and glory of the physician, seems practicable. The nearest approach we can have to it is the appointment of qualified sanitary inspectors.

If in any way doctors could be paid according to results, their emoluments increasing with the health, and diminishing with the diseases of the community, we might probably lower the death-rate to its normal standard. On this point there is one very striking illustration. Convicts were once transported to the British Penal Colonies in private vessels by contract, at so much a head for the number embarked. The ship-owners were respectable men, the officers of the ships perhaps as good as could be selected, but the mortality was frightful, amounting to 50 and even 60 per cent. during the voyage. At length the form of contract was altered. Instead of the ship-owners being paid per head on the number embarked, they were only paid per head on the number landed alive; so that the ship-owners lost by every person who died on the passage. This form of contract changed the whole face of things. Attention, or the efficient stimulus of interest, was directed to the causes of the mortality; ventilation and other appliances were sedulously attended to; the merchant, at his own proper cost, provided a medical officer to take charge of the convicts, and the remuneration of that officer was proportioned to the number landed alive. The result was a mortality of only one and a-half per cent. The forty-eight to sixty-eight in a hundred, or more than half, were then, in the earlier voyages, simply murderednot wilfully, but by selfish and criminal neglect. If the salaries of municipal officers, the income of physicians, the pecuniary 
interests of all who are concerned with the public health could be reached in the same way, we should soon reach the minimum of disease and mortality. A shocking case; but are not people dying all around us from similar causes, the neglect of governments and the selfish greed of landlords and others?

In the meantime, I see nothing more important than sanitary education-the education of the whole people in the laws of health and sanitary science, based upon a sound knowledge of Human and Comparative Physiology. This should form the most important, the indispensable part of the course in every public and private school, college, and university, and enter into every competitive examination. If the laws of health were universally known-if they were regarded by every magistrate and municipality -if their maintenance came to be an honour, and their violation a disgrace, we should soon see as great a change as was effected in the health and mortality of the convicts.

Even with our imperfect sanitary arrangements much can be done to ward off a threatening epidemic. The yellow fever, it has been abundantly demonstrated, can be kept out of every American seaport by a rigid quarantine. A black frost kills the germs of the disease. It is probable that chlorine gas or some equally powerful disinfecting agent would destroy it. I was in Boston when the cholera first visited America, coming first to Quebec and Montreal by the River St. Lawrence. Boston was as much exposed as any seaport town, but an energetic Mayor and city government cleaned it thoroughly, and so filled the whole atmosphere with chloride of lime that we were nearly suffocated. There was not a case of cholera. Probably sulphurous acid-the fumes of burning sulphur-might have had the same efficacy, possibly Condy's fluid; but I should rather trust to chlorine.

When travellers visit malarious regions subject to intermittent or remittent fevers, they take quinine as a preventive. It is 


\section{Human Physiology.}

generally effectual, the drug seeming to paralyse the nerves so as to prevent the periodical effort of the system to expel the poison of malaria. The result is that both poisons are retained in the system, and their effects are felt for years. Quinine in intermittent fever seems to act like mercury in syphilis. The disease is masked-not cured-and the remedy may be worse than the disease.

It was once believed that vaccination, or inoculation from pustules on a cow (said to have been caused by purulent matter from a disease of horses' heels, called the grease), was a thorough preventive of small-pox. Recent experience has shown that it may rage as an epidemic in spite of compulsory vaccination, and there is abundant evidence that syphilis, scrofula, and other diseases of blood-poisoning are sometimes given with the so-called vaccine virus. As cleanliness, a pure diet, and general attention to the laws of health, are perfect protections against all danger from small-pox, there is generally no necessity of taking one disease, which may be virulent and even fatal, to guard against the risk of taking another. And for a government to compel people to have their own or their children's blood poisoned, rather than carry out general health regulations, which our highest medical authorities assure us are a safeguard against all zymotic diseases, is absurd despotism. Hundreds of cases have been collected of children dying, apparently, from the blood-poisoning of vaccination. Children previously healthy become diseased and die, and their parents go to prison rather than risk the lives of their other children. Surely it is better to banish the unsanitary conditions which make the spread of small-pox possible, than to poison even one helpless infant to death according to Act of Parliament.

Among the occasional causes of serious disease are animal and mineral poisons in the walls of our rooms. Green wall paper containing arsenic fills the air with arsenical vapour, and persons gradually become poisoned by living, and especially by 
sleeping in such an atmosphere. And the walls and ceilings absorb animal emanations and the matter of disease from the sick which they give out to poison others. In this way hospitals become pestiferous, and any room which has been filled with morbific matter may long retain and give it to successive occupants. All hospitals and sick rooms should be thoroughly disinfected by frequent. white-washing or fumigation with chlorine gas or sulphurous acid. The smoke of burning coffee, or rags, and the vapour of vinegar have also a degree of disinfecting efficacy.

Ergot, or the smut of rye, when it is allowed to get into bread, or in whisky distilled from rye, or eaten by cows so as to poison their milk, may be a cause of disease. A thorough inspection of all kinds of food, and drink, and all dwellings, and the atmosphere of all inhabited places by scientific and conscientious men, who would place the health and well-being of the people above all other considerations, would do so much for the prevention of disease, that the cost of poorhouses and hospitals, and the expense of doctors and drugs would be almost entirely saved; so that as a mere measure of economy, or the lowest kind of self-interest, such inspection, and all the sanitary measures connected with it, would actually save money, as well as health and life.

As a rule men will do what they see to be for their own interest, and their immediate selfish interest commonly is a stronger motive than any future good. Men own cattle, and if they know how, will take care of them. The higher the price of slaves, the more care is taken of their health by their masters. If our farmers and manufacturers had to buy their labourers and "hands," they would be careful of their health and habits in proportion to their cost. If every case of typhus brought a fine upon the landlord, every town would be free from it. If cholera involved as great a money loss as the cattle. plague, it would never again visit England. When it is the 
recognised moral duty, or the evident interest of the governing classes to give every human creature the conditions of health, we shall be freed from nine-tenths of our diseases.

I have spoken, in the chapter on Hereditary Transmission, of the prevention of hereditary diseases; and in future chapters I shall have to consider those moral, social, and political changes which will be necessary for the removal of some of the causes of disease, and the elevation of the human race to that condition which will ensure the greatest amount of health and general well-being.

\section{CHAPTER VI.}

MEDICAL SYSTEMS AND PRACTICE.

Priests Anciently Physicians-Hippocrates-Celsus-Galen-ParacelsusConflicting Theories of Disease and Medicine-Medical DelusionsHerbalists-Homøeopathy-Hydropathy-All Systems SuccessfulNature Cures-The Gift of Healing-Women as PhysiciansEclecticism.

THE priests of ancient Egypt were also the physicians, having the care of the health of soul and body; and it might be well if in our own day there were some of this unity-if our doctors of medicine paid more attention to the soul, and our doctors of divinity knew more of what is required for the health of the body. Priests seem to have been also physicians in the first ages of the Jewish nation, as they directed measures of cleanliness and the prevention of contagion; and great good might now be done if all clergymen were to teach from their pulpits the benefits of temperance, chastity, and the daily bath. If, indeed, religious teachers of every denomination were to suc- 
cessfully denounce the sins of gluttony, drunkenness, filth, and lust, there would be little need of doctors or medicines.

Hippocrates, a descendant of Esculapius (B.c. 460), wrote several works on health and medicine, and his treatment consisted chiefly, and often solely, in attention to diet and regimen. $\mathrm{He}$ wrote on air, water, and local influences. About 300 years before the Christian era medical schools and sects flourished at Alexandria, especially the two great sects of Dogmatists and Empirics, members of both of which are said to still exist in the medical profession. The Romans lived a long time, and had their best days without doctors. The first doctor who settled in Rome (B.C. 200) was a Greek, but his treatment was so severe and unsuccessful that he was soon banished, and we hear of no other for a hundred years, when one came from Bithynia, who acquired a great reputation by allowing his patients to drink plenty of wine and eat fully of all their favourite dishes, flattering their prejudices and consulting their inclinations. This eminent physician also has some followers. Celsus, the first native Roman physician whose name has come down to us, wrote about the beginning of the Christian era, and Galen wrote and practised a century later. The Arabians, and the Saracens in Spain, continued the study of medical science after the decline of the Roman Empire. In the $5^{\text {th }}$ century Paracelsus and the Chemical school began their ravages by the introduction of mercury, antimony, and other mineral medicines. Anatomy and physiology were first regularly studied in the r6th and 17 th centuries. To the Chemical school of medicine succeeded the Mathematical, the Vitalists, the Cullenians, and the Brunonians.

It is a mooted point whether the science and practice of medicine have caused more good than evil. In a multiplicity of conflicting theories but one can be true, and where there has been every variety of contradictory practice much must have been mischievous. When disease was believed to depend 
upon morbid humours in the blood, and the lancet and leeches were freely resorted to in almost every case of illness, and even for prevention of disease, many patients were killed. When it was held that the bad humours could be purged away by the continued use of violent cathartics, patients were poisoned and exhausted. When the most virulent poisons of the vegetable and mineral kingdom were prescribed in strange mixtures and large quantities many lives were sacrificed. Mercury was for centuries considered a specific remedy for some diseases, especially for syphilis and the conditions it produces, and as a powerful alterative in many cases. It is now acknowledged by nearly the whole profession that it is not a specific, and many believe that it has produced the worst evils attributed to the diseases it was given to cure. The lancet is almost wholly abandoned. Quinine, perhaps the only drug now considered by what are called regulars or allopaths a specific, is no longer regarded as such by the most enlightened, who attribute its action in intermittent fevers to its paralysing influence. The latest quasi-specific, cod-liver oil, given for scrofula and consumption, is a comparatively harmless article of diet, and cannot be shown to have any medicinal properties whatever. The most recent delusions-and if it were pulite one might call them quackeries-of the profession are the administration of beef tea and brandy, or other alcoholic stimulants, as remedies for disease. Beef tea, Liebig $0_{2}$ other, has no value either as food or medicine, as the most eminent chemists have demonstrated, and as must be evident to every person of common sense, since it is merely a watery solution of the salts which give flesh its flavour; the fibrine, gelatine, and fat being carefully excluded. In any case, a teaspoonful of Liebig could not possibly make more than its own weight of animal tissue. Alcohol is a stimulant powerfully exciting the nervous system, a poison in large dozes, and has little or no value as a curative agent. The best physicians of the allopathic schnol give very 
little medicine ot any kind, and are coming to rely more and more upon hygienic conditions and the vis meaicatrix nature, the healing power of nature, for the cure of all diseases.

The Herbalists reject the use of the lancet, mercury, and all minerals, and most violent drugs and chemical preparations, and rely upon roots and herbs, which instinct and intuition may have selected, and experience has shown to be useful. There is no doubt that the juices of plants, as well as those of many fruits, have mildly stimulating, cleansing, and tonic properties, useful in many diseased conditions.

Homœopathy, a recent medical sect founded by the German Hahnemann, has two principles of cure. The first is, that any substance which will injure the human system has a tendency to cure a similar injury; but secondly, the substance must be used in very minute doses. Generally a very minute quantity of a drug dissolved in a million, or many millions of times its. weight in alcohol, or similarly attenuated by rubbing down in sugar of milk, is given to cure symptoms which the same drug in large doses would produce. But such substances as chalk and charcoal are also used as homœopathic remedies. The theory is on its trial, and is finding a wide acceptance. Contagious and epidemic diseases prove the potency of matter in infinitesimal quantities. If an odour, a miasm, or germs too. small for the microscope to reveal, or too subtile for chemistry. to detect, can produce the most terrible diseases, equally minute quantities of matter may neutralise and cure. In any case homœopathy, with a wise regimen, seems to have no actively injurious influence, and it leaves the patient to faith, and hope, and the vis medicatrix natura.

About half a century ago, Priesnitz, a Silesian peasant, introduced the practice of hydropathy, or the water cure, a system in which pure air, a pure diet, and judicious exercises, are joined to the cleansing and invigorating effects of varivis baths, and the external and internal use of water. This system 


\section{Human Physiology.}

has been practised with great success at places specially adapted to the treatment over the Continent of Europe, in America, at Malvern, in England, and in various places in the United Kingdom.

There is a difficulty in arriving at a correct judgment respecting the efficacy of any and all modes of medical treatment. In the first place there is always a tendency to cure, an effort of nature to overcome and cast out disease, and substitute healthy for morbid action. A cut finger quickly and wonderfully heals. Nature mends a broken bone-all that surgery can do is to put and keep the parts in the right position, and bathe them in cold water to moderate inflammation. Surgery watches, but never heals. Doctors of the Expectant school do the same, giving no medicine, or only such as will excite hope and confidence in the patient. Even in virulent epidemics a large proportion of those attacked recover, whatever be the mode of treatment ; and the homœopathic hospitals, and those in which the negative or expectant system is followed, where there is merely good nursing and health conditions, have as large a proportion of cures, sometimes a larger, than those under the care of the so-called regular faculty.

And under any system of practice it is very difficult to say in most cases what is due to the prescribed treatment-impossible to know absolutely whether the patient might not have been better, or recovered more rapidly, without the medicine. Consequently we find equally honest, educated, enlightened men pursuing the most opposite systems, and that all systems are successtul. More, the most arrant quackeries, the most utter impostures, vaunt their wonderful cures. There is no doubt that every pill, every nostrum, every catholicon, advertised and puffed in the newspapers, even magnetic belts and skewasma, "act like a charm " upon those who have the faith to purchase and use them; and a man who will give a guinea for a bit of copper and zinc wire twisted together, and believe it can create and 
send a healing galvanic current through his body, has faith enough to be cured without one atom of galvanic action.

What is it then that cures? What restores the wearied limbs and wearied brain? What heals the bruise or cut? What unites the broken bone? What fills up the abscess with new flesh, nerves, and blood vessels? Not medicines of any kind. Nature heals-nature cures in all cases. The highest science can do no more than to give favourable conditions, remove obstructions, modify action, and in some cases assist nature and hasten her beneficent operations. A doctor may relieve an oppressed stomach by giving an emetic; he may relieve clogged and torpid bowels with a laxative medicine, or injections. He may cleanse the skin, and promote the unloading of the blood vessels by perspiration. He may relieve dis. tressing pain, and help the sufferer to rest and sleep. Better than all, perhaps, he can give sympathy, and inspire confidence and hope. And every physician, whatever his system of treatment, if it is not absolutely mischievous and murderous, does good; but does more with diet and regimen, and far more by sympathy and moral aid, than by all the other resuurces of the materia medica.

There is a gift of healing. Certain men and women have a natural vocation for the care and cure of the sick. They are clairvoyant of diseased conditions-sympathetic to such a degree often, that they are conscious of the aches and pains of people, and enter into a communion of suffering. Generally such persons are magnetic, or possess the power of giving relief by their presence, by the laying on of hands, by mesmeric passes over the seat of disease. Many have no knowledge or distinct consciousness of this power, but they are impelled to take hold of the sick, and stroke or rub them more or less vigouruusly. The hand of such a person laid on an aching head relieves it, as sympathy softens the pain of an aching heart. Their presence is comfort, their touch is strength. When a 


\section{Human Physiology.}

natural healer becomes a physician, his presence alone, without atom or drop of medicine, brings comfort, hope, faith, and the moral conditions of cure and the most powerful stimulants of vital action. Men of strong vitality impart life. When such men have great power of will, joined to a sympathetic nature and a desire to do good, they can work seeming miracles of healing. The power of what is called mesmerism, or animal magnetism, in the cure of disease has been demonstrated in multitudes of cases in private, and in the London Mesmeric Infirmary, founded by the late Dr Elliotson, under the presidency of Archbishop Whateley and the late Earl of Dunraven.

When such powers are known to exist, and are exercised, consciously or unconsciously, by a great number of persons, how can we know in any case how much is due to a medicine or mode of treatment, and how much to the moral or magnetic force that accompanies it? Is it not probable that the success of physicians depends far more upon this natural power, or gift. of healing, than upon the medical theories they have adopted, the systems they pursue, or the remedies they administer? It will be found that popular and successful physicians of every school have been strong, sympathetic men, able to help and heal ; men fitted to inspire faith in themselves and their treatment; for exactly the same measures and medicines fail in the hands of men with no true v $\sim$ cation for healing and unendowed with such gifts.

As women are more intuitive than men, quite as sympathetic, and, in many cases, quite as magnetic-to use a convenient word, which expresses at least an analogy-it follows that women have the right to be physicians; especially if either women or men desire their ministrations. In primitive societies the mother is the physician as well as the nurse of her family; and women who could add the skill acquired by experience to the gifts of healing were for ages the only physicians.

A wise physician will not be the slave of any system or 
theory, but be an eclectic so far as to be ready to avail himself of any and every means of doing good to his patients. One may not approve of the general use of emetics; but who would hesitate to give a tumbler of warm water and mustard, or ipecac, or even tartar-emetic, in a case of poison? The most rigid homœopathist might find it necessary to give castor oil or epsom salts in an emergency. We are sometimes compelled to make a choice of evils, or submit to a lesser evil for a greater good-and in such cases, the end sanctifies the means, whatever may have been taught or not taught by the Jesuits.

The first maxim in medicine is to do no harm. Nature, who is to do the work, must not be hindered, nor mischievously interfered with, nor have her forces diminished, as they used to be, and still are to some extent, by bleedings, blisterings, the administration of exhausting drugs, anodynes, opiates, or any of the poisons that lower and paralyse the vital powers. The vis medicatrix natura must exert its full energy. The physician is its valet, not its master. He may help, if he can, but he must never hinder. Loading with needless and hurtful food, exciting with stimulants, drenching with draughts invented to enrich the druggists, fussing with powders and potions, only hinder cure. Satisfy the patient if you can; but in some way not to do mischief. Satisfy the patient's friends if you must; but not at the patient's expense.

What the physician can do, is to give his patient, as far as possible, the conditions of recuperative action-light, pure air, perfect cleanliness of person, couch, and covering, quiet, cooling and healthful drinks at an agreeable temperature, the most grateful being pure soft water, toast water, or water slightly acid with fruit juices; frequent spongings and friction with soft towels or pleasant hands. He can remove obstructions; keep the bowels in good condition by cool injections, pure cold water being the best application to the mucous membrane any. 


\section{Human Physiology.}

where; and he may prescribe and rigidly insist upon the regimen the case requires.

The history of medicine shows us that it is not well to be the bigot of any system. Divine authority and its necessary infallibility, or demonstrated truth, can alone claim implicit faith and absolute obedience. No medical system has any such claim. The blind obedience given to the most absurd requirements of doctors who have no agreement among themselves, either in theory or practice, is doing a world of mischief. People who are democrats in politics, and free-thinkers in matters of religion, are blind slaves in medicine, where there is, in the variety of conflicting theories, opinions, and practice, no possible claim to authority. In the memory of our generation medicine has murdered millions-with the lancet, with opium, with mercury, with brandy, with the bad things it has done, with the good things it has failed of doing-with its absurd quackeries or its neglect of sanitary reform. The time is coming when the intelligence of the whole public in matters of health will abolish nine-tenths of the medical profession, and compel the remainder to less interested and more enlightened modes of teaching and practice. In the mean time every honest physician will do all he can to promote the general health of the community and that of his patients, to prevent as well as cure disease, and will, without regard to any system, choose the best methods of cure. Allopathic counter irritants certainly give relief in many cases; and anæsthetics save the suffering and exhaustion of pain, though they are not without cost to the system, and are in some cases dangerous to life. There is abundant testimony to the efficacy of some, at least, of the homœopathic preparations. A conscientious physician will not allow any prejudice to hinder him from using any remedy that he believes will benefit his patient.

And the wise and good physician can bring to the sick comfort, hope, courage, moral support; he can relieve want, remove 
depressing cares, anxieties, and annoyances; and, with the character every physician ought to have, and the means that should be placed at his disposal by the public authorities or benevolent societies, he can give to every patient the moral and physical conditions of cure.

\section{CHAPTER VII.}

HYDROPATHY; OR, THE WATER CURE.

Water Cure Natural-Its Wide Repute-Its Striking Effects-The Wet Sheet Pack-Water Cure in Miasmatic and Contagious Diseases-Diseases of Women-Childbirth-Turkish Bath and Artificial HeatDangers of Heroic Treatment-Law of Adaptation-Invigoration of Cold-Sitz Baths-Bandages-Apoplexy-Fasting-Cancer-Scrofula -Obesity-Change of Air-Consumption-Asthma- Will-LightFaith.

There is probably no system of treatment adapted to so wide a range of human ailments, so purely natural or physiological in its character, so speedy and certain in its results, under judicious management, as the one to which we have already alluded, known as hydropathy or the water cure, now adopted to a greater or less extent, and in more or less of its principles and applications, by the best practitioners of every school of medicine. The use of water in the treatment of disease is, in its broadest sense, natural. Drooping plants revive when we give them water. Fevered and wounded animals eagerly drink and bathe. A horse has been seen to go several times a-day and hold his wounded neck under a hydrant. Water forms ninety-five parts in a hundred of our blood and nerves, and seventy-five hundredths of our muscles and glandular organs-three-fourths of our whole bodies. Water is the solvent of all our food, and carries out of the body all its 
waste matter. We can live without foud much longer than without water. Purification is the first condition of health and cure: water is the great purifier. The second condition of cure is invigoration, and nothing is so invigorating as water, to herb, or beast, or man.

How natural are the principles and practices of water cure a moment's reflection will demonstrate. You cannot wash even your face, hands, and feet, without feeling its benefit. The daily washing of the whole body purifies and invigorates. Sea bathing is a glorious form of water cure. The washings and purifications of the Egyptians, Jews, Hindoos, and Mahomedans; the magnificent baths of every Roman city, and even the military stations of their most distant provinces, of which so many remains have been found in Britain; the Turkish hotair baths, with their shampooings, and hot and cold water washings, douches, and plunge baths ; the vapour baths of the Russians, with the final plunge in cold water or colder snow; the sweating and washing cures of the Red Indians; the natural hot springs, baths, and medicinal waters resorted to for health in all parts of the world, Spa, Vichy, Baden, Bath, Saratoga, Virginia, Arkansas, California, thousands scattered over the world; the Holy Wells, like those of Malvern, once the health resort of thousands who believed in their miraculous virtues, and which were none the less efficacious for the earnest faith which accompanied their libations and ablutions-are all but varied applications of the water cure, which is an instinctive mode of healing, or health giving, as old as the world, and applicable to all vegetative and animal life.

Cleanliness is the largest and most important condition of health, and we wash and are clean, applying the water cure not only to our persons, but to our food, clothing, dwellings, and all our surroundings. For every uncleanness the Mosaic dispensation had one remedy - the washing of purification. The Syrian leper was told to wash seven times in Jordan; miracu- 
lous healings were in the pool of Siloam; baptism is called "the washing of regeneration." Water is the symbol of cleansing truth, and is to the body what grace is to the soul. Water is in all nature the medium of life. Without water, light, heat, air, electricity, all other conditions of life and health are of no value.

Drinking pure soft water, such as trickles from the Malvern Hills, so pure that it can be used like distilled water for chemical purposes, dissolves morbid or diseasing matter, and carries it off through skin and kidneys. Daily bathing in such water not only cleanses the skin, but enlivens every nerve, and stimulates the action of every capillary. A sitz bath wonderfully strengthens the lower part of the spine, the lower bowels, and the generative organs, curing weakness in the back, constipation, piles, and ovarian and womb diseases. A douche strengthens the whole spine and nervous system, and the column of falling water seems to fill the whole body with electric vigour. The cold pouring and rubbing bath has produced very extraordinary effects of roused energy, quick reaction, relieved congestions, and sudden restoration of the powers of life. Priesnitz used it successfully in cholera; and in one case in New York a child, apparently dead of cholera and shrouded for its coffin, was by this means restored to animation and health.

But the most remarkable of all the discoveries and applications of the inspired father of hydropathy was the wet sheet pack. Wringing a sheet large enough to envelop the whole or a large part of the body out of cold water, and laying it on blankets, he wrapped it round the patient, then drew closely the blankets with a plentiful covering. There is first a cold shock, very agreeable in fever, then a glow of warmth, which gradually increases, to a profuse perspiration. In twenty minutes to an hour or more, the patient is taken glowing from the pack and quickly bathed in cold water. The sensation of 
this cold bath is simply delightful. Sheets and blankets are filied with the effluvia cast out by the skin, and must be taken away to be washed and aired. The effects are very sensible and remarkable. The pack relieves pain better than any opiate by a soothing action on so large a nervous surface. Fever is cooled at once, and a dry, harsh skin made moist and supple. The capillaries become full and active. Every one of the myriad glands of the skin sets to work to relieve the blood of its waste and morbid matter. Poisons laid up in the system, oppressing the nerves, are cast out, and may be detected on the packing sheet, always by the smell, often by the colour. Opium, tobacco, mercury in minute globules, bile and other substances, can be distinguished. Here is a wonderful purification. Each pack draws a certain quantity of morbific matter from the body, and a certain number gives it a thorough cleansing. The first slight shock acts as a tonic to nerves, bloodvessels, absorbents, and glands. Water is absorbed and afterwards expelled. There are actions of endosmose and exosmose through the sieve-like skin. The final bath and vigorous rubbing are tonic and invigorating in a high degree. It is certain that the wet sheet pack has more power and efficacy in carrying out the two great processes of cure, purification and invigoration, than all the medicines of all the pharmacopoeas from Hippocrates to Hahnemann. I know of no disease, and no condition of disease, in which it may not be used by a judicious adaptation to the reactive power of the patient. I have seen a wet sheet pack save the life of a child, by covering its body with the rash of suppressed measles, and a succession of them cure one given up to die of lung disease. Scarlet fever, smallpox, typhoid and typhus, pleurisy, pneumonia, rheumatic fever, in a word, every form of acute disease yields to the water treatment with a wonderful facility, and diseases that commonly last two or three weeks can be cured in as many days, simply because the purifying process set up by nature is expedited by 
the hydropathic process. Chronic diseases are cured more slowly, but as fast as the reactive energy of the patient will permit. Like causes produce like effects. Every diseased body must be purified, every weakened nervous system must recover its strength. Nature does the work, but does it easily and rapidly when there are all the conditions of healthy action.

The natural, hygienic, and hydropathic treatment, I believe to be beneficial in all cases, either alone, or in conjunction with other medicines and modes of cure. It should, indeed, always be combined with proper gymnastic or calisthenic exercises, with the movement cure, with the best system of diet, and especially the free use of juicy fruits, as in the famous grape cure, in which people are rapidly restored from the exhaustion of Paris life, by going to the vineyards, living out of doors, and eating nothing but bread and grapes. The water cure is specially adapted to all miasmatic diseases, cleansing the system with great rapidity, and robbing the most terrible and fatal of them-small-pox, scarlet fever, and typhus-of their terrors. In all such diseases the work of purification is wonderfully aided and accelerated, and no mother need fear any of the epidemic diseases of infancy and childhood if she have but a moderate knowledge of its applications. And for the "Contagious Diseases," specially so called, I believe there is no treatment so much to be relied upon. Syphilis, in all its modifications, yields more readily to this than any known method of treatment. Even in the best allopathic hospitals primary sores are now treated with cold water dressings : mercury is no longer relied upon to cure. Rest, a careful diet, and the spontaneous action of the skin and other excreting organs, are trusted to remove the virus; but this is a slow and uncertain method; whereas, the action of the skin excited by a series of packs and baths, surely and rapidly cleanses the system and cures the disease; and not only in its primary, secondary, and tertiary stages, but in its long train of conse- 
quences, running through successive generations, and showing themselves in the various forms of constitutional disease.

Of course, the water cure is specially adapted to every variety of skin disease; but the action of the skin, brought to its highest power, also derives from, and purifies, and relieves all the internal organs. A perspiration cures a cold, a fever, an internal inflammation or congestion, if of a slight character. In such cases a single vapour, or Turkish bath, or being rolled up in blankets, may be sufficient. But the daily wet sheet pack, with toning and invigorating baths, will reach deepseated, long-continued, and very severe and perilous cases of disease. There are diseases whose only termination is death; there are many cases of disease in which cure is sought too late-when the reactive and recuperative powers of the system are exhausted. At a certain stage, diseases of the brain, heart, lungs, kidneys, and bowels are hopeless of cure, but wherever there is enough vitality to cope with the disease, I believe the methods of hydropathy, judiciously applied, give the best aid to nature, and the best prospect of cure.

In the peculiar diseases of women, so numerous from our artificial and enervating modes of life, and so distressing, the wet sheet pack, the wet bandage around the hips, the sitz-bath and vaginal irrigations offer the most rapid and most perfect modes of cure. Through the whole period of pregnancy these processes strengthen the whole system of the mother, enable her to give pure blood and an energetic life to her child, and so invigorate the pelvic viscera that childbirth is freed almost entirely from all its dangers, and often from any sensation of pain. Mrs. Nichols, in her little book entitled, "A Woman's Work in Water Cure and Sanitary Education," says, "The world is scarcely prepared to believe that the processes of water cure relieve childbirth of nearly all its dangers and sufferings, yet this truth has many living witnesses. The writer had a large obstetric practice for several years, and has never had a 
patient who was not able to take a bath and sit up and walk the day after the birth of her child. In all the writer's practice, and in the practice of other water-cure physicians, she has never known an instance of the least evil resulting from judicious treatment, while the good effects upon the health of the child are enough to repay the mother for the little trouble and self-denial which will be a life-long benefit."

The Turkish or hot-air bath, now accessible in most large towns, is a mode of hydropathic treatment well adapted to many diseased conditions, and, as a luxurious means of cleanliness and health, should be introduced, as it easily might be, into every dwelling. All that is needed is pure air, raised to a temperature of from 100 to ${ }^{5} 5^{\circ}$ degrees Fahrenheit, a little soap, and plenty of hot and cold water. The heat opens the pores, and brings on profuse perspiration; soap and hot water cleanse the skin; the wash-down, douche, or plunge bath at the end restore the tone of nerves and skin, and prevent any danger of subsequent chill. For sudden colds, influenzas, rheumatic attacks, and the ailments and disorders of persons with considerable strength and reactive power, such baths have great efficacy. But in delicate constitutions, where the nervous power is exhausted, where the brain is irritable, where the patient cannot bear the excitement of circulation produced by heat, the Turkish bath cannot be used without great care in adapting it to the condition of the patient, and in some cases, even with the best care, it proves injurious.

The same must be said of the Russian, or hot-vapour bath, steam bath, lamp bath, and generally of all modes of applying artificial heat. The lamp bath is simply sitting naked in a chair over a spirit lamp, with or without a vessel of water over it, giving off steam. A box or blanket surrounds the patient. The body is enveloped with hot vapour, mixed with carbonic acid and the fumes of burning alcohol or methylated spirits. The perspiration relieves the system, and the cold bath which 


\section{Human Physiology.}

follows cleanses and invigorates-but the warm vapour relaxes and weakens, and the air is loaded with impurities. Great mischief may be done by these easy and agreeable applications.

It is much better, as a rule for constant practice, and in the cure of seriously diseased and debilitated conditions, to rely upon the reactive power of the system-the wonderful process by which we generate vital heat. We are never to overtask that power-this is the first maxim in hydropathy-but we are to use it, train it, and by exercise gradually increase it. The reactive power of the patient-his ability to get warm after a cold bath-is the fulcrum of the lever of cure. It is the measure of the possibility of cure. When we use artificial heat we weaken the reactive power. In many cases, the gain may be greater than the loss; but in others, and the more important ones, the loss is beyond compensation, and we have to husband the vital force on which cure depends with the greatest economy.

If artificial heat is, in most cases, to be avoided, there is even greater and more immediate danger from excess of cold. Heroic, or careless, slap-dash practitioners order long cold douches, or long deep or running sitz baths, to patients of low reactive power, and they come out blue, constringed, weak, shivering, miserable, and exhausted. In every case, the patient should come out of a bath in a red glow, or get warm with rubbing, and remain so. An after-chill shows that the bath has been too much for the reactive power. The patient should go into every cold bath warm from exercise or rubbing, and come out warm, or readily get warmed by exercise and friction, and the reaction of a quickened circulation.

It is difficult to explain the invigorating effects of cold. We speak of cold air as bracing. Franklin speaks highly of the cold-air bath, and found the exposure of his naked body to it very invigorating; but the effect of cold water is much more rapid and powerful. We test it by dipping a hand or foot into 
it, or by drinking a tumbler of cold spring or ice-water. It gives us a sensation of invigoration. The douche, or a stream of water falling several feet upon the spine, chest, and limbs for two or three minutes is followed by a feeling of extraordinary vigour. A common expression of a patient is- "I feel as though I could jump over a house." And this natural invigoration is not like that produced by stimulants. It is not followed by any reaction, or relaxed and weakened condition. Every cold bath, which is not beyond the reactive power of the system, is followed by a solid and permanent benefit. This may not, in all cases, be evident at once. In some cases of great exhaustion and low vitality the gain is slow-at first almost imperceptible; but after some months, and even years in some cases, nature triumphs over the disease, and the gain of health is gratifying in proportion to its apparent hopelessness.

As cure depends so much upon, or is measured by the power of the body to produce heat, it is evident that we must be careful in the use of every form of artificial heat. The temperature of rooms should not be above 70 deg., and clothing and bedcovering only sufficient for comfort; for natural heat accumulated in clothing becomes artificial, and weakens the nervous power. Warm baths, however pleasant and beneficial to the strong, are too relaxing to be habitually taken by the weak, and are only to be used by them in emergencies. Warm fomentations may sometimes be applied to relieve local congestions; but warm and hot sitz baths are seldom admissible; and when frequently given have a weakening effect on parts and organs which need tonic and strengthening treatment. Delicate persons may begin with tepid, or merely cool sitz baths, and make them colder day by day, until able to bear the water at its natural temperature.

A napkin wrung out of cold water and laid upon throbbing temples, on fevered and irritated lungs, or a disordered stomach and bowels, or upon the lower part of the abdomen, in diseases 
of the womb or ovaries; or a cold, wet bandage around the chest, stomach, or hips, gives such immediate relief, such comfort and strength, as to convince every one who uses them that water has a wonderful efficacy in the relief and cure of diseased conditions.

And water, as a medium of the application of cold and heat, is a remedy for the most urgent cases and dangerous attacks of disease. In apoplexy, physicians formerly bled the patient as soon as possible, and as much as they dared, to relieve the pressure on the brain. The patient had no blood to spare, and if he did not die at once, he was left in great weakness. The real requirement is to equalise the circulation; and the ready method is to get the feet and legs into hot water-a hot mustard bath if you will-while cold water is poured upon the head. When the balance has been gained, frictions with strong hands dipped in cold water over the whole body, and the wetsheet pack, with a spare diet, will effect a cure.

In all cases of acute disease, absolute fasting is the best remedy, or first condition of cure. Nature tells us that by taking away the appetite, and giving us a disgust at food; but friends, more kind than wise, make savoury messes and urge us to eat. Thin gruels, arrowroot, \&c., may do little harm, but we are better without them. In dyspepsia-in all diseases of the nutritive system, there is no cure like the hunger cure. Absolute fasting, and drinking and washing with cold water, will cure nine-tenths of all inflammatory and febrile diseases, from a simple cold to small-pox and scarlatina. As gluttony is the cause, fasting is the cure, of a host of diseases.

A common cold, which is often caused by a surfeit-the action of the skin, and its power of resistance weakened by overtasking the stomach-yields to an absolute fast, or a few days of very spare diet. An ordinary attack of fever gets well with rest, fasting, and drinking freely of cold water. Fasting is the best remedy for diarrhœa, and-what may seem a con- 
tradiction, but is not-fasting is also a remedy for obstinate constipation. In each case the alimentary canal is disordered, and needs rest. Rest, and the healing power of nature, restore healthy action; and healthy action is the cure of too little or too much. Overfeeding is a heavy tax on the vital powers, and a cause of constipation, piles, and many other diseases. For all these fasting, the hunger cure, or a very moderate and healthful diet, is a natural remedy, and an indispensable part of any proper medical treatment.

The cure, or arrest of development, of cancerous disease by hygienic and hydropathic modes of treatment demonstrates in. a remarkable manner their power over morbid conditions and constitutional diseases. A person who inherits a cancerous diathesis, in whose body are numerous tubercles which with ordinary modes of feeding and living would probably develop into fatal cancers, may by a pure diet, great cleanliness, and attention to all the conditions of health, entirely - arrest the progress of the disease. And even where it has begun, and made considerable progress, a careful diet of bread and fruit, constant bathing, a pure air, drinking soft water, and great cleanliness will arrest the progress of the disease, and in some cases bring about a cure. The morbid matter which seems to flow from all parts of the body to. the centre of disease, is cast out through the skin, lungs, kidneys, \&c., and the amount of this matter is diminished by a pure diet, while the eating of flesh, especially that of swine, unquestionably furnishes such matter, and hastens the development of, and greatly aggravates, all such diseases. If men lived entirely on fruit and the purest kinds of vegetable substances, I do not believe that any would die of cancer, and few, if any, of scrofulous or tuberculous diseases.

It is very painful to see scrofulous children, whose instincts revolt at eating flesh, and especially the greasy flesh of swine, compelled to live on animal food by their parents, 
because ignorant doctors, who have not the first idea of sound physiology or dietetics, tell them that they must eat meat-eat bacon, "to make red blood." As if the fat of bacon ever gave redness to the blood globules-as if the grass and grain on which sheep and cattle are fed did not abundantly supply them with red blood. I have never seen healthier, ruddier children than those brought up on a bread, milk, and fruit diet. I can have no doubt that pork produces scrofulous diseases, and that it was for sound sanitary reasons banished from the diet of Jews and Mahomedans.

Dietetic Medicine is especially necessary and efficacious in the cure of dyspepsia, and all diseases of the nutritive system. A sick stomach wants rest-and no drugs, no tonics or stimulants, will answer the purpose. In some cases an absolute fast for days or weeks, with only pure water to drink, will effect a cure. I have seen a confirmed dyspeptic fast for twenty-one days, taking only two or three ounces of food in all that time as an experiment; and the result was cure. Others have got well by living for several months on two or three ounces of very simple food a-day; gradually gaining health, strength, and even weight on such a diet. People doubt if one can live on "sixpence a-day." What is the cost of food to each person in a labourer's family of five, when rent, clothing, and the rest, as well as food must come out of the ordinary wages, I2s. or $15 \mathrm{~s}$. a-week? What could have been the cost of living in Ireland when men raised large families on wages of a shilling a-day? With the actual prices of food in this country it is quite possible to live, so far as food is concerned, on half of sixpence aday; and in certain states of disease of the stomach and bowels such a diet is the most important condition of cure.

And what shall be said of that dread disease, obesity? Making fat does not altogether depend upon the quantity of food. Graziers find that some breeds of cattle and sheep 
fatten more quickly than others upon the same diet. It is therefore a matter of idiosyncrasy. Fat mothers usually have fat daughters. But the quantity of food has something to do with it. We cannot lay on fat without in some way taking its elements into the system. The carbon must come from our food if the oxygen and hydrogen come from the air we breathe and the water we drink. Jockeys, prize runners, and prize fighters manage to get rid of their superfluous weight by careful diet, exercise, and profuse perspirations. They come to their best condition for the work they have to do by a training which is really not a bad sort of hydropathy; and I see no reason why every one who is too fat for looks or comfort should not rid himself of his superfluity in a similar fashion-by living chiefly on brown bread, eggs, cheese, and juicy fruit, avoiding all greasy, starchy, or sweet food, taking plenty of exercise, breathing air enough to burn up the carbon and hydrogen, and keeping the skin in a healthy and therefore active condition.

The influence of profuse perspiration upon the weight of jockeys, for example, shows that the size and weight of a person depends to a considerable extent upon the amount of water in his blood and cellular tissue. Stout people may be dropsical as well as fat; and for the relief of such dropsy we must depend chiefly upon the skin, which must be toned to healthy action by cold baths, abundant friction, exercise adapted to the strength, and the best adapted water cure processes;- -but here again the condition of the digestion, and the adaptation of food to the powers of the stomach, are very important.

Dropsy may often be cured-but when it is a symptom of the exhaustion of life, it is only a mode of dissolution-the surest sign of inevitable and approaching death. The extremities fill with fluid which the absorbents have no power to remove; fluids press upon the abdominal viscera, and 
may be drawn off by tapping, with temporary relief; when they are effused into the pleural cavity and press upon the lungs and heart the end is near.

Change of scene and change of climate are often prescribed for the cure or amelioration of diseased conditions. People say when a doctor cannot cure a patient he sends him away to die. It is true that no physician likes to have a patient die on his hands-but such advice is in many cases disinterested, and the departure of a patient is, of course, a pecuniary loss to the physician. It is also, in many cases, good advice. To hurry off a dying consumptive from the comforts of home to a sea side lodging is often a useless cruelty; but a change of air, of scene, of surroundings, is very useful in many cases. When one is dying of home-sickness, home is cure. The poor negro slaves described by Dr Livingstone in Central Africa, dying of simple broken-heart, and placing their hands over the heart when asked to show the seat of pain, would have quickly recovered had they been set free. To remove the cause of disease is often more than half the cure-and the cause may be the air one breathes, some subtle earth-influence, some moral contagion, the presence of uncongenial people, annoying and depressing surroundings. Change is cure. One may gain much by changing from a low to a high situation. A few hundred feet may make a world of difference. I write these lines some six hundred feet up the side of the Malvern Hills, which rise eight hundred feet above me; and every one feels the exhilaration of even these altitudes. The air is clear when the vast valley of the Severn is a sea of mist. The higher altitudes of the Alps are still more invigorating. We breathe more of a pure air, and expanding the lungs becomes a habit. So by the sea we take in draughts of a pure and stimulating atmosphere.

Consumptives in America, seemingly far gone in the dis- 
ease, recover by going to the Cross-timber regions of Texas, living and sleeping in the open air, and in the dry air of California; as in this hemisphere they make a longer fight for life in Upper Egypt; and might perhaps do still better living in tents in the higher regions of Algeria. Warn moist atmospheres soothe irritation, and people do not wear out so fast, but it may be doubted if they are so favourable to cure as cooler and drier situations. In early stages of consumption, horse exercise in all weathers-living in the saddle-has added many years to life. Those who sicken in a town may always hope for some relief from the purer air of the country; and there are cases of local disease, and remarkably that of asthma, which seem to benefit from any change, even from the most healthy country to the town.

But asthma is a very curious nervous disease, whose paroxysms may be brought on by very singular causes. The presence of a cat, the emanations from deer, the pollen of certain flowers will bring on an attack. Food influences it so much that no treatment seems of any avail without the strictest diet. If a patient will fast he can be healed. To give absolute rest to the stomach and excite the action of the skin by the most thorough water cure treatment are the two indications of cure. By such means I have seen cures in seemingly hopeless cases.

The force of the will in resisting disease, and promoting curative action, is very remarkable. It is seen in the will of the physician to cure, and in the will of the patient to recover. It is a triumph of mind over matter. I knew an officer in the American army in Mexico, who, wounded and in the hospital, was attacked with lockjaw, and told by the surgeon that he had not half an hour to live. He swore through his clenched teeth that he would not die, and through sheer force of will recovered. When the will force 


\section{Human Physiology.}

of the patient unites with that of physician and friends cures take place which seem miraculous. And the common impression is a true one, that dying people, whose recovery is impossible, are held in life by the earnest wishes of their friends who cannot let them go. The dying feel this, beg to be allowed to go, and finally turn away from the love that holds them uselessly to life.

I have spoken of light as a condition of health, and its absence as an evident cause of disease. It follows, of course, that it must be an important means of cure. Every invalid should have the clear, free light of open day. Curtained rooms for the sick are a great mistake. Even where light is painful to the eyes, and irritating to the brain, it is better to give local protection, than to shut up the patient in darkness. In most cases, the more a patient cari be out under the free sky the better. In the late wars the wounded recovered far better in light and airy tents than in any buildings used for hospitals. In the East the sick are brought out of the hospitals and laid in the sun. Apollo was the god of medicine in the Greek mythology. The sun pours out upon all the planets the forces of life, and health, and cure, and the direct rays of the sun upon the naked body are undoubtedly beneficial in many diseases. The skin of the face and hands, the parts exposed to air and light, is evidently more healthy than that of the rest of the body. As thick, dark clothing, dark rooms, and the shady sides of narrow streets produce scrofula, and the conditions which favour the mortality of miasmatic diseases, the free light of the sun must be a remedy for such diseased conditions.

And higher than sun and stars, source of their wondrous powers, the God of light and life can give us strength and health. "And the prayer of faith shall save the sick, and the Lord shall raise him up." Miracles of healing-marvellous cures beyond the power of medical science to produce or explain-if less frequent now than in some periods of the past 
are yet constantly occurring, as no one can doubt who takes the trouble to inform himself, if he can place any reliance on human testimony respecting any fact beyond his personal observation.

And, whatever theory may be formed concerning them, it is useless and foolish to ignore the facts of healing miracles, or the sudden cure of what seem incurable diseases. In these cures changes of the physical system, which, if they could occur, would require weeks or months in the ordinary operations of nature, are produced instantaneously, and by forces of which we have no conception. Diseased organs become healthy; lost matter is restored, or re-created. If it be held that such physical effects are produced by the faith, imagination, or expectation of the patient, then all physicians would do well to find the means of exciting such emotions. If they are produced by magnetism or mesmerism, the use of means so simple for ends so beneficent might well be more widely extended. If they are supernatural-miraculous-demonstrations of creative power, then they must have, for every thoughtful person, the highest possible interest. No fact is unimportant - but such facts have an importance inestimable. Scornful rejection is as unphilosophical as blind credulity. The searcher after truth may doubt, but he must examine; he may be slow to say "it is true," but he must never say "it is impossible." 


\section{PART SIXTH.}

MORALS AND SOCIETY.

\section{CHA PTER I.}

THE MORAL BASIS OF A TRUE SOCIETY.

The Law of Life-Human Disorder-Man a Social Being-Upward Tendencies of Humanity-Natural Conscience-Perception of Justice-The Laws of Morality Simple and Self-Evident-Morality the Basis of a True Society-The Morality of the Bible-War and Peace.

IN the preceding portions of this work I have described the actual condition of man in the highest civilisation to which he has attained; have considered the matter and forces which compose the material world and the phenomena of life; havebriefly described the organisation of the human body and its functions; have written, I trust, without offence to any reader, of the most important and vital laws of generation; and lastly, and I hope profitably to many, of health, disease, and cure. I have now to speak, as clearly as I can, and briefly as I must, of the principles and laws of morals and society, or ol that social organisation and life which is natural to man, and is therefore necessary to his best welfare and his highest happiness.

I do not need to prove-I have only to state the self-evident proposition that all the conditions of the life of man should be such as he is by his nature, or physical and moral constitution, adapted to, in harmony with, and fitted to enjoy. Something of this I have shown in the chapters on the conditions of healtb and the causes of disease. 
The law of life for every living thing is written in its organisation. We study the body of man, and find its adaptations and requirements as to food, clothing, shelter, exercise, cleanliness, \&c.-its relations to the physical world. We have but to study as carefully the mind or soul of man to understand the wants of his mental, social, and spiritual nature. All the faculties, sentiments, passions, or propensities of man, were made for his use and enjoyment, and they are all good in their orderly manifestation and gratification.

But it is obvious to every observer that man alone, of all creatures in the visible world, has fallen into disorder. $\mathrm{He}$ stands widely apart from all creatures in the evident fact that he was either created in disorder and demoralisation, or has fallen out of that harmony with nature which seems the natural or instinctive condition of all other creatures.

The law of progress does not explain the phenomenon. If there were such a general law, then all creatures should be subject to it; but we find the whole animal creation living in orderly relations with nature, simply following out their instincts, and having all the enjoyment of life of which they are capable. Man is in a very different condition. The misfortunes, vices, immoralities, and crimes, which deform and scourge human society, have no counterparts in the animal races. A few animals have become diseased by being brought into unnatural conditions by men. But in a state of nature all animals, as a rule, and almost without exception, enjoy health, and the social condition for which they were designed, to which they are adapted, and which gives them happiness.

Man alone has yet to attain to his natural condition. If individuals here and there have reached it, the race at large, and the great masses of every country, are far from the realisation of the peace, contentment, and happiness of a life in harmony with nature, and which answers the true end of our earthly existence. And no individual can have more than a 


\section{Human Physiology.}

very partial enjoyment even of the most fortunate conditions of personal and social life, when he sees around him multitudes suffering from ignorance, poverty, disease, vice, and crime. The race must be redeemed before even the most fortunate individual can be quite happy-in this world at least; or there must be perfect faith and trust in the Divine goodness, which is the foretaste of that perfect knowledge which belongs to a higher stage of existence.

Man is a social being. $\mathrm{He}$ is miserable in solitude. When man and woman are mated they are not long content. Other instincts, wants, or passions, demand gratification. They need parents to love and reverence, children to nourish and rear, friends to help them enjoy their comforts and pleasures. They need, in a word, society; and we know how imperfectly this great want is satisfied in the world around us.

All our faculties are social. Our intellect demands conversation, appreciation, admiration. Reading and writing, or correspondence, are partial substitutes, but what we enjoy much more is the animation of the living voice, the fire of the eye, the quick explanatory movements of the features, all the charm of refined and intelligent companionship.

Our mirth is social; our wit is wasted if we speak it not; our poetry must have hearers and readers; we make pictures and statues that they may be seen and enjoyed; our ambition, hope, pride, love of approbation, all refer to others-are social passions all. Our benevolence finds its objects in the world around us; our conscience, or sense of justice and right, regards our relations to our fellow-men. In these relations is all our true life, all our real happiness, and love to God finds its practical manifestation in love to our fellow-men. Chiefly and best, we love Him in nature and in man. Reason and Religion are here in perfect harmony.

But how, it will be asked, can we have a perfect society when men, of whom it must be composed, are so bad? Un- 
doubtedly we must have perfect individuals to form a perfect society, and a perfect society is needed to produce, train, educate, and develop perfect individuals. Bad men make a corrupt society-a corrupt society demoralises its members.

This is true, but humanity revolts at its own corruptions, mourns over its imperfections, and is ever aspiring at a higher and purer state. Many, discouraged at failures, hope for happiness in a future state of existence; but those who believe it possible that the will of God may be done on earth as it is in heaven, will never cease to labour as well as pray that this prophecy of prayer may be accomplished.

The upward tendency of humanity is shown in the general esteem for honesty, honour, benevolence, and all the noble and heroic virtues. Our ideal life is far above that to which we have attained. We find it in our romances, our poetry, and in the biographies of our best and greatest men-the favourite reading of all ages. In our dramas, even when performed in the lowest theatres, and most perhaps in those, honesty, selfsacrifice, fidelity, heroism, meet with generous applause; while meanness, treachery, selfishness, and cruelty, are heartily detested. Even in the stories and dramas of highwaymen and pirates they must be made brave, generous, and in some sort heroic, to gain the sympathy of even the lowest public.

When men are chosen by disinterested voters for offices of trust, mean and bad men are never knowingly elected. The lowest tribe wants its best man for chief. Soldiers and sailors respect and yield ready obedience to good officers. All men respect just laws and wise social regulations, even if passion or interest make them personally offenders. The light of conscience may be dim, but it is seldom wholly obscured; and when one does not know wrong from right, we no longer hold him responsible, or subject to blame or punishment. That human depravity is but partial, and not total, is shown in the fact that all languages have such words as right and wrong, 


\section{Human Physiology.}

good and evil, praise and blame, reward and punishment. Such words express the perception of man's true interest, of his duty, of the relation of actions to character. What we blame is a violation of a natural law. Gluttony, drunkenness, lust, uncleanliness, we see and feel are violations of the laws of purity and health. Fraud, theft, violence, and murder, are trespasses upon the rights of others, in which we also do violence to our own sense of justice and right. Seduction and adultery are personal injuries and social crimes. Detraction and slander are injuries to the individual, frauds upon society, and a still greater injury to those who are guilty of them. Conscience is, intellectually, the perception of the relations of good and bad actions to the individual and society; morally, it is the desire for the right for its own sake. We see and feel things to be right-in harmony with nature and the Author of Nature-just as we see a line to be straight, a circle to be round, a square not to be a triangle; just as we perceive and enjoy the harmonies of accords in music, or feel pained at discords. It is a moral sense analogous to taste or smell, sight or hearing; and, like these, liable to be perverted by education and habit. We need a healthy, pure, unperverted conscience, or sense and love of truth and justice, equity and harmony in all our relations, as a guide to the true life which will give us all we can have or wish of earthly happiness.

Morality is wonderfully simple. Its laws are self-evident, based in the nature of man, and therefore as easily recognised as the most fundamental mathematical truth. It is no more "a matter of opinion" whether things are right or wrong, than it is a matter of opinion whether two and two make four, or that the three angles of a triangle are equal to two right angles. Man has no right to injure himself, because he belongs to others - to God who made him, and to the society of which he is a member. He has no right to injure others; for his true relation to them is that of comrade, helper, friend, brother. 
Every command in the Decalogue is so utterly reasonable, and appeals so entirely to our own sense of right, that argument seems impertinent. Negatively, we must do no wrong, no injury to ourselves or others; positively, we are bound, by our relationship to our fellow-creatures, to love them as ourselves, as a part of our own being and life, and do them all possible good-we being so constituted, that the highest happiness of which we can conceive comes from our unselfish efforts to make others happy. Here is the true basis of human society: absolute justice-unswerving equity, which cannot wrong a fellowcreature, nor see him wronged without pain and protest-eager and heroic benevolence, striving for the good of all.

And it must be seen that there is no reality in the social theory that the rights and happiness of individuals must be sacrificed for the general welfare. The Almighty has made no such blunder. In a true social state, what is for the highest. good of each one is for the good of all; what benefits society benefits every individual of which it is composed. There is no such inequity as that thousands must be poor that one may be rich; that thousands must be killed with toil, and the hard conditions of the labouring poor, that a few may spend their lives in idleness and luxury. There is no equity, no justice, no right, no benefit in any such social condition. It is no more defensible than any other exercise of what has been called the right of the strongest--taking plunder and captives in war, or negro slavery, or the seizure of land by brigand chiefs, or the rack-rents of Irish landlords, or the robbery of caravans by Arab marauders, or any other act of savage or barbarian violence, or of civilised fraud and crime.

A true murality, which is essentially a true religion, will give us a true society. The whole spirit of the Bible, so seldom preached, so seldom written upon, so seldom enforced anywhere, is at war with all the injustice, the crimes, the cruelties, the false theories and inhuman practices of our actual civilisa- 


\section{Human Physiology.}

tion. What it teaches is justice, righteousness, or regard for the rights of all. What it inculcates is the brotherhood of man, which is utterly inconsistent with what we see around us; what it condemns is the oppression of the weak, the robbery of the poor, the selfishness of the idle and luxurious.

Our social state is one of war; class is arrayed against class in serried ranks, and the conflict is going on. What we need is peace, the love of God, and the brotherhood of man; not merely to be talked about on Sunday, but to become the reality of daily life. Let us consider how such an end may be accomplished.

\section{CHAPTER II.}

\section{HUMAN RIGHTS AND RESPONSIBILITIES.}

A True Society Natural-The Rights of Man-Individual Property in Light, Air, Water, Land-No Absolute Right of Property-Eminent Domain - Mines and Fisheries - Emigration - Responsibilities of Ownership or Possession-Production and Distribution.

A TRUE society must be natural-the spontaneous outgrowth of the nature of man, and adapted to his faculties, instincts, and needs. Men naturally group in families, and families unite by intermarriages, by mutual interests, for common enjoyment or common defence, into societies, and these group again into states and nations. But where many of these families are poor and ignorant, living in bad conditions, robbed of their rights by the selfishness of others, cheated by the cunning, oppressed by the strong, despised by the proud, society falls into great disorders, and becomes a curse instead of a blessing. Wanting the just satisfaction of their natural desires. for social life and its enjoyments, men seek for substitutes in 
vicious indulgences, or revenge in crime. It is, in many cases, the sting of injustice, the desperation of hopeless wrong, that drives men to evil.

The rights of man are not difficult to define, when we once see that they are based upon his nature. The rights of every organised being are written in its organisation. The tree has a right to space for growth, soil for its roots, air from which to draw its nourishment, and sunshine which is the condition of its life and growth. Animals require space, food, air, exercise, -shelter, and the social relations and conditions to which they are adapted. The zoophite clings to its rock, the oyster lies in its shell, the fish swims freely through the seas or ascends rivers. Buffaloes and wild horses live in herds, with a social organisation suited to their needs.

Man, it is said, has a right to "life, liberty, and the pursuit of happiness." The right to life includes the right to everything necessary for its preservation, its full development or unfolding, its highest enjoyment. Every man born into the world has a birthright to all the goods of life, and the extent of his right has no limit but his necessities, his requirements, his capacity of use and enjoyment, unless some limitation be found in the equal rights of others.

Earth, air, water, light, heat, all the elements of life are man's equal heritage. The earth is the common property of mankind, created for his use and enjoyment. It belongs to no man, and no one can rightfully occupy it to the injury of others. It is the common property of all-and this principle is conceded in the poor-rates levied upon the land, in all rates and taxes for the general welfare, in the right of every state to eminent domain or final control over all landed property, in all titles being vested in the crown, in the government taking land wherever needed for highways, fortresses, railroads, canals, and all public needs.

"May not a man do what he will with his own?" Assuredly 


\section{Human Physiology.}

not. Nothing is a man's own in that sense. All is for all. The earth is the Lord's, and is for His creatures. All the right any man can have to property is its use. He has no right to misuse, abuse, or destroy. A man who should cast gold into the deep sea, or set his houses on fire, would be treated as a criminal or a lunatic. It is every man's duty to his fellow-men, to society, to the state, to make the best use he can of the property under his control. But it is self-evident that no man has a right to let land lie idle, or to keep property of any kind from its proper use. If a few great proprietors were to convert their estates into hunting-grounds, it would raise the price of bread for every poor man in England. No ownership can give the right to desolate a country, and banish its inhabitants. The State can and ought to resume its rights over all property which is not managed so as to promote the public welfare. And this principle carries us a long way. If a government, acting for the people, can take land for railways, for public companies of transport, it can take it for agricultural, manufacturing, or mining associations-for any object which will promote the general welfare, rendering, of course, equitable compensation for vested interests in the expropriated domains; for the higher and highest law in every community is the general welfare and happiness of its members.

There is no absolute right of individual property in land, any more than in air or water. The tax-gatherer reminds every man that he cannot do what he will with his own. A share of his income is claimed by the state-that is, the general public, for the common needs. Men hold lands, and collect rents, and administer property by convention or permission, rather than of right, and are themselves tenants or stewards of the state, to which all property belongs. And one of the most important functions of every government is to secure to the whole population of a country its equal right to the use and enjoyment of all the wealth it contains. This is simple, natural 
right-justice-equity - the equality of man under the fatherhood of God.

No one pretends to personal property in sunshine, and yet. the light of the sun is the natural source of all the riches of the world. It feeds us, clothes us, gives us fuel, gives us life. No man has the right to cast the shadow of wall, or house, or tree upon land occupied by his neighbour. Diogenes asserted a natural right when he requested Alexander the Great to step out of his sunshine. No one thinks of monopolising the free air, and no one has a right to poison it for his neighbour's breathing. When people are pushed off the land and into crowded towns and pestiferous villages, and wretched dwellings, they are deprived of the natural right of every living creature to space, air, and light.

If the soil of a nation is the common property of its inhabitants, because necessary to the production of the food upon which they must all be fed, a principle admitted in the poor laws and all taxation, all other natural wealth must also be rightfully the common property of all. The navigation of all seas and great rivers, and the produce of all fisheries, must be free to all mankind. The ocean is the highway of nations, and there are no individual owners of whales or herrings. I see no reason why all the wild lands, forests, and game of a country should not be the common property of its inhabitants. Certainly all stores of wealth deep buried in the earth-salt, coal, iron, copper, tin, silver, and gold-cannot rightfully belong to the persons who chance to be in possession of the soil that lies above them. It is the law of many countries, and should be the rule of all, that all mines-all the treasures of the earthshould be held by the government for the common good. If the coal of England were so held, its use could be economised, its waste prevented, its cost to the consumer reduced, or the revenue derived from it would benefit him no less by reduced taxation. 


\section{Human Physiology.}

The rightful possession or use of land is the first condition of a true society, and no such society can exist until this first right is obtained. It is the condition of food, light, air, a healthy industry, security, home, family, friendship, recreation, every enjoyment of life. For all these there must be the basis of land-land for agriculture, gardens, dwellings, and all the needs of a comfortable and prosperous social condition. In unpeopled countries land can be found in abundance-millions of acres of the most fertile and beautiful lands are lying waste in Canada, the United States, Mexico, South America, Africa, Australia, etc. Societies can emigrate and easily acquire ample domains for the best social conditions and organisations.

But all cannot, or will not emigrate, and something must be done for the population that will remain at home. England is not to be unpeopled-the United Kingdom of Great Britain and Ireland will not probably, while the coal and iron last, have less than thirty millions of population. The people are to be educated-even the agricultural labourers. They have also begun to agitate for higher wages and improved conditions - that is, for a more bountiful share of the common heritagea larger portion of the produce of their own labour; and the time is at hand when the whole body of the industrial classes in England, those whose labour cieates all riches, whose brains and hands make the value of land, mines, and all the wealth of commerce and industry, will unite in far more formidable combinations than we have yet seen, with education, a powerful press, extended suffrage, the ballot, equalised parliamentary representation - the whole machinery of industrial and political organisation, to demand a larger share of the common wealth -an equitable division of the products of the earth, and the genius and industry of man.

If the men who own and govern England are wise they will examine all this question of the rights of man, and the true order of society, and do what they see to be just, and feel to 
be right, politic, and generous, before it can be demanded. No man can be blamed for being born to the inheritance of half a county, a dozen manufacturing towns, or of a square mile of the metropolis, or an income of a hundred thousand or a million pounds a-year-but it is an awful responsibility. The American or West Indian inheritor of a great plantation and a thousand negro slaves was in an exactly similar position. One day the British Parliament relieved the English planters of their responsibilities - a frightful and desolating war has changed those of the Americans. The fate of the great property holders, and thereby slave holders, of England is in their own hands for a little space. If they are wise they will settle the question of their duties and responsibilities justly and for the benefit of all concerned. If they are unwise, the government will settle it for them. If, using the power of their position, and their hereditary privileges, both as holders of property and holders of power, they resist a righteous settlement, it will still be settled for them sooner or later, and possibly in a manner not so well for them, or their children, or for England-even for those so - long and deeply injured-as might be done speedily and peacefully, if men would but do, in this and all things, as they would be done by.

The strong are the natural protectors and helpers of the weak-that is what they are for. The wise are the natural counsellors, leaders, and governors of the ignorant. It is their proper function. The rich have no obvious use in the world but to feed the hungry, clothe the naked, aid the suffering, and be the caretakers, guardians, stewards, and distributors of the world's wealth. They have no right to it for any selfish use or exclusive enjoyment. No man can have a right to more food than he can properly eat, to more clothing than he can comfortably wear, to more of the necessaries and luxuries of life than are proper for his comfort and enjoyment, with a due regard to the needs and rights, the comforts and enjoyments of 


\section{Human Physiology.}

those around him-of his neighbours-of all whom he can reach and benefit.

There is no right in any individual to waste the wealth which comes from the labour of others; no right to hoard it for his own selfish enjoyment; no right to lay it up so that his children can live in idleness upon the industry of others. All surplus of wealth is for the common welfare. The possessor holds it strictly in trust-for the good of all. His power to control and administer it is' a matter of sufferance, or agreement, convenient in an immature society; but the custom of disposing of wealth by will, so as to determine what use shall be made of it for generations to come, is often a serious wrong to the public. If there is no absolute right of property, or none beyond very narrow limits, there can be no right to control it after one's death. There is surely no right to make of it any capricious and inequitable distribution. The whole wealth of a nationnatural and artificial, or accumulated-should be held and used for the benefit of its entire population; and not, as now, to enable a few to live in idleness, and luxury, and splendour, while millions are in poverty and misery.

If we are really brethren-children of the same Father-no one of us can have the right to any luxury, while any one we can help is in want of the necessaries of life. Justice requires that every one should have the opportunity to live in comfort on the products of his industry-benevolence demands that those who cannot work should still be cared for. This is the communism, if you please to call it so, of the poor law, taught in every pulpit-and is simply the dictate of common humanity.

The production of wealth in this country, and probably in every country is, or might be, abundant for all the needs of its inhabitants, if there were no waste and no inequity of distribution. The land of England, under good culture, without the waste of making its produce into fermented and spirituous liquors, would afford abundant food for a much larger popula- 


\section{4 \\ Human Physiology.}

tion, saving for surplus wealth the proceeds of its manufacturing industry. Industrial armies could drain every bog, bring every waste under culture; and all England, under wise and heroic leadership, might be made one great garden of fertility and beauty, and the happy home of an orderly, intelligent, prosperous, and beautiful society.

\section{CHAPTER III.}

\section{LEADERSHIP.}

The Principles of Social Order-Every Body must have its Head-Illustrations in Music and Architecture-The Uses of an AristocracyCaptains of Industry-The Work for Noblemen, Landed Proprietors, and Capitalists.

IN every society, and every social movement, there must be order and subordination. It is the law of all organisation. Everywhere there must be some central, presiding, directing, and controlling power: In every plant and animal there is a central life; the brain governs the body; and the will centre governs the brain. When this central authority is free and energetic, and all nerves and muscles obey the will, we have orderly and harmonious movement, full of power and beauty. When there is disease and discord, we have erratic movement and distortion, epilepsy, chorea, palsy ; just as we have agitation, tumults, revolutions, and social demoralisation and decay in the body politic.

Every society, even among animals, must have its head or leader. One instinctively commands, the rest as instinctively obey. Children in their plays come into the same order. There is a foreman to every gang of workers; a stroke-oar in 


\section{Human Physiology.}

every boat; a captain to every vessel, from the smallest coaster to the largest ship, with unquestioned authority to command, and prompt obedience. All military enterprises, and all great works of every kind depend for their success upon the perfection of discipline, the wisdom of authority, and the zeal and intelligence of obedience. Every family must have its head, with its children and servants well governed. Every school must have the two elements of all social order-authority and obedience. And no social reform is possible-no philanthropic movement can possibly succeed without authority, energetic, just, and wise in its leaders, and thorough subordination and loyalty in all the members. There is heroic work to do, and we want heroes-born leaders of men, whom no toil will weary, and no difficulties will appal-men born to command, and possessed of those qualities of mind and heart that inspire faith, attract devotion, and command a ready, cheerful, enthusiastic obedience.

Music gives us the key to many harmonies; and leadership is the first and obvious necessity in the production of a grand musical work. Every instrument must be tuned to one pitch; every movement, every nuance of expression, must be under the control of a single mind, with whom all must be in perfect sympathy. A perfect orchestral band must be like an organised being, having one mind and heart. One central brain directs, and every other brain, nerve, and muscle gives ready and perfect obedience. Here is an example of order and subordination. There is here no assertion of freedom and independence, and any exercise of the right of private judgment in pitch or time, piano or forte, crescendo or diminuendo, would mar the performance. There must be a ready, full, loyal obedience to the commands of a rightful authority, or discord takes the place of harmony. And the higher and more important the work we have to do, the more necessary becomes this order, the stronger and more perfect should be the leadership, 
and the more loyal and hearty the co-operation of every member of the body, of which the leader is the head.

All our titles but describe the qualities and functions of the leaders of men. An Emperor is one who commands; a King. is the father of a people; a Duke is a leader; a Marquis is the guardian of a frontier; an Earl is a chief or leader ; a Lord is the supplier of bread; a Baron is simply a man; a Captain is. the head of the body he commands. And every body of men must have its head, and even mobs instinctively range themselves under leaders.

In all works that employ numbers, there must be plan, direction, oversight, command. This is notable in architecture and. engineering. There is the plan to work to, the master workman to direct, and careful obedience in all the details of the building, from the first foundation-stone to the last ornament.

Discussion, voting, government by majority, may have their uses somewhere-they answer as makeshifts or preparationsbut when real work is to be done, we must come back to the natural order of things. Brain and will must govern. The. minority must govern. The father must rule his family, the. captain his ship, the general-in-chief his army, without popular agitation, prolonged discussion, vote by ballot, division of theHouse, or any such cumbrous and mutinous machinery.

But how to find leaders? Happily, they are heaven-appointed -happily, in England, they are at hand, more or less trained. for their work, and all ready to enter upon it, if they will but accept their mission. Here is the use of an aristocracy. Every country has one of some sort-an aristocracy of genius, of position, of wealth; but in no country is there an aristocracy so rich, so cultivated, so powerful, so honoured and trusted, and, I believe, on the whole, so worthy of trust and honour, as in this country.

Of course, as an obscure stranger, I can have had but little opportunity for personal knowledge of the English aristocracy 


\section{Human Physiology.}

but I can read, and see, and hear. The honours paid to rank are evident, and must have some reasonable foundation. Centuries of training have given hereditary qualities which fit men for leadership. Truth, honour, heroism, must become habitual. Noblesse oblige. If a man of noble birth is false, unjust, niggardly, avaricious, tyrannical, he is considered a disgrace to his order, which proves that his order, as a rule, is distinguished for noble qualities. An ancient family and an honourable name are elements of great power; add the immense wealth of many members of the aristocracy, titled and untitled, and we have just such leaders of a social reformation as we require. They have only to see the work to be done, and the way to do it. Each one upon his own domain could organise a model society. Titles could remain undisturbed, and settlements be readily adapted to new conditions. If it were a man-of-war to command, every man would fall into his place and do his duty; if it were a military corps, there would be no trouble about order and discipline. Well, it is something better than either, more varied, more beautiful, more beneficent. It is a hundred families to make comfortable and happy; neat cottages to build, nice gardens to lay out and cultivate, children to educate, and young men and women to employ according to their abilities, drunkards to reform, idlers to set to work, the produce of the land to multiply, the social virtues to cultivate, and to take the lead in all the recreations and amusements suited to such a population.

Something like this has been done by two or three great manufacturers; but only to a small extent, and in an imperfect manner compared with what the same power, with more intel. ligence, might have accomplished. A manufacturer in the north of Ireland owns a village of some five thousand inhabi. tants, in which there is not one public-house, not one drunkard, nor pawnbroker, nor lawyer, and very little to employ doctor or policeman. The children are all at school; the people are 
all industrious and well-to-do; immorality is scarcely known; there is but little sickness, and the death-rate-and in a manufacturing town-is only eleven in a thousand! All this has been done by one man $-\mathrm{a}$ man of moderate ability and fortune, but with a conscience. Sir Titus Salt has built a handsome town, with good sanitary conditions, educational institutions, library, reading room, and many advantages not commonly enjoyed by manufacturing populations; and he enjoys the gratitude of the inhabitants of Saltaire. What is there to hinder every nobleman, every landed proprietor, every great capitalist in England doing what a man of justice and judgment ought to do for those from whose labour he derives his wealth? These men want what money alone cannot purchase-the honour of their fellow-men and their own esteem; and neither are to be had by a man wearing purple and fine linen, and faring sumptuously every day, while his fellow-men around him are living miserable lives, or wretchedly ending them by his neglect. I know that day by day more is being done. There are noblemen who visit the poor in their cottages, nurse them when sick, carry them in their arms. They are very good; but there is much more to be done-a deeper and more thorough work. What we want of the aristocracy of England is that they place themselves at the head of a social reformation which shall make her people solidly intelligent, thoroughly good, sober, honest, industrious, prosperous, with a diffused and general prosperity and security, and with all the refinement and culture possible to such a population. If a few were to set the example, others would follow it. When one model parish, model estate, model village is organised, a thousand will follow the good example, and all England will rapidly crystallise into a higher social, and thence a higher political condition. And England is a central nation, whose literature instructs, and whose example will be followed by, the whole English-speaking world. 


\section{Human Physiology.}

\section{CHAPTER IV.}

ECONOMIES OF A TRUE SOCIETY.

The Waste of Life-A Nation of Shopkeepers-The Robbery of IdlenessCo-Operation and Trade Reform-The True System of Trade-False Ideas of Gentility-Examples of True Dignily and Nobility-The Frauds of Labour-General Distrust and Social War-Higher Aspirations-Economy of Honesty-Efforts at Reform-Mr. Roebuck on Working-men.

Is any scheme of social organisation, economy of means, and the diminution of waste, which is the friction of social machinery, are among the first things to be considered. The production of wealth is perhaps'sufficient now, if it were well distributed, yet that production may probably be doubled, perhaps quadrupled, by improved culture and machinery in the future; but that is no reason for waste. All waste of time, energy, and wealth, is morally wrong. We have no right to spend our strength for naught, nor to give what we gain by our strength without equivalent. Time is money-money is foodfood is life. To waste life is to shorten life. It is suicidal. Therefore, in every social reform, we must study economies.

I have written elsewhere of needless food, drink, stimulants, intoxicants. These make half the cost of living. One wellarranged kitchen, with a competent head cook and four or five assistants, would save nineteen-twentieths of the fuel and labour expended in the culinary service of a hundred families. Every house could be warmed at half the present cost, and large edifices and towns with about one-tenth the coal and labour now used. These are very important items. The co-operative associations have shown that provisions and clothing can be bought at wholesale prices, and that the cost of distributirg 
commodities may be very largely reduced. Here is a double saving.

England has a vast army of shopkeepers, who have to be supported in what is equivalent to idleness-that is, useless labour, by a heavy tax levied on the whole community in the form of large profits and scandalous adulterations. A village of five thousand inhabitants has eight groceries, six drapers' shops, four shoe-dealers, three druggists, three ironmongers, three bakers, and so on with the whole variety of trades, and a corresponding number of assistants to pay and families to support. The cost to the community in profits ranges from ten to three hundred per cent. It is evident that this entire work could be done, in a well-arranged establishment, by one-tenth of the number now employed, and at one-twentieth of the cost, with better articles and a freedom from fraud and adulteration.

But this is only half the saving. Every person relieved from this needless business of petty trade would be free tc become a producer of something useful, and so enrich the community. Every man paid to be idle or uselessly employed, is a double loss; first, in what he is paid for doing nothing; secondly, in what we should gain if he did something. Knock a man on the head, and society loses what it might gain by his labour; pay him to be idle, and you lose what you pay and he consumes in addition. We lose the producing value of our soldiers and policemen, and we feed and clothe them besides. Each idle man, rich or poor, robs the community of the labour of all who supply his real or fancied needs. The rich man who keeps twenty servants, robs the public of the productive labour of twenty persons, and also of the labour of those who feed and clothe them. $\mathrm{He}$ and they render no equivalent. They are fed, clothed, sheltered, transported from place to place, and in every way provided for by the labour of the industrious; and every superfluous shopkeeper is in the same 
category. He lives upon the public, who are taxed in needless profits, and often by all the frauds of commerce, for his support.

Co-operation, merely in the purchase of goods by those who charge a profit to outsiders for their own benefit, is not a very important social reform, and is useful chiefly in showing that there may be a better system. But the whole system of trade and commerce needs a radical reform. It is immoral in principle, and demoralising in practice. There is no equity in buying cheap and selling dear. A thing is worth what it costs to produce it-worth its equivalent. There is a true value, a proper price for every article one can buy or sell. To take more, or to give less, is theft. If I sell an article for a penny more than its equitable value, I steal a penny. And trade is accounted dishonourable, and tradesmen are not considered gentlemen, simply and only because trade is dishonest, and therefore dishonourable. The highest noble in the land may exchange anything he has for its fair equivalent, but the moment he takes more he does a mean, dishonest, and disgraceful action, which is as bad as cheating at cards or picking a pocket. Commerce will be considered honourable when it is so; and it ought not to be a day before. In a reformed society all this would be changed. All exchanges of commodities should be managed by competent agents, and upon the rigid principles of justice and equity.

In a true system of trade, every article produced should be registered at the actual cost of its production, and the standard price should cover a fair average. Articles could then be exchanged, value for value, cost for cost, including, of course, transport, storage, etc. Profit, the speculating, gambling gains of trade, where ignorance or necessity are taken advantage of by unscrupulous greed, should be-banished from all decent society. It is a question of economy as well as justice. Proudhon said, "Property is theft." It is very true that much 
property is accumulated by means as dishonourable as most kinds of stealing.

As society is now constituted, we go on robbing and being robbed, with more or less wear and tear of conscience, because we see no other way. With society constituted as it really might be, instead of the truck shop, and tally shop, and credit shop getting working men in their power and stripping them of their earnings, every large employer of labour might easily arrange to have all his workmen supplied with everything they need of the best quality and the lowest price, which would be equivalent to a large advance of wages. And when a system of exchanges is fully organised, we shall have free trade in its reality-the exchange of all sommodities, labour for labour, at equitable prices, to be fixed by mutual agreement, neither party taking the slightest advantage of the other.

To the saving of useless labour, or the idle lives of shopkeepers, waiting, as Fourier said, like so many spiders in their holes for flies to come to the glittering webs spread out to catch them, we must add the utter abandonment of the idleless of fashion or gentility. It is the disgrace of England that honest work is considered disreputable. A lady or a gentleman will not be seen carrying a package in the street. The shopman must send it home. Thus every idler enforces useless labour. And the less assured the position of persons, the more scrupulous they are not to soil their fingers with any ungenteel employment. A nobleman will carry a basket or wheel a barrow if he likes-it will not compromise his dignity; but a clerk or a governess will not touch a paper parcel, for fear they should be mistaken for menials. 'There are thousands of ablebodied men and women living in wretched "genteel" dependence, who, but for this absurd notion of the disgrace of work, or ungentility of industry, might be useful members of society, contributing their share to supply the common needs of humanity It is time that men and women of rank and dignity 


\section{Human Physiology.}

should set an example to those who are trying to ape their idleness, and show them that no work is undignified if it be useful. I am not anxious to see noblemen engage in commerce until commerce becomes honest, and thereby noble; but I would gladly see men, who now exercise their stalwart limbs in rowing, shooting, hunting, and all the arduous and useless labours of sport, turn their energies of mind and body to something which would benefit their fellow-men. In America, in all the best days of the Republic, useful labour has been honourable, as it was in the first centuries of ancient Rome, and men were called from the plough-tail or work-bench to be governors of states. In England, there will be no true work until men and women of the highest rank are ready to engage in it, and set a good example to those who are so ready to imitate their follies and their vices. In an army, wherever the officers will go, their men will follow. It will be the same in the fields of industry.

And how any one, nobleman or gentleman, can think it noble or gentle to take money he has never earned-for which he has rendered no equivalent-out of the labour and taxes of the poor, who are in so many cases suffering for the necessaries of life, is a matter of profound astonishment. Surely the time must come, even in this world when justice will be done, and it will be rendered to every man accurding to his works. And when "the nobility and gentry" take their proper place as active leaders in all useful work; when honourable men and women make all avocations honourable, labour will become honest as well as trade. How far it is now from being honest, every person of any experience knows.

The frauds of labour, and of many kinds of manufactures, are as disgraceful as the speculations of commerce. We are cheated in materials, cheated in time, cheated in work. Does not the householder who sends for a plumber, or carpenter, or mason to do repairs, feel the dread of robbery--not the plunder 
of his household goods, but of equally dishonest practices? And the annoyance of such things, the helpless indignation they excite, the distrust; contempt, and hatred, are worse a thousand times than the money loss. And these feelings of distrust, contempt, and hatred, which come to "malice and all uncharitableness," become mutual, and extend to all classes of society, until all sympathy is lost, and all feeling of human brotherhood is destroyed. Employers and employed, traders and their customers, masters and mistresses and their servants, are at war with each other. It is a war of mutual distrust, which grows to mutual hate. Employers are hard, grinding, and greedy. Workmen and servants are sullen, cheating, faithless. The rich live upon the labour of the poor; the poor lose no opportunity to retaliate upon the rich.

And all this is the natural tendency of our social system; and what we find of honesty, truth, fidelity, honour, charity, and Christianity, comes from the actual superiority of human nature to its demoralising conditions. It is the struggle for a purer and higher life. Every man, however demoralised he may be by the customs of society, however entangled in this network of evils, has the ideal of a nobler life, and longs for its reality. What men have the idea of, and the aspiration for, can surely be accomplished. In all this, "attractions are proportional to destinies."

When labour and trade are alike honestly conducted, and justice and fidelity enter into all the relations of life; when idleness and uselessness become as socially disreputable as they are wrong; when all things are well made, because all work is well done, solidly, thoroughly, and upon honour, the saving of labour, care, trouble, loss, and waste will be immense; and the production of all the necessaries and useful ornaments of our life, the good and the beautiful, will proportionally increase. The social burthens, once well adjusted, will scarcely be felt as burthensome-the enjoyments of life, once equitably shared 
and universally participated, will have a double value. We shall all enjoy, in the peace of a good conscience, even the luxuries of life, when we know that we thereby deprive no one of its necessaries, or of any comfort or happiness.

I appeal in this matter to the common sense of every reader - to his judgment and his heart. As a rule, all men wish to be honest, upright, friendly, and faithful to each other. They admire such qualities; they wish to live in the constant enjoyment of all that constitutes good-fellowship. They feel themselves to be the victims of false and oppressive social relations and conditions. Hence all efforts at reform, political and social; hence the vast associations for mutual help; hence such philanthropic societies as those which can assemble from fifty to eighty-five thousand people in orderly annual holidays at the Crystal Palace. Mr. Roebuck, in an address at the opening of a club for tradesmen and clerks at Sheffield, expressed the common sentiment of intelligent and right-feeling men, when he said, "he wanted to see the working man an educated man, bold and upright, fronting every danger and difficulty that came in his path, and at the same time gentle and courteous, holding out a brotherly fellowship to every one. He wished to see the working man make himself part of this great country, and not an antagonist portion of it. What was there in the career of the working man, or small shopkeeper, that should render it impossible that they should sit down to a genteel dinner? What he hoped would come to pass at no very distant day, was, that the working man should be in his dealings, in his demeanour, and in every order of life, a gentleman."

Is it too much to hope for, to labour for, and to expect, that in a country of universal education, and the means of boundless wealth, every working man may sit down every day to what Mr Roebuck calls a genteel dinner? He once described the working man of his black country district as "a man who caressed his dog, cursed his wife, and kicked his children." 
Still I see no natural reason why he may not under a better influence become, "in his dealings, demeanour, and in every order of life, a gentleman."

\section{CHAPTER V.}

\section{SOCIAL THEORIES.}

Social Systems of Moses, Plato, the Early Christians-Communism of: the Religious Orders-Shakers, Rappists, Mormons-Owen, Cabet, Warren-Fourierism-The Phalanstery-Adaptation to English Life -Rural Associations-Social Organisation in Towns-Economics and Advantages-Working Men's Clubs-Suburban Societies.

THE question of the social organisation most conducive to the culture, growth, welfare, and happiness of humanity, has occupied the thoughts of the foremost men of all countries and ages. The system of the occupation of land established by Moses is worthy of the study of every political economist. 'The government was a pure theocracy-judges were of Divine appointment-the lands were equitably distributed to every tribe and. family, from which they could not be alienated. Plato imagined. a commonwealth founded upon the thorough education and. perfect morality of all its members. The early Christian Church was a communism of worldly goods. All property was thrown into the common'stock-laid at the feet of the apostles, who themselves worked with their hands and made the rule- "If a man will not work, neither shall he eat." To the common fund every one contributed according to his ability, and from it received according to his need. The Religious Orders of the Roman Catholic Church, some of which have lasted for several centuries, are all based upon the same. 
principle. There is individual poverty, or the renunciation of private property, and perfect obedience to the rule of the order, and the superiors who administer the rule. In the Middle Ages most of the Religious Orders had an industrial character, as a few still have. The monks felled forests, drained marshes, made roads, built bridges, founded schools, colleges, and universities, built churches and cathedrals, and were the vanguard of civilisation. Religious orders are still among the foremost in many countries in works of education and charity.

And it is a curious fact, which the social reformer will do well to consider, that the experiments of our own time in social organisation which have had most success, have been governed by the religious element. For example, the Shaker societies in America have been perfectly successful as industrial associations. They are all rich, moral, industrious, and religious in their own strange fashion; with well-cultivated domains, plain comfortable dwellings, flocks and herds, and admirable manufactures. They live in celibacy, adopt children, taking them by scores from workhouses, and live in a simple communism, without the natural enjoyments of marriage and paternity, and with a pious renunciation of the pleasures of taste, art, and all amusements, except the singing and dancing which enter into their religious exercises.

The Rappites in America are also religious communists, but married, and having families. They have large villages, and great farms, with all property in common, and form prosperous communities, with every appearance of material success.

The Mormons have grown, during the lifetime of many of them, to a population of 100,000 ; in spite of, perhaps in consequence of, violent persecutions, by which they were driven from Ohio, Missouri, and Illinois, and finally across the American continent to the great valley of Utah, where they founded a city, government, and religion, and have become a large and prosperous community. The Shakers prosper, and even increase 
in numbers, without marriage; and the Rappites, with the usual monogamic marriage. The Mormons have had a still more striking success with the Oriental, Jewish, and Mahommedan institution of polygamy-every Mormon being obliged, as a religious duty, to marry as many wives, and raise up as many children for the Lord as he can support. In these three typical cases religion appears to be the central, controlling, vivifying element; Anne Lee, Rapp, Joseph Smith, and his successor Brigham Young, widely differing in faith and practice, have yet all appealed to the religious sentiment in man, and have all had a certain measure of success. The social experiments in which this element has been neglected have, so far as I am aware, been unsuccessful.

The most important of these in recent times have been the communistic experiments of Owen and Cabet, and some attempts to found industrial associations according to the theories of the grandest of modern social philosophers, Charles Fourier. Robert Owen, after some success in educating and making comfortable a manufacturing village in Scotland, founded an agricultural community at New Harmony, Indiana. They had plenty of fertile land, sufficient capital, many earnest and clever men and women; but no efficient government. Holding all things in common, they adopted the democratic principle of government by majority, and while they debated on the best methods of agriculture, the fields were unploughed, and the corn unplanted. Discord brought famine, and the community was scattered. Josiah Warren, one of the New Harmony communists, zealously laboured to introduce two principles of social organisation, or disorganisation-one political and moral, the other politico-economical. The first was "The Sovereignty of the Individual, to be maintained at his own cost;" the second, "Cost the Limit of Price." The first taught the absolute freedom of every individual to do as he liked, so long as the effect or consequence of his action rested 


\section{Human Physiology.}

with himself, or did not injure another. But as every act of one's life which has any effect does concern others for good or ill, Mr Warren's liberty goes no further than that of the most rigid of moralists. It is only the right to do right. His commercial maxim is of more importance. In all trade, or exchange of commodities, he contended that the price of every article was to be fixed, not by any urgency or slackness of demand, nor by competition of anxious dealers or combinations to raise prices, but by the actual cost-that is, the time, labour, and kind of labour used to produce it; reckoning in also the actual cost of distribution. Profit, he held, was robbery. The equitable price of everything was what it cost to make and sell it; and the merchant or retail trader should be paid a fair price for his time and work, and no more. In this way labour is exchanged for labour, and none can get rich. at the expense of their neighbours.

The social system of Fourier is elaborate and magnificent. I take the liberty to transfer to these pages a very brief sketch of it written by me for Chambers's Encyclopadia:-

"Fourierism, the social system invented by Charles Fourier, is contained in his published works, in a large collection of unpublished MSS., and in the writings of Considerant, Lechevallier, Brisbane, and others of his disciples. It differs materially from the systems of Communism strictly so called, and all. other social theories, and professes to be based upon natural laws, and capable of being carried out on mathematical prin. ciples, as fixed and certain as those of geometry, music, or colnurs. The earth and human society, Fourier taught, are in their crude and infantile stage. The period of the race will be 80,000 years, the latter portion of which will be its declining. phase, as the present is its ascending. The middle term will be a long period of maturity, prosperity, and happiness. What we call civilisation, Fourier considers a false and imperfect condition, with poverty, crime, ignorance, idleness, repugnant. 
toil, disease, wasting wars, general antagonism, oppression, and misery. He believed that association would produce general riches, honesty, attractive and varied industry, health, peace, and universal happiness. Considering attractions and repulsions the governing forces of all nature, and that God has distributed them for the happiness of all his creatures, he held that 'attractions are proportional to destinies,' or that the desires or passions of men, their aptitudes and inclinations, if they could have free scope, would infallibly produce the highest condition and greatest happiness of which they are capable. He believed in a universal harmony, flowing from and centering in God, the author of all harmonies, and that there is therefore a principle of 'universal analogy.' Seeing that all things, from suns and planets to atoms, range themselves in groups and series, according to certain fixed laws of attraction and repulsion, he laboured to discover the kind of human society that must eventually form itself in obedience to those laws. This is the association or phalanstery, which is to consist of 400 families or 1800 persons, which number he found included the whole circle of human capacities. These should live in one immense edifice, in the centre of a large and highly cultivated domain, and furnished with workshops, studios, and all the appliances of industry and art, as well as all the sources of amusement and pleasure. When the earth is covered with palaces of attractive industry, the associations will also unite in groups and series, under a unitary government. There will be but one language and one government, and the conly armies will be the great industrial armies, which will drain swamps, irrigate deserts, plant forests, and effect the amelioration of climates. The system of Fourier does not propose to destroy, but rather to conserve property, position, and hereditary rights, nor does it war directly with morals or religion. The property of the association is to be held in shares, and the whole product of the industrial and artistic groups is to be divided into 


\section{Human Physiology.}

twelve parts, of which five parts are due to labour, four to capital, and three to talent. The apartments are to be of various prices, and the styles of living to vary in luxury and cost; but the poorest person in the association is not only to be secure of comfort, but his minimum of enjoyments will be greater than the present social arrangements can give to princes and millionaires; while these will have opened to them pleasures of which they can now scarcely have a conception. The economies of the large scale in the phalanstery reduce by two-thirds the expenses of living, while an attractive and scientific industry would quadruple the products of civilisation.

"The passions of the human soul to which the system of Fourier would give full scope, he described as the five sensitive - sight, hearing, taste, smell, touch ; four affective-friendship, love, ambition, and paternity; three distributive-the emulative, alternating, and composite. In these he found the springs of industry and true society. Emulation, the desire of success, honours, rewards, is the great stimulant to exertion; alternation of employments makes work a recreation; and the composite passion requires combinations of charm and enjoyments which only association can give."

It is probable that some modification of this system would be found best adapted to the character, habits, and conditions of the English people. Every great estate is a domain ready prepared for such an association. The castles and noble mansions scattered over the country, such as some noblemen own by dozens, and keep up in useless grandeur, need but a little expansion and adaptation to make them suitable phalansteries. In the organisation of an association, the domain and buildings would go in as so many shares of the stock; every tenant farmer could put in his capital, stock, and tools; and those who could give nothing else, would contribute their labour as now. First of all, every one would have shelter, clothing, food, the minimum of a comfortable subsistence, in the best conditions 
for health, and a reasonable enjoyment of life. The proceeds of industry would then be divided according to labour, skill, and capital invested, upon the most equitable system that could be devised; and with the economies of the large scale, the zeal, enthusiasm, and energy of combined labour - the employment of labour-saving machinery and scientific methods of agriculture, expenditure would be so diminished and production so increased, that while the reward of the simple labourer would be doubled or trebled, the general increase of wealth would be far greater than it can be with our present modes of industry and expenditure.

And every such association would have its educational, artistic, and social advantages, beyond what we can imagine. There would be occupation for every talent; gratification for every taste. Music, painting, the drama, and eloquence would be cultivated, and not only would individual compete with individual, but group with group, phalanx with phalanx. Every association would of course have its library, reading-room, theatre and concert-room, outdoor and indoor amusements and recreations; and the constant interchange of visits, especially of the most accomplished artists of different associations, would be an endless source of interest and improvement.

If one such association were formed as carefully as it ought for a trial so important, and under such leadership as could be desired, and should succeed as every one can see that it ought to succeed, similar associations would be rapidly formed until the whole country crystallised into a new and beautiful social order, with but little injury to any existing interest, and with great advantage to every class of society.

The social organisation of towns has its own difficulties, being much less natural in its character than that of agricultural districts. As the land produces the greater part of our food and clothing, and may produce all the necessaries of life, while its cultivation is a labour of love-a healthful, varied, interest- 
ing, and beautiful occupation, with work adapted to both sexes, and all ages, and all kinds of talent and skill, in farms, gardens, horticulture, the care of cattle, sheep, fowls, bees, the dairy, preservation of fruits, etc.-people would find great attraction and pleasure in such associations. But our towns are very ugly, very monotonous, and it is probable that large portions of them will be abandoned and swept away. Those which are not will have to be rebuilt; for the present dwellings of a large portion of the population are a disgrace not only to civilisation, but to humanity. Twenty square miles of London need to be newly laid out, and entirely rebuilt.

An architect of genius could contrive edifices which would give an industrial society, composed of its various groups, such dwellings as would give them every sanitary condition and domestic and social convenience-seclusion and society-the comfort of each, and the convenience of all ; pleasant suites of rooms, light and airy corridors, great dining halls, and rooms for recreation; nurseries and schoolrooms for the children; light, airy, and pleasant work-rooms-all the external requirements for a cheerful and delightful existence. Noisy occupations should be in places apart, and motive power could be supplied by each association.

One person could buy every article required, and save the time of a hundred visits to shops and markets, with an immense economy in cost. One cook, with a few assistants, could prepare the daily meals-varied, abundant, healthful, and delicious-of a hundred families. One head-laundress and her group, with steam and machinery, could do all the washing. One head-nurse could superintend the care of all the younger children; while the older would be three hours a-day in school, and five or six at work, which, if performed in pleasant groups, and varied from hour to hour, would be as good as play, leaving ample time for the sports and amusements of childhood. Some children would, from pure attraction, help and thereby 
learn to work in kitchen, laundry, nursery, in the group of cleanliness, waiting on the tables, and all the processes of an orderly and beautiful life.

Assuredly such a thing is possible. One man of head and heart and means could begin it, picking his families carefully, as one should for a first essay. And what a change from the ugly, grimy, monotonous, sad life of the London artisan it would be-from the narrow streets, stifling courts, and wretched dwellings of the poor-from the drunken public-house, and dirty little shops-from the children playing in the gutters and educated in the slums-from the vice and wretchedness, the crime and misery among which so many intelligent and skilful workmen are compelled to pass their lives and bring up their families. Instead of all this they might have, at a less cost, and for less painful labour, spacious and healthy dwellings on wide streets, enclosing beautiful gardens, neat and comfortable clothing, well-prepared meals, with good library and readingroom, pleasant recreations, and enlivening social enjoyments.

Working men's clubs are a move in the right direction, but they leave out the working men's sweethearts, wives, and children. They separate men from their families, and all the charm and benefit of female society. If they provide workmen with something better than the dram-shop, still they desolate the home. All clubs are partial and imperfect; the full realisation is to be found in a social organisation which shall include both sexes, all ages, widely varying talents and capacities, and unite industry, art, and society.

In the reorganisation of large towns, or centres of industry and art, politics and literature, commerce and finance, it is probable that very beautiful social organisations would be formed in their suburban districts. One can imagine the lovely heights in the neighbourhood of London-Hampstead, Highgate, the Surrey Hills, Surbiton, Richmond, crowned with the palaces, clustered villas, and cottages, and gardens of such 
associations in which very moderate salaries would yield frincely accommodations. The whole region-would be one beautiful garden, but productive as well as beautiful; filled with fruit trees, vines, and fruit-bearing shrubs. There is no need that ground should be useless to be ornamental. What can be lovelier than a country filled with pear, apple, cherry, and plum trees in blossom or fruit, filling the whole atmosphere with their delicious fragrance. Belts of evergreens here and there should screen them from the cold blasts of the north. Nutbearing trees are among the finest for beauty and shelter. Light open palings should take the place of our high ugly walls, which destroy all beauty of prospect; but with a proper social organisation, few fences of any kind would be required.

The soil, enriched by the matter now wasted as noxious gases in the atmosphere or filth poured into the rivers and sea, would become more and more fertile, and, with the regulation of heat and electricity, double and quadruple its productiveness. Domestic cares and labours would be so diminished by combined labour, or what an American lady has called "co-operative housekeeping," that great numbers of ladies and children would become skilful gardeners, competing with each other in producing the finest fruits and flowers, not to send to market, but to ornament every table and furnish an important portion of every repast.

Croquet if you please; but I can fancy pretty hoes and rakes, watering engines, and other gardening tools, employed by groups of horticulturists, vine-dressers, and florists, quite as interesting. Bands might play, and fountains leap and splash; and life be filled at once with all uses and all delights. We have yet to learn the interest, dignity, and happiness of really useful labour.

In the variety of tastes and capacities in every large society, there would be found persons who, from natural inclination, the 
bent of genius, or pure attraction, would engage in every necessary occupation; even in those which many consider the most repulsive. Is it not evident that men are born scavengers, when we see how eagerly they discuss the sewage question? Look at the list of cookery books-treatises on gastronomy, at all prices. What curious inventions of washing and wringing machines, churns, and cheese presses, apple and potato parers, cherry. stoners, egg beaters, knife cleaners, and the like! A few clever men and women would find their true vocations, and therefore their highest happiness in doing, with the aid of machinery, all the cooking, laundry work, and what is called the house-keeping of a large society, and with wonderful economies of time and cost. The clothing, tailoring, dressmaking, and millinery would enlist the best artistic taste and skill, and the invention and making of beautiful, graceful, and becoming costumes would become a passion. There would be no following of stupid, absurd, and unbecoming fashions. Dress would express character, and be adapted to age and employment. Every man, woman, and child would wear the most healthful, convenient, agreeable, and characteristic costumes. Dress. would be a language, an art, an expression of the true life; and no longer a tasteless conformity or monstrous absurdity.

And many of the fashions of our daily life would be abolished or delightfully changed. Where people were constantly meeting each other in work or recreation, they would not go about leaving cards and making formal insipid calls. With much interest and variety in daily life people would no longer give or attend the formal parties, so troublesome, tiresome, expensive, and unsatisfactory. People would be drawn to each other by pure attraction and congeniality; they would be repelled by any unsuitedness to each other; and, equally free to approach to or recede from each other, all associations would be natural, spontaneous, and therefore useful and happy. In the world as it is, vast numbers pine in utter loneliness, when there are all 
around them those who need their society, and with whom they could be happy; and, on the other hand, many are wearied and disgusted with what is called "society." There is no solitude like that of a crowd in which we have no acquaintanceor a crowd of acquaintances in which we find no true companionship. When all the physical wants of humanity are satisfied, there will still be abundant scope for all kindness, benevolence, and the purest love of charity in satisfying the higher, and ever expanding wants of the soul.

Whenever people are brought into nearer relations and closer contact with each other, their manners become of more importance, if possible, than their morals, since a man may be very honest and well disposed, yet very disagreeable. To associate with others, people must be neat and cleanly, must have no repulsive and disgusting habits, and be kind, civil, obliging, and courteous in their behaviour to each other. Crabbed, snarling, complaining, rude, disputatious people are nuisances in any society. The essence of politeness is unselfishness-a regard for the welfare and pleasure of others. It is the union of good taste, tact, delicacy, a nice adaptation, and active benevolence; free from fussiness, officiousness, obtrusiveness, and ostentation. The politeness of manner which flows from or is largely tinged with vanity centres in selfishness. It is a desire that others shall be pleased with us. The higher kind comes from benevolence, and is a pure desire to please and benefit others.

The bad manners of great numbers of people show the need of more intimate associations rather than the opposite. They are to be civilised-to be taught how to behave, as well as how to live. Contact with gentle and refined people is the very thing they need. Their first impulse would be to "clean themselves," make themselves decent, and put themselves on their nicest behaviour. People tend to be what you take them to be. They readily conform to the manners of those about them. They naturally imitate those whom they recognise as 
their superiors. The presence of a lady is often enough to change the manners of a whole assemblage.

The English people might undoubtedly be brought by precept and example to behave as well as French people of a corres. ponding class; and these, the poorest working population of Paris, are neat in their dress, civil, respectful, and polite in manner, careful of the rights of others, never elbowing, never crowding, asserting their own dignity, and never encroaching upon others. At the entrances of French theatres no one is ever crowded. The people take their places behind each other and wait their turns for hours. I saw thousands of the people of Paris, near the close of the siege, their faces white with hunger, standing patiently in long lines, each quietly waiting his turn to be helped. An English crowd is generally disagreeable and dangerous from selfish impatience, and disregard for the rights of others. Sometimes their bad manners become murderous, as when all are intruding, pressing upon, and personally assaulting each other, and some are thrown down and trampled to death.

The remedy for all this is a sense of justice, a constant, habitual regard for the rights of others, and the discipline and habit of attention to the welfare, the convenience, and happiness of those around us, and all with whom we come into contact or proximity. Children from their earliest years should be trained to an unselfish consideration for the pleasure of others; and taught the delight of doing good. In all schools, civil, deferent, polite, conciliating, and obliging manners should be as carefully taught as the rudiments of learning. Manners really influence the character. Our thoughts and feelings are moulded by our actions. We make acts of virtue, until they become habitual and spontaneous, just as by placing ourselves in the attitude and using the forms of devotion, the feeling is awakened.

And the influence and example of a few persons will speedily 


\section{Human Physiology.}

mould and train a whole community to good manners, and then to good morals, just as bad influences and examples produce the opposite effect. If "evil communications corrupt good manners," it is no less sure that associations with pure, true, refined, and heroic persons tend to the development of purity, truth, refinement, and heroism. The influence of a sovereign, a court, an aristocracy for good or evil, upon the manners and morals of a whole community is well known; and every one is an educator of others, in proportion to his position, force of character, and nearness of association with them. Robinson Crusoe should be a gentleman for his own sake. Every one, however isolated, should be able to respect himself, and should treat himself with civility and politeness. And the bare possibility that there may be invisible intelligences around us, seeing us and reading our thoughts, should be a motive to good conduct. But when we live in society, and our conversation and actions must produce some effect upon all who see and hear us-all who come into the sphere of our personality, thought, and life-our responsibility becomes evident. No man can ask: "Am I my brother's keeper?" "We are all members, one of another."

\section{CHAPTER VI.}

\section{DIFFICULTIES OF SOCIAL ORGANISATION.}

The Difficulty of Caste-What should determine Social Position-Moral Influences of Association-Habit and Education-Feminine Helplessness-The Difficulty of Bad Manners-Masculine Professions-The Religious Difficulty.

THE difficulties in the way of any new social order must be fair $\_$considered, and some of them are very great. The first 
that will present itself to many persons is the difficulty of caste. Everywhere in England we find first, second, and third class. They stand wide apart-farther in England than in any country in the world. Nowhere is there such pride of rank and riches, such exclusivism, such inhumanity. The noble and the wealthy - those we call the gentry-may be kind, gracious, affable, condescending; but affability and 'condescension are in themselves the assertion of a rigid caste distinction. The members of the different social ranks cannot sit together, eat together, be educated together, nor even confess themselves miserable sinners together. The children of the three social grades seldom intermingle. A boarding school for the daughters of the nobility and gentry cannot receive the most beautiful, the most talented, the most lovely and accomplished daughters of a wealthy and respectable tradesman; and no more can the daughter of an artisan hope to be educated with the young ladies of the grade above her. The lady who marries even a man of genius born in a lower rank than her own seldom recovers her social position. And if people mingled together in such societies as philosophers and philanthropists have imagined, such mesalliances might be of constant occurrence.

What is to be done? So far as caste is artificial, unjust, and inhuman, and stands in the way of human progress and happiness, it ought to be abandoned. So far as it is natural, right, and in accordance with the best interests and feelings of our nature, it ought to be retained. Intimate personal assóciations should be governed by fitness and attraction, and by no other rule. In an association there can be no poverty, as we see it now, with its wants and vices. The minimum will suffice for every want; and rank, where people become truly known to each other, will depend far more upon personal qualities than the advantage of birth, or the accident of position. Even now genius and moral worth go far to make men noble. Dickens; once a poor boy in a blacking factory, was buried in Westmin- 


\section{Human Physiology.}

ster Abbey; and Nilsson, a few years ago a peasant girl, fiddling and singing for pennies at country fairs, was married there in an assemblage of the best society in England. Not a few of the recognised great men and women of England have come up from the middle and lower ranks of life. In the society of the future, it will be what you are, rather than who you are, that will determine social position. Even now a Premier commoner makes Lords temporal and Lords spiritual. A "literary adventurer," if a man of genius, may govern an empire-appoint one man Viceroy in Ireland, another in Canada, and a third in India; create a Duke, and then describe him in his next novel. And the time is at hand when, even more than now, the character and genius, or the real worth of a man or woman, will make their position in every society. In a true society, every individual will find his proper place, and have the consideration which really belongs to him; and this is one of the chief reasons why we should labour for the establishment of a true society, and of a public opinion which will sweep away social injustice, and judge every one according to his works, which is the only righteous judgment.

If the feeling and habit of caste can be overcome, we have another objection to meet-the thought or the dread that the freedom of social intercourse, such as would exist in an association of combined industry, and education, and art-in such a social state as might be-would lead to immorality. And those who make this objection may know something of the actual morals of fast young men and girls of the period-they may go to the French plays, and read some fashionable novels, and glance at the reports of the court for matrimonial causes. Are there no scandals in high life? Are the London streets all purity and propriety? Are the pretty villas of the garden suburbs of the metropolis tenanted by chaste demoiselles? Are there no seductions, adulteries, infanticides?

As far as there can be guarantees for moral conduct, they 
would be found in a large and varied society, where would be far greater opportunities than now exist for finding congenial partners in marriage; occupation for all the faculties; the interests of friendship and ambition; watchful oversight, and wise guardianship and counsel; with a thousand inducements towards pure and honourable conduct, and fewer temptations to immorality and profligacy. People who are busy, active, interested, full of employment, and full of enjoyment, are not the ones who "go to the bad." They behave best when fully and happily employed. It is idleness and ennui that tempt to dissipation and vice. The happy do not get drunk; the prosperous need not steal; the active and ambitious, full of occupation, and surrounded by friendly appreciation, do not plot villanies or perpetrate outrages. And in such a society as might be, all would be able to marry who wished to do so; no one would be obliged to marry for money or a support; and no poor girl could be tempted by sheer necessity to sell herself to a life of shame. Seduction by fraud, or the promise of marriage, would cause the instant banishment of the seducer; and every flagrant violation of honesty or morality would meet with a like punishment. Educated in such a social state, women would be stronger, more self-reliant, and far less than now the victims of the selfishness and vices of men.

I think it will be seen at once that such an association would be the best possible security against most of the vices of civilised society, while drunkenness, and bad habits of various kinds which make some people nuisances to others, a healthy public opinion would find ready means to reform.

The education, habits, occupations, and professions of men, the places in which they are fixed, and the ruts in which they move, undoubtedly present difficulties to any scheme of social reform or re-organisation. Transitions are painful; habit is a second nature; but when great evils are to be remedied and 
great objects to be gained, corresponding efforts and sacrifices must be made.

A large portion of our population is now educated for uselessness. Nearly all the women of the middle and upper ranks of life are without employment. Few of them are able to prepare food, make clothing, or attend to the ordinary duties of a household. They know little of science, and their art is limited to a superficial knowledge of a few accomplishments. The utter helplessness of great numbers of women of the upper and middle classes, if by any calamity left unprotected, is really appalling. They can do nothing useful; many would scorn to work if they knew how. Their only resources seem to be, to become governesses, for which few are well qualified, and companions-dependants upon, and parasites of, those who are able to maintain them.

Young men are educated for the church, law, medicine, army, navy, civil service, engineers, architects, and commerce; a great number have no occupation, follow no profession, and render no service to the society on whose productive industry they, and those who serve them, are a heavy burthen.

In the future there will be no place for the drones, and thefunctions of many others will become extinct. When nations have advanced a few steps farther in wisdom and equity, they will learn war no more, the sword will be turned into a ploughshare, and the only armies will be the armies of industry, which will subdue the earth, and not diminish, but increase its population. They will open up the jungles of the tropics, drain the marshes, irrigate the deserts, and war against famine and pestilence, instead of creating them. In these armies and naval expeditions there will be opportunities for the exercise of the highest talent and heroism. There will not be a solitary Livingstone lost in African deserts, but expeditions equipped with the resources of empires to carry the light of a beneficent civilisation into the darkest regions of the world. 
In the future lawyers will scarcely be needed, for all ques. tions will be decided upon the principles of equity. When commerce becomes a system of exchanges on a large scale, and easily managed; when the motives and opportunities for fraud and crime have been alike removed; when all property, and the proceeds of all industry, are equitably distributed, there can scarcely be such a thing as a distinct legal profession. And when perfect sanitary arrangements exist in every society, and good habits of living become universal, we may very nearly dispense with drugs and doctors. A very few surgeons would answer all requirements. Nearly the whole class of useless consumers would become producers; the hours of toil would be diminished; those of art, intellectual improvement, and recreation increased; and the surplus energy of the world would be directed to the subjugation of nature, and the education of the human race.

There remains, however, a really serious difficulty, and one not of an imaginary character. It is one that now exists, splitting our present society into conflicting elements, and making great trouble in all efforts at social improvement. It is the religious difficulty. How are Christians and Infidels to live together in harmony? The strongest motives which govern one class have no influence over the other. What peace can there be between Trinitarians and Unitarians, when the most solemn act of the worship of one is simple idolatry to the other? How can we form societies of Roman Catholics and Protestants - those governed by the authority of an infallible Church and Pontiff-these asserting and exercising the right of private individual judgment on every question of faith and morals? How can we hope to bring together Churchmen and Dissenters-those who believe that Christ and His apostles taught one doctrine, and those who have divided as if they believed that $\mathrm{He}$ and they taught twenty? How, to narrow the case, could we hope for harmony in a society composed of 


\section{Human Physiology.}

High Churchmen, or Ritualists, Broad Churchmen, or Liberals, and Low Churchmen, or Evangelicals-what some wit has called "the Attitudinarians, Latitudinarians, and Platitudinarians" of the Establishment?

The difficulty is very real and very great-far the greatest difficulty, I believe, in social organisation. It is existing and, active now-a serious obstacle to improvement, a source of vexation and annoyance, a perpetual conflict in every grade of society. Toleration is often but indifference-the exclusion of all religious subjects from conversation in general society is a truce and not a peace. Archbishop Manning may be willing to work with Anglicans, Unitarians, and Quakers, in some great philanthropic object, such as the suppression of drunkenness; but we cannot expect the conflicting elements of religious sectarianism to come peacefully together in industrial and social organisations.

Still, in some way, the difficulty must be met and overcome, even for peace in our actual social conditions. If the Almighty has revealed a religion to man, it is the true one and excludes all others. There cannot be two conflicting truths, not to speak of a score or a hundred. The right rejects and excludes the wrong. If there be a Church, or organic Society, holding the truth, and divinely authorised to teach it, of course there can be but one such body, and that one must be infallible, or it. might lead men into error, which would destroy its whole function as a Church with authority to settle controversies.

If such a Church could be found, and the strong and earnest injunctions of the scriptures to be of the same mind, of the same doctrine, with one Lord, one faith, one baptism, could be obeyed, then all Christians, surely, could unite in one society, and religion would be the strong bond to hold it peacefully together, and the love to purify, and ennoble, and sanctify it, and make earth what it should be-the foretaste of the blessedness of heaven. If religion be the bond that binds men 
to God, it ought to unite them to each other. There should be, at least, the desire to be right - to see and accept the truth: and always the charity that never faileth, and which is the greatest of Christian virtues.

God is one. Nature is one, because He has created-creates it, presides over it, and it is the expression of His Wisdom, Power, and Goodness. Religion is one, the relation of man to his Creator. There cannot be two contradictory revelations, or true creeds, or churches. Men born and educated in error cannot be blamed for it; to wish to be right is, in the highest sense, to be right; but we are bound to use our reason-to use our best efforts to see what is right, and heartily accept it. A man should no more persist in error in religion than in science. He should no more adhere to a false faith than to a false multiplication table, or false weights and measures. It would be a great convenience if all men had the same weights and measures, as well as the same principles of calculation, and it is more important that they should have the same religious faith, the same principles of conduct, the same bond of union to God and to each other. A considerable uniformity in modes of worship would also be a great convenience, and will become more so when the facilities for travel are increased, as they soon will be. All the people of one village should be able to worship God in one assembly, with the beauty and grandeur of such unity; and not, as now, divide up into a dozen little chapels and conventicles. There is something very grand and noble in a great cathedral with its assembled thousands of worshippers, all uniting in solemn acts of prayer and praise. It seems very clear that the world can never become Christian, until Christians are united. Hindoos and Chinese, Buddhists and Mahommedans, have the right to say: First agree among yourselves as to what you wish us to believe, and then we will listen to you.

The first thing to determine seems to be this: Has God, by 


\section{Human Physiology.}

a direct revelation, given a religion to man, or has he left him to form for himself as many as he likes? If the latter, we have only to construct one as useful and agreeable as we can devise, having first decided that some kind would be either useful or agreeable.

But if we decide that there is a religion, revealed by God, for the benefit of man, then it is our highest interest and duty to find and accept it; and that religion of necessity excludes all others. And that religion must be perfectly adapted to the nature and wants of man. It may and must be marred by human imperfections on its human side, but in itself, and as divinely given, it must be divinely pure, holy, good, and beautiful-a religion of heroism and sanctity, of the highest love to God, and the most unselfish devotion to the good of men.

And the test of a true religion must be that it satisfies the religious wants of man, as that of a true society is that it satisfies his social wants. It should appeal in the strongest way to all his higher faculties and penetrate and sanctify every portion of his life. It should consecrate the ties of family, friendship, and society; inspire the ardour of benevolence and charity; give unity to science; become the object and highest expression of art. Such a religion, such a church, such a worship, should unite the grandest and most impressive architecture, the noblest sculpture, the highest genius in painting, the sublimities of music, the charm of poetry, the moving power of eloquence, every symbol, every ceremony, every sacrament that can elevate the soul of man and unite him to God. It must be human in its means and adaptations, because it is made for and adapted to humanity. It must be divine, uniting men to each other in a common brotherhood, and restoring them to unity with God.

If all men could unite in a religion, so comprehensive, so divine as to satisfy all the wants of the soul, and give it the foretaste of perfect felicity, the work of social organisation 
would be easily and speedily accomplished. High religious motives form the lever, which, resting on the solid fulcrum of a common faith, can move the world. But with twenty fulcrums and antagonistic forces, what can we have but discordant and disorderly action!

In the divisions that unhappily exist, and which we should do all in our power to end, I see no way but for the members of each sect or denomination to form their own society. They can scarcely be separated more than they are from their fellowChristians, and there would be some advantage in the peace of unity even if they were wrong, as of course they must be, some of them, so far as they differ from each other. It would not be convenient to have the members of an otherwise harmonious association filing off every Sunday to different places of worship, with rival preachers striving to convert each other's flocks to their own modes of belief. I cannot believe in the success of any compact social organisation made up of conflicting religious elements; for the more earnest, conscientious, and zealous the people were, the greater the difficulties of such an association. Where people are indifferent-where religion is a mere matter of education and custom, or a polite conformity, it may not so much matter; but when it is a real and important element of life and motive of action, every one can see that religious differences might be very uncomfortable and very disastrous. The rule of prudence then should be one mode of faith for each association-every member giving at least, as in some schools, an outward conformity. If this were done, the sad and deplorable religious difficulty might be evaded-but every one can see how desirable it is that all such differences should be settled once and forever by the discovery of the true faith, and the true church, and their universal recognition.

I have barely glanced at what will seem to many the most formidable difficulties in the way of such a social reform as is in evident preparation-the depravity of man, and the igno- 
rance, uncouth manners, brutal conduct, and uncomfortable habits of great masses of our population. They are difficulties, no doubt, but not objections. They are just what every kind of reform and progress has to contend with and overcome. It is the grand work in which the best social organisation should engage-to instruct the ignorant, soften and refine the rude and barbarous, train men and women in good manners and morals, industry and honesty, sobriety and virtue. If only nice and cultivated people are to come together to enjoy the greatest amount of happiness in each other's society, leaving the poor and ignorant, the rude and vicious to their fate, we need not trouble ourselves about their failure or success. "Society" may drive round and round in Hyde Park, crowd balls and operas, applaud noble and heroic pigeon-shooters, and amuse itself as it will to the end of the chapter. But the work of the true philanthropist is to improve the condition of humanity, and the worse that condition the more need of energetic, self-sacrificing, and heroic efforts for its redemption.

\section{CHAPTER VII.}

GOVERNMENT AND POLITICAL ECONOMY.

Social Tendencies-Functions of Government-Circulation of Intelligence

- Transport of Goods and Passengers-Insurance-Distribution of the Necessaries of Life-Order and Regulation of Social Interests-Diabolic Elements of Political Economy-The True Principle of Wages-Rent.

THE tendencies of society in the most advanced nations to social organisation are very marked, but the modes, so far, are narrow and imperfect. We have unions for improving the condition of different trades by mutual support in strikes for 
higher wages; large guarantee societies like the Free Masons, Foresters, Odd-Fellows, \&c., raising funds by a general tax for the support of the sick and the burial of the dead; clubs of various kinds for similar objects; companies to insure against fire, shipwreck, accidents, and injuries. These are all modes of partial association, more or less mutual and equitable in their operation. When we have gone a few steps farther, all these will be swept away, or rather merged in the general industrial and social organisations which will perform all their functions-which will remove anxiety, and make want impossible.

When the functions of government- the central administration of all the social organisations of a country-and the areas of all countries will become a matter of convenience rather than ambition-are better understood, most of these private, partial, mercenary, and costly companies, each with its corps of needless officials and its train of idle consumers, will be dispensed with. The most advanced governments have shown what can be done in this way by a few examples. The British Government distributes letters, newspapers, books, money, and small parcels of merchandise over a vast empire with a facility, despatch, certainty, and economy that seem marvellous. I place a penny stamp on this Part of this Book, and it is carried, fast as steam can convey it, to the farthest corner of the United Kingdom. Threepence carries it to Canada or California, and fourpence to New Zealand, by way of San Francisco. Here is demonstration of the power of combined action.

Surely the government that carries our letters, and books, and small parcels of merchandise; that keeps our money, pays us for its use, and sends it in the smallest sums over a large part of the world; which guards us with its police, and protects us and our commerce with its diplomatic and consular, military and naval establishments, could just as well do a few other things more safely and far more economically than they are 
now done by private companies of speculators or investors, who look to their own profit rather than the advantage of the public. The government has added the telegraph to the PostOffice department, and assumed the entire function of the rapid distribution of intelligence. The government of the nation should be the centre of its whole life, and control the circulation of not only its nerves, but its arteries and veins. It should have the railways as well as the telegraphs; both should be worked with the greatest possible economy and efficiency, not for the profit of individuals, not to support idle people in luxury, but for the general good; and any margin of profit, if allowed at all, should go to diminish other taxation. And an important part of the foreign mail and transport service ought to be carried on by fleet naval transports-the property of the whole people, administered for their use. There is no principle to prevent the government from carrying a ton of merchandise, as well as a pound; or a passenger, as well as a packet. Ten mile stamps, issued by the government, might carry each passenger and his luggage on every railway, at the cheapest possible rate, and with comforts of travel now unthought of.

And all insurance of property of all kinds, and life insurance, and insurance against accidents, might be done by the government with great economy and advantage. The police would guard against frauds, and prevent and extinguish conflagrations. Every vessel registered, and every cargo entered, should be by the same act insured. Such oversight and guardianship of the government would make it every man's interest to be loyal; and the government would be what it should be ever-the head and heart of the nation.

And I would go much further than this. Whatever is for the general welfare of the whole country, is the proper function of the general government; whatever is for the common welfare of the people of any town or district, is the function of the municipal, or local government. The making, repairing, and 
cleansing of streets and roads; the superintendence of all build ings; the restraint and removal of all nuisances; the supply of water, gas, and hot air in pipes for general warming purposes; and probably in time the supply and economy of fuel, seem to me proper functions of local government. Certainly the supply and distribution of the absolute necessaries of life should never be subject to the greed of individuals or soulless corporations. It should be in the power of every man to purchase, at the lowest possible price, and of the best possible quality, every article of absolute need-shelter, clothing, food, water, light, fuel, or heat. It is the right or duty of the government, acting for the whole people, to see that no individual be left at the mercy of speculators, adulterators, fraudulent tradesmen, and all those who live and grow rich upon the necessities of their fellow-men-who are morally, and should be considered and treated legally, as so many thieves and robbers-the common enemies of mankind.

An orderly society, having its basis in the constitution of man, must be the natural outgrowth of his faculties, needs, desires, and aspirations. It must be what his nature requires, and not merely his lower, distorted, uncultured, or perverted nature, but his highest talents, his noblest sentiments, his immortal yearnings for the true, the beautiful, and the supremely good.

Our actual society is to a large extent based upon the lower propensities of man-upon a nature disordered and perverted, or uncultured and incomplete. It rests upon selfishness; whereas man's social character is essentially unselfish, friendly, philanthropic, and heroic. Our political economy teaches that every one should seek his own interest and advancement at the expense of his neighbours. Our religion, and the best in us that responds to its requirements, teach us to love our neighbour as ourselves, and to seek our own highest good in the welfare and happiness of those around us.

The selfishness on which our social state and its political 
economy are founded, is seen in the contests between employers and the employed, the former getting labour at the lowest price by which men, women, and children can be driven by starvation to work - a state which is, in some respects, worse than the chattel slavery which it has succeeded. This greed of men who grow rich upon the toil of their fellows, has naturally aroused the animosity and antagonism of the labouring classes against them, and a fierce war is everywhere raging in what should be the peaceful domain of industry. The question of wages is a perfectly simple one, to be settled upon principles of equity. As it is one of the most important interests of society, it should be settled by the State, or courts, or commissions of its appointment-by intelligent and disinterested men, who should fix upon the proper share of every worker in the value of his work. The industry of the nation is a national interest, and justice between man and man is precisely what we want of a government. To take the labour of any one without a just equivalent is theft. To take wages or salary of an individual employer, a public company, or the State, without rendering an equivalent service in return, is a deliberate breaking of the commandment-" Thou shalt not steal." All employers who underpay those who work for them are thieves and robbers. All workmen who sham and cheat their employers' customers by dishonest work, are in the same disgraceful category. And every one knows that our social state is full of the frauds and vices, the strife and crime of a selfish, disorderly, unregulated, unjust, and unnatural industry, based upon free competition, and the law of demand and supply - the law that allows every man to seize all he can of his neighbour's goods, and his neighbour's life, for his own advantagc- which scoffs at honesty and equity, laughs at philanthropy, and has for its purely diabolic motto, "Every one for himself, and the devil take the hindnost." From this selfish principle in societyjustified by the maxims of a so-called science, which is opposed 
to the true nature and requirements of man, as it is to morality and religion-come all the frauds and immoralities of commerce, all the oppressions of the poor, all slaveries, all conflicts, up to that culmination of all the horrors of human civilisation - the deliberate slaughter of men by each other, singly in murders, and with all the power of nations in war.

Therefore, before there can be a just and humane society upon any system of organisation, the whole selfish system of political economy must be abandoned. The diabolic maxim, every one for himself, must give place to the humane and Christian one, "Each for all." For Christian is human-only a restoration of what is highest in man to its rightful place. Christianity is the restoration of humanity, which is, in fact, either as cause or effect, or both in reciprocal action, the organisation of a true society. Every system of morals and religion has this for its object-to enable duty, conscience, the sense and perception of right and justice, and the elements of love and benevolence, to triumph over the baser, sensual, and selfish elements of human character-to bring human nature into the true order of the subjection of the lower to the higher facultiesheroic self-government-heroic assertion of the right.

Now there is no true heroism, no true humanity, certainly no true religion in buying cheap and selling dear. In each case a man robs his neighbour. What he should do is to give for every article he buys its actual value as nearly as he can ascertain it; and no one should ask for what he sells, what he can get-taking advantage of the buyer's necessity or ignorance to pick his pocket-but its true value, or exact equivalent in some other commodity. In most things this can be settled with sufficient accuracy.. One can judge nearly enough of the value or equivalent of a bushel of wheat, in apples or potatoes, oil or wine. When it comes to clothing, furniture, articles of taste and luxury, there is more difficulty ; but honest men, wishing to be just to each other, and scorning to take a base advantage, 


\section{Human Physiology.}

despising theft, prizing honour and uprightness more than gold, cannot go far amiss. And the rule is the same in respect to wages. The employer knows what is the value to him of each man's labour-knows the share in the proceeds of labour which each man receives. The labourer often cannot know this. He knows only his own necessity. The lash is over his back; wife and children to feed are so many strands; it is work or starve - work for what the employer chooses to give, or combine together for a wages war. The right to use force against force, constraint against constraint, is conceded by public opinion and the government; and both stand by, idle spectators of the fight when they ought to interfere at once for justice and peace. It is more necessary than military efficiency or naval supremacy, on which such vast sums are expended. The government gathers and publishes information of increase of population, or the prevalence of diseases in men and animals, of the mortality of towns and rural districts, marriages and births, all the statistics of revenue and commerce; would it be much to add the rate of wages in different employments, from skilled artisans to needlewomen, in every district in England, with the cost of living in each? Would it be much to establish, in connection with the Post-Office, perhaps, a National Labour Exchange, by which the demand for labour and its price in every district might be known in every other? Would it be much to give also the same information with respect to colonies, with the cost of getting to every point where land is cheap and labour well paid? People as heavily taxed as Englishmen are, might have, at least, any information which would possibly enable them to better their condition, according to the selfish rule of demand and supply, and the diabolic rule of free competition, or devil take the hindmost.

But we want something better than this-better than a more intelligent fight-beiter than facilities for getting by force what should be instantly conceded as a matter of simple right-of 
justice and humanity. Every man who finds himself, by no fault of his own, in possession of a portion of the soil of these islands, should set himself at once to make that soil, and the rain and sunshine it receives, of the greatest advantage he can to his fellow-creatures. What men commonly do is to get the highest rent they can for themselves. High rent means large production, and large production is for the general welfare. No . doubt; but this does not justify the process. The farmer is harassed to pay the rent, and the labourers are overworked and underpaid. They live in miserable hovels, and are deprived of the necessaries of health and life. If large production justifies this, it would justify slavery - the hired overseer, and gangs of negroes working under the whip.

What I think a landed proprietor should do is this: $\mathrm{He}$ should seek for men of honesty and intelligence, as his friends and co-workers, and say to them-God has given me charge of so much of His earth, and air, rain, and sunshine, and I want you to help me to do the best I can with it for our fellow-men. Take it, make it fertile and beautiful, and make those who help you comfortable and happy; draw on me for the capital you need, and we will all share equitably in the fruits of our labours. Could not such a man, with a family to help him, a clergyman to aid and counsel him, teachers to instruct, skilful and devoted men to organise and direct in agriculture, horticulture, and such manufactures as could be conveniently established, assemble around him a society of which he would be the centre and head, and in which all human virtues could expand, from which at least the coarser vices could be banished, and which would give the best conditions of human improvement and happiness? Every principle of political economy might be violated. No one might buy cheap or sell dear, there might be no higgling of the market, no free competition, no devil take the hindmost. The strong might bear the infirmities of the weak, not trample them under their feet-men might help to bear each other's burdens. 


\section{Human Physiology.}

And the farmers-captains under this commander-might in the same way assemble the families whose labour was to make the soil fruitful, and make with them the same amicable and just compact. "Work faithfully under my direction," one might say, "and you shall have your rightful share of the avails of your industry, and of our joint success. If Providence blesses us with good harvests, we will share together our prosperity. If there come bad seasons and harvests, we will bear our misfortunes together. You shall have comfortable and healthy dwellings, gardens for vegetables, fruit, and flowers, where you can keep bees, and yards for poultry. From the stores of the farm you can draw provisions and clothing as you have need, and within proper limits, at cost price. There are good schools for your children, which they must regularly attend, a church to go to on Sundays, a doctor to see you if you are ill. A large room has been provided where you can read, or amuse yourselves in bad weather, so that you will have no need to go to the alehouse. If any man gets drunk, his pay will be stopped. At the third offence, he will be paid off, and must leave. We must have sober, industrious men; good order and good morals. Remember, every man is now my partner, and he must consult my interest and reputation and his own. If any one does not, of course the partnership will be dissolved."

I do not know how English agricultural labourers would respond to such a speech-nor in what spirit they would enter upon such an engagement; but I have faith enough in human. nature to be sure that generosity will be rewarded with fidelity. And every owner of mine, or mill, or manufactory in Great Britain might call his "hands" together around their "head," and make with them a similar arrangement, guarded as prudently as circumstances might require, but planned and carried out in the spirit of justice and magnanimity which should govern all human relations. This would be genuine co-operation, which could soon be carried out into all the details of life, so 
as to secure to all engaged in it, the economies of the large scale in all the cost of living, and the highest productiveness of labour by increased efficiency in machinery and educated skill.

Only, in manufactures and commerce there is a difficulty. As paid free labour could never compete with slave labour, so it may be thought that well paid labour could not compete with ill paid; that the partnership or co-operative principle would have to work against half-paid and half-starved operatives. But it is only in the rudest labour of producing a few of the great staples of commerce that slave labour has been successful. All skilled labour is free-as far as there can be freedom under the prevailing system. Co-operation will give a still higher class of workmen, with great enthusiasm, great economies, and enhanced production. There will be no limit as to hours but that required by health, machinery can be run night and day by relays of workmen; there will be no trades union rules to limit the amount or keep down the quality of labour. Every man will in a spirit of generous emulation do his best to stand well with his fellows, for all will be interested in the greatest economy and the greatest production, and each one will be held to his duty by the interest of all. Just as in a military corps no soldier dares to act the coward; just as in a game of cricket every player does his utmost to make his side win, in the same esprit de corps the workmen in associated industry would far outdo anything that the wages system has ever achieved.

And, in an incredibly short time, just as the louts and roughs of our towns and villages are transformed into neat and orderly soldiers, so the whole class of working people would be changed into intelligent, sober, self-respecting, friendly and courteous members of society, having its interests at heart, and labouring not more for personal advancement than the general welfare and happiness.

I have supposed that, in the first steps of this great transition, 


\section{Human Physiology.}

each farm of an estate might become a co-operative association; but it is evident that greater economies of expenditure and production and a higher order of social organisation could be secured, were a whole estate or parish formed into one association-and the more self-sustaining and self-supplying the better. What we need is variety of occupation, suited to every variety of tastes and capacities. For that we ought to have in every large association, agriculture, horticulture, the breeding of animals, landscape and flower gardening, the care of fowls and bees, dairy work, several branches of manufacture, and something of the ornamental and artistic, as ceramic work or sculpture, where the materials could be found, and work in wood and metals; on lakes and rivers, fish culture; fisheries all around the coasts; and everywhere the planting of groves and orchards, the beautifying of nature, and that high culture of the earth which will enable every square yard to use its air and sunshine to the best advantage. We think England beautiful-it is; but genius, taste, enthusiasm, embodied in social organisations, would in a few years transform it into a glowing paradise.

And it is to be observed that every change is to be made in conformity to some human requirement-to supply a demand in the very nature of man. We want honesty in our dealings; comfort and security; friendliness and good-fellowship; mutual help; congenial society; combined effort for the general good; increased production of wealth, not for individual greed, but for the happiness of all; the free play of the higher sentiments; religion made practical; religion a living faith in the lives of men and all their relations with each other. This we cannot have in the existing social order, nor under the rule of its political economy. We can have it only in a social state in which man can live his true life, and unfold the highest faculties of his nature.

The evils which now afflict society depend upon, and seem 
to be inseparable rom its actual organisation, and the principles by which it is governed. As long as the competitive system of wages and isolate industry exists, there will be poverty. With poverty there will be disease, ignorance, drunkenness, and immorality. The liquor trade belongs to the system of demand and supply, and the supply creates the demand. Employers league with liquor-sellers to degrade labour for their own gain. The vast multitude of non-producers live upon the toil of those who work, and add to the extortions and oppressions of capital ; and upon all presses the burthen of rent, of interest upon capital, of the public debt, of an enormous taxation, a huge expenditure for army, navy, law, police, prisons, prostitution, and the labour of the industrious pays for all; for the grain made into beer and spirits, the land wasted in growing hops, the millions worse than wasted on tobacco, the support of every drunkard and pauper and lunatic, and all disabled by intemperance and its kindred vices; the pay of every soldier, naval sailor, policeman-the waste of profligacy and prostitution.

Does our society give us enough enjoyment to compensate for all this, and make us content with our burthens? Do we not rather stagger on, grumblingly bearing them, because we have seen no better way? The better way is for every man to do what he can, be it much or little, to give men first the idea, and then, as soon as may be, the practical realisation of a new . social order-the order of justice and humanity.

If there be no absolute ownership of land, or real property, but that which belongs to the whole population of the country, as represented by or personified in the State, where is the right to buy or sell, and receive rents from property? A man can transfer to another, or leave to his heirs, only such rights as he has ; and in England all real property is held by lease from the Crown, which represents the eminent domain of the State or people. All the great estates were bestowed by the Crown, not 


\section{Human Physiology.}

absolutely, but in fee, for some service or consideration. The land was to be cared for, cultivated, pay something to the sovereign, and furnish soldiers for the general defence. This lease, or limited "ownership, can be transferred to another, with the sovereign's consent-that is, by legal conveyance; and the great lord, in like manner, leased portions of his estate to his vassals. The so-called owner of an estate is therefore an officer of the State, a steward of the property committed to his charge, and he is morally, and should be legally, bound to administer it and expend its revenues for the welfare of his tenants and of the general public. Hence the inequities or iniquities of exorbitant rents, rack rents, and the grinding oppression of farmers and labourers; hence the real and great grievance of landlords who do not live on their estates, but spend all the revenues they can draw from them at a distance, and often in foreign countries. In this way Ireland has for centuries been drained of the wealth that should have been expended upon the dwellings, comfort, and education and industry of the people. The right to receive rent for property is limited, as is the right to the property itself. It is a question not of demand and supply, which is the right of might, the struggle of greed and want, or what strength can exact of weakness, but of equity; equal and exact justice. So much should every man receive; more he has no right to demand. 


\section{CHAPTER VIII.}

\section{EDUCATION.}

Its Power Limited by Natural Differences-Effects of Early TrainingClassical Learning, Pagan-The Motives of Education-Success in Life-Competitive Examinations-True Object of Education-Must be Physiological-Education of the Bodily Powers, Senses, and all Faculties.

Philanthropists may sometimes make the mistake of expecting too much from education. Owen thought the whole character of man was made by his surroundings, and the influences to which he was subjected in his early years. He took too little account of original character, or hereditary predisposition.

Those who have observed human nature know that children differ in their cradles in intellectual and moral capabilities. They have capacious and well-proportioned brains, or small and deformed ones, good or bad bodily organisations, and vary in all degrees from idiocy to genius, and from the most sensual and cruel dispositions to the most refined and gentle.

And these original traits of character can never be wholly eradicated by any education or training. We cannot, the proverb says, "make a silk purse of a sow's ear;" but we can, it is answered, make a purse. An idiot cannot be transformed into a genius; but experience has shown that even idiocy can be greatly improved. We may not be able to make naturally awkward and ungainly people models of grace and elegance, but we can make them less awkward, less ungraceful. The effects of early training are wonderfully shown in all bodily exercises. The boy who has a good dancing-master, or who goes through military drill, or learns gymnastics, shows the effect of the training all his life. Mere association with gentle well-mannered people is an education in carriage and manners. 
The mere rudiments of education, learning to read, write, and reckon, have great value as far as they go. They are keys to knowledge, but they may have little influence on character or manners. We must train people for what we wish them to become. If we wish them to be honest, we must train them to honesty; and a great deal of our education, or the influence of our surroundings, is in quite another direction. Truth, gentleness, benevolence, order, obedience, and all the duties which human beings owe to each other, the habits and virtues which make the benefit, comfort, and delight of human society, children can be educated in from their tenderest years, their unsocial faults restrained, and all the social virtues brought into vigorous and habitual action.

There are schools in England where every boy is said to acquire, from the general tone of the school, the example of those about him, the traditional behaviour of class after class, more or less of the bearing, manners, and habits of a gentleman. Such schools may not be remarkable for learning or science, but they give a certain stamp of breeding and character which is considered very desirable. And there are schools for young ladies which have a similar influence. If men and women of the highest and purest character, gentlemen and ladies, who have had the best opportunities for culture, would devote themselves to teaching the children and youth of England, as some devote themselves to teaching heathen children in foreign missions, great good might be accomplished. We need here at home, in every town and village, a great deal of true devotion and missionary zeal.

The faults of education are those of our society. We educate our children for the world as it is; and society educates in its own manners and morals, and so perpetuates and intensifies its evils. Mr. William Howitt, in his notes to "The Mad War Planet," makes a vigorous protest against the Pagan character of our classical education. Boys at the High Schools of Eng. 
land, and young men at the Universities, study almost exclusively the writings of Pagan authors, filled with anti-Christian pride, vain-glory, revenge, and lust. 'Even the clergy of England spend years in studying heathen poets, whose works are full of shameful indecencies and immoralities.

But the motives of education seem to me as bad as its. methods. The great object is, not learning for its own sake -not the pursuit of literature or science, but success in life. It is to pass examinations and obtain degrees, to cram and compete ; and cramming for competitive examinations, straining the memory to answer a certain number of questions, seems. to me alike disastrous to mind and character. And such a method can never answer the purpose intended. A good memory, a flippant readiness in answering questions, a tricky adroitness in preparation, is not the character wanted for posts of trust and honour. Character, manliness, courage, honesty, humanity, cannot be crammed, nor ascertained by competitive examinations; but they may give us any number of superficial memorisers, tricksters, prigs, and hypocrites. No examination in science and languages can give us the noble and heroic qualities needed in the leaders and governors of a people.

The success in life for which education is intended to prepare the young of both sexes of the middle classes is a very unreal sort of success. It is the pursuit of wealth, often by means the most dishonourable and inhuman; it is the attain ment of a higher social position, without reference to its use fulness or happiness. It is to enable the young to marry well, which means to marry money, or to marry into a good family, a "good connection."

Success in the Church is a good living, such we see advertised in the columns of the Times and the Church papers; several hundreds a-year and easy duty in a pleasant country, with good society, hunting and fishing, and the prospect of preferment. In the law, it is a tremendous strain of work-an 


\section{Human Physiology.}

income of twenty or thirty thousand pounds a-year, with ermine and a peerage in the distance. In medicine, rooms crowded with patients, pockets full of guinea fees, royal patronage and knighthood. Men of business, engineers, contractors, merchants, bankers, brewers, look forward to great fortunes, landed. interests, seats in Parliament, the transition into county families, noble alliances, baronetcies, peerages.

This is the competition of life which follows competitive studies and examinations - the carrying out of the competitive principle, by which each one seeks to mount on the shoulders of his less fortunate comrades, fills his pockets with the gains of their industry, wins money, reputation, a fortunate marriage, and all that makes success, by luck or skill, by impudent audacity and shameless fraud, by means which give rogues an advantage, because honourable men scorn to make use of them. There are great and noble exceptions to all this; but in the scramble, the game of life, the fierce competition and gambling for success, it must be that the hardest and worst qualities of some men give them an advantage over the highest excellences of character in others, and that social state must be radically defective, where greed and craft can lead to wealth and power, and the success of one is the impoverishment of many. The blot of our actual society is its gambling character-is in the fact that the gain of a few is made up of the losses of millions. In a true society all would advance, all improve in condition, all grow in knowledge, in wealth, in. virtue-not equally, for talents and capacities are unequal, but all in their degree, so that the gain of one shall never depend upon the loss of another, but the good of each be a benefit to all. This is the object, as it is the test, of a true social organisation.

And all education should have this object-to prepare men for, and improve them in, such a social condition. Children should be trained to a horror of lying-even in trade; to a horror of stealing-even in selling bad or adulterated merchan- 
dise, and in unjust profits and gains; a scorn of all dishonestyeven in taking advantage of the ignorance or necessities of others for gain; a love of truth and fidelity in work, in service, in all dealings and all intercourse with each other. Every child might be taught, and I believe nearly every child has the ability to learn, the purity, the honesty, the unselfishness, the regard for the rights of others, the devotion to the welfare or others and the highest good of all, which are the elements of every noble character, and the true motives of action in all our relations to our fellow-men. A child can understand the Fatherhood of God, and the duties of men to each other as brethren of one great family; the beauty of love, and the ugliness of hate; the benefits of order and purity, and the evils of disorder and impurity. Every child can learn more or less of its own nature, its relations to those around him, and the duties which are involved in those relations. More or less every child can be trained by precept and example to gentleness and truth, honesty and virtue; and in a true society all influences would tend to strengthen and perfect that character, which it should be the great object of education to form.

And a true, integral, comprehensive education, which is the natural right of every human being, must be based upon human physiology - founded upon the constitution of manmust be in harnony with the nature it is intended to draw out, unfold, and bring into vigorous and happy activity.

In a complete education all the bodily powers should be exercised and brought into their full strength and use, in work and play, in feats of industry and gymnastics. The young should be taught to walk and run; ride, dance, and swim; stand and move with dignity and grace, use their hands with dexterity, play musical instruments, handle tools, and engage in useful industries. The eager activities of childhood can readily be turned into many useful channels, and with young children three-quarters of their waking hours may be profitably 


\section{Human Physiology.}

directed to bodily exercises, and plays, or work as interesting as any play, that will give useful training to nerves and muscles.

The senses also must be educated. The sight should be trained to the accurate perception of forms and colours; symmetry and harmony; the observance of the wonders and beauties of nature, and its reproduction in art. The earlier all this begins the better. The ear has its own education in speech and music, in a refined and graceful eloquence, and, where the musical ear exists, in melody and harmony. Conversation and reading aloud, singing and playing on musical instruments, belong to the education of the sense of hearing, the faculty of imitation, and of the æsthetic and intellectual faculties. Taste and smell have also their education, sometimes a very bad one; for people learn to eat, drink, and smell many things useless and hurtful. The proper education of these senses includes the science of cleanliness, the blending of sweet odours, and the selection and preparation of healthful and pleasant food-the whole science and art of a refined gastronomy. There is, therefore, great need of the cultivation and education of the senses of both taste and smell. Touch enters largely into all mechanical dexterities, and the manipulations of art. Without it we could not use tools of any kind, play on musical instruments, prepare food, make clothing, a raw, paint, model. All these operations, therefore, educate the sense of touch.

And every faculty of man, every propensity, every sentiment, from the perception of order or number, to love, reverence, hope, charity, conscience, and the highest elements of heroism and religion, are to be educated, trained to use, strengthened, and perfected. Man has no faculty which may not be regulated, ordered, and perfected for the highest use, by the power of his own good will and the aid of others; and this training of humanity to its highest condition, this repression of whatever 
is evil, and culture of what is good, is the great work of edtcation, not only in childhood and youth, but through our whole earthly existence. It is never too late to mend-we are never too old to learn. Our whole life should be an education in right-thinking, right-feeling, and right-doing. We must ever "cease to do evil; learn to do well." Our life on earth seems to have for its chief object our education and preparation for a higher life in the future, the whole eternity that lies before us; and the only real success in life to which any one can attain is in getting that preparation for ourselves, and assisting our fellow creatures in the true ends of our earthly existence.

\section{CHAPTER IX.}

\section{SOCIAL PRINCIPLES AND PREPARATION.}

Remedies for Social Wrongs-Revolutions-Division of Property - Burthens of Labour-Abuse of Riches-True Uses of Wealth-Rapid Social Transformations-Individual Preparation-Orderly Progress-Training in Honesty-A True Society can only be founded in Equity-The Speaker, Earl Derby, Lord Napier-The Human Constitution the Model of Human Society.

THE tree is known by its fruits, and I have shown in the first part of this work some of the fruits of the present constitution of human society. With the humane and just, to know an evil is the first step toward the remedy. In the progress of the world many wrongs have been righted, many reforms have been accomplished; and for whatever men have the will to do to better their condition, a way will be found. But there is a choice of ways and methods. There are harsh and rough ways, and smooth and easy ways. The mode by which the 


\section{Human Physiology.}

reforms of the French Revolution of I 793 were accomplished was very terrible. Better a gradual change than a volcanic eruption of human passions-a saturnalia of blood and crime.

And it is doubtful if the reforms accomplished were worth what they cost. To seize the land and divide it in small parcels among the people is not the way to constitute a true society or best method of life, but may hinder it, and be an aggravation and perpetuation of petty selfishness. The hereditary aristocracy and great proprietors, dispossessed, exiled, or murdered, were a loss to the nation from which it has never recovered. France wants to-day what England has-a class of men able and ready to become leaders in every great national and social movement. The superiority of Germany to France in the late war was in the leadership of her nobility. Emperor, Kings, and Princes executed the plans of Bismarck and Von Moltke.

To divide the soil of England among the people, in their present condition and with their present social organisation, would be of little advantage. A few years would see a large portion of it in the hands of greedy capitalists. The rest would be converted into ugly little farms; the timberwould be destroyed; and all sorts of nuisances deform the country. In the same way higher wages mean, to great masses of people, not more of the comforts and true enjoyments of life, but more beer, gin, and tobacco; more selfish sensuality and waste of life. Better the present system, with its gradual ameliorations, than violent changes for which people are unprepared, which are based upon no true principle, and which can result in no permanent benefit. So much I cheerfully concede to a cautious and wise conservatism. No one can be more solicitous to preserve all that is just and good and beautiful in the present social stateno one more anxious to avoid the errors and crimes of violent political and social revolutions. Happily, the English people are conservative in their character, traditionally and habitually loyal, and but little liable to excitement and disorder; but they 
are at the same time practical, resolute, and persevering in demanding and carrying out what they recognise as real measures of reform.

The burthens which oppress the labour of England-labour which creates all wealth and bears all burthens-must be removed. Justice demands that the toils and the pleasures of life be more equally distributed. The national debt is a machine which abstracts thirty millions of pounds a-year from the producers of wealth, and gives it to the consumers. It is a contrivance by which some thousands of men and women live in idleness on the labour of their neighbours. A considerable portion of all the revenues of the country is a contribution gathered from millions of the poor, to enable a few to live in affluence and splendour. The taxes levied upon beer, spirits, tobacco, tea, coffee, etc., go to pay exorbitant salaries, sinecures, pensions, profits to contractors, the needless cost of diplomacy, and the huge waste of war and warlike preparations. And these wasteful expenditures of government are but a small portion of the great waste of life. The vast sums expended in gluttony, in drink, in smoke, in the cruel and demoralising sports of the upper classes, in the vagabondage, prostitution, and crime of the lower, come out of labour, and might be saved for the benefit of honest industry. Count the millions paid in exorbitant rents, in squandered rates, in the profits of banking and insurance, in the revenues drawn from interest and usury, and the needless and unjust profits of retail trade, and we shall have some idea of the burthens now unjustly laid upon those who work.

An educated people, as the English will soon be, even to the poorest, will see all this injustice, and will demand, and finally command, that it shall cease. There is no solid foundation for any government or any society but in right, in honesty, in equity. Every one can see and feel that the existing social system is wrong - a contradiction of religion and an outrage to humanity. 
Of course it must come to an end; and it will be either by social conflicts-the struggle and warfare of the poor against the rich, with all the sufferings and dangers of such a contest; or by all classes uniting to form a new order of society, based upon principles of equity and humanity, by which rich and poor, every class in the community, will be raised to a higher and happier position - a social order in which there will be free play for all the talents, all the faculties of man-in which industry will have its rewards, and worth of every kind appreciation and honour.

What every nation has the right to demand is, that the national wealth, land and water, air and sunshine, forests and mines, annual products and accumulated riches be administered and used for the benefit and highest good of the entire population. This is also the evident responsibility and duty of every person in possession of land or money, or any means by which he becomes the receiver, steward, caretaker, of the products of labour. Finally, every man must render to God and his fellow-men an account of this stewardship. The unjust getting, the inhuman holding, the careless squandering, the selfish abuse of riches may involve every crime from petty larceny to murder. This is why we read so often, "Woe unto you, rich!" This is why it is said, "How hardly shall they that have riches enter into the Kingdom of God!"

Still, the heaped up riches of the world, in the hands of just and enlightened men, will become the basis of a true society. Immense wealth is immense power for good, as well as for evil; and some rich men have shown a noble generosity, and in some respects a real regard for the rights of their fellow men. A nobleman who opens his parks and gardens, his state apartments and picture galleries, one day in a week to the public; who lends his collection of works of art for exhibitions; who entertains his tenantry and neighbours on the birthday of his heir with dinners, balls, and fireworks; who distributes coals 
and flannel to poor cottagers, shows some sense of his duty to his fellow men. It is something to give people an annual holiday; to let the pale and grimy children of the London streets see the green fields and breathe the sweet air of the country once a-year; to scatter alms from one's abundance. It was good-natured ostentation for a Midland Earl to send the jewels he had given his beautiful Countess to the Exhibition, includa coronet that cost $£ 250,000$, containing a single diamond worth $£ 30,000$-but it would be better to attend to the sanitary condition of the fever-stricken towns from which his princely revenues are drawn. Yet these very riches, in the hands of wiser men, may be of incalculable benefit; and even the hardest avarice may be of use in collecting and saving what other forms of selfishness would have utterly wasted and lost.

I have no quarrel with wealth, and its distribution among an ignorant population would be a great evil. I have no war with landlords. They hinder improvements, but they still more prevent deformity and waste. An educated, benevolent, tasteful proprietor of a great domain cannot well be spared from the existing social state; and with a little more enlightenment, and a finer sense of justice and humanity, he is the destined chief, the providential organiser and leader of the society of the future.

We are to prepare ourselves for the destined advent of that society. Every social condition supposes a higher and a better one, because the law of humanity is a law of progress, wherein man differs from every other earthly creature. And this process is not wholly dependent upon time. Under favourable conditions, societies form with great rapidity. Palestine, Egypt, Greece, Rome, and the Europe of the middle ages, gave us brilliant examples of such possibilities. How rapid was the revival of learning and the arts! How wonderfully are the discoveries and inventions of our own time transforming the 


\section{Human Physiology.}

world! No one can read the histories of the religious Orders, of the Missions of Paraguay, of the Reformatory of Mettray, and similar institutions, without coming to the conviction of the practicability of great and rapid reforms in human society. A man with a genius for order, discipline, and command, will convert a mob into an army. A musician, with similar qualities, will organise music. Politicians will constitute states, kingdoms, empires. There must be men capable of organising society.

Meantime, the work we can all do is one of individual, personal preparation. As the stones and timbers were shaped for the temple, so we should form and polish ourselves for a true society, clearing ourselves of bad habits and prejudices, purifying our lives, training all our faculties, gaining the knowledge and skill we shall require in the varied occupations of a more complete social organisation, educating ourselves in all ways for a purer and higher life. At first, the most advanced individuals will form the society; and this society will then form, mould, educate, and perfect all its members. The children born and trained in such a society will be of a higher order of humanity, and each generation may be expected to preserve the good attained, and take a step in advance. Here will be united the highest conservatism with the most rapid progression. All the knowledge, skill, culture, and wealth of society will be preserved, with a constant addition. When wear and waste are reduced to a minimum, and the power of production increased by every advance in science, the increase of wealth will be incalculable. Working men demand that their hours of toil be diminished to twelve, ten, and even eight. It is probable that in a well organised association the time devoted to the labour necessary for the production of all the comforts of life would never exceed four hours; but works of art, literature, science, would be carried on with an enthusiasm that would take no note of time. The lives of all men and women would be full 
of attractive industry and all uses, and therefore of the enjoyment of the highest happiness.

There is nothing destructive in the preparation for a better social state, and there need be no disorder in its inception. On the contrary, the whole progress should be orderly, and one of improvement of our actual conditions. We cannot take the first step without gain. Cleanliness, a pure diet, the disuse of intoxicating drinks and tobacco, the improvement of our minds and manners, the cultivation of the high Christian virtues of purity, temperance, order, patience, industry, and honesty, can do no harm in any social state. We cannot educate ourselves too thoroughly, or too carefully train all our faculties to the best uses. There is no danger of our being too kind, too. helpful, too unselfish, too full of the feeling and expression of the charity that covereth a multitude of sins, and is the crown of all virtues. There is no preparation for any future so good! as making the best we can of the present.

And in the education of the young, the same rule holds good. Let it be useful. Many of the employments of life are almost. or entirely useless-some terribly hurtful. It is best to let thesedie out. No man with a conscience would deliberately educatehis daughter for a life of shame; but how many do uncon-. sciously educate daughters for the most terrible fates. Every miserable woman is somebody's daughter. And sons are no less. educated to lives of profligacy and crime, or to the idleness that leads to them. And people go on in the bad ways of the world, because they see no hope of anything better in this life, or in any life. The hope of a higher life in the next world gives men a motive to live a better life in this. The hope of a higher social condition here must, I believe, also stimulate men to the effort to prepare for it-to become fitted for its requirements. and its enjoyments.

And the element which must pervade all education andi preparation for a better life on the earth is what we most need 


\section{Human Physiology:}

for any decent life whatever-is honesty, the sense of right, the practice of equity. And any employment or profession, or mode of life in which honesty would be a disqualification, should be abolished or reformed. It is stated, on what seems good authority, that almost the entire liquor-traffic is dishonest, not only as to prices, but in scandalous frauds and adulterations. Adulteration of seeds is said to be the rule of the trade. Nearly all the milk sold is watered. The art and mystery of a large part of our trade and manufactures consists of skilful simulation and adulteration. Before people can think of being honest men, true men, righteous men, all this must cease. Young men, instead of being trained to lie and cheat, must be trained to honesty and equity. The phrase, "His word is as good as his bond," should not be an exceptional eulogy. No lawyer should think, or presume, or dare to tell a lie to a court or jury. No doctor should take a fee for useless advice or needless medication. The simple rule of honesty must be carried out in every trade, calling, and pursuit. A true society cannot be made up of thieves and liars. If all this rank dishonesty and robbery is a matter of education and custom, the education must be reformed, and such customs must be abolished.

Once men are honest, the work is more than half accomplished. Once men are really willing to do as they would be done by, and live in justice and equity, society is more than half reformed. When the will has been found, we shall not lack the way. The Speaker of the House of Commons has proposed to the labourers on his estate to take them into a limited partnership, agreeing to take their savings as an investment, and pay then from two-and-a-half to ten per cent. for every shilling they contribute. So far, so good. Let him agree to give them an equitable share of the produce of his fields for their labour, which is every day invested in them, and he will make a much greater advance in the right direction. The real and ready remedy for every industrial difficulty is for employers and work- 
men to be honest to each other. There is a magic in honesty - a charm in the right-a power in justice which compels all men's respect and acquiescence.

A true society can be founded in equity, and stand secure on that foundation;-never on fraud and falsehood, wrong and injustice. There can never be a true human society based on physical force, contest, war. And these are the elements of our present society, in which it is held that every man has a right to all his ancestors got by fraud or force, and all he can get by similar means. The highest authorities hold that working men may combine to get the highest possible price for their labour, without regard to its real value. They also pretend that capitalists may combine to get labour for the lowest possible price, and with an equal disregard to right and justice. So distinguished a senator as Earl Derby asserts this right of robbery. In the same way a few surgeons might combine to make a millionaire give half his fortune or the whole for an operation which would save his life. Such a principle of political economy creates a society of Ishmaels-every man's hand against his neighbour-and is the exact opposite of every humane and Christian principle.

As I am writing the concluding paragraphs of this work, there comes to me the address of Lord Napier and Ettrick, as President of the Social Science Congress at Plymouth. This enlightened diplomatist and statesman said: "With reference to real property, it should never be forgotten for one moment that Great Britain stands apart and alone in the civilised world. Real property is transferred and transmitted under laws, customs, and influences which all combine with irresistible increasing power to produce consolidation. Primogeniture, entail, traditional predilections, the exigencies of fashion and recreation, and the accumulation of capital are working incessantly together to promote great aggregations of land in the hands of a few. The statistics of landed property have not been verified with 


\section{Human Physiology.}

any accuracy, but it would be hazardous to estimate the number of estates above the dimensions of a garden or a paddock at more than 100,000 in a country which numbers more than $26,000,000$ of inhabitants, and there are but few counteracting. agencies at work to mitigate the perilous progression towards monopoly. It may be broadly asserted that in no country does so large a proportion of the population live in lodgings as in Great Britain, or in separate habitations as tenants at will; in no country do so many live on the land of others without a lease or with a terminable tenure; in no country are the prerogatives and delights of property vested in such a restricted number. The proportion of those who possess to those who possess nothing is probably smaller in some parts of England at this time than it ever was in any settled community, except in some of the republics of antiquity, where the business of mechanical industry was delegated to slaves. France, Germany, Italy, Russia, Switzerland, the United States, the British Colonies-all the countries which count for something in the world, which propagate ideas, or offer examples, or present points for comparison, which fascinate by their past or which possess the promise of an expansive future-all have committed acts or adopted principles and measures which conduct them on a path directly opposed to that on which the destinies of England are still impelled. An alteration of the laws of England affecting real property, a movement towards its repartition and diffusion must be advocated from motives of philanthropy and policy; and, happily, this is not difficult. The possession of the soil and the habitation ought, when associated with some culture and elevation of mind, to carry with it patriotism, or devotion to the State, loyalty or attachment to the representative of sovereign power, independence, self-respect, and respect for the rights of others. It should nourish and prolong the exercise of mutual duties and affections in the family, and sweeten life with many salutary recreations and pleasures." 
I have tried to suggest some methods, by which men may prepare for a social organisation, or conditions of social life, better adapted to secure their welfare, than those which now exist around us, and to indicate the modes in which highe forms of society may have their beginnings. In this, as in all things, we must follow the natural order. The wide branching, perfect tree grows from its microscopic germ, by gradual add ${ }^{-}$tions. The human body, the type of a perfect human society; grows also from its germ, developing, expanding, and perfecting itself, from conception to birth, from birth to maturity. The laws of life and health, of training and education, of moral and spiritual development, for the individual, are the same laws that must govern the inception, growth, and perfection of a true society. A community requires the same order, the same justice, the same watchful care, the same harmonious adaptation of part to part-each to all and all to each-that exists in the healthy human body. The blood which is the life must freely flow to every member. The brain, through its nerves of sensation and motion, must feel all and govern all. Every member of society must have his rights, and the satisfaction of all real requirements, all the conditions of a useful and happy existence, just as every organ of the body must have its nervous force, its proper nutriment, its natural activity. The spiritual life corresponds to the material - and the life of society corresponds to that of the individual. And individual and social diseases have: the same correspondence. There are social dyspepsias and constipations, social fevers, social paralyses, social insanities

In the human system, healthy, right-acting organs make a healthy body, and a healthy constitution forms and preserves healthy organs. So of man and society. Every leaf works for the tree, and the tree gives its sap to every leaf. Through nature this rule holds good-the law of all for each and each for all. All things work together for good in every true organisation, and what is best for each is best for all. The law is 
absolute equity, or such an approximation to it as human judgment can give; absolute justice, administered with generosity and benevolence; the rule of right in all things, which may still be supplemented by active philanthropy, enthusiastic devotion to the welfare of others, and heroic efforts for human welfare and happiness.

The rule of right regulates all things, material and spiritual, while the rule of wrong throws everything into discord and disorder. "Seek first the Kingdom of Heaven and its righteousness-its justice-and all things shall be added." The first element of Christian life is "to do justice ;" the second is "to love mercy." We have simply to carry religion into life-to make it practical as well as sentimental; so that "whether we eat or drink, or whatever we do, we do all to the glory of God:" and the only glory ot God we can be consciously concerned in is the well-being of His creatures. - Inasmuch as ye have done it unto the least of iinese ivcy orernren, ye have done it unto Me." There can be no doubt that the Almighty has more regard to one act of honesty, one deed of benevolence, than thousands of prayers and praises-that saying "Lord," "Lord," glorifies Him less than doing the things He has commanded. The essence of religion is to unite ourselves to God in doing His work-in not only saying "Thy kingdom come, Thy will be done on earth"-but earnestly ordering this kingdom of iustice, and doing this will of God, which is the highest good and greatest happiness of all His creatures.

When we make our religion vital, a principle of life, so that our manners and morals, our politics, political economy, our whole business, and all our relations to our fellow men shall be just, equitable, reasonable, and humane, there will be no difficulty in organising a true society. It will be as natural a process as the growth of plant or animal. The laws of such a society, its principles, and methods, are in the very nature of man. His undeveloped and perverted nature makes the dis- 
cordant and unhappy social condition, which perpetuates and intensifies ignorance, selfishness, and demoralisation; but man has only to turn to righteousness, turn to right, turn to health. wholeness, holiness, in heart and life; he has but to "cease to do evil, and learn to do well," and every motive and action of nis true nature will tend to the formation of a true society, which has its foundation in nature, in the laws of God, and in the constitution of man.

In man are all the possibilities of humanity. What we conceive we can will ; and what we will we can accomplish. With God all things are possible, and $\mathrm{He}$ is with all who earnestly desire to do His will on earth, as it is done in heaven. No doubt we have all eternity to work in; but the work of this life is very clear and very urgent. Whatever may be the activities and enjoyments of the life of the future, this present needs all our energies. Man is to be regenerated, and the earth redeemed. He who reforms his own life does much; he who makes one spot of earth more fertile and beautiful does well; he who cultivates the minds and hearts of men, making them hate injustice, scorn vice, and love honesty and virtue, and all those pure and noble thoughts and deeds which make up the sum of Godliness, is a faithful servant; and the highest earthly dignity is to be a servant of the servants of God.

Power to serve humanity-material, intellectual, or moral power-is the measure of responsibility. 


\section{WORKS BY DR. AND MRS. NICHOLS.}

Human Physiology, the Basis of Sanitary and Social Seience. 496 pp., crown 8vo, 70 illustrations 66

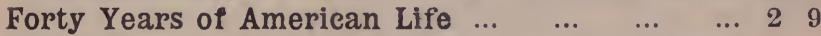
Social Life : Its Principles, Relations, and Obligations. $\begin{array}{llllllll}\text { Elegant cloth gilt, } 3 \mathrm{~s} . & \ldots & \ldots & \ldots & \ldots & \ldots & 3 & 3\end{array}$

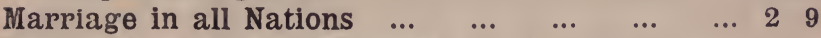
Health Manual and Memorial of Mrs. Mary Gove $\begin{array}{llllllll}\text { Nichols } & \ldots & \ldots & \ldots & \ldots & \ldots & \ldots & \ldots\end{array}$

Papers on Childbirth without pain or danger, also containing Articles on Consumption : its Cause, Prevention, and Cure. By T. L. Nichols, M.D. ... $\quad \ldots \quad 1 \quad 3$

A woman's Work in Water Cure and Sanitary Education By Mrs. Nichols. 140 pp. Paper, 1s.; cloth

The Clothes Question Considered in its relation to Beauty, Comfort, and Health. By Mrs. Nichols... 1

The Diet Cure: "Eating to Live." The Relation of Food and Drink to Health, Disease, and Cure. 96 pp.,

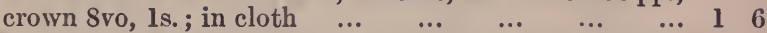

The Beacon Light, Physiology for the Young: a Revelation of the Hidden Dangers in the Path of Life.

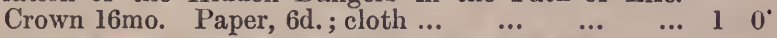

The Science of a Cheap and Healthy Diet; or,

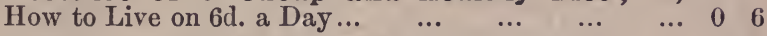

A Scamper Across Europe: Malvern to Vienna $\quad \ldots \quad 0 \quad 6$

Rheumatism: Acute and Chronic. By Dr. Allinson. Its Cause, Symptoms, Complications, and Cure ; also, Its Prevention by Hygienic Means _... ... ...

Forbidden Fruit; or, Revelations of Egyptian Mysteries.

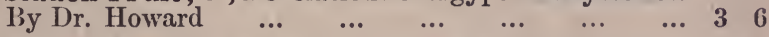

Count Rumford: How he banished Beggary from Bavaria $\quad \begin{array}{lll}0 & 6\end{array}$

The Gift of Healing, a Letter to Mothers on the Prevention and Cure of the Diseases of Women and Children.

By Mrs. Nichols

How to Cook: Theory and Practice. 500 Dishes. 7d.; $\begin{array}{llllllllll}\text { cloth } \ldots & \ldots & \ldots & \ldots & \ldots & \ldots & \ldots & \ldots & 1 & 0\end{array}$

Dyspepsia (commonly called Indigestion): its Nature,

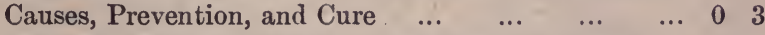

The Water Cure at Home: Describing the best Pro$\begin{array}{llllllll}\text { cesses of Hydropathy } & \ldots & \ldots & \ldots & \ldots & \ldots & 0 & 1 \frac{1}{2}\end{array}$ 
Account of an Invention for the Home Treatment of Constipation, Piles, Fistula, Vaginal Weakness, and

many Diseases of the Generative Organs of both Sexes $\quad \begin{array}{ll}0 & 2\end{array}$

$\begin{array}{llllllll}\text { Vegetarian Cookery } \ldots & \ldots & \ldots & \ldots & \ldots & \ldots & 0 & 2\end{array}$

Civilized Man, setting forth the Darker Side of the

$\begin{array}{lllllll}\text { Actual Condition of Humanity } & \ldots & \ldots & \ldots & \ldots & 1 & 0\end{array}$

Matter, Force, and Life-Matter a Mystery-What is

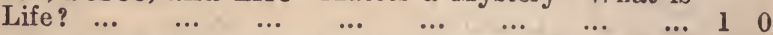

The Human Body-its Form our Highest Ideal... $\quad \ldots . .10$

The Laws of Generation and Sexual Morality $\ldots$... 1

\section{PUBLIC AND PRIVATE OPINION.}

The following Extracts from Notices of Dr. Nichols' different Works by the press and in private letters, are copied from a much larger number in the first volume of the HERALD OF HEALTH, and they are fair samples of the general opinion formed of his writings by all intelligent and right minded people.

\section{"HOW TO LIVE ON SIXPENCE A-DAY."}

"Full of the most useful information-the production, evidently, of a learned, thoughtful, philanthropic man."-Weekly Despatch.

"Sound and practicable-we confidently recommend it to all true philan. thropists."-Mechanics' Magazine.

"One of the books of the year."-Temple Bar.

"A capital and most practical little book, and we have no doubt that while every labouring man would live the better by following the precepts of Dr. Nichols, no one of whatever rank of life could fail to be interested by his practical advice on food."-Labour Neros.

And the "private opinion" expressed in letters to Dr. Nichols has not been less emphatic. Thus-

A Working Man at Nevocastle-on-Tyne.- "I have tried the experiment of living $m$ sixpence a-day, and find it to work well, and I find myself in much better health since I tried it. It is shameful what a waste there is in this country with the working class and everybody.

A Medical Student of Co. Durham.- "I obtained 'How to Live on Sixpence aDay' about two years ago, and since reading it I have been enabled to live on fivepence a-day with more comfort and pleasure than I did on more than five times tho imount before."

$A$ Gentleman writes from Clapton Park, London:- "I have tried several of themodes of diet recommended in 'How to Live on Sixpence a-Day,' and find it quite possible to live on much less, and that with great advantage to my health. When your books become widely known, poverty will diminish and wealth become universal."

\section{"HOW TO COOK."}

The Labour Ners, considering the interests of the working classes, says :- "This is an infinitely better book than many more pretentious compilations, and we corfidently recommend it to the consideration of every housewife. We sadly want lessons in cooking in this country; and Dr. Nichols' book will be found a very good teacher."

"For moderate households or general use, we have met with no treatise on gastronomy that can compare for practical utility with 'How to Cook;' and we firmly 
believe, with the author, that 'one month's training in its principles and rules would make a good reliable cook of any intelligent servant.' "-Spcrting Gazette.

\section{"COUNT RUMFORD."}

This little book has given great satisfaction. The Malvern Advertiser says- "II should be obtained and read by every one who wishes to see the history of a valuable and ennobling reform told in an exceedingly happy style."

The Examiner says-" "It contains a great deal of truth and sterling advice; it gets at the roots of many social problems, and should have a large circulation."

$A$ Gentleman writes from Bolton:- "I have read all your works and am dolighted with them. As Count Rumford banished beggary from Bavaria, your books, if followed out in practice, would banish beggary, ignorance, disease, vice, and crime from the whole world. If I were rich, I would buy a large quantity for distribution."

$\triangle$ Lady writes from Ellwengen, Germany:- "Mr. Leidke, at Turin, has had the kindness to send me your excellent little work, 'Count Rumford,' which 1 have been reading with the highest satisfaction; so much the more as your name is already well known to me by your 'Human Physiology' and 'How to Live on Sixpence a-Day ;' and as it is written in the same pure spirit of true philanthropy, I cannot help thinking that it ought to be read and well understood by the German people."

\section{"SOCIAL LIFE."}

of this book, first published under the title of "Behaviour," press and public have spoken in the highest terms, as will be seen by the following notices:-

"A more valuable compendium of manncrs we have never seen. It not only teaches what is necessary for the external polish of a gentleman, but it also wisely inculcates the principles of that higher refinement which is the characteristic of the man and Christian. It treats of all subjects that are associated with the proprieties and amenities of life."-The Norfolk News.

"We have read the work with the greatest pleasure; and in closing it, we do not know which to admire most-its useful practical suggestions for reforming, educating, refining, and polishing our whole life and socicty, so as to bring out their highest use and beauty; or the full, clear, and incisive style in which it is written throughout. Dr. Nichols has written many useful works; but to prove he is a thoughtful, wcll-read, observant, elever, kindly gentleman, commend us to this modest treatise."-Public Opinion.

" 'Behaviour' is as superior to the usual books on etiquette as natural roses to artificial ones, and affords fascinating reading. Good marners include a care of the person and health, tasteful dressing, agreeable deportment, a pleasant manner, clear speech, and in all things, great and small, consideration for the feelings and rights of others. 'A serene gaiety, a courageous meeting of all the troubles and trials of life, is supremely good conduct and good manners. True politeness is cosinopolitan,' says Dr. Nichols, 'it goes like sunshine round the globe.' Some of the sunshine of the author's own individuality irradiates this litile book and reaches the heart of the readers, and we feel persuaded that it could not have been written but by a truly chivalrous and courteous gentleman."-Drawing-Room Gazette.

\section{"HUMAN PHYSIOLOGY THE BASIS OF SANITARY AND SOCIAL SCIENCE."}

This is Dr. Nichols' most comprehensive, most philosophical work, and it bas me: with entlusiastic appreciation. Perhaps the best newspaper review was one which sppcared in the Birmingham Daily Post, which, in the course of a long, able, and earnest article, said:--"In this remarkable volume, Dr. Nichols has condensed the studics of many years into a popular form. He writes simply, frankly, fully-he is never pedantic, or obscure, or dull. In the course of his five hundred pages there is not a line which is not only worth reading but remembering, for to a large majority of readers most of the facts and inferences will be wholly ncw. While profoundly thoughtful and philosophical, every page is so clearly written, every fact is so fully stated, every law is so perfectly explained, that every one will not only thoroughly understand but fully appreciate the work. The volume is full of facts 
of vitsl importance, of arguments interesting and most important to men and women too; and even on sexual matters, too generally veiled or wholly excludec from such works, Dr. Nichols writes with a simple frankness and delicate taste which will make his volume equally acceptable and valuable to all ages and all conditions of life. Aftcr a careful reading of the whole volume, it is simple justice to say that there is not a phrase or a fact introduced which could not and should not be understood by all persons of reasonable age. Dr. Nichols has evidently no nostrum to recommend, no system to puff, no establishment to advertise; but he is content to give the results of the readiug, observation, and experience of a long and varied life, and to explain in a most convincing and common-sense style, the structure of the body, the laws of health, the causes of disease, and thus to assist in the future amelioration of the condition of humanity."

Similar reviews appeared in many English periodicals, which we have not space to copy. A German periodical says:- "Dr. Nichols is well known to the German thinking people as the author of 'How to Live on Sixpence a-Day,' which has lately appeared in a German translation. At the end of last year appeared an important work by him, under the title of 'Human Physiology the Basis of Sanitary and Social Science,' in which the material, spiritual, and moral aspects of our being, above all our position in nature, are trcated of in the most widely embracing and popularly scientific manner, conceived and carried through in a love of truth and practical wisdom not to be mistaken."

Tho Weekly Register, a leading Roman Catholic journal, says:- " Human Physiology' abounds in instructive and interesting matter, and though touching at times upon subjects which require mucli delicacy of handling, we must say we have not a fault to find with the suthor's tone or language."

That adinirable compendium, Public Opinion, says:- "The spirit of the wort throughout is excellent."

Some of the highest opinions of the work have come to the author in private letterw:-

$\Delta$ Gentleman writes from Shefield:-"I have read and re-read it with such delight as I have scarcely ever had in reading any other book. To me it appears to be -as far as a book can be- one of perfection: it contains the philosophy of man's soul, life, existence, and destiny, from his cradle to his grave, in a nutshell. It is science and morality, religion and poetry and philosophy all at once. I wish every porson, especially every young person, in the land could get it and read it."

$A$ distinguished London Clergyman writes:- "I am deep in gour "Human Physiology, and enjoying every word of it. It is a little sad, thouggis, to think of it coming into one's hand at forty-six instead of sixteen years of age. I have promised my dear children the privilege of reading it. You are to be thanked and admired beyond all praise for handling these subjects with such skilful refinement and delicacy."

4 Lady near Dundee.- "I have just risen from the perusal of "Human Physiology,' and I must express my most unqualifed admiration of it. I cannot help wishing it were in the hands of every intelligent person in the land."

$A$ Clergyman of the Church of England, an M.A. and F.R.A.S, writes:- "I have read your 'Human Physiology' with deep interest. It is a noble, logical, and philosophical work, and will do immense good. It is eminently a book for the times, and does infinite credit to your head and your heart. It deserves a vorld. vide circulation."

\section{"ESOTERIC ANTHROPOLOGY."}

\section{(MYSTRRIUS OF MAX.)}

This is, in some respects, a book of even more practical value and importanc than "Human Physiology." It deals more with Disease and its Treatınent. It is a handbook of health. For men and women it is a book of books. Get both if you can, but if you can afford but one, get "Esoteric Anthropology." Don't be trightenod by its compound Greek name. It is really olle of the simplest, plainest books ever written. " "Esoteric Anthropology' is," the author says, "as its namo implies, a private treatise on the physical and moral nature of man. It treats of his struoture or constitution, orgens, functions, sexes, relations, the condit!ous of 
health and happiness, and the causes of disease and misery. Specially and very thoroughly it treats of the relations of men and women to each other, of the nature and uses of marriage, and the laws of a wise and healthy reproduction. It shows how the two sexes must be related to each other to insure painless maternity und bealthy offspring. It teaches, in short, the elements of human progress and wellbeing."

The following were among the testimonials to the value of "Esoteric Anthropology " on its first publication in America :-

Dr. W. MI. Stevens, of Forest City Water Cure.-CI look upon it, after a careful perusal, as the most wonderful book ever written. It makes a new era in literature and social life.".

Dr. E. Dodge, Oswoego, New York.- "This book contains more that is weighty in fact and sound in philosophy-more that is useful in medical science and effective in medical art-more that is purificative and elevative of man, than any one work, in volumes few or many, that has ever graced the Librarie Medicale of civilisation."

Alonzo Lewis, Esq., the Poet and Historian.- "My judgment is, that this is not only the best book on the subject on which it treats, but the only true and satisfactory one ever written."

The testimony of English readers, since the publication of the carefully revised and partly re-written English edition, has not been less emphatic :-

A Patient at Matlock. - "If I could have seen and read such a work thirty years ago, it would have been priceless to me." [This is the testimony of many others.]

A Gentleman from Manchester. - "I have read your book, "Esoteric Anthropology,' with very great satisfaction, and there is one part of 'it whose importance cannot be over-rated, viz., the chapters on sexual relations; and considering the consequences of ignorance, the importance of affording reliable information on those subjects seems greater than in any other branch of sanitary science"

1 Missionary in the Fiji 1slands writes:- "I bought 'Esoteric Anthropology' in Sydney, Australia, when I was preparing to come down to these Islands as a nissionary some years ago. That book I have found to be a most excellent com. panion in this out-of-the-way place, and have many a time thanked you for it. I $\mathrm{m}$ thoroughly satisfied with the book. Doctors are scurce in Fiji. Nearly two years ago ny wife was confined, and, as I was doctor, monthly nurse, and every. thing else, I followed the plan I thought best, and that was the plan of your "Esoteric Anthropology." All went on well, and I have spoken of your plan of treatment to nyy friends."

A Glasgow Surgeon writes in "Human Nature" -- " Esoteric Anthropology" is one of the best popular works on physiology that we have seen. Dr. Nichols writes with frankness on subjects usually shunned by popular writers, but ignorance concerning which has led to incalculable misery. He is never dull nor obscure; and subjects often made repulsive by dry technicalitics under his treatment become attractive and fascinating. It is a multum in parvo of medical science."

\section{"FORTY YEARS OF AMERICAN IIFE."}

This was the first book Dr. Nichols published in England (edition of 1864 in 2 7ols. $8 \mathrm{vo}$ ), and it was widely and well reviewed and noticed, as will be seen by the collowing extracts :-

"Dr. Nichols has broken now ground-ground that has been little more than touched by any of his predecessors-and given us an exccedingly clear, pleasant, and varied series of sketches of American life and manners, surprisingly free from the customary defects of such works. No book we have ever read gave us anything so clear and vivid an idea of American life. As a description of American homes, and Americans at home, this book is the best we lave seen."-Saturday Reviev.

"The descriptions of life in New England forty years ago, and in New York at the present day, are really admirable. His narrative has that greatest of charms, that be entirely sympathises in his heart even with the weaknesses which his intellect confesses. Indeed, the early chapters of the first volume, in which he deseribes the State of New Hampshire during his boyhood, are perfectly idylic. In conclusion, we heartily recommend Dr. Nichols' book. It is thoroughly amusing, 
instructive where he relates his own experience, and everywhere racy of the soil of which it treats."-Spectator.

"An interesting book, written with extraordinary vivacity, and full of amusement and instruction."-Literary World.

"Having read, we may say, all that has been written on American affairs since the war began, whether by English or Transatlantic pens, we can confidently affirm that Dr. Nichols is by far the most intelligent and trustworthy, because the most temperate, frank, and impartial of those writers."-Dublin University Magazine.

"Dr. Nichols' power lies in the force and truthfulness with which he recals the incidents of his past life, the manners and pursuits of the society with which he was familiar in his youth, the men whom he has known, the scenes he has visited. His book will give both pleasure and instruction to every intelligent person who consults it."-Guardian.

"We can scarcely recal a case since Washington Irving in which an American author has received a warmer or more unanimous welcome in England. When an author has satisfled the Quarterly, the Examiner, and the Saturday Review, he may well be content. In winning this English welcome, Dr. Nichols has yielded nothing to English prejudice. It is rare, indeed, that we bestow such unmingled praise, and for the reason that we rarely meet with a work that so nearly merito unqualified commendation."-1ndex.

THE DIET CURE : An Essay on the "Relations of Food and Drink to Health, 1 Disease, and Cure." By T. L. NICHOLS, M.D. (Post Free, 1/.) The titles of the twenty-one chapters of "The Diet Cure" will give the best idea of its scope and method. They are:-Health-Food-Water-Blood-The Natural Food of Man-Disease-Prevention and Cure-The Question of Quantity-The Question of Quality-Principles of the Diet Cure-Medical Opınions on the Diet Cure Of Diet in Acute, Scrofulous, and Nervous Diseases-The Diet Cure in Dyspepsia-The Diet Cure in various Diseases-The Population Question-Some Practical Illustrations-Air and Exercise-Personal Advice. The Oldham Chronicle, at the end of a column of review and quotation, says :- "The Diet Cure' (pp. 96) is a bright, cheerful, thoughtful, and useful essay on the relations of food and drink to health, disease, and cure. Fourteen thousand copies have already been sold, and the demand for it is increasing in leaps and bounds. The work is highly important to all who desire to get the most good from their food, and to enjoy the best health at the least expense."

Monthly, Price Twopence. By Post, 2s. 6d. per annum.

The herald OF Health. Edited by C. Leigh Hunt Wallace. The Object of this Paper is to assist in bringing about the Physical RegeneraTION OF MAN by means of educating its Readers in such ways of living as will enable them to CURE, ERADICATE, and PREvent Disease, and at the same time MaINTAin and Develop the highest possible standard of Health. Post Free of Nichols \& Co, 23 Oxford Street, W.

Herald of Health Cases sent post free for $1 / 9$. Made in various colours, having the wrapper design beautifully executed in black and gold, and forming an elegant receptacle for loose copies either for the library table or shelf, and in which your newsvendor will get the year's 12 copies cheaply bound.

Nichols \& CO., Publishers, 23 Oxford Street, W.,

AND THROUGH ALL BOOKSELLIERS. 
"DYSPEPSIA (commonly called Indigestion), one of the Dravest of human afflictions: Its NATURE, CAUSES, Prevention, and Cure." Dyspepsia is not only a very common disease, but it is a cause or complication of almost all diseases. It is a central difficulty, and makes the lives of thousands poor and painful, weak and miserable. As we cannot live without food, we cannot live well unless our food is properly digested. Undigested food is a foreign body in the stomach, and a source of irritation and exhaustion-we are better without it. Post free for Three Penny Stamps.

Syringe Enemas at 5s.; with Vagina Tubes, 6s.

Children's Bottle Enemas, 2s.

Fell's Hygienic Friction Towels, as recommended by the late Dr. Anna Kingsford, 3s. 3d.

INVALUABLE TO SUFFERERS OF INFLUENZA, ALSO FOR

RHEUMATIC AFFECTIONS.

\section{PORTABLE TURCO-RUSSIAN HOT-AIR OY VAPOUR BATH.}

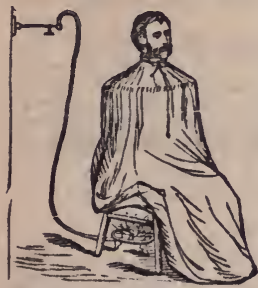

This Bath enables anyone to take a Hot-Air or Vapour Bath in his bedroom. The patient sits in a common chair; his body is enclosed in a robe which retains the heat while it allows a certain degree of transpiration, and the head is free to breathe, so that patients can take this bath who cannot bear the ordinary Turkish Bath. Free perspiration is induced in fifteen or twenty minutes, and a wash down of cool or cold water, and a good rubbing, complete the operation. Very delicate patients have taken this form of bath daily for months with great advantage.

Is sweating weakening? Quite the contrary. Send four penny stamps for "A Plea for a Turkish Bath," and satisfy yourself before you purchase the article.

The Price of the Bath for Gas, with $8 \mathrm{ft}$. of Tubing, is 25s. With Spirit Lamp, 218. Full directions accompany.

\section{PORTABLE FOUNTAIN BATH Or RISING DOUCHE.}

For the home treatment of constipation, piles, fistula, protrusion of the lower bowel, falling and displacement of the womb, vaginal weakuess, diseases of the prostrate gland, ovaries, testes, and many diseases of the generative organs of both sexes.

A full account of this Invention sent to any address on receipt of stamped and directed wrapper.

PRICE 55s. FULL DIRECTIONS ACCOMPANY.

Cheques crossed "London and Westmirster," payable to-

Nichols \& Co., 23 Oxford St., London, W.

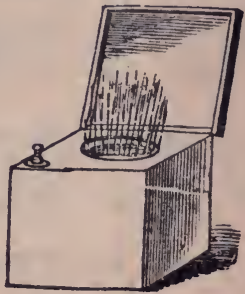


Work on Diet and Hygiene.

\section{MAN'S BEST.FOOD.}

By WILLIAM CARPENTER.

PRICE 4 d.

TO SEEKERS AFTER ANCIENT WISDOM.

Now Ready, cloth gilt, 3s. 6 d.

A Reprint of a valuable work on Hygiene, entitled,

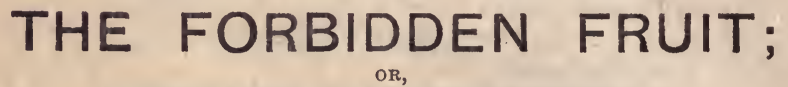

REVELATIONS OF EGYPTIAN MYSTERIES.

The great pre-disposing cause of man's infirmities is herein lucidly explained (that all who run may read).

\section{RHEUMATISM,}

ACUTE AND CHRONIC;

Its Cause, Symptoms, Complications, and Cure; also, Its Prevention by Hygienic Means.

PRICE 6d.

By T. R. ALLINSON, L.R.C.P., L.R.C.S., etc.

The Funniest Book of the Season.

\section{"THE CONFESSIONS OF A VEGETARIAN."}

\section{PRICE 1s. 1d.}

Chapter I. - Why I became a Vegetarian.

II - I join a Vegetarian Society and attend a Soiree.

III - My First Lecture.

IV - "Fiat experimentum in corpore vili."

V. - How it feels to be a "Faddist."

VI - I go the "whole gooseberry."

VII.-And am obliged to seek medical advice.

VI1. - I begin to understand VEGETARIANISM and calculate it don't suit me.

IX.-So I give it up and adopt a rational method of living.

\section{NICHOLS \& CO.,}

(EST. 1870)

Dublisbers and Exporters of Tbygienic Literature.

Also New and Second-hand Catalogue on Hypnotism, Animal Magnetism, Mesmerism, Massage, Palmistry,

Phrenology, Physiognomy, Physiology, and Spirituulisin, etc., etc.

23 OXIOID STIEEM, UONION, W. 


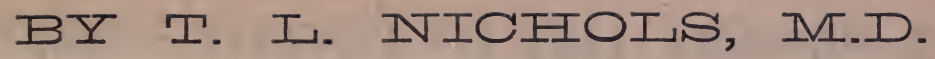

A COMPLETE MANUAL OF HEALTH.

\section{ESOTERIC ANTHROPOLOGY (MYSTERIES OF MAN)}

A Comprehensive and Confidential Treatise on the Structure, Functions, Passional Attractions and Perversions, True and False Physical and Social Conditions, and the most Intimate Relations of Men and Women.

\section{(The book so unjustly anathematised by Mr. Justice Wills in the late Mysterious Pimlico Case.)}

"Esoteric Anthropology," in its 24 chapters and 340 compactly-printed pages, treats of Man and his Relations - the Chemistry of Man-Human Anatomy - Principles of Physiology - the Organic System - the Animal System-the Function of Generation-Impregnaticn-Morals of the Sexual Relation - Evolution of the Fœtus-Pregnancy - Systems of Health-Conditions of Health-Causes of Disease-Curative Agencies-Processes of Water Cure-Diseases and Treatment-Inflammation and Brain Diseases-Diseases of Respiration - of Digestion - of the Generative System-Gestation and Parturition-Lactation and Management of Infants-Death and Immortality.

" 'Esoteric Anthropology' is one of the best popular works on physiology that we have seen. Dr. Nichols writes with frankness on subjects usually shunned by popular writers, but ignorance concerning which has led to incalculable misery. He is never dull nor obscure; and subjects often made repulsive by dry technicalities, under his treatment become attractive and fascinating. It is a multum in parvo of medical science."-Human Nature.

$A$ Gentleman in the East India Civil Service writes :- "It is a book of books; one that every one ought to have by him or by heart. It is such a complete manual of health as 1 have never before seen, and also a manual of marital rights and duties which no one should be without. I am lost in admiration of the purity of the chapters on this subject."

HUMB NISBET says :- "If I do not agree with Dr. Nichols in his preface when he calls it 'private'-my manhood preventing me from seeing any sense of necessity for keeping a work like this private, when such a production as the Song of Solomon is put into the hand of childhood-I must in honesty own to the benefit I have received from the wisdom and advice lavished throughout the pages, and would like to share the good with all my kind. But with the utter shamelsssness of society shame it is hard to fight-the inconsistencies of the word-worshippers, who swallow the adjective and ignore the noun. The chapters on human anatomy I recommend to artists, as the simplest and most condensed writing I have yet read on this subject. The words to lovers I would fling out to the million."

150,000 Copies of this work having now been issued to the general public is, we consider, the best testimony of its value as a Hygienic Guide.

Bound in cloth, price $5 / 3$; in paper covers, $3 / 3$; book post. PROFUSELY ILLUSTRATED WITH 50 ENGRAVINGS.

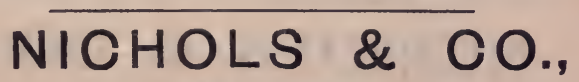

Dublísbers,
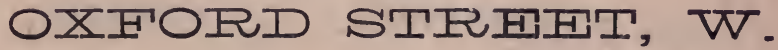


\section{A SPECIAL LIST OF PRIVATE WORKS}

\section{BY YARIOUS AUTHORS.}

Midwifery and Diseases of Woman. By J. Shew, M.D.,

Hints on the Reproduetive Organs and their Diseases and

Cure,

Home Treatment for Sexual Abuses. By R. T. Trall, M.D.,...

Chastity. By Graham,

The Laws of Generation and Sexual Morality. By T. L. Nichols,

M.D.,

Wedlock ; or, the Right Relations of the Sexes. R. S. Wells,

Uterine Diseases. By R. T. Trall, M.D., $\quad \ldots \quad$... $\quad \ldots \quad$...

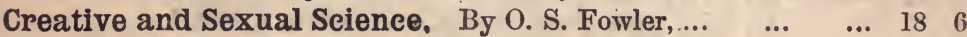

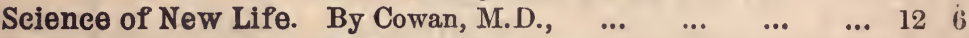

Sexual Physiology. By R. T. Trall, $\ldots \begin{array}{lllllll}\ldots & \ldots & \ldots & \ldots & \ldots & 5 & 6\end{array}$

Relation of the Sexes. By Mrs. Duffey, $\quad \ldots \quad$...

Tokology : a Book for Mothers. By Mrs. Stockham. Cloth,

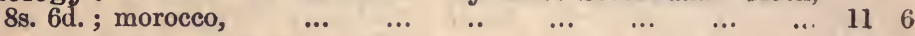

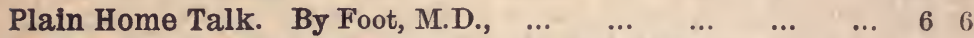

For Girls : a Special Physiology: By Mrs. Shepherd, ... $\quad \ldots \quad 4 \quad 43$

Chastity. By Dio Lewis, M.D.,... $\quad \ldots \quad$...

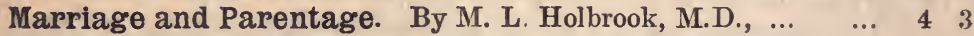

Physical Culture for Home and Sehool. By D. L. Dowd, $\ldots 6^{6}$

Hydropathic Eneyelopædia. By R. T. Trall, M.D., $\quad \ldots \quad \ldots \quad \ldots 16 \quad 6$

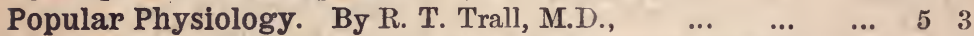

Diseases and Derangements of the Generative System, $\quad \ldots \quad 3 \cdot 9$

Chronic Diseases, especially the Nervous Diseases of Woman.

By D. Rotch,

The Art of Massage. By A. Creighton Hale, ... ... ...

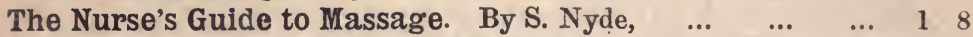

Private Instruction in Practical Massage. By Dr.J. D.Balkan, $\quad 1 \quad 1$

Lectures on Massage. By T. S. Douse, $\quad \ldots \quad$...

Full and Comprehensive Instruction How to Mesmerise.

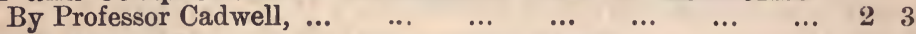

Animal Magnetism. By A. Bimet and C. Fiere, $\ldots \begin{array}{lllll}\ldots & \ldots & \ldots & 5 & 6\end{array}$

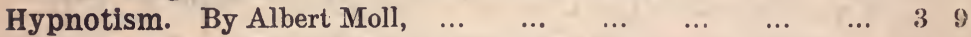

Mesmerism, with Hints for Beginners. By Captain James, ... $\quad 2 \quad 9$

Practical Instructions in Animal Magnetism. By Deleurze, ... 886

Hypnotism; or, Animal Magnetism. By Rudolph Heidenhain, 29

\section{NICHOLS \& CO.,}

Ip ublisbers,

23 OXFORD STREHT, W. 




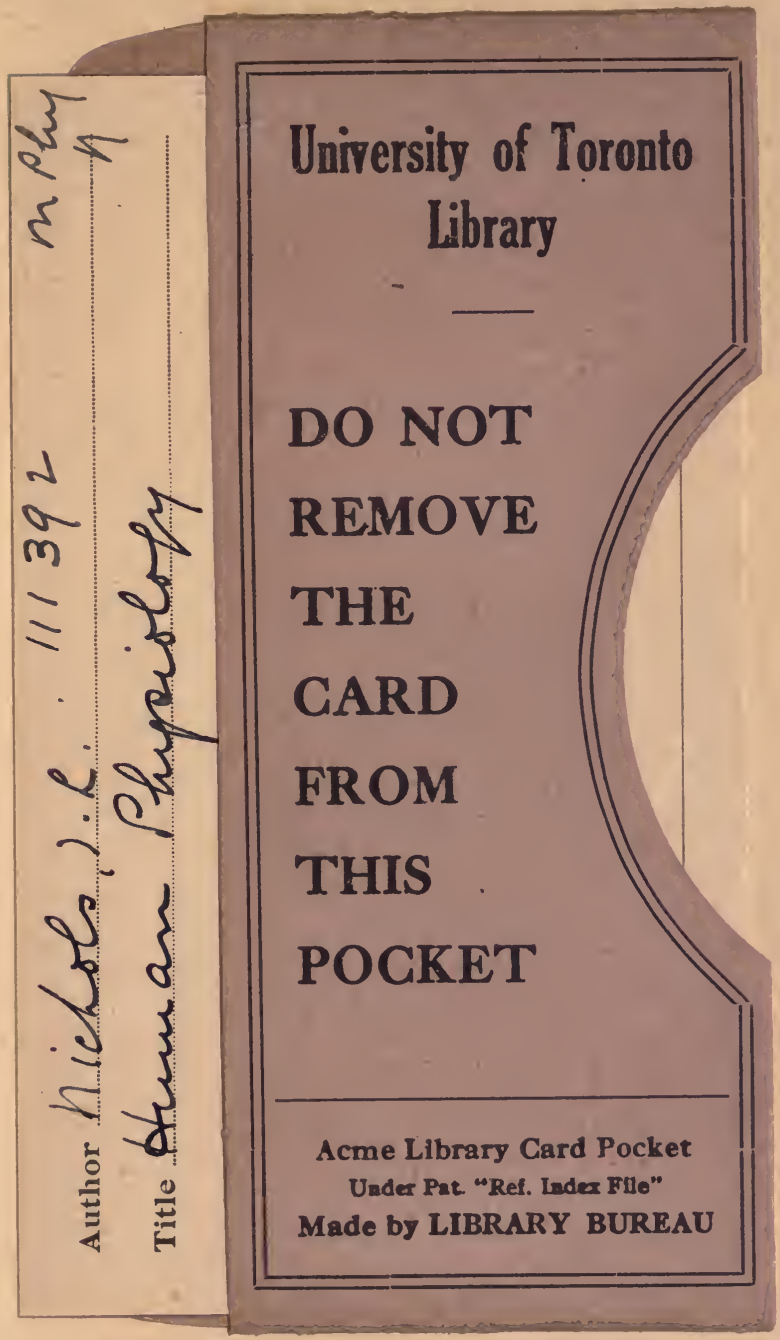


